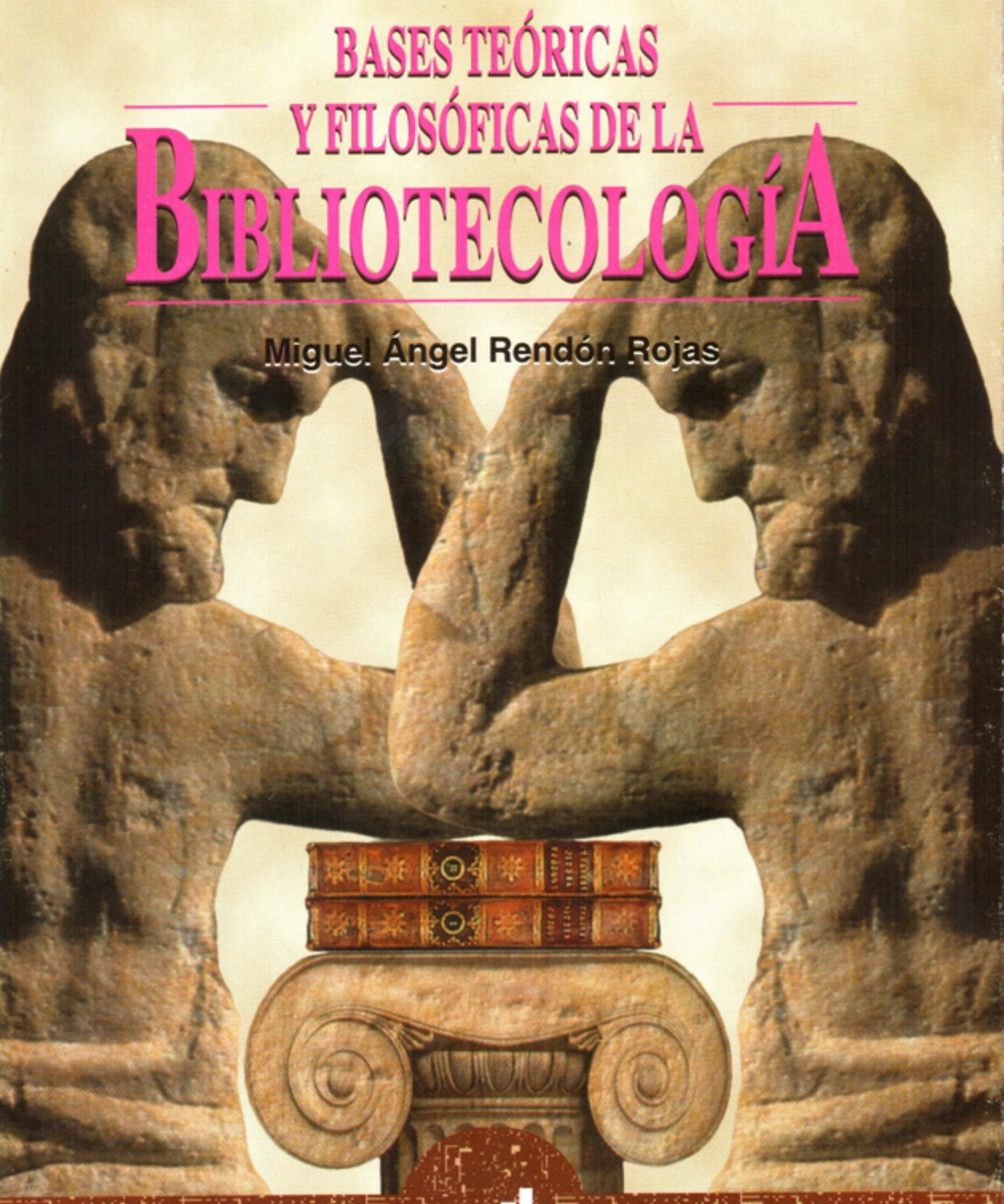




\section{La presente obra está bajo una licencia de:}

\section{http://creativecommons.org/licenses/by-nc-sa/3.0/deed.es MX}

\section{Atribución-No Comercial-Licenciamiento Reciproco 3.0 Unported}

Eres libre de:

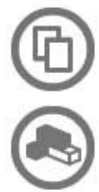

copiar, distribuir y comunicar públicamente la obra

hacer obras derivadas

Bajo las condiciones siguientes:

Atribución - Debes reconocer la autoria de la obra en los términos

especificados por el propio autor o licenciante.

No comercial - No puedes utilizar esta obra para fines comerciales.

D Licenciamiento Reciproco - Si alteras, transformas o creas una obra a

partir de esta obra, solo podrás distribuir la obra resultante bajo una licencia

igual a ésta.

\section{Esto es un resumen fácilmente legible del: texto legal (de la licencia completa)}

\section{En los casos que sea usada la presente} obra, deben respetarse los términos especificados en esta licencia.

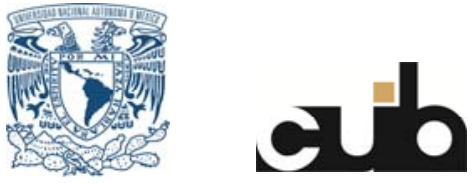


Bases teóricas y filosóficas de la bibliotecología 
COLECCIÓN

SISTEMAS BIBLIOTECARIOS DE INFORMACIÓN Y SOCIEDAD Centro Universitario de Investigaciones Bibliotecológicas 


\title{
Bases teóricas y filosóficas de la bibliotecología
}

\author{
Miguel Ángel Rendón Rojas
}

Universidad Nacional Autónoma de México 2005 


\section{Z665}

R45 Rendón Rojas, Miguel Ángel

2005 Bases teóricas y filosóficas de la bibliotecología / Miguel Ángel Rendón Rojas. -- $2^{\mathrm{a}}$ ed. -- México : UNAM, Centro Universitario de Investigaciones Bibliotecológicas, 2005.

xvi, 183 p. -- (Sistemas Bibliotecarios de Información y Sociedad)

Incluye postfacio

ISBN: 970-32-2679-5

1. Teoría de la Bibliotecología 2. Filosofía 3. Epistemología I.t II. ser.

Diseño de portada: Ignacio Rodríguez Sánchez

Segunda Edición 2005

DR ๑ UNIVERSIDAD NACIONAL AUTÓNOMA DE MÉXICO

Ciudad Universitaria, 04510, México D.F.

Impreso y hecho en México

ISBN: 970-32-2679-5 
Agradecimientos

Al Ser que se devela y oculta en la temporalidad

A mis padres

A Caro

A mis amigos y seres queridos que en su momento me enseñaron que aunque ontológicamente los trascendentales del ente son la unidad, la verdad, la bondad y la belleza; existencialmente lo trascendente del ser humano es el amor y la amistad

Al Centro Universitario de Investigaciones Bibliotecológicas de la UNAM, en particular a la Doctora Elsa M. Ramírez Leyva, que en su momento me brindó su apoyo para la realización de este proyecto de investigación. 



\section{Contenido}

PRólogo a la SEgUndA EdICIÓn. . . . . . . . . . . . . xi

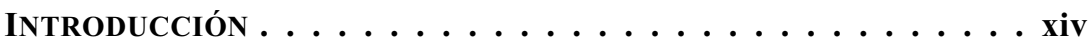

\section{CONSIDERACIONES \\ INICIALES}

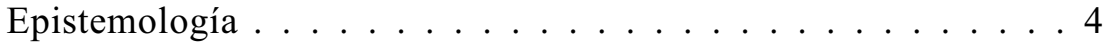

Positivismo ..................... . . . . . . .

Falsacionismo . . . . . . . . . . . . . . 9

T. Kuhn y las revoluciones científicas . . . . . . . . . 11

El anarquismo epistemológico . . . . . . . . . . . . 21

Los Programas de Investigación Científica de I. Lakatos . . . . . 22

La hermenéutica filosófica . . . . . . . . . . . . . 26

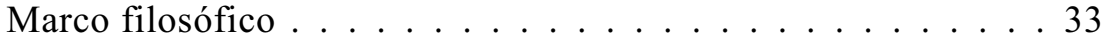

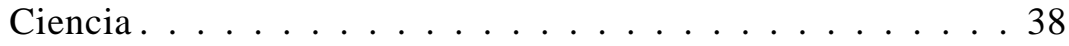

Ciencias del espíritu . . . . . . . . . . . . 38

\section{LA FUNDAMENTACIÓN DE \\ UNA DISCIPLINA}

Diferentes aspectos de la fundamentación de una ciencia. . . . . 45

Diferentes aspectos en la fundamentación de la bibliotecología . . . . . . . . . . . . . . . . . . . . . . . . . 48

Fundamentación filosófica . . . . . . . . . . . . . . . 48

Fundamentación teórica . . . . . . . . . . . . 50

Fundamentación extrateórica . . . . . . . . . . . . . 50

Fundamentación metodológica. . . . . . . . . . 51

Fundamentación lógica . . . . . . . . . . . . . . . . 52 


\section{FUNDAMENTACIÓN FILOSÓFICA ONTOLOGÍA}

La objetividad de la bibliotecología . . . . . . . . . . . . . 59

El hombre como poder ser y la bibliotecología . . . . . . . . 60

La enajenación y la bibliotecología. . . . . . . . . . . . . . 6 62 67

Disciplinas prácticas y teóricas . . . . . . . . . . . . . . . 67

La dialoguicidad como elemento objetivo y necesario del campo bibliotecológico. . . . . . . . . . . . . 70

Las relaciones informacionales y la ciencia bibliotecológica . . . . . . . . . . . . . . . 73

\section{FUNDAMENTACIÓN TEÓRICA ANÁLISIS DE TÉRMINOS}

Anotaciones metodológicas . . . . . . . . . . . . . . 81

Término, objeto y concepto . . . . . . . . . . 81

Definición de términos . . . . . . . . . . . . . 88

Información. Concepto central en bibliotecología . . . . . . 88

El problema de la naturaleza de la información

en bibliotecología . . . . . . . . . . . . . . . . . . . . . . . 88

Acercamiento filosófico . . . . . . . . . . . . . . . . . 990

Información como cualidad secundaria . . . . . . . . . . 992 92

El mundo de la información . . . . . . . . . . . . . . . . . . 997

Información y conocimiento . . . . . . . . . . . . . . . 103

Necesidad de información. . . . . . . . . . . . . . . . 106

Usuario . . . . . . . . . . . . . . . . . . . . . 115

Documento . . . . . . . . . . . . . . . . . . . . 120

Tipos de documentos según su lugar ontológico

y la actividad cognoscitiva que propician . . . . . . . . . 127

Libro . . . . . . . . . . . . . . . . . . . . . . . . . . 130

Documento y $\beta 1 \beta \lambda \mathrm{os}$ (biblos) . . . . . . . . . . . 134

Institución informativa documental . . . . . . . . . . . 136

El profesional de la información documental. . . . . . . . 143 


\section{FUNDAMENTACIÓN FILOSÓFICA GNOSEOLOGÍA}

Hacia la precisión del núcleo duro del programa de investigación científica en bibliotecología . . . . . . . 150 Teoría sintáctica de la información . . . . . . . . . . . . . 152 Teoría semántica de la información . . . . . . . . . . . . . . 155 Enfoque pragmático de la información . . . . . . . . . . 158 La ciencia bibliotecológica . . . . . . . . . . . . . 161 La bibliotecología como empresa o institución educativa . . . 173

Conclusiones . . . . . . . . . . . . . . . . . . . 179

BIBLIOGRAFÍA $\ldots \ldots \ldots \ldots \ldots \ldots \ldots \ldots \ldots \ldots \ldots$ 



\section{PRólogo A LA SEGUNDA EDICIÓN}

T a primera edición del libro Bases teóricas y filosóficas de la bibliote_cología vio la luz en 1997 y después de algunos meses se agotó su tiraje por lo que fue necesaria realizar una reimpresión de la misma en 1998 en la que se añadió un postfacio para de cierto modo actualizar el texto. Sin embargo, dicha reimpresión poco tiempo después también corrió con la misma suerte. Dada la importancia del tema y el interés que ha suscitado en cierto número de lectores, entre los que se cuentan profesionales, docentes, investigadores y estudiantes del área informativa-documental, estaba pendiente la tarea de ofrecer una nueva edición de este trabajo.

Ahora presentamos al lector la segunda edición corregida y aumentada de la presente obra, misma que refleja el camino que he recorrido en la reflexión y estudio de este tema después de la última reimpresión de este libro. Gracias a los comentarios, críticas y reflexiones de mis alumnos y colegas en los diferentes cursos y eventos académicos en los que he tenido la oportunidad de exponer mis ideas, he descubierto la necesidad de precisar y complementar algunas de ellas e incluso abrir nuevos derroteros por donde pudiera fluir libremente el pensamiento y llegar a conclusiones que reafirmaran la propuesta teórica que sostengo sobre las bases teóricas y filosóficas de la ciencia bibliotecológica.

Entre las principales novedades que presenta esta edición en comparación con la anterior se cuentan que se agrega un apartado especial para la exposición de la concepción epistemológica de I. Lakatos sobre los Programas de Investigación Científica, compuestos, según ese autor, por un núcleo duro y por un cinturón protector; cuestión que posteriormente se aplica a la ciencia bibliotecológica y nos sirve para identificar su núcleo 
duro, que le proporciona identidad como disciplina, y su cinturón protector, que da la posibilidad del cambio teórico pero sin perder la tradición.

Asimismo la fundamentación ontológica se complementa con algunas tesis tomadas de la filosofía hermenéutica de Gadamer y Habermas principalmente, quienes hablan sobre la "dialoguicidad" e historicidad del ser humano, y aprovechamos esas ideas para resaltar cómo estas características esenciales necesitan del saber bibliotecológico para actualizarse, lo que nos lleva a concluir la importancia, necesidad y objetividad de la bibliotecología.

Dentro de este mismo apartado también se añade la fundamentación sobre la objetividad del campo fenoménico de la bibliotecología mediante una analogía con la teoría clásica de la economía política, la cual devela relaciones de producción existentes independientemente de la voluntad del hombre. De esta manera se propone la tesis de la existencia de "relaciones informacionales documentales" que se dan independientemente de la voluntad del hombre y que son estudiadas por una disciplina determinada.

Con respecto a la fundamentación teórica se aborda de una manera más detallada la distinción información-conocimiento tomando en cuenta las fuentes de cada una de ellas, la actividad necesaria para obtenerlas y los resultados propiamente dichos, así como también sus implicaciones para la bibliotecología dentro de una sociedad de la información o una sociedad del conocimiento.

Dentro de la discusión del concepto documento se introduce una distinción sobre los diferentes tipos de documento según el mundo ontológico al que pertenezcan de acuerdo con el autor que los creó y con la función cognoscitiva que cumplen; y también se dedica un apartado al análisis del sentido olvidado de biblos que en cierta medida aclara y le abre horizontes al término bibliotecología.

Por último, en la fundamentación gnoseológica se afina el concepto de Sistema Informativo Documental como categoría central (núcleo duro en la terminología de Lakatos) para identificar y distinguir el conocimiento bibliotecológico, y se aleja así el peligro de utilizar el concepto de interdisciplina como un artificio para esconder la falta de identidad de la disciplina. 
Finalmente es una obligación moral reconocer a todos los que hicieron posible la aparición de este libro, al departamento de publicaciones del CUIB, principalmente al Lic. Francisco Xavier Gónzález por su paciencia al revisar el original y acertados comentarios, a mis alumnos y alumnas de la Escuela de Bibliotecología de San Luis Potosí, de la licenciatura de ciencias de la información documental de la Universidad del Estado de México y de la licenciatura en bibliotecología de la UNAM por su contagioso entusiasmo por aprender y la responsabilidad que originaron en mí para poder enseñarles algo.

Sabemos que al soltar de la mano este libro y dejarlo caminar libremente empezará a comunicar nuestras ideas, pero al mismo tiempo él tendrá "sus verdades" que decir y el lector "sus verdades" que descubrirá personalmente. Esperamos que ese encuentro sea provechoso para todos y motivo de reflexión, análisis y crítica; para que de este modo sirva como un instrumento de conocimiento y autoconocimiento. 


\section{INTRODUCCIÓN}

1 presente texto está dirigido a trabajar aquellos aspectos filosóficos, Cteóricos y metateóricos, necesarios para el desarrollo de la investigación en el ámbito bibliotecológico; por lo que, dadas las características del desarrollo histórico de la bibliotecología, siempre ligada a una actividad práctica, este estudio, que representa una investigación para la investigación, resulta fundamental para dicha disciplina. Si bien el fenómeno relativo al uso y registro de la información surge vinculado a los procesos propios de la invención de la escritura, el conocimiento bibliotecológico se mantuvo reducido a los intereses de las élites culturales, y no fue sino hasta principios del siglo XIX, con la aparición de la idea del servicio público bibliotecario; es decir, con base en exigencias pragmáticas, cuando se plantea la necesidad de generar un conocimiento que permitiera analizar los fenómenos relacionados con el uso y organización de documentos para brindar un servicio más eficaz. Esta necesidad y la ulterior evolución de los fenómenos relacionados con el proceso informativo-documental motivaron la realización de un trabajo teórico que abarcaba el análisis del apartado conceptual de la disciplina, una reflexión sobre su campo de estudio, sus límites, funciones y prerrogativas, además de una serie de consideraciones respecto al nombre mismo de la disciplina que se fue dando en torno a términos como bibliografía, biblioteconomía, documentación, bibliotecología y ciencias de la información.

Por otro lado, la aplicación de métodos cuantitativos por parte de Bradford en la década de 1940, mismos que expone en su libro Documentation, da lugar a la creación de conceptos cuantitativos y a la generación de métodos y regularidades empíricas, lo que ofrece la posibilidad de un 
acercamiento positivista al problema epistemológico de la bibliotecología. Este hecho origina diversas corrientes respecto a la forma de enfocar el objeto y método de estudio de la bibliotecología, lo que a su vez provoca la proliferación de términos, de temas y líneas de investigación derivados de estudios pragmáticos y empíricos.

Asimismo, la bibliotecología actualmente está sujeta a un proceso no sólo de desarrollo evolutivo connatural a toda disciplina, sino a un proceso de transformación que se acelera bajo el influjo de la vida contemporánea y por factores de toda índole: culturales como la "informatización" de la sociedad; de carácter teórico, como la especialización de las teorías y la interdisciplinariedad; de tipo tecnológico, como el cambio producido por la revolución tecnológica en cuanto al almacenamiento, conservación, organización, recuperación y transmisión de la información; y de naturaleza económica como la mercantilización de la información y el gran valor agregado que pueden crear los servicios de información frente a las ascendentes expectativas de los usuarios de acervos, quienes los emplean con fines didácticos y de investigación científica o para desarrollar actividades productivas, comerciales, especulativas financieras o políticas.

Dentro de este proceso de transformación se pretende aprovechar los conceptos acerca del manejo y organización de la información que han sido generados en diferentes áreas del conocimiento, pero conservando -aunque sea para polemizar con ella- la idea tradicional de servicio a usuarios, lo que, como ya indicamos dio origen a la preocupación por desarrollar el conocimiento bibliotecológico. Para nosotros resulta importante incluir esos nuevos términos y conceptos dentro de un marco que considere como un aspecto fundamental los problemas inherentes al derecho que tiene el individuo a acceder a la información documental organizada por medio de unidades de información como bibliotecas, bancos de datos y centros de información, entre otros, y que ve el proceso informativo como parte de los fenómenos relativos a la libre circulación de los documentos; problema vinculado, a su vez, con procesos de acumulación social del conocimiento y consideraciones filosóficas acerca de la liberación humana.

Este proceso de transformación ha ocasionado la revaloración de los paradigmas científicos elaborados anteriormente, por lo que, siguiendo el esquema kuhniano del desarrollo científico, nos encontramos en el periodo de crisis, antesala de la revolución científica, que tiene lugar cuando se 
adopta un nuevo paradigma. Pero para saltar a una nueva "matriz disciplinar" en la que se encuentren referencias que respondan a interrogantes planteadas por el cambio y nos proporcionen el marco para desarrollar la disciplina en un "periodo normal", es necesario replantear las bases teóricas y filosóficas de la bibliotecología.

Teniendo todo esto presente, nuestra investigación versará sobre el análisis del objeto de la bibliotecología y de sus conceptos fundamentales, con la finalidad de fundamentar epistemológicamente la estructura teórica de la disciplina, determinar su lugar dentro de las ramas del saber humano y sus relaciones con otras disciplinas, y encontrar los elementos necesarios para establecer prospectivas sobre el desarrollo de la investigación bibliotecológica y sobre su valor social.

Para cumplir con esta tarea se proporciona en primer lugar el marco filosófico dentro del cual se va a trabajar, que se puede resumir en pocas palabras como un realismo cognoscitivo dialéctico. Posteriormente se enuncian las diversas fundamentaciones que se deben realizar para fundamentar una disciplina: filosófica, teórica, lógica, metodológica y extrateórica. En este estudio nos limitaremos a las fundamentaciones filosófica y teórica. 


\section{Consideraciones iniciales}



$7^{1 \text { presente trabajo es el resultado de una reflexión epistemológica so- }}$ Cbre la bibliotecología. Este hecho demuestra la visión multidisciplinaria de la investigación, cosa que por un lado indudablemente la enriquece pero que por el otro origina ciertas dificultades. La pregunta que surge es ¿quién puede realizar este tipo de estudios, un filósofo con ciertos conocimientos en bibliotecología o un bibliotecólogo con algunos conocimientos filosóficos? En este caso la investigación fue realizada por un filósofo que trabaja directamente en un ambiente bibliotecológico, lo que le dio la oportunidad de conocer de cerca el objeto de su reflexión epistemológica.

Teniendo en cuenta que los lectores de esta investigación no serán epistemólogos profesionales, considero necesario realizar ciertas acotaciones para centrar nuestro tema y facilitar la comprensión de los lectores. En primer lugar, si vamos a discutir problemas epistemológicos, entonces hablaré brevemente sobre cómo se utilizará el término 'Epistemología', vocablo muy usado por la comunidad bibliotecológica, pero que en ocasiones es impreciso. En segundo lugar para que se comprenda mi postura filosófica se enunciarán las principales respuestas de las diferentes escuelas epistemológicas, para saber qué tomamos de ellas y qué dejamos de lado. Por último, en tercer lugar, si vamos a fundamentar a la bibliotecología como ciencia debemos aclarar lo que entendemos por ciencia y de esta manera precisar las características que debe poseer la bibliotecología para considerarla como disciplina científica. 


\section{EPISTEMOLOGÍA}

Consideraremos aquí a la Epistemología como sinónimo de Filosofía de la Ciencia. ${ }^{1}$ Sin embargo esto nos conduce a un nuevo problema: el de aclarar lo que entendemos por filosofía, para posteriormente limitar ese primer concepto mediante la adición de otro, que es el de ciencia.

Como nuestro objetivo no es escribir un trabajo de filosofía "pura", no nos adentraremos en las discusiones filosóficas que han mantenido durante siglos las diferentes escuelas y corrientes sobre el concepto de filosofía, ni tampoco efectuaremos, como se hace en los libros dedicados a la epistemología, un análisis profundo y muchas veces pedante de lo que es la ciencia; cuestiones que nos alejarían de nuestro tema inicial. Aportaremos únicamente las nociones que consideramos necesarias sobre esos conceptos para que nos sirvan como guía en nuestro estudio.

A la filosofía la entenderemos como un proceso de búsqueda y una doctrina que refleja algunos resultados de esa búsqueda; como una actitud interrogadora ante la realidad y unas respuestas a esos cuestionamientos. ${ }^{2}$ Lo que distingue a la filosofía de otras búsquedas y cuestionamientos es la naturaleza de las preguntas que se plantean, la visión que se tiene del objeto sobre el que se indaga, y las herramientas que se utilizan para llegar a las respuestas acerca de las interrogantes planteadas.

Así pues, podemos decir en primer lugar que la búsqueda y fundamentación filosófica se desarrolla como una reflexión racional sistemática realizada dentro de un cuerpo teórico que ha sido elaborado dentro de una tradición secular específica; es decir, se trata de una reflexión hecha con ayuda de un instrumento racional, el cual posee un aparato conceptual y categorial propio, y unos métodos rigurosos y generales de razonamiento.

1 En la tradición anglosajona el término más común es el de Filosofía de la Ciencia, mientras que en la tradición continental se utiliza el término epistemología. Sin embargo, existen autores que prefieren utilizar el término epistemología por temor a la palabra filosofía. Según ellos, la epistemología es una disciplina seria que ha proporcionado estudios interesantes en el análisis lógico, histórico y sociológico de la ciencia, mientras que en la filosofía se realizan discusiones abstractas y obscuras, divagaciones sin un resultado efectivo. Cfr. P. Thuillier La manipulación de la ciencia. Madrid: Fundamentos, 1975. pp. 13-21.

2 Esto es en el aspecto cognoscitivo, pero la filosofía tiene su aspecto de ser una "cosmovisión"; es decir, una guía para responder a la pregunta de la relación del Yo con el no-Yo, a la cuestión del lugar de Sujeto en el mundo y la sociedad. 
Entre los métodos especiales desarrollados por la filosofía y utilizados por ella podemos destacar a la lógica, ${ }^{3}$ la dialéctica, ${ }^{4}$ la fenomenología ${ }^{5}$ y la hermenéutica. 6

En segundo lugar, las preguntas que la filosofía le plantea a la realidad son, con palabras de Aristóteles, una búsqueda de los principios de las cosas; esas interrogantes son entre otras: ¿qué es esa realidad, qué la identifica como tal y la diferencia de otras? ¿cuál es el material que conforma esa realidad y cómo es su estructura? ¿cuál es su origen, de dónde proviene y quién es su creador? ¿por qué y para qué existe esa realidad?

En tercer lugar, la filosofía generaliza el objeto que estudia y de esta forma la realidad que se interroga es vista como una totalidad, que puede ser el Ser en general o seres particulares como el universo, el hombre, o seres creados por éste como la belleza y el arte, la bondad, los valores, la sociedad, la política, la religión, el conocimiento en general o el conocimiento científico - la ciencia- en particular. De esta manera, de acuerdo con la realidad analizada, encuentran su origen las diferentes disciplinas filosóficas,

3 La lógica es una herramienta del trabajo intelectual que nos permite, con base en estructuras que no poseen un contenido concreto de enunciados, relacionar esas estructuras para obtener otras con la plena certeza de que si las primeras son verdaderas, las segundas necesariamente también lo serán. Es importante señalar que la cuestión sobre la verdad o falsedad fáctica de las estructuras iniciales no es objeto de la lógica sino de la disciplina a la que pertenecen.

4 El método dialéctico, por ser uno de los métodos que más manejamos en nuestro análisis, será tratado a lo largo de este trabajo; la manera como lo entendemos será expuesta más detalladamente cuando describamos el marco filosófico del que partimos.

5 El método fenomenológico nos da la posibilidad de "ver" las cosas, en sí mismas, de llegar al $\varepsilon 1 \delta \circ \varsigma$. Este método nos enseña a poner "en paréntesis" todo lo que sabemos de la cosa y nos mueve a describirla tal como aparece ante nosotros, sin prejuicios ni valoraciones. Así, una vez que se va describiendo el objeto se van desechando las propiedades accidentales presentes, para irnos quedando solamente con las propiedades esenciales del objeto analizado.

6 El método hermenéutico nos permite acercarnos al estudio de la realidad, principalmente la humana, de tal manera que se le permite "hablar" a esa realidad, y se entabla de esta forma un diálogo con ella como con un Sujeto. En ese diálogo el investigador y el texto están en igualdad de circunstancias y poseen los mismos derechos; el objetivo del diálogo es tratar de comprender el texto con base en la individualidad del interlocutor y sin hacer violencia sobre él, sin encuadrarlo en una interpretación basada en la visión, los intereses y los valores del intérprete, o subordinándolo a "sistemas" que lo despersonalizan; sino que la comprensión se realiza respetando el "mundo-vida" de lo que se interpreta; es decir, respetando su contexto histórico, social, cultural, su lenguaje, y su particular visión y percepción del mundo. 
como la ontología, la filosofía de la naturaleza, la antropología filosófica o filosofía del hombre, la estética, la ética, la axiología, la filosofía social, la filosofía política, la filosofía de la religión, la teoría del conocimiento o gnoseología, y la filosofía de la ciencia o epistemología, que es la que nos interesa.

De acuerdo con todo lo anterior, por epistemología o filosofía de la ciencia entendemos la reflexión racional que tiene como objeto la ciencia; y dicha reflexión se realiza con ayuda de un instrumental filosófico hecho de conceptos, métodos y categorías. Esto es, las preguntas generales que se plantea toda reflexión filosófica se le plantean a la ciencia, por lo tanto, lo que se investiga es ¿qué es la ciencia? ¿en qué se distingue este tipo de conocimiento de otros? ¿cómo se obtiene y se justifica tal conocimiento? ¿cuáles son las condiciones necesarias y suficientes para que se dé el conocimiento científico? ¿cuál es su función y su finalidad? Y ¿cuáles son sus límites?

Las distintas corrientes epistemológicas ofrecen diferentes repuestas a las preguntas planteadas. Para tener una visión general de ellas, manejar ciertos términos especializados que se emplean en epistemología y comprender mi posición como epistemólogo -porque ésta resulta del diálogo con otros interlocutores de quienes se toman ciertas tesis y se descartan otras-, resumiremos las escuelas epistemológicas que más influyen en este trabajo.

\section{POSITIVISMO}

Esta corriente epistemológica inaugurada por A. Comte en el siglo pasado es una de las que más ha influido en la visión actual que se tiene de la ciencia. Nacida dentro del paradigma de la modernidad comparte con él la creencia en el progreso científico, el cual se realiza en un proceso evolutivo y acumulativo. El modelo científico que se sigue y al que toda disciplina tiene que aspirar para poseer la propiedad de ser científica es el de las ciencias naturales. Por lo tanto toda teoría debe ser semejante a las ciencias naturales; y una de las características específicas de éstas es la utilización del método científico (empírico, experimental y matemático) para su desarrollo. El positivismo reconoce como único y exclusivo garante para realizar y justificar la investigación científica ese tipo de método. En la primera mitad del siglo XX, A. Ayer, R. Carnap, C. Hempel, O. 
Neurath y M. Schlick, entre otros, continuaron con la tradición positivista de la ciencia inaugurada por A. Comte, pero le agregaron el instrumental lógico desarrollado por Frege-Peano-Russell-Whitehead, con lo cual surgió el neopositivismo. ${ }^{7}$ Según estos pensadores todo enunciado tiene sentido sí y sólo si es un enunciado con contenido empírico, que puede ser verificado empíricamente; o si es una tautología lógica que, aunque no tiene información sobre el mundo, es una verdad necesaria que sirve para relacionar los enunciados empíricos, de tal manera que se obtienen inferencias correctas a partir de ellos.

De una manera muy simplificada, el esquema de cómo se hace la Ciencia, según los positivistas, se puede representar de la siguiente manera:

Experiencia empírica $\longrightarrow$ Enunciados observacionales $\longrightarrow$ Teorías

Todos los positivistas son empiristas y por consiguiente afirman que el conocimiento en general, y el conocimiento científico en particular, se origina con la experiencia que nos proporcionan los sentidos. Los enunciados observacionales son expresiones lingüísticas que reflejan una experiencia, es decir, describen fielmente lo que se capta por los sentidos, y son susceptibles de confirmarse empíricamente. Como es sabido, los datos que proporcionan los sentidos siempre son concretos y singulares, por lo que el enunciado observacional también siempre es concreto y singular, y regularmente se incluyen en él las coordenadas espaciales y temporales del fenómeno observado, las circunstancias y condiciones de la observación, la descripción misma del fenómeno y, en ocasiones, los datos del observador. La teoría está constituida por generalizaciones confirmadas sobre los datos empíricos y está formada por leyes generales. Una ley científica es la expresión de ciertas regularidades en la relación entre fenómenos, ${ }^{8}$ y su forma lógica es el de un enunciado universal implicativo:

7 Bajo esta denominación abarcamos al positivismo lógico del Círculo de Viena, al Empirismo lógico y a la Filosofía Analítica anglosajona.

8 En ocasiones se dice que una ley es más que una simple regularidad, porque refleja una relación de causalidad entre los fenómenos, es necesaria y universal. Otros autores expresan que una ley es una relación entre esencias. Sin embargo, un positivista consecuente no acepta estos enunciados porque para él carecen de sentido: la relación causal y la noción de esencia no son empíricos ni términos lógicos. La primera es una noción psicológica, un hábito humano de agrupar fenómenos que ocurren en una secuencia temporal constante (Hume) y la segunda es simplemente un término vacío sin referente. 
$\forall x(A(x) \supset B(x))$ : Para toda $x$, si $x$ tiene la propiedad $A$, entonces $x$ tiene la propiedad $B$.

La función epistemológica de la teoría es, con base a la leyes que la componen, explicar y predecir los fenómenos que estudia. Hempel y Oppenheim son quienes proporcionaron la noción clásica de lo que se entiende por explicación y predicción. Explicar es deducir lógicamente a partir de leyes generales y condiciones iniciales (explanans) lo que se explica (explanandum), teniendo ya presente lo explicado; y predecir es esa misma operación, pero cuando aún no está presente lo que se explica.

Si $L_{1}, L_{2}, L_{3}, \ldots L_{n}$ son Leyes generales, $C_{1}, C_{2}, C_{3}, \ldots C_{n}$ son condiciones iniciales, $P$ es el fenómeno a explicar o predecir y la raya horizontal representa la consecuencia lógica, entonces tenemos la siguiente deducción lógica:

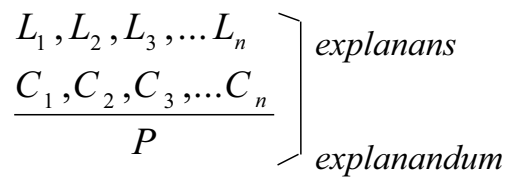

El paso de los enunciados observacionales a las leyes es una generalización efectuada como consecuencia de un proceso muy complejo, (que incluye cuantificaciones, experimentos, elaboración y confirmación de hipótesis, etcétera, lo que todos conocemos como pasos del método científico). Cuando la hipótesis es confirmada por un hecho empírico, se dice que la hipótesis pasa a ser teoría. Pero es en este momento cuando el positivismo, como todo empirismo, se enfrenta a un grave problema: el problema de la inducción. La inferencia a partir de unos casos singulares, como lo son los datos empíricos, a una ley general, es un procedimiento inductivo, pero el problema de la inducción consiste en que no es posible justificar la inducción como método, es decir, no tenemos "derecho" a utilizarla. La forma lógica del razonamiento inductivo es el siguiente:

$A\left(a_{1}\right) \supset B\left(a_{1}\right) \quad$ Si el objeto $a_{1}$ tiene la propiedad $A$ entonces tiene la propiedad $B$.

$A\left(a_{2}\right) \supset B\left(a_{2}\right) \quad$ Si el objeto $a_{2}$ tiene la propiedad $A$ entonces tiene la propiedad $B$. 
$A\left(a_{3}\right) \supset B\left(a_{3}\right) \quad$ Si el objeto $a_{3}$ tiene la propiedad $A$ entonces tiene la propiedad $B$.

$A\left(a_{n}\right) \supset B\left(a_{n}\right) \quad$ Si el objeto $a_{n}$ tiene la propiedad $A$ entonces tiene la propiedad $B$.

Por lo tanto:

$\forall x(A(x) \supset B(x)) \quad$ Para toda $x$, si $x$ tiene la propiedad $A$, entonces tiene la propiedad $B$.

Donde la última fórmula es la conclusión y las demás son las premisas.

Según el mismo marco teórico del positivismo, la inducción se podría justificar lógicamente o empíricamente. Lógicamente no se justifica porque el razonamiento que nos proporciona no es un razonamiento donde haya una consecuencia lógica; es decir, no necesariamente se da el caso de que si las premisas son verdaderas la conclusión también lo será, sino que es posible, nada lo impide, que las premisas sean verdaderas y la conclusión falsa. Por otro lado, tampoco es posible justificar la inducción empíricamente, porque el hecho de decir: "la experiencia indica que hasta ahora la inducción nunca ha fallado, por lo tanto nunca fallará", es estar usando la inducción en ese razonamiento y de este modo se utiliza lo que queremos justificar para justificarse a sí mismo.

Esto señala que la confirmación o verificación no se puede dar, no es posible demostrar la validez de una generalización del tipo $\forall x(A(x) \supset$ $B(x))$ a través de casos concretos como $A\left(a_{1}\right) \supset B\left(a_{1}\right), A\left(a_{2}\right) \supset B\left(a_{2}\right), A\left(a_{3}\right)$ $\supset B\left(a_{3}\right), \ldots A\left(a_{n}\right) \supset B\left(a_{n}\right)$; nada impide que encontremos una $a_{n+1}$ tal que sea $A$ pero no sea $B: A\left(a_{n+1}\right) \& \neg B\left(a_{n+1}\right)$, que haría falsa a la conclusión.

\section{FALSACIONISMO}

Ante el problema anterior, los epistemólogos se pueden refugiar en el probabilismo o en el escepticismo, lo que implica un duro golpe al ideal racionalista que movió al movimiento positivista. Otro tipo de respuesta a la imposibilidad de confirmar empíricamente las leyes generales es la de K. Popper, que él mismo denominó "Racionalismo Crítico" y que se conoce también como falsacionismo. Popper afirma que lo importante no es confirmar la verdad de enunciados generales (cosa por demás imposible), sino demostrar su no-verdad. El científico debe buscar un hecho empírico que 
demuestre la falsedad de la teoría; es decir, debe falsearla. La ciencia se desarrolla, según Popper, desechando teorías que han sido falsificadas, y de esta manera el hombre va obteniendo un conocimiento cierto: sabe con seguridad que el conocimiento que tenía era falso, "se aprende de los errores". Si la teoría resiste una serie de falsaciones, eso demuestra que es una "buena teoría", que es mejor que sus predecesoras, pero no nos prueba que es verdadera sino solamente que "no es falsa por el momento", donde no-falso no es equivalente a verdadero. La falsación propuesta por Popper también se fundamenta en premisas positivistas lógicas, porque la falsación se basa en principios del empirismo y de la lógica formal. Por un lado, lo que falsea a la teoría es un hecho empírico y, además, la teoría debe estar expresada en un lenguaje que la haga potencialmente falseable; esto es, en un lenguaje que exprese hechos empíricos. Por el otro, el mecanismo de la falsación es una demostración lógica. Si la Ley que se pretende falsear es $\forall x(A(x) \supset B(x))$ y el hecho que la falsea es $A(a) \&$ $\neg B(a)$, entonces a partir de esta última forma obtenemos la negación de Ley inicial, la demostración realizada es la siguiente:

1. $A(a) \& \neg B(a)$

2. $\neg(A(a) \supset B(a))$

3. $\exists \neg(A(x) \supset B(x))$

4. $\neg \forall x \neg \neg(A(x) \supset B(x))$

5. $\neg \forall x(A(x) \supset B(x))$
Premisa. Es un hecho confirmado empíricamente.

De 1 por la equivalencia $\neg(A(a) \supset B(a)) \equiv A(a) \& \neg B(a)$.

De 2 por introducción del cuantificador existencial $\exists$.

De 3 por la equivalencia $\neg \forall x \neg A(x) \equiv \exists A(x)$.

De 4 por eliminación de la doble negación.

Sin embargo el falsacionismo también presenta limitaciones. En primer lugar aunque defiende la capacidad de conocer, ésta se limita a conocer lo que es falso, pero no la verdad.Y en segundo lugar es difícil tener un criterio seguro que nos indique cuándo un hecho empírico realmente está falseando la teoría. Siempre existe la posibilidad de encontrar explicaciones sobre por qué un hecho contradice la teoría; podemos aducir la existencia de condiciones adicionales desconocidas, o la imperfección de los instrumentos utilizados, o la falla en los cálculos realizados, etcétera; es decir, una falla en la teoría no nos lleva inmediatamente a deshacernos de ella, sino al contrario, se vuelve objeto de una investigación que aclare el fenómeno anómalo. Unos ejemplos típicos de que hechos empíricos que claramente contradecían a la teoría no eran tomados como 
falsaciones son la desviación de la órbita de Urano a lo predicho por la Teoría Newtoniana, o los movimientos no circulares de ciertos astros, que iban en contra de la Astronomía de Ptolomeo. ${ }^{9}$

De esta manera la historia de la ciencia nos muestra que la comunidad científica no deshecha tan fácilmente una teoría sino que trata de conservarla hasta que esto ya es imposible. Esto llevó a T. Kuhn a desarrollar su idea sobre la estructura de la "revolución científica".

\section{T. KUHN Y LAS REVOLUCIONES CIENTÍFICAS}

$T$. Kuhn analiza la forma en que se ha venido construyendo el conocimiento científico a través de la historia para de esta manera poder entender qué es lo que caracteriza a la ciencia como tal. Según Kuhn el devenir del conocimiento científico pasa por diferentes etapas, cada una de las cuales se diferencia de las otras por la relación que tienen con lo que él llamó "paradigma científico". Por desgracia el mismo Kuhn, en la Posdata de 1969, reconoce que en su "[...] texto original no deja ninguna cuestión más oscura o más importante" 10 que la de paradigma. Al intentar clarificarlo, en ese mismo escrito, distingue dos sentidos de paradigma: como logro o solución de un problema reconocido por la comunidad, y como "constelación de compromisos de grupo"; a este último, que es el sentido de paradigma como marco de investigación y que es el que más se ha utilizado, "para evitar confusiones" sugiere llamarlo "matriz disciplinaria". 11

9 De acuerdo con los cálculos realizados por los astrónomos según la Teoría de Newton, Urano debería seguir cierta trayectoria en su órbita, pero en realidad se apartaba de ella. Los científicos no desecharon la Teoría newtoniana sino que buscaron una explicación a dicha anomalía, y sugirieron la hipótesis de la existencia de un planeta, con determinada masa y a una distancia concreta, que influía con su fuerza gravitacional sobre Urano, lo apartaba de la órbita original y hacía que siguiera la trayectoria que se observaba. Al buscar dicho planeta y no encontrarlo no se falseaba la teoría, se seguía buscando, hasta que por fin fue descubierto Neptuno. Otro caso es el de los planetas que no seguían una órbita circular perfecta alrededor de la tierra como lo deberían de hacer de acuerdo con la Teoría de Ptolomeo, pero ese hecho no llevó a desechar la teoría sino que se explicó el fenómeno por medio de epiciclos.

10 Thomas Kuhn, Posdata: 1969, en La estructura de las revoluciones científicas. México: FCE, 1996. Duodécima reimpresión. p. 278.

11 Ibid. p. 279. 
Dentro de la matriz disciplinaria, existen, según Kuhn, varios componentes, de los cuales analiza cuatro. El primero, que denomina "generalizaciones simbólicas", "[...]parecen leyes de la naturaleza, pero para los miembros del grupo, su función a menudo no es tan sólo esa [...] funcionan en parte como leyes, pero también en parte como definiciones de algunos de los símbolos que muestran". ${ }^{12}$ Según parece este componente proporciona la posibilidad de compartir un "juego de lenguaje" entre la comunidad, lo que ofrece la posibilidad de tener una terminología, una semántica y el uso de un lenguaje común.

El segundo componente de la matriz disciplinaria son los compromisos ontológicos compartidos, que son creencias en modelos particulares que pueden incluir la creencia en la existencia de ciertos objetos y procesos, o en la aceptación de ciertas analogías o metáforas. Esto ayuda a "[...]determinar lo que será aceptado como explicación y como solución de problemas [...] en la determinación de la lista de enigmas no resueltos y en la evaluación de la importancia de cada uno". ${ }^{13}$ Este componente ofrece la posibilidad de compartir un "mundo" que merece ser estudiado y que al mismo tiempo ofrece las soluciones para los problemas que plantea.

El tercer elemento de la matriz disciplinaria está constituido por los valores compartidos por la comunidad epistémica. Los valores mencionados por Kuhn son los que se refieren a la amplitud y precisión en las predicciones, a la fecundidad para formular y solucionar enigmas, a la sencillez teórica, y a su coherencia interna y externa con otras disciplinas. Este componente orienta la intencionalidad (direccionalidad) de la actividad investigadora.

El cuarto componente, aunque no el último restante, se refiere a los ejemplos paradigmáticos, "[...] las concretas soluciones de problemas que los estudiantes encuentran desde el principio de su educación científica [...] y que les enseñan, mediante el ejemplo, cómo deben realizar su tarea".

Con base en ese concepto central de paradigma o matriz disciplinaria, T. Kuhn afirma que las diversas disciplinas científicas se desarrollan de acuerdo con una estructura general que comienza con una etapa "precientífica" (preparadigmática) en la que "[...]excluyendo los campos,

12 Ibid. p. 281.

13 Ibid. p. 283. 
tales como las matemáticas y la astronomía, en los que los primeros paradigmas firmes datan de la prehistoria, y también los que, como la bioquímica, surgieron por la división o la combinación de especialidades ya maduras", 14 no existía una opinión única, sino la competencia entre diversas escuelas sobre qué se debía investigar (compromiso ontológico), cuáles eran los conceptos centrales (generalizaciones simbólicas), las respuestas correctas (ejemplos paradigmáticos), los instrumentos técnicos y metodológicos que se debían emplear, las interpretaciones "canónicas", etcétera. Este periodo termina cuando los distintos investigadores aceptan, por consenso, un mismo marco de principios básicos para hacer su investigación (paradigma) integrándose ellos mismos como comunidad científica y reconociéndose como tal, con lo cual aparece el periodo de "ciencia normal". Durante esta etapa, la ciencia normal se dedica a resolver enigmas, esto es, a resolver problemas científicos, pero siguiendo las "reglas" establecidas por el paradigma; es decir, reconocen los problemas, recolectan datos, los interpretan y analizan, todo de acuerdo con el modelo que establece el paradigma. El marco de principios básicos se acepta y no se cuestiona ni se considera problemático o sujeto a revisión; y se trabaja todo el tiempo con las mismas reglas de juego, lo que permite que se dé la acumulación de conocimientos. El paradigma es una promesa de ampliar exitosamente el conocimiento resolviendo enigmas, pero si existen fracasos la culpa es de la poca capacidad de los investigadores y no del marco de principios aceptados. Sin embargo siempre llega un momento en que la ciencia normal, debido a su amplitud explicativa y al aumento de su contenido informativo (cuanto más se diga, más riesgo hay de equivocarse; quien dice nada, nunca se equivoca; si se dice poco, hay poco riesgo de cometer errores) se enfrenta a un problema que no puede resolver, no por falta de habilidad del científico, sino porque en cierta forma "[...] la naturaleza ha violado las expectativas, inducidas por el paradigma, que rigen a la ciencia normal" 15 y se resiste a ser resuelto con las herramientas instrumentales y teóricas del paradigma. Ese fenómeno no debería existir, no tiene concepto ni explicación teórica. Esos problemas que el paradigma reinante no puede resolver se llaman anomalías, las cuales no

$14 \quad$ Ibid.p. 40.

15 Ibid.p. 93. 
conducen inmediatamente a la falsación, sino que se dejan a un lado esperando el momento en que el paradigma, enriquecido con nuevos descubrimientos o el perfeccionamiento de instrumentos, los pueda resolver. Sin embargo puede suceder que dada la importancia teórica de las anomalías, el peso de evidencias que no pueden ser ignoradas o simplemente el tiempo que transcurre sin que sean resueltas, exijan ser explicadas, pero no lo son; entonces dichas anomalías están directamente en contra de los fundamentos del paradigma y ahí comienza la etapa de "crisis" y con ella la ciencia extraordinaria. ${ }^{16}$ En esta etapa los investigadores tienen la oportunidad de ensayarlo todo. "Los primeros intentos de resolución del problema seguirán de cerca las reglas establecidas por el paradigma; pero al continuar adelante sin poder vencer la resistencia, las tentativas de resolución involucrarán, cada vez más, alguna coyuntura menor o no tan ligera del paradigma [...] las reglas de la ciencia normal se hacen cada vez más confusas". ${ }^{17}$ De esta manera, "[...] cada vez más, la investigación [se va] pareciendo a la llevada a cabo por las escuelas en competencia del periodo anterior al paradigma". ${ }^{18}$ Finalmente la crisis se termina cuando el paradigma en tela de juicio se muestra capaz de resolver las anomalías o surge un paradigma alternativo que parece ofrecer una respuesta a la anomalía, además de que promete guiar la investigación por un camino fructífero de soluciones de enigmas, lo que comenzaría así la lucha por lograr un nuevo consenso, hasta que el paradigma alternativo vence y es aceptado por la comunidad científica, y de esta forma se realiza una revolución científica. ${ }^{19}$ Al principio el nuevo paradigma tiene unos pocos adeptos, pero poco a poco se va imponiendo hasta ser el dominante. De esta manera empieza un nuevo periodo de ciencia normal y se repite el ciclo una vez más.

El anterior desarrollo de las ciencias puede ser representado esquemáticamente de la siguiente manera:

16 Por ejemplo la crisis de la física clásica derivada de las contradicciones entre la electrodinámica y la mecánica, la demostración de Michelson de la inexistencia del éter y las transformaciones de Lorenz.

17 Ibid. p. 136-137.

18 Ibid. p. 121.

19 Un ejemplo de revolución científica es el nacimiento de la física de la relatividad. 


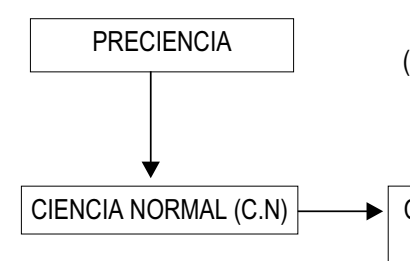

(No existe paradigma científico ni comunidad científica)

(Aparece un paradigma científico y es aceptado por la comunidad científica)
CIENCIA EXTRAORDINARIA (C.E) CRISIS

(El paradigma aceptado no puede resolver algunas anomalías, se realizan intentos de resolverlos y aparecen paradigmas alternativos que compiten con el anterior)
REVOLUCIÓN CIENTÍFICA (R.C)

(Un nuevo paradigma desplaza al anterior al ser aceptado por la comunidad científica) C.E $\longrightarrow \ldots$ (El ciclo se repite)

Es importante señalar que el paradigma se acepta a través de mecanismos extrarracionales; finalmente son la propaganda y el poder los factores determinantes que lo imponen. Esto es debido a que una comunidad científica no es algo abstracto sino algo concreto, con sus líderes que manejan el presupuesto, los comités editoriales, la aprobación de los planes de estudio, las comisiones dictaminadoras que eligen la planta de docentes e investigadores, etcétera; es decir, aquellos que deciden qué, cómo y quiénes van a desarrollar la ciencia. Por supuesto esos dirigentes escogen a quienes están de acuerdo con su paradigma. 20

La visión kuhniana del desarrollo científico es atractiva en cuanto toma en cuenta factores que otros han ignorado, como son el papel comunitario de la actividad científica y, sobre todo, su historicidad, avalada por muchos ejemplos proporcionados por la historia de la ciencia.

Sin embargo en nuestra opinión el modelo kuhniano deja un sentimiento de insatisfacción al concebir el desarrollo de la ciencia como rupturas entre paradigmas, como grandes saltos de una forma de hacer ciencia a otra, sin que se puedan homologar completamente, ni decidir cuál de ellas es "más

20 Un análisis de mi posición de los líderes intelectuales en la comunidad científica puede encontrarse en: Miguel Ángel Rendón Rojas. "Debate sobre epistemología de la Bibliotecología”, en Investigación bibliotecológica. № 21, Vol. 10. CUIB/UNAM, 1996. 
verdadera", porque los nuevos conocimientos no reemplazan a la ignorancia sino a otros conocimientos de tipo distinto e incompatible. ${ }^{21}$ Esas rupturas y saltos se deben a lo que Kuhn denominó inconmensurabilidad entre paradigmas, la cual resulta de un constructivismo, que aunque no es tan radical como el del idealismo subjetivo de Berkeley, en el que el sujeto llega a crear, en el sentido ontológico, la realidad, sí es un subjetivismo de tipo kantiano porque si bien se reconoce la existencia de un mundo dado que no varía pese a los cambios de paradigmas, éste permanece en el nivel obscuro y desconocido de "la cosa en sí", que sólo puede ser "visto" a través del paradigma que le da forma (Gestalt); y por consiguiente, si cambia el paradigma, cambia la forma de verlo. 22

De esta manera la inconmensurabilidad nos conduce en primer lugar a un solipsismo colectivo porque plantea un abismo entre los mundos de comunidades científicas con diferentes paradigmas, debido a que "[...] quienes proponen los paradigmas en competencia practican sus profesiones en mundos diferentes". ${ }^{23}$ Asimismo, la inconmensurabilidad determina una incapacidad de comunicación entre distintas comunidades paradigmáticas puesto que aunque los nuevos paradigmas "[...]incorporan ordinariamente gran parte del vocabulario y de los aparatos, tanto conceptuales como de manipulación [...] es raro que empleen exactamente del modo tradicional a esos elementos que han tomado prestados [por lo que] el resultado inevitable es lo que debemos llamar [...] un malentendido entre las dos escuelas en competencia". ${ }^{24}$

Sin embargo cabe señalar que en otros escritos Kuhn reconoce la existencia de elementos comunes entre distintos paradigmas ya que inconmensurabilidad no significa intraducibilidad total o incomprensibilidad, sino únicamente que dos teorías están articuladas en lenguajes que no son completamente traducibles entre sí, lo que permite cierta traducibilidad, aunque no "punto por punto". A pesar de que no puede darse una traducción completa, se puede llegar a la "comprensión" gracias a la interpretación, ya que traducción e interpretación son quehaceres distintos. La primera consiste en una

$21 \quad$ Ibid. p. 154.

22 Por supuesto que el paradigma que actúa como elemento de síntesis en la forma de construir el mundo para la comunidad científica no es una forma a priori de conocimiento.

23 Ibid. p. 233.

24 Ibid. p. 231 
actividad casi mecánica, donde una secuencia de palabras en un lenguaje es sustituida por otra secuencia en otro lenguaje, sin que haya pérdida de significado; esto es, se puede encontrar una relación isimórfica entre esos lenguajes. ${ }^{25}$ Por el contrario, en la interpretación no se utilizan dos lenguajes donde uno se "vacía" en el otro, sino que se tiene el lenguaje original a interpretar y es necesario aprenderlo, vivir en él y ver a través de él. Como lo señala Kuhn: "Cualquier cosa que se puede decir en un lenguaje puede, con suficiente imaginación y esfuerzo, ser comprendida por un hablante de otro lenguaje. El requisito previo para tal comprensión, sin embargo, no es la traducción sino el aprendizaje del lenguaje". ${ }^{26}$ Pero la imposibilidad de la traducción "punto por punto" en algún momento nos llevará a encontrar en otro lenguaje algo que aunque se comprende no es posible traducirlo; así por ejemplo, “[...]las personas bilingües reportan repetidamente que hay cosas que pueden expresar en uno de los lenguajes que no pueden expresar en otro". ${ }^{27}$ Lo anterior simplemente significa que algo se entiende pero no se puede hablar de ello. ¿No cabría aquí recordar el aforismo de Wittgenstein que dice que de lo que no se puede hablar es mejor callar?28

En segundo lugar, la inconmensurabilidad tiene como consecuencia el hecho de adoptar un concepto de verdad acorde con ese constructivismo internalista atenuado. De ahí la afirmación de que el nuevo conocimiento reemplaza a otro distinto y no a la ignorancia o al error. Todo enunciado que está de acuerdo con el mundo creado, con la forma en que se percibe ese mundo, es verdadero; con la agravante de que esa forma es producto del enunciado. Así pues, los enunciados "el agua es un elemento" y "el agua está compuesta de hidrógeno y oxígeno"; "el sol gira alrededor de la tierra" y "la tierra gira alrededor del sol"; "los seres vivos no evolucionan" y "los seres vivos evolucionan"; "el flojisto es causa de

25 Isomorfismo es la cualidad de dos conjuntos entre los cuales se puede establecer una correspondencia biunívoca entre sus elementos; esto es, a cada elemento de un conjunto se le puede relacionar uno y sólo un elemento del otro conjunto.

26 T. Kuhn, "Dubbing and Redubbing: The Vulnerability of Rigid Designation", en W. Savage (ed), Scientific Theories. Minnesota Studies in the Philosophy of Science. Vo. XIV. Minneapolis: University of Minnesota Press, 1990. pp. 298-318. p. 300.

27 T. Kuhn, “Afterwords", en P. Horwich (ed) World Changes. Thomas Kuhn and the Nature of Science. Cambridge, Massachusetts, 1993. pp. 311-341. p. 324.

28 L. Wittgenstein, Tractatus Lógico Filosófico. 6.523. 
la combustión” y "el oxígeno es causa de la combustión”; "los procesos de autoría, publicación y distribución de documentos son autónomos y claramente diferenciables en sus pasos y actores" y "los procesos de autoría, publicación y distribución de documentos coinciden"; "la biblioteca es un espacio físico que posee colecciones organizadas y personal que da servicio a usuarios presenciales" y "la biblioteca no es un espacio físico y no posee co- lecciones organizadas aunque da servicios a usuarios a distancia" son verdaderos cada uno en su matriz disciplinaria, sin que exista la posibilidad de contrastación entre ellos. Consideramos que negar un realismo externo de un ser que, en palabras de Heidegger, se de-vele y des-cubra, no lleva a este tipo de relativismo epistémico.

En tercer lugar, puesto que la elección entre paradigmas es una transición entre inconmensurables y no existe ni un mundo común, ni un lenguaje común, ni percepciones comunes, entonces dicha elección no está justificada ni por la lógica, ni por la experiencia neutral, ni por una prueba algorítmica. Por ello es necesario recurrir a la persuasión (eso sí "con buenas razones"), a la fe en el poder del nuevo paradigma, a la fidelidad profesional, e incluso a la autoridad extracientífica, para que tenga lugar la "conversión" al nuevo paradigma. ${ }^{29}$ Pero siempre con la certeza un poco triste, como lo escribió Max Planck, de que "[...] una nueva verdad científica no triunfa por medio del convencimiento de sus oponentes, haciéndoles ver la luz, sino más bien porque dichos oponentes llegan a morir y crece una nueva generación que se familiariza con ella”. 30

Consideramos que en el desarrollo de la ciencia en general la tradición tiene cabida, no como prejuicios dogmáticos aceptados por fe, autoridad o fidelidad y que pueden ser cambiados por otros gracias a una conversión, sino como premisas que permiten interrogar, interpretar e interpelar al objeto de estudio que ontológicamente existe en sí, aunque epistemológicamente haya sido construido (;pero siempre con base en su primacía ontológica!) y que son aceptadas precisamente por aportar y permitir respuestas sobre ese objeto de estudio. La inconmensurabilidad no es tal, la intraducibilidad total no existe gracias a ese mundo externo que posibilita

29 T. Kuhn, La estructurade las revoluciones cientificas. México: FCE, 1996. pp. 234-246.

30 Max Planck, Scientific Autobiography and Other Papers. pp. 33-34. Citado por Kuhn, T. Op. Cit. p. 235. 
el diálogo interparadigmático y no sólo intraparadigmático, que al final de cuentas es un monólogo.

Si existen la posibilidad de la comprensión, con todo lo que ello implica: la posibilidad de compartir sentidos y significados; el mundo externo y la verdad como la adecuación de los enunciados con ese mundo, entonces, a menos de correr el riesgo de recaer en el psicologismo ampliamente criticado por Husserl y desmentido por el desarrollo de la lógica en el siglo XX, eso muestra la posibilidad de la comunidad de comunidades, por lo menos en sentido epistémico y dialógico porque se comparte un mundo ideal (sentidos y significados) en la comprensión y un mundo material con los referentes en el mundo externo. Si se "ve" otra cosa, como un tipo de nieve que los esquimales perciben claramente y nosotros no; o un gas que Lavosier llamó oxígeno y Priestley "aire común con una cantidad menor que la usual de flojisto"; o un objeto que algunos llaman "libro electrónico" y que para otros es todo "menos libro"; siempre es posible "ir a las cosas mismas" ideales (sentidos) o materiales (referentes) para llegar a un acuerdo, por supuesto si se tiene la suficiente apertura para querer hacerlo y no negarse, como le sucedió a Galileo con sus oponentes, quienes tomaron la posición de "no querer mirar a través del telescopio". Pero ese acuerdo que se alcanza no es el resultado de un consenso o negociación, ni se hace con base en mi o nuestra verdad, sino con base en la verdad que corresponde a cierto análisis de la realidad. Ahora bien, como la teoría es un sistema en donde existe una red de enunciados y conceptos que están interconectados, dependen unos de otros y se modifican mutuamente, entonces si dentro de ese sistema se introduce un nuevo concepto o enunciado que lo contenga y explique, se van a ver modificados todos los demás conceptos y enunciados. Pero esto significa que la tarea es clarificar y no negarse a aceptar nuevos conceptos. Se podría preguntar iy si los cambios son tan fuertes que se llega a un nuevo paradigma? Nuestra respuesta es que si esos cambios están de acuerdo con la realidad, nos ayudarán a profundizar en nuestro conocimiento y no a romper con conocimientos anteriores que como tales están en concordancia con la realidad, aunque tal vez en otro nivel de profundización u otro enfoque, de ahí el paralelismo y la intraducibilidad "punto por punto" entre algunas teorías que parecen estudiar lo mismo. 
Según nuestra opinión, uno de los problemas de las revoluciones científicas que se nos proporcionan como ejemplos es que nos muestran cambios de paradigmas erróneos a otros que no lo son (de la teoría del flojisto a la teoría de la combustión de Lavosier; de la astronomía de AristótelesPtolomeo a la astronomía de Galileo-Newton; de la teoría del creacionismo fijista a la teoría de la evolución) en los que, por supuesto, tienen que ser abandonados los primeros. ${ }^{31}$ ¿Pero qué sucede con avances con otros enfoques que no tienen que ser abandonados, por ejemplo con la física de Newton y la física de la relatividad, donde no se dan rompimientos, sino que los físicos en todas las universidades se siguen educando en los dos paradigmas? De manera semejante en el campo de la ciencia bibliotecológica ¿un profesional de la información documental no estará obligado a estudiar los supuestos dos paradigmas: el tradicional, que se centra en el mundo de los impresos, su organización y servicio en unidades informativas bien determinadas - bibliotecas, archivos- y el nuevo, que estudia entes más abstractos como la información y el conocimiento y no sólo su organización sino su gestión, o fenómenos novedosos como documento electrónico y biblioteca virtual, entre otros? ¿No le ayudará ese estudio del primer paradigma para comprender y buscar las respuestas a las preguntas que le plantean las nuevas realidades? ¿No es el afán de realizar

31 Aunque estamos conscientes de que semejante afirmación en el mundo postmoderno actual puede parecer "la última pretensión del racionalismo y positivismo ya superados para alcanzar la verdad" e incluso para el mismo Kuhn el hablar de un paradigma erróneo y otro correcto carecería de sentido. Pero considero que el realismo y el concepto de verdad como adecuación son los únicos instrumentos para huir del relativismo. Un ejemplo dramático que por cierto se rehuye (¿porque carece de importancia, por ignorancia o porque resulta incómodo?) es el cambio de paradigma en medicina propuesto, pero sin resonancia mundial en su momento, por el médico húngaro Ignaz Semmelweis, de cuando se desconocía e incluso se burlaban de la asepsia, a cuando ésta se descubre y practica. A las mujeres que morían por fiebre puerperal por supuesto que no les sería indiferente el hecho de que hubieran podido haberse salvado si esa nueva idea (paradigma) hubiera triunfado en el pensamiento médico con anterioridad. ¿Puede haber algo más fuerte que la vida misma que rompa la inconmensurabilidad? La afirmación de que los enunciados: "las causas de una infección se deben a la existencia de microorganismos que pueden ser eliminados y con ellos la infección misma", y "las causas de una infección no se deben a la supuesta existencia de microorganismos, por lo que es tan innecesario querer eliminarlos o no", son ambos verdaderos dependiendo del paradigma en que se afirmen, sólo puede ser expuesta en discusiones "filosóficas, especulativas", pero nos exponemos a recibir una bofetada si lo hacemos ante los que sufrieron una pérdida por una infección que pudo haber sido evitada. 
una ruptura con la tradición lo que obliga a "reinventar" de la nada lo que ya se tenía sobre descripción, organización y recuperación de documentos? ¿Por qué otros tienen que hacer esas tareas semejantes si ya existen profesionales que lo han venido haciendo durante años? ¿No es más bien por eso, que quienes tienen el conocimiento (bibliotecólogos) no se han dado a la tarea de ponerlo en correspondencia con la realidad actual, y que quienes no tienen ese conocimiento (ingenieros, administradores principalmente) han tratado de hacerlo, lo que ocasiona en gran parte la confusión, la introducción de conceptos sin definir, de términos ambiguos? Nuestro diagnóstico es que si bien existe una realidad nueva, que nos obliga a readaptar y desarrollar el conocimiento, que nos proporciona el elemento de innovación, también es cierto que no se debe partir de la nada, lo cual salva la tradición. La cuestión no es sustituir unos conocimientos por otros, sino profundizar, complementar, desarrollar unos conocimientos que se tienen y, sólo si es necesario, desechar otros que se creían tener pero que no eran tales. ${ }^{32}$

\section{EL ANARQUISMO EPISTEMOLÓGICO}

De esta manera paradójica, las corrientes que deseaban salvar la racionalidad y encontrarle un fundamento al conocimiento científico, nos condujeron al relativismo. La reacción filosófica contra el ideal cientificista y el monopolio del método científico fue una crítica a ese ideal y al método científico, y renunció a todo fundacionalismo. Una corriente que refleja ese deseo de salirse de una normatividad metodológica es el anarquismo metodológico de P. Feyerabend.

Según Feyerabend la historia de la ciencia demuestra que no existe un método único en la investigación científica sino que, por el contrario, existen tantos métodos cuantos científicos haya. Cada investigador tiene la libertad de crear su propio método, porque si existiera uno solo, razona Feyerabend, esto coartaría la libertad del científico, por lo que en nombre de un humanismo completo y teniendo en cuenta que la actividad científica

32 De lo que se ha dicho anteriormente, se puede deducir el concepto de conocimiento, desde el punto de vista epistémico -no negamos la posibilidad de otro tipo de conocimientosque manejamos: enunciado aceptado (creencia) verdadero y justificado. Si resulta que no es verdadero, por mucho que haya sido aceptado y creído por la mayoría, simplemente no es conocimiento. 
es una actividad creativa - la cual no es posible sin una libertad de acción completa-se concluye que no es posible la existencia de un único método científico. El lema que ha pasado a ser representativo del anarquismo metodológico es “todo vale". Si el científico cree que determinada técnica, procedimiento o cualquier uso de instrumentos, le permitirá avanzar en su investigación, es libre de emplearla sin considerar que lo prohíbe o lo permite cierta metodología.

Así pues, teniendo presente de una manera global las características de las corrientes epistemológicas descritas y adoptando ideas que consideramos positivas y desechando las que consideramos negativas daremos nuestra visión de ciencia y ciencia social para que de acuerdo con ese modelo podamos fundamentar la bibliotecología.

\section{LOS PROGRAMAS DE INVESTIGACIÓN CIENTÍFICA DE I. LAKATOS}

El epistemólogo húngaro, Imre Lakatos, propone un modelo mediante el cual explica el desarrollo histórico de la construcción del conocimiento científico, y un elemento central de dicho modelo es el concepto de Programas de Investigación Científica. ${ }^{33}$ Para Lakatos el desarrollo de la ciencia no es el resultado de la confrontación entre una teoría y los hechos, sino de la competencia de dos teorías que se confrontan ante un mismo hecho. Esto es, no se trata de que una teoría única aspire a explicar un fenómeno, y de que del resultado de si lo consigue o no dependa su desarrollo o eliminación, sino de que existen dos teorías que tratan de explicar un mismo fenómeno. El progreso del conocimiento científico dependerá de cuál de estas teorías explique el fenómeno implicado de manera satisfactoria, tras lo cual se dejará a la otra como una opción que no tiene perspectiva y por lo tanto no vale la pena ser desarrollada.

Las teorías en competencia surgen y se desarrollan dentro de un programa de investigación. Según Lakatos, cada uno de los programas de investigación científica está constituido por tres elementos. El primero de ellos es el núcleo duro, que contiene las leyes, conceptos y supuestos fundamentales

33 Los trabajos donde podemos encontrar las ideas de Lakatos sobre los Programas de Investigación Científica son entre otros: "Falsación y la metodología de los programas de investigación científica" y. "La historia de la ciencia y sus reconstrucciones racionales". Ambos reunidos en Imre Lakatos, La metodología de los programas de investigación cientifica. Madrid: Alianza Editorial, 1983. 
que le dan la característica definitoria al programa de investigación, gracias a él el programa de investigación científica tiene una identidad propia. Este núcleo es infalseable por la decisión metodológica de los especialistas; es decir, no se puede atacar ni modificar, "está fuera de toda negociación”. Así por ejemplo, el núcleo duro de la física clásica está compuesto por las tres leyes del movimiento de Newton más su ley de gravitación universal; el núcleo duro de la astronomía de Copérnico-Galileo contiene la tesis de que el sol está inmóvil, y de que los planetas, entre ellos la tierra, giran alrededor de él y la tierra tiene un movimiento de rotación sobre su eje.

El segundo elemento del programa de investigación científica es el cinturón protector formado por hipótesis auxiliares, condiciones iniciales, conceptos y terminología auxiliares, teorías, etcétera. Dicho cinturón se encuentra bajo la dirección que marca el núcleo duro y respetando los principios que éste le marca buscará ampliar las explicaciones de los fenómenos. Asimismo, como su nombre lo indica, su función es proteger al núcleo duro del programa de posibles falsaciones. Todas las refutaciones serán recibidas y absorbidas por el cinturón protector que es el que se puede modificar desechando, introduciendo o transformando algunos de sus elementos. Así por ejemplo, si el comportamiento de los planetas difería de lo predicho por la astronomía copernicana, se defendía el núcleo duro de ese programa añadiendo o modificando epiciclos a las órbitas de los planetas que en un principio se creían circulares, cambiando el cálculo de la distancia de la tierra a las estrellas, introduciendo nuevas condiciones iniciales, etcétera.

El tercer componente del programa de investigación científica es la heurística o conjunto de reglas metodológicas que indican lo que se debe hacer o está prohibido realizar en el proceso de investigación. De acuerdo con esto último, la heurística puede ser negativa o positiva. La primera nos indica lo que debemos evitar: atacar el núcleo duro; mientras que la segunda nos guía sobre qué caminos se deben seguir para resolver los problemas que se van presentando, indicándonos cómo se ha de completar el núcleo duro para que pueda explicar los fenómenos, cómo cambiar y desarrollar las variables refutables, y cómo modificar el cinturón protector.

Ahora bien, el cambio de un programa de investigación científica a otro se da no como el cambio de paradigmas en Kuhn, por una conversión casi 
mística gobernada más bien por la psicología social del conocimiento, sino por una evaluación racional con base en el dictamen de lo progresivo o degenerativo de los programas y no de una teoría aislada de ese programa. Cuando en una serie de teorías dentro de un programa se encuentran unas teorías que logran realizar nuevas explicaciones y predicciones que sus predecesoras no hacían, el programa de investigación es teóricamente progresivo, y si además de eso dicho contenido teórico es confirmado, resulta que el programa de investigación es empíricamente progresivo; y en caso contrario se dice que es degenerativo. Una teoría puede ser reemplazada por otra que posee mayor contenido empírico confirmado, pero de ahí no se sigue que el programa de investigación se abandone, sino que, gracias a que se encontró otra teoría, continúa vigente. El programa de investigación se cambia cuando todo él es degenerativo; esto es, cuando ya no se encuentran nuevas teorías con mayor contenido empírico que amplíen su alcance de explicación y predicción, además de que tiene un programa rival que es progresivo.

Esta concepción del desarrollo de la ciencia nos proporciona la posibilidad de conciliar los opuestos: innovación y tradición, ya que dentro de un mismo programa tienen cabida la tradición dentro del núcleo duro, y la innovación dentro del cinturón protector. Lo anterior nos servirá para demostrar que la tradición y la innovación tienen lugar en el desarrollo de la ciencia bibliotecológica y de la información.

Sin embargo no retomamos totalmente las ideas de Lakatos sin ninguna modificación, sino que proponemos una interpretación que nos parece necesaria. En primer lugar, consideramos que la inmunidad a la falsación del núcleo duro no es el resultado de un acuerdo metodológico entre los especialistas, sino la consecuencia que posibilita comprender y explicar la realidad misma. Tener unos principios iniciales a partir de los cuales se interpreta la realidad, no implica el ponerse y no querer quitarse unos anteojos de determinado color para ver la realidad de ese color, sino sólo tener un punto de apoyo, sacado de la realidad y para ver ésta, que sirva como principio de un camino interpretativo. Los principios del núcleo duro de la Genética de Lysenko o de la Lógica "proletaria" (dialéctica) soviética, por ejemplo, no permitían la interpretación del fenómeno estudiado sino su velación, y mucho menos permitían la valoración crítica de esos principios, de tal modo que no eran principios que abrieran sus puertas a la 
investigación, sino unas cadenas que la impedían, por lo que había que abandonarlos.

En segundo lugar, proponemos una noción de programa de investigación científica más amplia aún que la sugerida por Lakatos. Así por ejemplo, tendríamos un programa de investigación en biología cuya parte central (núcleo duro) sería la idea de la evolución frente a otro programa cuyo núcleo duro sería el fijismo. Dentro del primer programa se desprenden la teoría de Lamarck, que explica el cambio morfológico por adaptación al medio ambiente con base en su tesis fundamental de que la función crea al órgano y de que la transmisión de esto es hereditaria, pero que posteriormente fue sustituida por la teoría de Darwin con su tesis de selección natural y ésta, a su vez, fue complementada por la teoría integral de la evolución (neodarwinismo) que incluye además ideas de la genética, la ecología y la biogeografía. Para Lakatos el programa de investigación sería la teoría de Darwin frente a la teoría de Lamarck, que no llegó a crear otras teorías.

En tercer lugar, otra aportación que le hacemos a Lakatos y que puede parecer contradictoria es la idea de que el núcleo central puede ir modificándose sin que por ello cambie el programa de investigación. Esto sucede cuando se descubre que lo que se consideraba el "corazón" de dicho programa no lo era, sino que a su vez se desprende de otro núcleo más profundo pero no contradictorio con él, el cual determina no que se deseche el núcleo anterior sino su conservación, ahora como una teoría dentro del cinturón protector, y al mismo tiempo la aparición de otras teorías, cada una de ellas en un contexto determinado pero abarcado y contemplado por el nuevo núcleo central. Así sucede con la teoría de Darwin y el neodarwinismo dentro del programa evolutivo e incluso, nos atreveríamos a decir, con la física clásica, de la relatividad y cuántica, las cuales "trabajan" en su contexto epistemológico determinado, con su "porción de realidad", y la explican. Estas tres últimas se circunscriben dentro de un programa de investigación física que concibe el movimiento como desplazamiento de "cuerpos" en coordenadas espaciales y se excluye totalmente a una física aristotélica que define al movimiento como cambio "cualitativo" en general de la "materia". Todas ellas no se desechan sino que coexisten, aunque no sean casos límite, generalizaciones o deducciones unas de otras. 


\section{LA HERMENÉUTICA FILOSÓFICA}

Una corriente filosófica que como toda visión de este tipo tiene dentro de su campo de reflexión todos los ámbitos de la realidad y en consecuencia la teoría de la ciencia, es la llamada hermenéutica filosófica. En sus inicios la hermenéutica era considerada como el arte y la técnica de interpretar textos. El mismo término hermenéutica a primera vista tiene semejanza con el nombre de Hermes, el dios mediador entre el Olimpo y los hombres, y si no etimológicamente sí al menos simbólicamente, se encuentra ligado al origen de la palabra griega $\varepsilon \rho \mu \eta v \varepsilon i ́ \alpha$ (hermeneia). Hermes es el mensajero de los dioses que traduce la voluntad divina a un lenguaje inteligible para los mortales. En filología tuvo un lugar especial, puesto que era una herramienta para interpretar los textos de autores clásicos que escribieron en otro contexto lingüístico e histórico, por lo que eran de difícil acceso para los lectores de una cultura distinta. El judaísmo y el cristianismo, como religiones que contienen las verdades reveladas por Dios en un libro por antonomasia, la Biblia, le dieron mucha importancia a la interpretación de la Sagrada Escritura para descifrar un sentido oculto detrás del sentido literal, por lo que también en ese campo la hermenéutica tuvo un gran desarrollo. Otro campo donde la hermenéutica se desarrolló, debido a la necesidad de interpretar y aplicar en cada caso concreto las leyes y normas, fue el jurídico. De este modo, ya desde la antigüedad se establecieron las tres esferas tradicionales de la hermenéutica: la hermenéutica filológica, la exégesis bíblica y la hermenéutica jurídica.

Posteriormente, durante la Edad Media, el Humanismo Renacentista, la Reforma, la Contrarreforma y la Ilustración, la hermenéutica recibe aportaciones que la enriquecen como arte de la interpretación. Pero será durante el Romanticismo, con su renovado interés por la tradición, las leyendas y los cuentos, cuando se sentarán las bases para un nuevo enfoque de la hermenéutica.

Hasta la Ilustración se pensaba que los textos eran generalmente comprensibles, por lo que no se consideraba necesario un ejercicio interpretativo especial, éste se requería sólo en el caso de oscuridad en ciertos pasajes, por lo que se afirmaba el principio de acuerdo con el cual in claris non fit interpretatio. 
Pero el teólogo alemán Friedrich Schleiermacher, en virtud de que partía de una visión antropológica según la cual los otros son esencialmente un misterio para el sujeto, no estuvo de acuerdo con el principio anteriormente mencionado. Debido a la lejanía entre el yo y el alter cualquier expresión, no sólo la escrita, sino incluso la oral es susceptible de ser mal entendida, de ahí que la hermenéutica intervenga en toda interpretación interpersonal, y que todo comprender sea una interpretación. ${ }^{34}$ De esta manera, la comprensión en general, no sólo en la filología, en la exégesis y en la jurisprudencia, se convierte en el problema central de la hermenéutica. Este autor pretende fundamentar teóricamente el procedimiento que comparten los filólogos, teólogos y juristas; desea llegar a las raíces más originarias de la comprensión y convertir a la hermenéutica en arte y análisis del acto mismo de comprender. ${ }^{35}$ Para Schleiermacher comprender requiere "meterse" dentro del autor; esto es, en su intención y en sus pensamientos. ${ }^{36}$ En efecto, si el acto de comprender es la inversión del acto de hablar -puesto que en la comprensión debe llegar a la conciencia el pensamiento que subyace en lo que se dice; y además todo decir se basa en un pensar anterior- entonces es claro que la tarea fundamental de comprender consiste en retornar, a partir de la expresión, al pensamiento que la anima: "Lo que se busca es aquello mismo que el hablante ha querido expresar". 37

Schleiermacher propone metodológicamente propone dos momentos en la interpretación: el gramatical y el psicológico. En el primero se debe explicar la expresión a partir del contexto general de la totalidad del lenguaje al que pertenece dicha expresión. En el segundo analiza el texto como parte de la vida del autor, y por tanto investiga la motivación que movió al autor a realizar esa comunicación, el lugar temporal que ocupa la obra en el contexto de su vida y de sus demás obras, y el momento histórico en que se escribió el texto.

$34 C f$. Mauricio Ferraris, La hermenéutica. México: Taurus, 2000.

35 F. Schleiermacher, Monólogos. Barcelona: Anthropos, 1991. Introducción. p. XVIII.

36 Cf. F. Schleiermacher, "Hermeneutics", en Hermeneutics: The Handwritten Manuscrips. Missoula, Montana: Scholar Press, 1997. pp. 21-40.

37 F. Schleiermacher, Allgemeine Hermeneutik von. 1809/1810. p. 1276. Citado en Grondin, Jean. Introducción a la hermenéutica filosófica. Barcelona: Herder, 1999. p. 110. 
Una de las consecuencias de la interpretación psicológica es que es posible introducirse en las intenciones del autor y conocer más detalladamente los factores que tuvieron influencia en la expresión del autor, cosa que éste no pudo hacer, ya que le fueron "dados" y sólo los vivió. En cambio el intérprete puede distinguir esos factores a posteriori, lo que da como consecuencia que después de la comprensión, con palabras de Gadamer, sea posible "[...]comprender al autor mejor de lo que él mismo se habría comprendido". Aunque existen algunas recomendaciones para la interpretación gramatical (conocer la sintaxis y semántica del lenguaje en que está escrito el texto, situarlo dentro del contexto general del lenguaje en cuestión, establecer el género literario), para la interpretación psicológica, que es la más importante, no es posible que haya principios y reglas para llegar al sentido original del autor, en tal caso se habla de tener una sensibilidad muy fina que permita "adivinar" la intención del autor. 38

Otro aspecto importante para la hermenéutica que se debe destacar en la obra de Schleiermacher es lo que se ha llamado el círculo hermenéutico. Para el teólogo alemán "[...]cada cosa particular sólo puede ser entendida a partir de lo general cuya parte es y viceversa". ${ }^{39}$ Lo individual debe ser comprendido desde el todo, pero éste no puede estar dado de antemano sino que se va conformando de partes, aunque es más que eso. Así el acto de comprender se mueve dentro de la relación parte-todo-parte. Desde el punto de vista gramatical, el todo es el género literario desde el cual se puede iluminar el texto singular que surge de aquél; y el texto a su vez proporciona elementos para comprender mejor el género literario. Desde el punto de vista psicológico, lo singular es el texto como acto de una individualidad y se debe explicar desde la totalidad de la vida del autor; y ésta a su vez queda más clara si se comprende el texto expresado en un momento particular de la vida del autor.

Después de Schleiermacher, otro autor que presenta una propuesta original y novedosa para la hermenéutica es el también alemán Wilhelm Dilthey. El análisis que realiza Dilthey parte de su esfuerzo por encontrar una fundamentación metodológica para un tipo de conocimiento específico que versa sobre el hombre, su historia y sus creaciones culturales. El

38 Cf. Jean Grondin, Op. cit. p. 114.

39 F. Schleiermacher, Monólogos. Barcelona: Anthropos, 1991. p. 41. 
positivismo había proclamado que existía un solo método para hacer ciencia: el método científico, que como ya se mencionó era empírico, matemático y tenía como función explicar los fenómenos a partir de leyes generales. Ante esa pretensión absolutista del método científico, las ciencias humanas y sociales quedaban desprotegidas debido a la dificultad que se presentaba al intentar emplear dicho método para estudiar el ámbito humano.

Por su parte Dilthey afirmaba que existen dos tipos de ciencias, las $\mathrm{Na}$ turwissenschaften (ciencias de la naturaleza) y las Geistenwissenschaften (ciencias del espíritu). Las ciencias de la naturaleza estudian los fenómenos que existen independientemente de la actividad humana (materia, energía, átomos, cuerpos celestes, piedras, células, animales, plantas, etcétera) y descubren leyes que expresan conexiones causales que existen entre éstos, por lo que su función es explicar (Erklären) los fenómenos de la naturaleza. Por su parte las ciencias del espíritu estudian al ser humano y sus creaciones (devenir histórico, sentidos y significados, valores, objetos culturales) y su cometido es comprender (Verstehen) lo acaecido. De esta manera, la comprensión aparece una vez más como problemática central de la hermenéutica, pero ahora como herramienta metodológica de las ciencias del espíritu.

El camino propuesto por Dilthey para llegar a la comprensión es "revivir" el sentido original dado en la acción. Lo anterior implica una relación de empatía que permite compenetrarse con los acontecimientos, así el sujeto se introduce en lo interpretado, y desde dentro trata de conocer todo las relaciones significativas que tienen lugar en el objeto de interpretación. Este método tiene el inconveniente de querer "revivir" los sentidos originales sin considerar que las circunstancias del sujeto que interpreta son otras, por lo que resulta casi imposible "revivir" exactamente el sentido original. Consideramos que se debe hablar más bien de un "recrear" los sentidos originales, respetando lo que nos dice el autor, pero interpretándolo desde nuestro nuevo contexto.

Posteriormente un paso decisivo en la aparición de la hermenéutica filosófica fue el llamado "giro ontológico" de la comprensión, realizado por Heidegger. Hasta ese momento, la hermenéutica era considerada como una herramienta que había ido "creciendo" desde un instrumento para la interpretación de textos, hasta el método propio de las ciencias del 
espíritu. Sin embargo Heidegger le otorga a la hermenéutica un status ontológico, convirtiéndola así no en un medio para conocer, sino en una forma de ser. La comprensión es uno de los existenciarios, un modo fundamental del ser del hombre. En cuanto el hombre es un ser-en-el-mundo; esto es, que no existe en la soledad, sino que se encuentra dentro de un "todo", rodeado de los otros y lo otro; y al mismo tiempo es un ser temporal que se proyecta hacia el futuro en un continuo hacerse, debe organizar ese todo para planear su proyección. Esa organización es precisamente la comprensión. Por su parte, esta última también fundamenta otro de los conceptos básicos de la hermenéutica: la interpretación. Según Heidegger, "[...] el proyectar del comprender tiene la posibilidad de desarrollarse. Al desarrollo del comprender lo llamamos 'interpretación'..."40 Así pues, la comprensión es un elemento inseparable de la constitución ontológica de la existencia del ser del hombre, es un modo de ser antes que un modo de conocer.

El nacimiento de la hermenéutica filosófica, propiamente dicha, se le atribuye a H. G. Gadamer, quien indica que el ser, como aparece ante el hombre, no puede ser otro que un ser con sentido; esto es, un ser interpretado, pero ese sentido no es algo dado, sino que se va creando al mismo tiempo que el hombre se va formando. Es por ello que la filosofía no puede ser otra que una filosofía hermenéutica, que consiste en analizar el sentido del ser y el sentido del ser humano y de sus creaciones. Entre los principales conceptos que maneja Gadamer se destacan el de comprensión, formación, tradición, horizonte hermenéutico, lenguaje y diálogo.

La comprensión es otorgarle sentido a la realidad, el ser humano se distingue de los demás seres porque vive en un mundo de sentidos y no puede existir de otra manera. Sin embargo, ese mundo de sentidos se va construyendo conforme el ser humano se va formando. La formación es la "culturización", "humanización" que se le va dando al Ser del hombre junto con el Ser-del-otro (naturaleza, sociedad, individuo, artefactos, etcétera) quien al mismo tiempo no es otro ajeno totalmente (objetividad total como dirían los positivistas), sino un otro que aparece en y con la perspectiva del Ser del hombre, no creándolo pero sí dándole sentido. Según Gadamer la formación se contrapone a lo natural, ya que “"por este

40 M. Heidegger, El ser y el tiempo. México: FCE, 1982. p. 166. 
lado él [el ser humano] no es por naturaleza lo que debe ser'; por eso necesita de la formación." 41 De este modo aparece lo cultural como lo contrario a lo natural: "[...]la formación pasa a ser algo muy estrechamente vinculado al concepto de la cultura, y designa en primer lugar el modo específicamente humano de dar forma a las disposiciones y capacidades naturales del hombre". 42

Pero en el proceso de formación, culturización (cultivación), no se puede hablar de un "formador" del ser humano, de un agente privilegiado que forme, "la formación no conoce objetivos que le sean exteriores", sino más bien se habla de un formarse, de un construir su ser siendo: "[...]la palabra 'formación' despierta más bien la vieja tradición mística según la cual el hombre lleva en su alma la imagen de Dios conforme la cual fue creado, y debe reconstruirla en sí."43 Gracias a la formación, la conciencia se eleva por encima de la inmediatez de su estar ahí, como ser natural, hacia la generalidad, como ser cultural, por lo que "[...]la esencia general de la formación humana es convertirse en un ser espiritual general."44

Al mismo tiempo la formación nos conduce no sólo a la generalidad sino también a la comunidad: "La formación [...] no [...] trata de cuestiones de procedimiento o de comportamiento, sino del ser [...] [la] característica general de la formación [es] mantenerse abierto hacia lo otro [...] El sensus comunis no significa en este caso evidentemente sólo cierta capacidad general sita en todos los hombres, sino al mismo tiempo el sentido que funda la comunidad." 45

Ahora bien, si la formación ayuda a llegar a la comprensión, a convertir a los hombres en seres generales y a formar comunidad, al mismo tiempo no hay que olvidar que el ser humano se encuentra dentro de la historicidad, por lo que unos factores esenciales dentro de la formación y la comprensión son la tradición y el horizonte hermenéutico. Para que sea posible la comprensión es necesario que existan ciertos elementos como prerrequisitos para poder ver y entender lo que se presenta. La comprensión no puede partir de la nada, sino que requiere de una tradición

41 H. G. Gadamer. Verdad y método. Salamanca: Sígueme, 1997. p. 41.

$42 \quad$ Ibid.p. 39.

43 Idem.

44 Ibid.p. 41.

45 Ibid. p. 46-50. 
heredada del pasado, expresada en pre-juicios que permiten realizar una pre-comprensión y ver, aunque sea de forma previa, lo que posteriormente será objeto de interpretación. ${ }^{46}$ Pero la sola tradición no basta para 1legar a la comprensión, también se debe tomar en cuenta el contexto concreto en que se encuentra el sujeto y desde el cual se realiza la interpretación. Lo anterior significa que el sentido que se crea siempre necesita de la tradición, por un lado, y de una visión siempre nueva dada por el contexto desde donde se realiza la nueva interpretación, por el otro. La conjunción de esos dos momentos -tradición y contexto particular-es lo que se denomina horizonte hermenéutico. El término horizonte "hace referencia a algo lejano, pero que pertenece al ámbito de la visión, tanto en su sentido físico como, metafóricamente, en el intelectual."47 Debido a que el ser humano siempre existe en forma concreta y el contexto histórico y personal de los sujetos nunca puede coincidir exactamente, el horizonte hermenéutico de interpretación siempre es distinto y la comprensión es una actividad nueva, aunque no llega a darse una subjetividad absoluta en la creación de sentidos debido a que el Ser es uno, aunque pueda ser visto desde diferentes horizontes.

El lenguaje llega a ser parte central en el planteamiento de Gadamer, porque es en él, donde se asienta el Ser con sentido. Retomando la idea de Heidegger de que "el lenguaje es la casa del ser" se expresa que el lenguaje no es un mero instrumento de comunicación, sino que éste forma parte esencial del proceso hermenéutico, “[...] toda interpretación se desarrolla en medio de un lenguaje que pretende dejar hablar al objeto", es el modo fundamental de operar de nuestro ser-en-el-mundo y la forma de construir el mundo; vivimos con un lenguaje y en un lenguaje.

La relación en el mundo para la creación y recreación de sentidos se realiza a través del diálogo, cuando intérprete y texto comparten sus horizontes y la finalidad es encontrar una fusión de horizontes; es decir, se busca en el hablar y escuchar, en el respeto y la igualdad, encontrar el sentido

46 Algo totalmente nuevo no puede caer dentro de la visión del intérprete, siempre es necesario tener cierta información que prepare el terreno para ver algo. Así por ejemplo una placa radiográfica con sus "manchas" es incomprensible para alguien que no está familiarizado con esos objetos, pero un especialista, que ha recibido la preparación necesaria, ya tiene elementos para interpretar esas "manchas".

$47 \quad$ Ibid. p. 373. 
compartido que nos conduzca a la comprensión y no a la dominación. Éste es un momento muy importante para las ciencias sociales y humanas porque permite llegar a un tipo de conocimiento del sujeto. Sólo a través del diálogo es posible conocer las intenciones, valores, intereses, sentidos y significados del sujeto. Aunque la intención de la hermenéutica filosófica no se proponía ser un instrumento metodológico para el conocimiento, se puede desprender esa consecuencia.

\section{MARCO FILOSÓFICO}

Para realizar nuestro estudio, es necesario tener un marco filosófico claramente delimitado que le proporcione base y unidad a nuestro análisis. Por supuesto que habrá inconformes con nuestros supuestos filosóficos, sobre todo porque que las tesis que conforman ese marco filosófico no son proposiciones demostrables sino principios, y como tales no sujetos a la demostración, por lo que lo único que se puede hacer es mostrarlos.

Sin embargo la ausencia de un compromiso filosófico serio, aunque nos da la oportunidad de tener un campo de acción más amplio, nos puede llevar a una falta de coherencia al no haber un eje rector que nos dirija. Así por ejemplo en el libro de E. Curras La información en sus nuevos aspectos, en los capítulo 5 y 6 , donde se propone analizar ciertas corrientes filosóficas que fundamenten a la bibliotecología o documentación, como ella le llama, se observa cierta inconsistencia. La documentación cumple con requerimientos de escuelas que entre sí son incompatibles: del causalismo, del empirismo, del racionalismo, del positivismo y del pensamiento de Hermes Trimegisto(¡!). Si se analizan esas corrientes se verá que el empirismo negó la causalidad (Hume), que el empirismo y el racionalismo son escuelas contrarias, y no se diga del positivismo con su ideal científico frente al Corpus Hermeticum un tanto esotérico. Ante este hecho se tiene la impresión de que con el afán de darle una base filosófica a la documentación se hecha mano de lo que está al alcance.

Pues bien, enunciaremos las principales tesis que adoptamos. Consideramos necesario partir de una premisa ontológica que establezca la existencia real del mundo circundante, es decir el Realismo, y la capacidad del sujeto para conocerlo. El Ser es lo primero, pero el SER en sí no existe, sólo es, lo que existe son entes concretos con un ser determinado por una esencia; la unión de la esencia y el ser nos da el ente que es lo que 
se nos presenta, y toda la acción encaminada (dirigida) a esos entes estará en función de su ser específico.

El reconocimiento de objetos reales, cada uno de ellos con un modo de ser específico, nos ayudará a adecuar los métodos de estudio a ese modo de ser determinado, lo que nos proporcionará una metodología objetiva, ya que si prescindimos de esta premisa podemos caer en el subjetivismo metodológico (anarquismo) o en el dogmatismo metodológico. El primero aparecerá debido a que el sujeto (investigador) utilizará el método que a su juicio le parezca útil y, según él, le ofrezca mejores resultados. Pero si bien es cierto el hecho de que existe una diversidad de métodos, esto no implica que no haya unidad, que haya solamente un convencionalismo metodológico. Esta unidad está dada por la naturaleza del objeto estudiado. Si un método resulta adecuado es porque el ser del objeto exige ese método, no es porque de una forma arbitraria se haya creado ese método y el objeto de estudio se haya sometido a él; al contrario, el método se creó con base en el objeto.

La premisa de la primacía del ser también nos evitará caer en el absolutismo metodológico que es propio del positivismo. No es posible que todas las ciencias utilicen el mismo método, debido precisamente a que el ser de cada objeto está determinado por diversas esencias que los hacen diferentes, por lo que esos seres deben de ser estudiados de diversas formas.

Se habla de diversidad de la naturaleza de los objetos en cuanto que son objetos de estudio de una disciplina, no en cuanto lo que son en sí. Así por ejemplo, la esencia de un tigre en cuanto tigre es muy diferente a la de un oso en cuanto oso, pero el método para estudiarlos puede coincidir porque ambos comparten la propiedad de ser seres vivos y la biología los aborda desde ese punto de vista y los estudiará de una manera distinta a como lo haría la psicología animal, si se acepta la existencia de esa disciplina, o la física, si es que le llegaran a interesar esos objetos, la cual los tomaría únicamente como cuerpos que tienen determinado peso y volumen y que están sujetos a determinadas leyes físicas. Así también, seres tan disímiles como un cuerpo celeste (el sol), un isótopo de un elemento químico (el ozono) y los seres vivos son estudiados conjuntamente por la Ecología porque se consideran como elementos de una clase que tiene una característica común. Por otro lado, un mismo objeto: “el sol” puede ser estudiado con diferentes métodos según la característica que se determine 
como esencial para su estudio: es un cuerpo celeste, un elemento del sistema ecológico o un objeto de culto religioso; en el primer caso se utilizarán modelos matemáticos exactos para calcular la fuerza de gravedad que ejerce sobre otros cuerpos celestes, pero la experimentación sería muy difícil emplearla; en el segundo caso la matemática ya no ocupa un lugar central, pero es posible emplear la observación y hasta cierto punto la experimentación; en el último caso no se puede recurrir ni a las matemáticas ni a la experimentación, sino a la investigación e interpretación de monumentos y otros documentos que testimonien el culto del sol en determinadas culturas.

Si se pierde de vista la prioridad ontológica se llega a un caos, pues incluso la verdad y las leyes científicas se pueden definir con base en situaciones cambiantes como son los paradigmas establecidos por la comunidad científica, los resultados pragmáticos obtenidos o los cánones establecidos por los grupos de poder. Pero no se debe olvidar que esos paradigmas, esos resultados o cánones tienen valor no en sí mismos, sino porque se adecuan a la realidad estudiada.

De esa premisa ontológica (realismo) y de la premisa gnoseológica (capacidad del hombre para conocer) se desprende el concepto de verdad que utilizaremos, consistente en el concepto clásico de verdad que dio Aristóteles, el cual expresa que la verdad es la adecuación del enunciado con la realidad: "Decir que el Ser no es o el no-Ser es, es falso; decir que el Ser es y el no-Ser no es, es verdadero." 48

La relación no es: si existe consenso en una teoría entonces es verdadera esa teoría, sino al contrario: existe consenso porque la teoría es verdadera; de la misma manera no aceptamos el condicional que expresa que si hay coherencia entonces hay verdad; sino que, la verdad implica la coherencia, y tampoco estamos de acuerdo en que si una teoría es útil entonces es verdadera, sino más bien en que si una teoría es verdadera entonces puede ser útil.

Ahora bien, la práctica se puede entender como un criterio último de verdad, pero después de la observación, experimentación y verificación, después del empleo de los métodos deductivos, inductivos, estadísticos y otros. La práctica no puede ser tomada de una manera subjetiva (como en

Aristóteles. Metafisica, $1011 \mathrm{~b}$. 
el pragmatismo en donde se la identifica con la utilidad), sino como un proceso objetivo de transformación y asimilación de la realidad, proceso no individual sino colectivo, social e histórico. Más aún, la práctica se utiliza para falsear la teoría, como se infiere de la implicación expresada anteriormente: si la verdad de una teoría implica su utilidad y si en la práctica se comprobó que no es útil, entonces por "modus tollens" obtenemos que esa teoría no es verdadera. 49

Por otra parte es conveniente agregarle a esas premisas una visión dialéctica, consistente no sólo en que todo está en movimiento y cambio, como comúnmente se cree, sino que todo está interrelacionado y que cada elemento o momento es a un mismo tiempo absoluto y relativo. Dentro del análisis de ciertos fenómenos se presentan varios elementos que son contrarios entre sí: "abstracto y concreto", "lógico e histórico", "tradición e innovación”, "individuo y sociedad”, "saber-no-saber”, ·verdad del autor-verdad del texto-verdad del intérprete", "sintaxis-semánticapragmática", "verdad relativa y verdad absoluta", etcétera. La dialéctica nos conducirá a no rechazar a alguno de los contrarios, sino a aceptar a los dos (tres), pero sin absolutizarlos.

Utilizando la dialéctica como método de conocimiento nuestra posición filosófica no será ni relativista, ni dogmática, ni ecléctica. No se cae en el relativismo porque no se absolutiza lo relativo, ni tampoco se llega al dogmatismo porque no se absolutiza lo absoluto; y no es algo ecléctico porque no se unen mecánicamente ideas contrarias ni se busca el punto medio entre ellas, sino que se enfatiza su unión y diferencia. Lo relativo tiene su elemento de absoluto y lo absoluto lo tiene de relativo. Esta visión dialéctica es de suma utilidad cuando se analiza la verdad como absoluta y relativa. En ocasiones la verdad absoluta se "absolutiza"; es decir, se la concibe como una verdad última, total, completa y por lo tanto eterna, o, por el contrario, a veces la verdad relativa se "absolutiza" y se concibe el proceso del conocimiento como algo que nunca nos dará la verdad. Pero la posición

49 Modus Tollens (modo que riega) es una regla de inferencia según la cual se concluye la negación del antecedente de una implicación si se niega su consecuente. Esto es "si $P$, entonces $Q$ " y "no $Q$ " se obtiene "no $P$ ".

Simbólicamente:

1. $P \supset Q$

2. $\neg Q$

3. $\neg P$ 
dialéctica nos indica que una proposición es a la vez verdadera en forma absoluta, al mismo tiempo que relativa. En efecto, cuando una proposición enuncia la existencia de cierto estado de cosas, tal vez en un marco teórico determinado, y en la realidad se da ese estado de cosas, esa proposición es verdadera y no puede ser falsa, siempre que se dé ese marco teórico y ese estado de cosas, el enunciado será verdadero; pero eso no implica que el enunciado diga "todo" lo que se tiene que decir sobre el estado de cosas; se puede ahondar en la descripción o explicación de ese estado de cosas, se pueden encontrar otras relaciones, etcétera. Pero el hecho de que no diga todo lo que hay que decir, no lo convierte en falso, ni da pie a negar lo poco de verdad que esté diciendo. Esa poca verdad no se convierte en falsedad. 50

De esta manera la dialéctica también nos ayuda a no caer en una dicotomía absoluta entre las ciencias naturales y las ciencias del espíritu; cada una tiene su lugar, sus características (esas las hacen absolutas), pero a la vez tienen puntos de contacto, influencia recíproca (eso las hace relativas).

Confieso que en el momento actual es arriesgado hablar de dialéctica, cuando el marxismo, considerado como sinónimo de ella parece haber pasado de "moda", [de verdad como adecuación y realismo,] y cuando el postmodernismo nos invita al consenso, al subjetivismo o al pragmatismo; pero mi única respuesta es que el hecho de que dedique mi tiempo a escribir muestra que yo existo, y si alguien no está de acuerdo con mis conclusiones mostrará que alguien ha leído el documento; es decir, muestra que existen mis lectores, mi documento y que tales lectores han entendido lo que he escrito. Pero si se empeñan en que se les demuestre la existencia de las cosas reales y la capacidad de conocerlas, les concederemos su inexistencia o incapacidad para comprender y no tendremos por qué argumentar con nadie o con alguien que no nos puede entender.

50 Un ejemplo sería la tan discutida relación entre la física clásica y la física de la relatividad: si un cuerpo se mueva a una velocidad inferior a la velocidad de la luz, las leyes de la primera describen perfectamente el movimiento, pero cuando el movimiento del cuerpo se acerca a la velocidad de la luz, entonces funcionan la leyes de la relatividad. La relación entre esas dos teorías es diferente que la que tienen con la física de Aristóteles; las dos primeras son "verdaderas", la primera describe el fenómeno en condiciones "más pobres" que la segunda, pero la tercera es falsa. 


\section{Ciencia}

Después de la derrota del ideal fundacionalista, para algunos pensadores la investigación epistemológica parecería ociosa y un tanto anacrónica, tal vez más de un filósofo postmoderno opinaría que dicha problemática debería ser archivada junto con el proyecto inacabado de la modernidad, que se caracterizaba por su culto a la racionalidad. Pero consideramos que es un hecho la existencia de la ciencia y su desarrollo, por lo que podemos estar seguros de que aún no ha llegado el irracionalismo, o el fin de la historia y de los metarrelatos.

Esa misma existencia fáctica de la ciencia nos da testimonio de que existe una forma específica de conocer el mundo, y que se caracteriza por ser verdadera, ${ }^{51}$ justificada, ${ }^{52}$ que utiliza herramientas del pensamiento racional (conceptos, juicios y raciocinios), que tiende a la generalidad y busca regularidades, ${ }^{53}$ que está plasmada en teorías como sistemas de enunciados con una estructura determinada, y que tiene la función de describir, explicar, predecir y comprender la realidad.

\section{Ciencias del espíritu}

Según el objeto de estudio de las ciencias, tradicionalmente se las ha dividido en dos grupos. Nosotros, siguiendo la terminología de Dilthey, las llamaremos Ciencias de la naturaleza y Ciencias del espíritu, las primeras tienen como objeto de estudio fenómenos que existen independientemente del hombre y las segundas estudian al hombre y sus creaciones. ${ }^{54} \mathrm{Y}$ debido a que incluimos a la bibliotecología en las Ciencias del espíritu centraremos nuestra atención en esta clase de Ciencias.

Las Ciencias del espíritu poseen el mismo rango y "cientificidad" que las Ciencias de la naturaleza; ambas tienen un objeto de estudio propio, están compuestas por un sistema de enunciados verdaderos y justificados, etcétera. Sin embargo a consecuencia de la especificidad del objeto

51 Más adelante explicaremos la noción de verdad que manejamos, por ahora solo constatamos que es una verdad por adecuación entre lo que se enuncia y la realidad.

52 Ciencia es el producto de una actividad específica, como lo es la investigación científica, justificado [el producto] con una metodología obtenida mediante el manejo de conceptos, y luego relacionando esos conceptos y enunciados con otros mediante un nexo lógico, causal o probabilístico.

53 Recordemos que de lo particular y contingente no hay ciencia, según Aristóteles. 
de estudio de las Ciencias del espíritu existen características propias de estas ciencias y es necesario dejar de compararlas con las Ciencias naturales; es un error tener como paradigma científico a las Ciencias naturales y declarar que si una disciplina no cumple con los requerimientos que presentan las Ciencias de la naturaleza (la utilización del método empírico, la manipulación de variables, la cuantificación, el descubrimientos de leyes) esto implica que esa disciplina no sea científica. Como se podrá observar el concepto de ciencia que dimos en el apartado anterior es más débil que esas características y permite incluir en él a las Ciencias del espíritu.

De esta manera, las Ciencias del espíritu poseen unas propiedades específicas y se diferencian de las Ciencias naturales no sólo por su objeto de estudio sino por su función epistemológica, el carácter no nomológico de sus enunciados generales y el método utilizado para estudiar su objeto. Los enunciados de las Ciencias del espíritu también son verdaderos, pero esos enunciados más que explicar y predecir (cosa que también pueden hacer a su manera) y manipular (lo que ya no hacen tanto), tienden a comprender. Donde por comprender entenderemos el hecho de poder señalar el sentido de una acción; además, si los objetos de los enunciados de las Ciencias del espíritu son principalmente acciones, entonces es fácil percibir la importancia de la comprensión en este tipo de ciencias.

Asimismo, dentro de las Ciencias del espíritu no encontraremos enunciados nomológicos categóricos y cuantificables; ni tampoco relaciones del tipo de la ecuaciones de la electrodinámica de Maxwell o leyes como la de gravitación de Newton, la ley de Coulomb o la famosa segunda ley de la termodinámica; por el contrario, los enunciados generales de las Ciencias del espíritu tienen un carácter teleológico, indican tendencias y son de carácter hipotético. La historia y la sociología trabajan con proposiciones semejantes, así tenemos el siguiente enunciado: "[...]si existe una crisis de legitimidad de la clase gobernante,

54 Esta terminología la considero más apropiada que los términos "Ciencias duras" y "Ciencias blandas", los cuales son incluso estéticamente poco elegantes y denotan una discriminación entre los dos tipos de ciencias, lo mismo que los términos "Ciencias exactas" y, siguiendo estrictamente la división lógica de conceptos, "Ciencias no-exactas". Pero incluso en la Ciencia contemporánea, la exactitud ya no es una prerrogativa científica, se habla cada vez más de "indeterminación”, "probabilidad”, etcétera. 
errores en la toma de decisiones, ruptura en las élites en el poder, mayor participación de las masas, entonces se da un proceso de transición política". Ese enunciado es de carácter hipotético y expresa una posible tendencia pero no es necesario, ya que diversos factores contingentes influfluyen en su actualización. 55

Ahora bien, eso no significa que las Ciencias del espíritu proporcionen un tipo de conocimiento relativo, en el sentido de subjetivo; porque el contenido de los enunciados de esas Ciencias es capaz de ser justificado. Aunque el método para justificarlo no sea el Método científico como se lo considera tradicionalmente (experimental-matemático), sino uno basado en inferencias deductivas, análisis y síntesis de los fenómenos estudiados, e interpretaciones hermenéuticas.

Pasemos ahora al problema de la fundamentación de una ciencia.

55 El mismo Marx, quien pretendió descubrir las verdaderas leyes que rigen el desarrollo social, reconoció la importancia de otros elementos y condiciones en el funcionamiento de esas leyes, por lo que no se podía hablar de regularidades universales y necesarias; señala que "hechos sorprendentemente parecidos, pero que ocurren en contextos históricos diferentes, producen resultados completamente distintos. A través de un estudio de cada una de estas formas de evolución por separado y luego comparándolas se puede encontrar fácilmente la clave de ese fenómeno, pero nunca se llegará a eso mediante el pasaporte universal de una teoría histórico-filosófica general, la suprema virtud de ser super-histórica". Marx, K. "Carta al editor de Otyechestvenniye Zapisky". (1877), en Correspondence 1846-1895. New York: International Publishers, 1936. pp. 352-355. p. 355. 


\section{La fundamentación de una disciplina}



1 explicar lo que entendíamos por epistemología dijimos que ésta le
plantea ciertas preguntas a la ciencia, pero para contestar dichas
cuestiones es necesario resolver antes algunas tareas específicas. En este apartado describiremos más concretamente las tareas que se deben resolver para fundamentar un disciplina y cómo se aplica ese esquema a la bibliotecología.

La fundamentación de una disciplina no es un problema que siempre hay que resolver; en determinado momento un cuerpo teórico puede desarrollarse de una manera extensiva acumulando datos empíricos y creando conceptos, teorías, leyes y principios para un grupo o grupos de fenómenos, o formando técnicas para resolver "enigmas" que se le presentan, soluciones que no son sólo para casos concretos sino que explican, predicen o controlan fenómenos generales; es decir, que dicho cuerpo teórico puede ser caracterizado como científico.

Pero en un momento de su desarrollo histórico ese proceso acumulativo no es suficiente para satisfacer el ulterior avance de la ciencia, y de esta manera nace la necesidad de ordenar, jerarquizar e interrelacionar todo el conocimiento obtenido hasta ese momento para que dicha disciplina se constituya en un sistema capaz de explicar en su totalidad, y no fragmentariamente, los fenómenos para los que fue creada, de modo que se pongan de manifiesto todas las relaciones e interrelaciones entre conceptos, principios y leyes que subyacen implícitas en esas técnicas creadas para satisfacer necesidades prácticas.

Mas aún, ante la cantidad de datos acumulados nace la inquietud de volver la vista hacia la misma ciencia y cuestionarse sobre ella; es en este momento cuando se puede decir que se ha alcanzado un grado de madurez suficiente como para reflexionar sobre ella misma. 
Antes existía la preocupación por investigar los fenómenos que se tenían y debían conocer y por resolver tareas que se presentaban, pero ahora la investigación se vuelve sobre la propia ciencia. Se hace un cuestionamiento sobre su propia identidad, sus límites, sus finalidades y sus medios. Es decir nace la necesidad de fundamentar esa disciplina, de hacer objeto de estudio a la misma ciencia, o sea, de hacer Metaciencia. Este fenómeno no es tanto una crisis interna, como un síntoma de crecimiento y madurez. ${ }^{1}$

En el desarrollo de las ciencias podemos observar un claro ejemplo de este fenómeno en la historia de las matemáticas. En la segunda mitad del siglo pasado cuando, después de más de dos milenios de desarrollo, esta ciencia había realizado asombrosos avances en áreas como la aritmética, el cálculo integral y diferencial, el álgebra y la trigonometría entre otras, los matemáticos se empezaron a preocupar por fundamentar su ciencia. El matemático y filósofo alemán G. Frege desarrolló un programa para cumplir esta tarea y se preocupó por definir y aclarar conceptos tales como "axioma", "variable", "número", "clase", "deducción o demostración” y otros. Para esto creó un lenguaje formal nuevo que fue el cálculo lógico matemático y analizó con ese instrumento el contenido de las matemáticas, es decir por primera vez hizo METAMATEMÁTICAS. ${ }^{2}$ Sin embargo, dado que el objetivo perseguido por Frege no fue alcanzado, otros científicos como B. Russell, A. Whitehead, G. Peano D. Hilbert,L. E. Brouwer y A. Heyting continuaron con esa tarea. ${ }^{3}$

Un fenómeno similar ocurrió en la física a partir de fines del siglo pasado y principios de éste luego del nacimiento de la física de la relatividad y física cuántica. El avance de la ciencia siguió su curso, pero los científicos se cuestionaron sobre el nuevo significado que adquirían conceptos que

1 Es interesante señalar que una situación similar la podemos observar no sólo en el desarrollo de las ciencias sino también en el desarrollo de la personalidad humana. La psicología evolutiva nos explica cómo en la adolescencia, después de un largo periodo de crecimiento, cuando el ser humano ha alcanzado cierta madurez, el joven empieza a cuestionarse sobre su propia identidad; su "yo" lo contrapone al "no-yo" para saber quién es, qué lugar ocupa en este mundo y cómo relacionarse con él.

2 Frege, Gottlob. Conceptografía. Un lenguaje de fórmulas semejante al de la Aritmética para el pensamiento puro. Los fundamentos de la Aritmética. México: UNAM, 1972.

3 Russell, B. y A. Whitehead, Principia Mathematica. Madrid: Paraninfo, 1981. Hilbert, D. y P. Bernays. Grundlagen der Mathematik. Berlin: J. Springer, 1934. A. Heyting, Introducción al Intuicionismo. Madrid: Tecnos, 1976. 
tradicionalmente manejaban, tales como materia, causalidad, sujeto y objeto de la investigación, tiempo y espacio, entre otros. Los físicos manejaban esos términos de acuerdo con fórmulas y modelos matemáticos dentro de su ciencia, pero empezaron a reflexionar sobre esos modelos y sobre los métodos utilizados en su quehacer científico; es decir empezaron a hacer filosofía de la física, y así aparecieron los trabajos de E. Mach, H. Reinchenbach, R. Carnap y O. Neurath los cuales buscaban los principios filosóficos que fundamentaran la Física. 4

Si estas dos ciencias con una historia tan larga y tantos siglos de desarrollo se cuestionaron sobre sus fundamentos, la bibliotecología, que tiene una historia mucho más reciente, puede hacer lo mismo sin intimidarse por ello.

\section{DIFERENTES ASPECTOS DE LA FUNDAMENTACIÓN DE UNA CIENCIA}

Mucho se ha hablado y escrito sobre la fundamentación de la bibliotecología, 5 pero considero que es necesario especificar en qué consiste esa fundamentación y qué tareas hay que realizar para llevarla a cabo.

La fundamentación de una disciplina abarca diversos aspectos que no muchas veces se aprecian. Se debe realizar una fundamentación filosófica, una fundamentación lógica, una fundamentación metodológica, una fundamentación del cuerpo teórico y una fundamentación extrateórica. Esto no quiere decir que se trata de pasos que se deben realizar con una secuencia determinada, sino de aspectos de un todo que se complementan e interrelacionan, y que dependen unos de otros; se puede decir que si se realizan unos se estarán realizando los otros. Nuestro objetivo final será encontrar las respuestas a las preguntas ya antes señaladas que se plantea la

4 R. Carnap, Fundamentación lógica de la Física. Buenos Aires: Sudamericana, 1969. E. Mach, Knowledge and error. Holland: D. Reidel, 1976. Reichenbach, H. The philosophy of space \& time. New York: Dover, 1958.

5 Así por ejemplo J. Shera observa que sólo cuando el proceso bibliotecario sea un sistema con un cuerpo teórico determinado y el servicio bibliotecario sea el fruto de un conocimiento debidamente fundamentado será cuando se pueda hablar de que la bibliotecología obtuvo la cualidad de ciencia con derecho propio. J. Shera, Knowing books and men; Knowing computers, too. Littleton: Libraries Unlimited, 1973. p. 9. También Deyanina Sequeira expresa la misma necesidad al plantear el problema de que "Hace falta buscar cuáles son las bases epistemológicas de la profesión [de la bibliotecología, M.A.R.]." Sequeira Ortiz Deyanira. La Bibliotecología como ciencia. San José, Costa Rica: Publitex, 1988. p. 9. 
epistemología ¿qué es esa ciencia? ¿qué estudia? ¿cómo lo estudia? ¿para qué lo estudia?

La fundamentación filosófica consiste en utilizar categorías, principios, teorías de la filosofía para solucionar problemas ontológicos, gnoseológicos, y axiológicos de la disciplina analizada. Estos fundamentos filosóficos dependen de una concepción filosófica y deben de ser capaces de estimular el desarrollo de la ciencia, dar una explicación de su existencia, estimular su desarrollo y coadyuvar a su utilización práctica.

La fundamentación ontológica exige determinar la forma de existencia de los entes con los que trata la disciplina, el status ontológico de los objetos a los que se refieren los enunciados y las leyes de la teoría. Como consecuencia de la fundamentación ontológica se debe dar una fundamentación gnoseológica, es decir justificar la existencia del objeto de la teoría en la realidad y especificar el enfoque particular que se estudia de él, o, como dirían algunos filósofos, determinar el objeto quod y quo de la disciplina. ${ }^{6} \mathrm{La}$ ciencia tiene como objetivo reflejar la realidad (claro no de una manera absoluta sino con cierto grado de profundidad que se irá ahondando a medida que la ciencia se desarrolla); es decir, debe haber una adecuación de la teoría con la realidad, lo que significa que los enunciados de la disciplina deben ser verdaderos y esa verdad debe proporcionarnos una explicación del trozo de la realidad que estudia, debe hacerla mas comprensible, ayudarnos a predecir y controlar los fenómenos estudiados.

De acuerdo con la naturaleza del objeto que se estudia debe buscarse una fundamentación metodológica, es decir, es necesario precisar los métodos usados para construir y desarrollar la disciplina, y determinar si se usarán métodos empíricos, estadísticos, deductivos o de análisis, dependiendo del objeto estudiado y del que más se adecue para descubrir la verdad.

Por otro lado, la fundamentación del cuerpo teórico de la disciplina consiste en analizar, esclarecer y precisar los conceptos fundamentales de dicha teoría, especificar sus leyes y principios, y hacer obvias las teorías en las que se basan ciertas técnicas utilizadas con fines prácticos.

6 La fundamentación gnoseológica es una consecuencia de la fundamentación ontológica puesto que nuestra gnoseología depende directamente de la posición ontológica adoptada. Si partimos de una ontología dialéctica, nuestra gnoseología también será dialéctica; y si la primera es idealista, la segunda también lo será. 
Posterior o simultáneamente se debe llevar a cabo la fundamentación lógi$\mathrm{ca}$, lo que significa determinar las relaciones existentes entre los elementos ya analizados, clarificados y precisados del cuerpo teórico de la disciplina. Una relación primordial entre los enunciados de una teoría debe ser su consistencia; es decir, que no debe haber contradicción entre ellos. Esta consistencia puede ser semántica y sintáctica en el caso de las teorías formalizadas. En el primer caso no deben encontrarse dos proposiciones tales que una afirme una cosa sobre un objeto y otra que simultáneamente sobre el mismo aspecto y sobre el mismo objeto la niegue. En el caso de la consistencia sintáctica no debe darse una situación tal que una proposición sea teorema (esté demostrada) en esa teoría y al mismo tiempo sea teorema su negación.

Pero la consistencia es sólo una relación lógica que debe darse dentro de la teoría, si bien es cierto que es condición esencial y necesaria para que se pueda hablar de disciplina científica. Dentro de la fundamentación lógica se deben buscar también qué conceptos y leyes son independientes; es decir, sirven como principios para generar conceptos y leyes que no dependen a su vez de otros. Se debe esclarecer cómo se deducen a partir de esos principios el cuerpo teórico de la disciplina y los principios extralógicos que se utilizan para que toda la estructura de la teoría tome un carácter sistemático. Es decir, hay que encontrar la "lógica de la teoría", las relaciones de independencia, de subordinación, de compatibilidad, de identidad entre los enunciados. Esta operación es la complementación de la anterior, la síntesis del análisis.

Asimismo es indispensable poner de manifiesto la fundamentación extrateórica, esto es, analizar el lenguaje, los principios, leyes y métodos de otra teoría que se usan para resolver los problemas de la disciplina estudiada. Es necesario determinar cómo se emplean los instrumentos exportados de otras áreas y si mantienen el mismo sentido o si al utilizarse en un campo específico la connotación semántica cambia.

De una manera abstracta se puede decir que lo primero es determinar el objeto de estudio. Por supuesto que tal cosa sería lo ideal, pero muchas veces eso que debe ser lo primero es lo último: resultado del estudio realizado preliminarmente. Así, por ejemplo, en el caso específico de la fundamentación de la bibliotecología, R. Lafuente expresa la necesidad de incluir una síntesis del conocimiento bibliotecario (lo que en nuestra terminología equivale a realizar la fundamentación teórica y lógica; es decir, reunir, 
aclarar, ordenar, evaluar, encadenar y sintetizar el cuerpo teórico de la bibliotecología, utilizando como elemento extralógico la explicación teleológica) y a partir de él encontrar el objeto y el método (fundamentación filosófica y metodológica) de la bibliotecología. ${ }^{7}$

\section{DIFERENTES ASPECTOS EN LA FUNDAMENTACIÓN DE LA BIBLIOTECOLOGÍA}

Por lo tanto de acuerdo con nuestro plan establecido anteriormente para fundamentar la bibliotecología, las tareas por realizar serían las siguientes:

\section{Fundamentación filosófica}

La postura ontológica tomada como base de nuestro análisis (Realismo) nos obligará a definirnos con respecto a lo que es la biblioteca, el libro y el usuario; por lo que la selección de materiales, su clasificación y catalogación serán ya no una actividad subjetiva y arbitraria sino objetiva y basada en las características de esos tres componentes básicos de la bibliotecología; y también las leyes bibliotecológicas tendrán un carácter objetivo. En el campo axiológico se tomarán en cuenta los valores que se desean alcanzar en función al enfoque que se le dé al usuario, por lo que será necesario determinar si se le considera Zoon politicon, Homo sapiens, Homo faber (o tal vez Homo habilis), o un conjunto de relaciones sociales, un ser creado a imagen y semejanza de Dios, o un ser en-sí consciente de estar condenado a ser libre y que desea liberarse de esa libertad, o de otra forma, para que en función de la idea aceptada, podamos organizar nuestro quehacer bibliotecológico. Si nuestra acción va encaminada a desarrollar el ser del usuario como lo concebimos entonces es un valor; si lo degrada o frena su desarro1lo, es un antivalor. Ésta es una tarea esencial, para fundamentar la bibliotecología se debe realizar una tarea filosófica-antropológica de análisis del usuario, o si se desea exportarla de una concepción filosófica determinada, cosa muy difícil porque cada concepción absolutiza su posición; mas bien

7 Lafuente, R. "La síntesis crítica del conocimiento bibliotecológico: su valor para la investigación bibliotecológica", en Investigación bibliotecológica. Enero-junio 1988. v. 3, n. 6. pp. 3-10. 
sería la nuestra una síntesis dialéctica (no ecléctica) de algunas de ellas. Claro que siempre se tendrán divergencias debido a que las escuelas filosóficas nunca se han puesto de acuerdo, pero es indispensable ocupar una posición lógicamente consistente, compatible con el conocimiento científico y la realidad y que nos ayude a desarrollar nuestra disciplina (es interesante señalar cómo la bibliotecología soviética-rusa, parte en este punto, de un supuesto que le ha dado unidad -la concepción marxista-lo que le ha permitido desarrollarse como escuela y obtener importantes resultados).

En el campo gnoseológico es necesario determinar el objeto de estudio de la bibliotecología, identificar los problemas a los que se va a dedicar, delimitar su campo de acción y responder a las siguientes preguntas: ¿la bibliotecología es ciencia, técnica o tecnología? ¿es una rama de la ciencia o ciencias de la información? ¿cual es su relación con la bibliografología, la informática (en el sentido de Mijailov), la archivología, la museología? ¿la bibliotecología tiene puntos de contacto con las ciencias de la comunicación, la teoría de la información y la cibernética? ¿qué es lo que rige la diversidad y la unidad en la especialización de las ciencias?

En ocasiones se utiliza el término "epistemología” para designar la investigación y fundamentación del conocimiento científico, dejándole a la gnoseología la tarea de analizar el conocimiento en general. ${ }^{8}$ Como el conocimiento científico se caracteriza por el grado de generalidad, universalidad y necesidad obtenido de una manera metódica, entonces una fundamentación epistemológica abarcaría, aparte de la fundamentación gnoseológica, lo que nosotros hemos llamado fundamentación metodológica, fundamentación teórica y fundamentación lógica. Hemos optado por diferenciar todas esas fundamentaciones por razones metodológicas para que de esta manera aparezcan más claras las tareas que hay que realizar y se ponga de relieve la relación estrecha que tiene la fundamentación gnoseológica con la filosófica, ya que la concepción ontológica de la que partamos condicionará la gnoseología o teoría del conocimiento que adoptemos.

8 Bunge, M. Epistemología. Barcelona: Ariel, 1980. 


\section{Fundamentación teórica}

El lenguaje de una disciplina ocupa un lugar muy importante puesto que es la herramienta con la cual se designarán los conceptos que la constituyen. Por lo tanto se debe aspirar a tener una terminología propia, suficiente y precisa. Podemos decir que la correcta formación, introducción y unificación de términos ayuda al ulterior desarrollo de un campo particular de conocimiento. Se deben evitar equivocidad, tautologismo y relativismo, lo cual nos evitará caer en confusiones, vaguedades, ambigüedades y en un vacío de sentido.

Por lo tanto es necesario definir conceptos claves en bibliotecología tales como información y conocimiento, flujo de información, necesidad de información, registro de información, documento, usuario, biblioteca, centros de análisis y referencias, centros de información, clasificación, actividad bibliotecaria; todo esto estableciendo claramente la especificidad que tienen estos conceptos en esta área del conocimiento y la diferencia que tienen esos términos en otras disciplinas como la filosofía, la teoría de la información, la archivología, la ciencia de la información, la pedagogía, el periodismo y otras.

Al mismo tiempo es necesario especificar la teorías y leyes que subyacen en la actividad bibliotecaria, por ejemplo los principios que rigen los diferentes tipos de clasificación bibliotecológica.

\section{Fundamentación extrateórica}

Es necesario determinar qué conceptos, técnicas y métodos se toman de otras áreas de conocimiento; por ejemplo de la cibernética y teoría de la información al automatizar el quehacer bibliotecológico; de la psicología al analizar la psicología del lector, sus motivaciones e intereses, y de la sociología al estudiar el entorno socio-económico del lector, los factores sociales y culturales que influyen en la organización del trabajo bibliotecológico.

Si en el análisis filosófico determinamos cómo se toma al usuario ontológicamente para a partir de ahí establecer nuestra axiología y objetivos finales muy generales, y si en la definición teórica de usuario determinamos más particularmente qué entendemos por él cuando se acerca a requerir información bibliotecológica, en ese momento lo delimitamos más y lo colocamos ya como un usuario con características específicas: es un estudiante, 
un niño, un investigador, un político u hombre de negocios, y determinamos su entorno social: vive en la ciudad, en una población pequeña, etcétera.

Otras disciplinas también le aportan sus conocimientos a la bibliotecología y se debe poner en claro, por ejemplo, cómo y en qué la administración nos ayuda a realizar nuestra tarea; cómo la ciencia política nos puede orientar para actuar en condiciones políticas bien concretas de una manera más eficaz. También la pedagogía, la lingüística y la semiótica le hacen aportaciones a la bibliotecología, es necesario establecer cuáles y cómo.

\section{Fundamentación metodológica}

En este apartado el objetivo es analizar los métodos que se adecuan al objeto de estudio de la bibliotecología, cuáles son éstos y cómo se aplican. Se puede dar el caso de que el objeto de estudio no esté aún totalmente delimitado, entonces por una parte se habrá de tener una hipótesis de cuál es ese objeto de estudio y por otra analizar los métodos que históricamente se han utilizado y que han dado resultados positivos, infiriendo de esta manera, tomando en cuenta todos nuestros supuestos filosóficos, teóricos y extrateóricos, si nuestra hipótesis es correcta o, si no lo es, cambiarla.

Entre los principales métodos que debemos analizar para determinar su aplicación en la bibliotecología tenemos el lógico-deductivo, que se utiliza para clasificar y catalogar los documentos, de esta manera se obtiene un sistema que tiene ciertas relaciones entre sus elementos. Se debe especificar si estas relaciones son a nivel sintáctico (entre símbolos e independientemente de su contenido, aunque de éste partimos para simbolizar los documentos) o a nivel semántico (relaciones entre contenidos) o incluso a nivel pragmático (relaciones entre símbolos y usuarios) o si se dan todos estos niveles a la vez.

Cabe aclarar que en la lógica contemporánea los niveles sintáctico y semántico tienen un grado de desarrollo mucho más alto que el nivel pragmático, el cual apenas se está empezando a estudiar. Históricamente primero se buscó la formalización y axiomatización de sistemas lógicos; después, con 
los trabajos de A. Tarsky la atención se volvió hacia los problemas semánticos y últimamente se está buscando crear sistemas en los cuales tenga un lugar el sujeto, el cual había sido excluido de la lógica. ${ }^{9}$

Otro método del que se sirve la bibliotecología es el hermeneútico, empleado para la interpretación de documentos. Es necesario establecer cómo se garantiza la objetividad y fidelidad al analizar nuestros documentos cuando realizamos ciertas actividades bibliotecarias. Qué pasos y procedimientos se deben seguir y cuáles condiciones se deben de observar para obtener el resultado deseado. ${ }^{10}$

Asimismo, ya que se realizan investigaciones de campo y se utilizan métodos estadísticos para detectar necesidades de información, intereses de los usuarios, errores en la organización del trabajo bibliotecario, etcétera, será indispensable establecer las bases teóricas de estos métodos para que nuestro trabajo sea científico.

\section{Fundamentación lógica}

En la fundamentación metodológica ya indicamos que es necesario analizar la estructura de los sistemas bibliotecológicos de clasificación y encontrar qué tipo de relaciones existen entre sus elementos, esto también es parte de la fundamentación lógica y, podríamos agregar, semiótica.

Al mismo tiempo se debe analizar cómo se relacionan los distintos conceptos entre sí. Por ejemplo, el contenido del concepto de "información" ¿es más amplio, estrecho o idéntico que el de "conocimiento"? y si uno está incluido en otro, entonces, agregando ciertos datos iniciales, de este último se puede deducir lógicamente el primero. Así también, del concepto de información, como más amplio, se pueden ir generando, por operaciones lógicas, conceptos más limitados tales como flujo de información, necesidad de información y otros.

9 Tarsky, A. La concepción semántica de la verdad y los fundamentos de la semántica. Buenos Aires: Nueva Visión, 1972. Montague, R. "Pragmatics and Intensional Logic", en Synthè, 22 (1970), pp. 68-94.

10 Gadamer, Hans-George. Philosophical Hermeneutica. Berkeley: University of California Press, 1977. Coreth, E. Cuestiones fundamentales de la Hermenéutica. Barcelona: Herder, 1972. 
Por último, obvio es que se debe demostrar la consistencia de la teoría bibliotecológica; no debe haber contradicciones entre sus enunciados y si se tiene la sospecha de que éstas tienen lugar es necesario establecer si realmente los enunciados hablan sobre el mismo objeto, bajo el mismo aspecto y tienen las mismas premisas gnoseológicas. Se puede dar el caso de que aparentemente exista contradicción pero que, como se diría en términos hermeneúticos, el contexto sea distinto. Ahora bien, si realmente hay contradicción entre algunos enunciados, necesariamente uno es verdadero y otro falso, por lo que se deberá verificar cuál es el verdadero y desechar el falso.

Para nuestra investigación, como su título lo indica "Fundamentación teórica y filosófica de la bibliotecología", nos centraremos en la fundamentación filosófica (ontológica y gnoseológica) y en la fundamentación teórica (análisis de conceptos) De esta manera, pasaremos a la fundamentación ontológica en el siguiente apartado. 

Fundamentación filosófica Ontología 

$A \begin{aligned} & 1 \text { analizar una disciplina desde el punto de vista filosófico se presenta } \\ & \text { en primer plano el problema del status ontológico de su objeto de estu- } \\ & \text { dio, de sus conceptos, enunciados, leyes y estructuras. Según U. Mou- }\end{aligned}$ lines el análisis y clarificación de ese status ontológico corresponde en primer término al científico que trabaja y desarrolla esa disciplina, pero que por motivos prácticos no lo hace porque se dedica esencialmente a la investigación propia de su área, "por ello es legítimo y hasta fructífero que el filósofo de la ciencia se ocupe de analizar los compromisos ontológicos que en principio el científico hace o debería hacer."

Los elementos componentes de la disciplina deben ser objetivos en el sentido de que versan sobre una parte de la realidad, y las leyes de la teoría deben expresar relaciones entre objetos dadas independientemente de la voluntad del sujeto. Para nuestro análisis es importante no confundir la relación de los contrarios subjetivo-objetivo con la de ideal-objetivo. La primera expresa un par de categorías contradictorias de sujeto y objeto, dentro del esquema del conocimiento, que se excluyen mutuamente; podemos decir que una visión subjetiva ocurre cuando el objeto se pierde en el sujeto cognocente y lo contrario, lo objetivo, consiste cuando el objeto es opuesto claramente al sujeto, está frente al sujeto y se da como es, además de que puede ser captado como tal no sólo por el sujeto que conoce, sino por todo sujeto potencial de la comunidad epistémica, lo que L. Villoro llama intersubjetividad. Por otro lado, lo ideal y lo objetivo no son categorías contrarias, no se excluyen la una a la otra, sino que cada una de ellas expresa una relación diferente, la primera una relación genética y la segunda, como ya se indicó, una forma de existencia opuesta al sujeto; algo ideal, genéticamente dependiente del sujeto y por consecuencia podría decirse subjetivo, puede ser objetivo en cuanto en última instancia depende de la realidad y puede llevar

1 Moulines, Ulises. Exploraciones metacientíficas. Madrid: Alianza Editorial, 1982. p. 328. 
una existencia independiente del sujeto, aunque funcionalmente actúa opuesto al sujeto y en esa instancia puede ser investigado por este último, el cual tiene que descubrir las relaciones y funciones de los entes ideales; baste con recordar los números en las matemáticas o los objetos de la lógica, que son entes ideales pero que tienen una existencia objetiva.

Después de esta breve aclaración, observamos que si utilizamos el método fenomenológico para estudiar el objeto de la bibliotecología, encontramos en un primer paso, al desechar todos los conocimientos anteriores, todos los "prejuicios", con palabras de Husserl al encerrar en un paréntesis todo juicio sobre esta disciplina, que la bibliotecología trata de seres humanos, de bibliotecas, de documentos, de información y de los conocimientos que buscan esos seres humanos en esos documentos, de las actividades que desarrollan las bibliotecas para que esos seres humanos obtengan esa información y del conocimiento que requieren, a la vez que ellas mismas crean ciertos conocimientos y otros documentos.

En la fundamentación gnoseológica y posteriormente en la teórica se deberán, como ya lo hemos indicado, analizar y describir estos elementos y sus relaciones, pues lo que nos importa en este momento es el hecho de que con base en su simple presencia podemos llegar a la conclusión, ya que el hombre es un ser social, de que la biblioteca es una institución social, de que el documento y el conocimiento tienen un carácter social, y de que la bibliotecología pertenece al campo de las ciencias sociales, cuestión que ya O. S. Chubarian destacó colocando a la bibliotecología como una ciencia que estudia una de las formas de comunicación social masiva. ${ }^{2}$

La objetividad y la existencia de leyes en las ciencias sociales, así como el método propio de ellas han sido objeto de largas disputas entre diferentes corrientes filosóficas, las cuales se han acentuado principalmente en el siglo pasado y en el presente. Podemos recordar la posición del positivismo o del materialismo dialéctico los que, cada uno empleando sus métodos característicos, afirman la posibilidad y necesidad de esa objetividad; o la posición de las escuelas neo-kantianas (Rickert), de Dilthey o la corriente de la hermenéutica contemporánea, pasando por el anarquismo metodológico, que diferencian claramente los campos del conocimiento humano y

2 Chubarian, O. S. Bibliotecología general. La Habana: Editorial Científico-Técnica, 1976. p. 9. 
le asignan a cada uno de ellos ciertas características específicas, incluyendo su método propio.

Esta situación de criticismo ante la objetividad de la disciplina se agudiza más aún si ella, como es el caso de la bibliotecología, responde a fines prácticos y su cuerpo teórico depende de la utilidad que puede tener para resolverlos, lo que deja el camino abierto para el arbitrio del sujeto, ya que existen varias opciones para alcanzar el fin deseado, y si el sujeto escoge una de ellas es porque "le parece" la más adecuada, aunque hubiera podido haberse decidido por otra.

\section{LA OBJETIVIDAD DE LA BIBLIOTECOLOGÍA}

Para abordar esta problemática, como ya hemos indicado anteriormente, consideramos necesario partir de una premisa ontológica que podemos resumir con el término de realismo (la prioridad del ser de una realidad externa e independiente del sujeto) y una premisa gnoseológica que reconozca la capacidad del sujeto para conocer esa realidad.

De acuerdo con la visión fenomenológica del objeto de la bibliotecología podemos decir que este último es algo existente independientemente del sujeto en el mundo real. Ese objeto está dado en la interrelación de documento-biblioteca-usuario, y en la búsqueda de éste último para satisfacer sus necesidades de información, cognoscitivas y estéticas, pudiendo añadir necesidades sociales, económicas y políticas. El documento, con la salvedad de que posteriormente se dará una definición más estricta, se toma como un producto social y cultural, que es el resultado de la objetivación del espíritu humano. ${ }^{3}$ La biblioteca es el espacio que propone las condiciones necesarias para satisfacer las necesidades mencionadas del lector y el "lugar" donde no sólo se conserva la producción intelectual impresa de la humanidad, sino donde se puede dar y se da el autoconocimiento del espíritu humano objetivado y se permite su desarrollo. El usuario es el ser humano (ideal) que

3 Esto se podría interpretar dentro de una concepción hegeliana, pero sin olvidar la premisa ontológica de la que partimos. Si se objetiva el espíritu, no se trata de un espíritu Absoluto, sino de un espíritu colectivo (la Humanidad estrictamente como sujeto independiente no existe, pero existe a través de los seres individuales) y que se conoce a sí mismo al reflexionar sobre sus obras, al hacer metaciencia o filosofía de sus creaciones. 
por su estructura ontológica exige o puede exigir satisfacer ciertas necesidades que emanan de su ser específico.

La objetividad de la relación entre estos elementos está determinada por su misma existencia objetiva (quizá algunos de ellos ideales, como la información), además de que son la necesidades del ser humano la fuente de toda actividad bibliotecaria, y de que esas necesidades emanan, como se expresó en el párrafo anterior, de su estructura ontológica, no son inventadas o creadas artificialmente, si acaso serán más educadas o sofisticadas para ser satisfechas de determinada manera.

\section{EL HOMBRE COMO PODER SER Y LA BIBLIOTECOLOGÍA}

Esta afirmación encuentra su fundamento en el análisis fenomenológico que hizo Heidegger del ser del hombre (en El Ser y el tiempo). Como se recordará, Heidegger expresa que el ser del hombre se caracteriza no por lo que es, sino porque siempre está en proceso de ser, siempre se halla frente a un complejo de distintas posibilidades, de las cuales no todas necesariamente se realizan. El hombre siempre está referido a su ser como a su posibilidad, se descubre al hombre como "poder ser". El poder ser es el sentido mismo del concepto de existencia, y la esencia del hombre es la existencia. ${ }^{4}$

El ser del hombre está referido a la posibilidad no en un monólogo abstracto consigo mismo, sino inmerso en un mundo concreto de cosas y otras personas, es por esto que el ser del hombre es un Ser-en-el-mundo. El hombre como existencia hace su proyecto dentro de ese mundo, encuadrando las "cosas" del mundo en su proyecto, por lo tanto ellas tienen cierta significación, las cosas antes que ser simples presencias son instrumentos y su utilizabilidad o su significado en relación con nuestra vida es su modo de darse más originario. Esto no quiere decir que las cosas sean todas medios que empleamos efectivamente, sino que se presentan a nosotros ante todo provistas de significación.

Esta significación está dada en cuanto el instrumento está constituido en función de otro (el instrumento nunca está aislado, siempre es instrumento para algo, es usado por alguien en ciertas circunstancias, está hecho de algo) y por lo tanto posee el carácter de denotación. Pero propiamente el instrumento

4 Aunque cabe aclarar que para Heidegger sería un error muy grave hablar de una esencia del hombre, se estaría pasando de la ontología a la metafísica. 
no es para denotar sino para usarse. Sin embargo, existe un objeto al cual la función denotativa es algo constitutivo, la utilidad concuerda con su capacidad denotativa, ese objeto es el signo, el cual se interpreta como las instrucciones para usar instrumentos.

Por otro lado, Ser-en-el-mundo no es sólo estar en medio de una totalidad de instrumentos, sino el estar familiarizado con una totalidad de significados. El hombre a través de una pre-comprensión, que es cierto "patrimonio de ideas", ciertos "prejuicios" que se tienen, y del adecuado uso de los signos, llega a una comprensión que articula los significados. De esta semilla se desprende la concepción que el Heidegger tardío haría sobre el papel del lenguaje en la ontología. El lenguaje no es sólo el sistema de signos por antonomasia y que como tal nos proporciona el significado de las cosas (nos da las instrucciones para emplear los instrumentos), no sólo es el receptor en donde se transmite el patrimonio de ideas que permite la pre-comprensión, sino que el lenguaje es "la casa del ser" porque al nombrar al ente lo hace aparecer y donde no hay lenguaje no hay apertura del ente.

Para nuestros fines es suficiente constatar el hecho de que el hombre como proyecto que se realiza en un mundo de cosas necesita una orientación para llevar éste a cabo, y también necesita unas instrucciones para desenvolverse en ese mundo; necesita del lenguaje para encontrarse con el ente y necesita del patrimonio de ideas que le permitan tener una pre-comprensión para llegar a la comprensión; y uno de los instrumentos (entre otros) que satisface estas necesidades es la actividad bibliotecológica, de ahí su objetividad, su importancia y el lugar privilegiado que debe poseer en su proyecto. Efectivamente, mediante esta actividad se le ofrecen al hombre unas instrucciones (información y conocimiento) para desenvolverse en el mundo, se le proporciona la tradición cultural impresa en documentos para que obtenga la precomprensión que lo llevará a la organización de sus conocimientos y, por último, si el lenguaje es la casa del Ser y la biblioteca es la casa de uno de los tipos de lenguaje, entonces la biblioteca guarda al Ser y además si recordamos la noción de verdad de Heidegger como develación del Ser entonces en la biblioteca está el Ser que tiende al hombre para revelarse a él.

Al mismo tiempo, si recordamos los conceptos de Heidegger de "existencia auténtica" y "existencia inauténtica", también podemos llegar a fundamentar la objetividad e importancia de la bibliotecología. El hombre en el 
mundo se puede realizar de una manera irreflexiva y acrítica en un cierto contexto histórico-social, en sus prejuicios y en el modo "común" de ver y juzgar las cosas, vive en la cotidianidad y se esconde en la generalidad, en el anonimato del "se", piensa lo que se piensa, usa lo que se usa y actúa como se actúa; esta forma de existir es llamada por Heidegger como inauténtica. Pero si esas opiniones generales las elige para adoptarlas conscientemente en su proyecto, y se apropia de las cosas mismas, que son instrumentos y significados y la interpretación surge de ellas para él, la existencia es auténtica. La biblioteca le proporciona la oportunidad al hombre de llegar a una existencia auténtica a través del lenguaje; el lenguaje le descubre el ente y así la posibilidad de apropiarse de él e incluirlo en su proyecto.

Por otro lado, parecería que dos pensadores tan disímiles como Marx y Heidegger no pueden coincidir en un sólo punto, pero si disminuimos el grado de abstracción, dejando de hablar de una ontología pura, para pasar a algo más concreto, encontramos que Marx expresó la idea de que los hombres antes que hacer historia, ciencia u otra actividad espiritual necesitaban vivir; pero para vivir es necesario poseer cierta información que nos permita orientarnos en este mundo y actuar de una manera congruente con la realidad y ciertos conocimientos (desarrollados a lo largo del proceso histórico de la humanidad), los cuales proporcionan las posibilidades no para adaptarse al medio pasivamente, sino para transformarlo, característica propia de la especie humana; y según nuestro enfoque esa información y conocimientos se obtienen (entre otras cosas) con la ayuda de la actividad bibliotecaria. Por lo que una vez más encontramos la fundamentación objetiva de esa actividad, no es la ciencia la que determina el Ser, sino el Ser lo que determina la existencia de la disciplina.

\section{LA ENAJENACIÓN Y LA BIBLIOTECOLOGÍA}

Por otro lado, si continuamos con el análisis del pensamiento de Marx, el Marx filósofo de los manuscritos de 1844, llegamos a otra fundamentación ontológica de la bibliotecología mediante el concepto de enajenación. Si anteriormente se habló de la "utilidad práctica", si se nos permite utilizar esa expresión, ahora se hablará de una "utilidad cognoscitiva".

Al analizar el proceso de producción, Marx descubre que el hombre objetiva su esencia en el producto de su trabajo; es decir, cada cosa hecha por el 
hombre posee parte del hombre mismo. En este fenómeno no existe nada anormal, una esencia objetivada no es aún una enajenación, ésta comienza cuando se pierde el control sobre la esencia propia objetivada, debido a que el producto del trabajo (que es o tiene parte de la esencia de su productor) no pertenece a su creador, no es de él. ${ }^{5}$

El trabajo objetivado, el producto, pertenece a otro que se apropia de él y de esta manera el producto se enfrenta a su creador. Marx llegó a la conclusión de que para que no haya enajenación el productor debe de ser el dueño de su producto y propone "[...]la real apropiación de la esencia humana por y para el hombre;[...] el retorno del hombre para sí [...] el retorno pleno, consciente [de la propia esencia], logrado dentro de toda la riqueza de la evolución anterior [...] como humanismo acabado."6

Si nosotros, siguiendo el hilo de ese razonamiento, descubrimos que la humanidad como sujeto ideal (ser genérico, ser universal) ha sido el creador de obras plasmadas en documentos, entonces para que no haya enajenación, cada hombre, como parte de esa humanidad debe "apropiarse" de ellas, por supuesto que no materialmente, sino espiritualmente, idealmente, puesto que estamos hablando de creaciones espirituales. La esencia de la humanidad plasmada en esas obras debe de llegar a personas individuales que al conocerlas se apropian de esa esencia y entonces no sólo no hay enajenación, sino autoconocimiento del espíritu humano. De aquí los conceptos de documento como objetivación del espíritu humano y de la biblioteca como uno de los lugares donde no sólo se da información y conocimientos, sino en donde se realiza el autoconocimiento del espíritu humano objetivado.

5 "El producto del trabajo es el trabajo que se ha plasmado en un objeto, el objeto es la objetivación del trabajo [...] la objetivación [se manifiesta] como la pérdida [...] como enajenación ... La enajenación del obrero en su producto significa no sólo que su trabajo se ha transformado en un objeto, en una existencia externa, sino que esta existencia está fuera de él, es independiente de él y ajena a él y representa un poder propio y sustantivo frente a él ... se enfrenta a él como algo extraño y hostil." Marx, K. y F. Engels. Manuscritos económico-filosóficos de 1844. Bogotá: Editorial Pluma, 1980. p. 69.

6 Marx, K. Op. cit. p. 105.

Dejemos por el momento a un lado la solución político-económica de fondo (abolición de la propiedad privada sobre los medios de producción) que propone Marx y quedémonos con la visión filosófica de enajenación que viene desde Hegel. (No por desechar la postura política perdamos la semilla filosófica que puede dar muchos frutos). 
Ahora bien, es claro que no se afirma la necesidad de que cada ser humano tenga conocimiento de todas las creaciones que a lo largo de su historia la humanidad ha creado, cosa por supuesto imposible de realizar dada la limitación en tiempo, recursos y capacidad de asimilación de cada hombre particular y la magnitud de obras creadas, además de que últimamente conforme pasa el tiempo se acelera la producción de estas creaciones; sino que únicamente se expresa el hecho de que potencialmente se dé esa posibilidad de conocimiento, que se va a actualizar de acuerdo con las necesidades del lector. No es indispensable que un sociólogo, por ejemplo, tenga que conocer lo que se ha escrito sobre física teórica, pero sí que si en un determinado momento surge la necesidad de hacerlo lo pueda hacer; cosa que no era posible con un libro de Trosky en la Rusia soviética después de los años treinta, o con trabajos de instituciones militares o las obras de escritores de la Grecia Antigua en el mundo contemporáneo.

Por otro lado, Marx afirma también que si existe el producto enajenado y si el producto no es otra cosa que el resumen de la actividad, de la producción, entonces la producción misma, el proceso por el cual se creó ese producto ha de ser necesariamente un proceso enajenado. ${ }^{7}$

Ahora bien, si analizamos este fenómeno en el campo de la cultura y particularmente en el de la bibliotecología, podemos observar cómo la biblioteca y la actividad bibliotecaria en general son importantes no sólo para los posibles usuarios, sino para el autor (literato o científico) de los documentos.

El autor al crear su producción documental (literaria o científica) actúa como ser individual y ser genérico, y de acuerdo con el concepto de enajenación analizado, en el primer aspecto su obra debe de pertenecer a él mismo y en el segundo a la humanidad en general; de lo contrario la actividad por la que creó esas obras sería una actividad enajenada. Ahora bien, en ambos casos el autor produce en función de un lector, escribe para ser leído (de ahí que se diga que la ciencia es comunicable en esencia), por lo que podemos decir que el modelo ideal consiste en que el autor escribe para el lector y este último lee esas obras sin otros condicionantes más que su necesidad. Pero la forma en que se realiza la apropiación de la obra en esos diversos planos no es igual e incluso puede presentarse una contradicción entre ellas.

7 Marx, K. Op. cit. p. 70-71. 
En el plano individual el autor persigue ser dueño de su obra y de los beneficios que de ella pueda obtener, la obra debe de pertenecer al autor (de ahí los derechos de autor que se reconocen en el mundo contemporáneo) y debe de crear libremente sin presiones; podemos recordar a Dostoievsky quien escribe siempre bajo la presión económica y de los editores, o al conde León Nikolaivitch Tolstoi que no tiene tales. Precisamente por estar inmersos en una sociedad mercantilista, en donde, según expresión de Marx, rige un fetichismo, el autor puede preferir trabajar donde haya más retribución económica aunque menos lectores (los trabajos de investigación realizados por instituciones elitistas). Pero por otro lado, en el plano general, sin el lector el hombre como género está sin realizarse, la producción espiritual es una actividad enajenada y no por esto el autor va a renunciar a sus derechos para que se editen sus obras gratuitamente en bien de la humanidad. ${ }^{8}$

Es aquí donde la biblioteca, aún en esta sociedad mercantilista, puede conciliar esta contradicción respetando los derechos de autor, y al reconocer que existen otras instituciones privadas que cobran sus servicios, ${ }^{9}$ poner al alcance de los que así lo deseen (según el tipo de biblioteca de que se trate) los documentos para que éstos tengan lectores. Por lo tanto, si el autor escribe para ser leído, para el lector, la biblioteca le proporciona lectores al autor, por lo que éste último no depende de la coyuntura económica, y de esta manera el autor individuo y el autor genérico tienen sus lectores.

De esta manera podemos constatar la diferencia entre una bodega, una tienda de libros y la biblioteca. El lugar donde realmente encuentra su ser el documento es en esta última institución, donde puede ser apropiado por los lectores, en tanto que en la primera sólo es un lugar donde se lo almacena sin esperanzas de ser consultado, y en la segunda aparece no en su ser auténtico sino como mercancía, en tanto que fue creado no para ser intercambiado por otra mercancía (el dinero) sino para ser leído.

8 Éste es un problema económico-social, los bibliotecarios no lo van a resolver por completo, mientras exista la sociedad capitalista, donde las relaciones son mediatizadas por la mercancía (el dinero), ese problema estará presente.

9 Es interesante constatar que en otras áreas no menos importantes para el desarrollo del Ser del hombre como la educación y la medicina, coexisten pacíficamente instituciones privadas y estatales, pues hay la posibilidad de elección para satisfacer las necesidades educativas o de salud; lo importante es que estén al alcance de todos. 
Sobre lo afirmado anteriormente puede surgir la sospecha de que nuestro planteamiento tiene matices "redentoristas o salvacionistas" al colocar la objetividad y necesidad de la ciencia bibliotecológica en el papel que juega esta esfera para evitar la alienación y alcanzar la existencia auténtica. ${ }^{10} \mathrm{En}$ primer lugar cabe aclarar que tales conceptos de redención y salvación pertenecen a una esfera ajena a la epistemológica y colindan con lo religioso, lo ideológico y cierta filosofía cuasireligiosa, ${ }^{11}$ por lo que en nuestro trabajo no tienen cabida, y una extrapolación en su interpretación sería incorrecta por principio. Nuestra propuesta consiste únicamente en mostrar que el mundo informativo documental hunde sus raíces en una necesidad ontológica del ser humano, y que su aparición se da en función de cumplir no una misión, entendida ésta como actividad desinteresada para alcanzar un fin ideal supremo, sino de servir como instrumento para la existencia y el desenvolvimiento del ser del ser humano. El hecho de que cada individuo, una sociedad particular o la especie humana en general la utilice para desarrollarse o manipular es una elección ética y, como tal, individual, libre y consciente. Los bibliotecarios o profesionales de la información documental en general no son misioneros de ninguna manera, por lo que la afirmación de que "no creemos que la misión del bibliotecario sea desalienar o hacer auténtico al género humano" 12 se encuentra fuera del contexto de nuestro discurso; simplemente se reconoce que dichos profesionales son instrumentos ontológicos que posibilitan alcanzar el autoconocimiento o la existencia auténtica, no son causas de esto último ni mucho menos mensajeros de la buena nueva, simplemente son agentes que participan, como los médicos, científicos, artistas, etcétera, en el desenvolvimiento del ser. El documento puede ser un instrumento "terriblemente eficaz" para manipular, pero lo mismo puede ser el arte, simplemente recuérdese el papel que jugó en los regímenes autoritarios del siglo XX, y no por ello Heidegger dejó de reconocerlo como el instrumento más adecuado para la expresión del ser. El fin no es alcanzar la utopía, la tierra prometida, la salvación, sino sencillamente brindar los medios necesarios para que el ser se reconozca a sí mismo en su

$10 C f$. Brown César, Javier. Elementos para una teoría bibliotecaria. México: ENBA, 2000. pp. 32-33.

11 Por ser la antesala de lo religioso, o por ser el sustituto de la religión (marxismo-leninismo).

12 Brown, Cesar Javier. Op. Cit. p. 33. 
camino. El hecho de que un instrumento de este tipo -ciencia, arte, tecnología- se utilice con miras mesiánicas surge cuando se subordina a una Idea (con mayúscula) que se declara como la única verdadera, autosuficiente y absoluta a la que deben someterse todos y todo, de lo contrario se está fuera de la verdad y por consiguiente, por el bien y la verdad, se está en la obligación de reeducar (Pol-pot, Mao, misioneros), eliminar (Hitler, Satlin, Pinochet, Inquisición) o simplemente curar su falta de capacidad para ver la luz y por lo tanto recluir en un hospital psiquiátrico (Brézhnev). Pero en ese caso se pretende tener una absolutización y monopolio de la verdad, del bien y de la belleza, negando la libertad, la otredad y, al fin de cuentas, la posibilidad del error y el mal que irónicamente son condiciones de la verdad y el bien. ${ }^{13}$

Por otro lado, sería interesante preguntar a quienes critican nuestra posición de dónde sacaron la cita de Heidegger, por ejemplo, de un libro en donde dejó plasmado su pensamiento, libro que se encuentra en una colección bibliotecaria esperando que un lector escuche su mensaje y de esta manera conozca lo que el espíritu humano ha creado a lo largo de su historia; o por qué se tomaron la molestia de escribir un libro, si no es que tenían la seguridad de que ese documento llegaría a un lector tal vez lejano en el tiempo y el espacio, pero que serviría para poner un ladrillo en el desarrollo del pensamiento de la humanidad. La praxis social muestra la corrección de nuestras conclusiones, no la extrapolación y descontextualización de nuestras ideas.

\section{DISCIPLINAS PRÁCTICAS Y TEÓRICAS}

Por último abordaremos la cuestión del carácter pragmático de la bibliotecología. Se ha criticado a ésta de ser una disciplina eminentemente práctica, de que sus reglas se han diseñado para alcanzar fines pragmáticos concretos y de que no se ve claramente su estructura teórica. Se recuerda la concepción de Aristóteles, quien afirmaba que la ciencia tiene por objeto obtener un conocimiento desinteresado y cuyo único afán es conocer por conocer; por lo tanto, si la bibliotecología no cumple con este requisito de contemplación teórica desinteresada, le es negado el carácter científico.

13 Un examen más detallado sobre esta absolutización ideológica como causa de los autoritarismos se puede encontrar en Rendón Rojas, Miguel Angel y Marina Dimítrieva Okolova. "La re-presentación extrema del estetismo, del intelectualismo y del moralismo en política”, en Analogía filosófica. Año X, N. 2, 1996. pp. 151-173. México, 1996. 
Sin embargo Marx descubre que esa posición no es la adecuada, puesto que todo se realiza con un fin, toda actividad, incluida la teórica, se efectúa movida por un interés: el de satisfacer necesidades reales; y las necesidades son el principio motor de toda actividad, incluso la filosófica, ya que la filosofía, conocimiento contemplativo por excelencia para Aristóteles, surge como respuesta a una necesidad, la de responder a la pregunta de cuál es la relación entre el Yo y el No-Yo, la filosofía pretende dar una cosmovisión racional que permita orientarnos en el Cosmos cuando los mitos no son suficientes para responder a esa cuestión.

Por otro lado, ya Husserl expresó y demostró la idea de que toda disciplina práctica descansa en un cuerpo teórico, en cuanto que sus reglas han de poseer un contenido teorético, separable de la idea del deber ser.

Expliquemos brevemente el razonamiento de Husserl y sus implicaciones concretas para la bibliotecología. Las reglas de la disciplina práctica expresan lo que debe ser, señalan una exigencia para realizar cierta actividad de determinada manera y con ciertas condiciones. Podemos a este propósito recordar las reglas de clasificación como elementos integrantes del conocimiento bibliotecológico, que precisamente nos indican cómo realizar una actividad.

Las reglas de la disciplina práctica incluyen en sí un juicio valorativo, en cuanto que si se respeta esa exigencia se alcanza un fin que se considera positivo. Pero esta exigencia tiene razón de ser sólo en cuanto el juicio de valor es válido. Por lo tanto la expresión "un $A$ debe de ser un $B$ " es equivalente a "sólo un $A$ que es $B$ es un buen $A$ " o "un $A$ que no es $B$ es un mal $A$ ". El concepto de "bueno" (valioso) o "malo" (no valioso) se aplica a cierta clase de objetos, los cuales se dividen en buenos y malos con base en ese concepto. Para poder pronunciar el juicio valorativo "un $A$ debe de ser $B$ ", necesitamos tener el concepto de "buen $B$ "; y este concepto no puede radicar en una arbitraria definición nominal, sino en una relación tal como se puso de manifiesto en el análisis ontológico arriba expuesto, "un $B$ es bueno en cuanto satisface necesidades reales emanadas de la estructura ontológica de un $D$ ”, si no las satisface entonces no es un buen $B$; y las satisface porque corresponde a características reales de objetos o a la relación entre objetos. Así la regla que expresa que en la industria alimentaria cierto producto debe ser preparado a una determinada temperatura, durante un tiempo preciso, etcétera, se debe a que 
el cumplimiento de esa regla satisface idóneamente la necesidad del hombre de alimentarse: las cadenas proteínicas, las vitaminas y otras substancias no se destruyen y pueden ser asimiladas; de lo contrario, si la temperatura o el tiempo de preparación es mayor o menor de lo prescrito por la regla entonces no se logra el objetivo deseado, y el alimento pierde sus propiedades alimenticias o permanece crudo. Esto es porque la regla refleja las características y relaciones objetivas entre "objetos" tales como temperatura, tiempo de cocimiento y estabilidad estructural (química) de vitaminas, proteínas, etcétera. En bibliotecología ocurre lo mismo, ciertas reglas se utilizan porque cumplen con la finalidad de satisfacer las necesidades del lector, enumeradas anteriormente desde una perspectiva de Heidegger, Hegel y Marx; además las cumple porque refleja relaciones objetivas entre objetos como son las características del documento y su simbolización, consistencia y completud en el sistema de símbolos y otras.

Como ya se puede observar de lo apenas afirmado, dentro de los enunciados normativos existe uno que les exige en general a los objetos de ese campo que satisfagan en la mayor medida posible las notas constitutivas del predicado positivo de valor. Esta proposición normativa ocupa un lugar privilegiado dentro del sistema de juicios normativos y se la puede llamar norma fundamental; es decir, con respecto a ella debe verificarse toda valoración que se realice dentro de la disciplina práctica.

De esta manera cada uno de los enunciados normativos tiene la idea común de la conmensurabilidad con la norma fundamental, pero además posee un contenido teórico propio que permite distinguirlos a unos de otros. La relación de conmensurabilidad entre la norma y lo sometido a la norma se caracteriza objetivamente como una relación entre condición y condicionado, relación que se presenta existente o no existente en la proposición normativa correspondiente. Así, toda proposición del tipo "un $A$ debe $\operatorname{ser} B$ " implica la proposición "sólo un $A$ que es $B$ tiene las cualidades $C$ ". La nueva proposición es puramente teorética y tiene su lugar en un cuerpo teórico (propio de esa disciplina o importada de otras); por lo tanto, si la ciencia práctica ha de merecer ese nombre es necesario que se investiguen científicamente las relaciones entre las relaciones objetivas que se trata de someter a norma y la norma fundamental, y para esto es indispensable que se estudie el fondo teórico de estas relaciones, con lo cual se entra en el campo de las 
ciencias teóricas. ${ }^{14}$ De esta manera se pasa, según nuestro planteamiento, a la fundamentación teórica de la disciplina.

\section{LA DIALOGUICIDAD COMO ELEMENTO OBJETIVO Y NECESARIO DEL CAMPO BIBLIOTECOLÓGICO}

En nuestro planteamiento para fundamentar la existencia ontológica de la esfera bibliotecológica también podemos recurrir a las ideas que maneja la hermenéutica filosófica. Como ya mencionamos anteriormente, la hermenéutica se acerca al estudio del ser humano como alguien más que como algo; esto es, el hombre se caracteriza por ser no un objeto presente, sino un sujeto que se presenta, se forma, y crea y recrea sentidos. Ahora bien, si partimos de la contraposición existente entre objeto y sujeto podemos descubrir algo esencial del sujeto que nos servirá para demostrar la objetividad y la necesidad del campo informativo documental.

Así pues, si el objeto es algo que "está ahí" inmóvil, esperando ser descubierto, mudo, que no habla; el sujeto, como lo contrario, es aquel que está en movimiento, el que descubre, el que habla. Pero ese hablar es más que la expresión de un mensaje, es también expectativa de recibir una respuesta, es compartir sentidos. El mismo lenguaje, vehículo por medio del cual se establece la comunicación, es un producto social; de esta manera, quien nada ha escuchado, el sordo, también es un mudo. Por lo tanto, el hablar necesita de un interlocutor.

Siguiendo ese razonamiento, ese interlocutor indispensable para el que habla no puede ser un objeto, porque el objeto no escucha y, lo que es más importante, no puede responder. En efecto, basta imaginar a alguien "platicando" con cosas inanimadas para sospechar de cierta anomalía en esa persona. En cierto modo se puede decir que los científicos interrogan la realidad, y que los artistas pueden conversar con la luna, las estrellas, etcétera, pero esto es una analogía, lo que todos ellos hacen es buscar sentidos en el reino de la verdad, del sentimiento o de la belleza, pero otorgándoselos ellos, no compartiendo sentidos. Lo anterior está más cercano al monólogo que al diálogo.

Por otra parte, el interlocutor tampoco puede ser el mismo sujeto que habla, porque eso también indica un estado anormal a excepción de los casos

14 Husserl, E. Investigaciones lógicas, 1. Madrid: Alianza Editorial, 1985. p. 60-65. 
de autorreflexión que sólo se realizan en ciertos momentos pero que no pueden extenderse todo el tiempo. No es posible que alguien esté hablando siempre consigo mismo, encerrado en sí, porque entonces o ese sujeto es infinito y contiene en él todos los sentidos, o es un sujeto sin crecimiento porque no tiene de donde obtener nuevos sentidos, ideas, correlatos. La primera opción claramente no es verdad, nadie puede vanagloriarse de tener la infinitud como atributo. Incluso, volvemos a repetir, el lenguaje que se necesita para "hablar" no es propiedad individual, sino una adquisición obtenida a lo largo de la convivencia social. De esta manera queda la segunda opción, un sujeto encerrado en sí mismo, es alguien enajenado que permanece estancado en su desarrollo como persona.

Así, podemos concluir que si el sujeto es quien habla, y ese hablar requiere de un interlocutor, y ese interlocutor no puede ser ni un objeto, ni el mismo sujeto que habla, entonces ese interlocutor debe de ser otro sujeto o sujetos. Así pues, para que un sujeto pueda existir como sujeto (el que habla) necesita de la existencia de otro sujeto (el que escucha y responde). Precisamente uno de los grandes descubrimientos y aportaciones de la hermenéutica filosófica es haber establecido este hecho: un sujeto no puede existir sólo; para que el sujeto se realice como tal, para que exista como sujeto, requiere de la existencia de otro sujeto.

La anterior conclusión se puede relacionar con el mundo bibliotecológico, que finalmente es el centro de nuestro análisis y nos puede ayudar a demostrar la objetividad y necesidad de ese campo y consecuentemente la importancia de su estudio. La derivación de la tesis demostrada por la hermenéutica a la bibliotecología es muy sencilla. Dentro del mundo bibliotecológico lo importante es que un individuo tenga acceso a la información gracias a la acción previa que un profesional realizó al seleccionar, conservar, organizar y ofrecer información. Sin esa acción previa no es posible que ese individuo en esa esfera encuentre los textos que requiere.

Si reflexionamos sobre ese hecho, descubrimos que el individuo busca esos textos no para otra cosa sino para encontrar un interlocutor. En efecto, cuando una persona busca información documental no lo hace para llenar, en un sentido literal, un "vacío" de información (las personas no son recipientes que se van llenando o alguien los va llenando); sino que lo hace para, en un sentido metafórico, "llenarse" él mismo, gracias a las ideas o sentidos 
que otros han expresado pero que pasan a ser parte de él no de una manera mecánica, directa e inmediata, sino después de una actividad de asimilación que implica un proceso de transformación de esas ideas y sentidos iniciales. Pero el hecho de que esas ideas y sentidos no vengan de la nada, sino de unos autores; de que al mismo tiempo esas ideas y sentidos recreados y asimilados no deben alejarse de la intención inicial del autor de manera arbitraria sino que deben depender de ella; de que pueden tener una perspectiva y unas consecuencias no previstas por el autor, pero pueden desprenderse de él; y de que si ocurre este último caso, siempre es necesario fundamentar esas consecuencias, significa que el individuo que tiene acceso a la información documental establece un diálogo con esos textos.

En efecto, al acercarse la persona a la unidad informativa documental quiere sumergirse en el mundo del lenguaje, que es un mundo no sólo de ideas y sentidos muertos y disecados que se guardan como "objetos acabados" y que se sacan en el momento indicado, sino un mundo vivo y dinámico, de sujetos, que al dialogar "reviven" y "recrean" esas ideas y sentidos. Esa persona al enfrentarse con los textos encuentra a los autores que los crearon, debe dialogar con ellos para que le desentrañen el misterio de lo que dijeron, debe de comprenderlos; esto es, interpretar sus escritos, y para ello debe de preguntarles si lo que está entendiendo está de acuerdo con su intención, no debe forzar la interpretación y poner en boca de alguien algo que no dijo; debe de sacar conclusiones de lo escuchado y proponérsela a los autores para que estén de acuerdo que es posible sacar esas conclusiones, aunque no siempre lo estarán con las conclusiones mismas. Todo lo anterior implica el diálogo entre sujetos. ${ }^{15}$

Ahora bien, si ya vimos que el encuentro de un individuo con otro, donde el primero habla y el segundo le contesta, es un diálogo entre un yo y el alter, que propicia que el primero se realice como sujeto; y que en el mundo bibliotecológico lo que se está realizando es precisamente ese diálogo, entonces es en el mundo bibliotecológico donde se está posibilitando que el sujeto encuentre sus interlocutores y de esta manera se realice como sujeto.

15 El problema de la lectura, de lo que es y de la actividad que requiere está fuera del marco de la presente obra. Únicamente podemos señalar que el leer es más que descifrar símbolos, es construir un universo de sentidos mediante la imaginación, la abstracción, la argumentación, la interpretación, el diálogo con el texto y con su autor. 
La cuestión no es trivial, hemos descubierto que la bibliotecología es uno de los elementos que ayudan a que el sujeto exista, es por ello que podemos con certeza afirmar la importancia, necesidad y objetividad de la bibliotecología: ella ayuda y participa en la realización del sujeto al permitirle que pueda dialogar con otros sujetos.

\section{LAS RELACIONES INFORMACIONALES Y LA CIENCIA BIBLIOTECOLÓGICA}

En nuestro camino para fundamentar la objetividad de la ciencia bibliotecológica recurriremos al pensamiento de Carlos Marx en contrastación con lo expresado por estudiosos del campo bibliotecológico como lo son Emilio Setién y Salvador Gorbea. Estos dos últimos investigadores propusieron que la "Bibliotecología es la disciplina de las ciencias sociales [...] que estudia la actividad bibliotecaria."16 Líneas más adelante aclaran que "La actividad bibliotecaria comprende [...] los procesos de formación, acumulación y uso del fondo bibliotecario, así como los métodos, técnicas y recursos que se utilizan en ellos, en sus relaciones con el medio social". ${ }^{17}$ De esta manera, observamos que un lugar muy importante en ese enunciado es la palabra actividad, el fenómeno a estudiar es "la actividad bibliotecaria", por lo que es necesario analizar el contenido de dicha palabra.

En términos generales, el sentido de actividad se entiende como la relación de un SUJETO ante un objeto, donde el primero actualiza sus capacidades para realizar un proceso, una operación, cumplir una tarea, para asimilar, transformar, crear o recrear un objeto. Así pues, encontramos que un elemento central dentro del concepto de actividad es que está estrechamente ligado con el sujeto, que la actividad implica una intencionalidad, una direccionalidad que es dada por el sujeto. Debido a lo anterior se puede decir que la actividad es "subjetiva", que la voluntad del sujeto la determina.

16 Emilio Setién Quezada y Salvador Gorbea Portal. "De la Bibliotecología al Sistema de Conocimientos Científicos Bibliológico-Informativo", en Investigación bibliotecológica. V. 8. N. 16. México: UNAM/CUIB, 1994. pp. 21-25.

17 Ibidem. 
Entendida de esta forma únicamente es posible estudiar cómo se realiza la actividad, pero no las leyes o los principios que la rigen, porque descansa en una elección volitiva y, podríamos decir, personal, del sujeto. Incluso, aunque no se niega la posibilidad de llevar a cabo un estudio de la actividad, éste se quedaría a un nivel instrumental que nos daría cuenta de los pasos seguidos para realizar esa actividad. Nos llevaría a descubrir el cómo, pero no el qué y menos aún el por qué. De este modo se privilegiaría un enfoque funcionalista, con todas las ventajas y limitaciones que eso implica. ${ }^{18}$

Al mismo tiempo, al considerar la actividad directamente ligada al sujeto que la realiza, y más aún si este sujeto es consciente, libre y racional, surge el problema de que dicha actividad aparecerá de diversas maneras, dependiendo de los sujetos que la llevan a cabo, con lo que se tiene una multiplicidad que haría imposible una generalización, condición sine qua non para el conocimiento científico. Así por ejemplo, dentro de la psicología, el conductismo prefirió como concepto central de su objeto de estudio la conducta en lugar de la actividad, porque la conducta se explicaba por la relación de causa-efecto entre el estímulo y la respuesta, pero dejaba a un lado el aspecto individual de cada sujeto. De esa manera se garantizaba la posibilidad de poder explicar, predecir y controlar el fenómeno estudiado. De manera semejante, la economía política como ciencia tiene por objeto, no las actividades de producción, distribución, circulación y consumo de los bienes materiales, sino la producción material como objeto dado, ${ }^{19}$ la que a su vez aparece como producción, distribución, circulación y consumo de los bienes materiales.

18 En general podemos decir que el funcionalismo como enfoque epistemológico permite un análisis detallado de las operaciones de un sistema, describe y predice las relaciones secuenciales entre un estado de cosas anterior y un proceso posterior que termina con un resultado y otro estado de cosas. Al mismo tiempo, el funcionalismo se plantea como "natural" y las operaciones realizadas que condicionan el paso de los input a los output se queda a un nivel descriptivo sin cuestionar las causas anteriores que determinan esas mismas operaciones. A nuestro juicio es indispensable investigar las bases sobre las que descansa el funcionamiento y no tomar éste como lo dado, por eso propugnamos por un enfoque crítico-ontológico.

19 "El objeto a considerar es en primer término la producción material". Marx, K. Introducción General a la Crítica de la Economía Política/1857. México: Siglo XXI, 1991.p. 33. 
Nuestra propuesta se basa en que la actividad, como hacer, es un momento posterior al ser, así pues, partimos de la premisa "primero ser y después hacer". Consideramos que la actividad, para que llegue a ser un concepto genérico despegado de la actividad individual, debe estar determinado por un elemento objetivo que la haga semejante en todos los sujetos que la realizan. Desde nuestro punto de vista, y retomando la idea de Marx sobre la interpretación materialista de la historia, identificamos unas relaciones informacionales, como elemento objetivo del objeto de estudio de la ciencia bibliotecológica. Expliquemos nuestra idea:

Según Marx, la historia se puede entender científicamente sólo cuando se dejen de tomar las ideas reflejadas en las cabezas de los hombres como lo inicial, y se descubra que esas ideas son el resultado de un reflejo de algo anterior y primario en el sentido ontológico y gnoseológico. El gran descubrimiento por el que se sentía orgulloso fue precisamente identificar ese elemento inicial, objetivo, que daba la posibilidad de una interpretación, con palabras de Marx, materialista de la historia. ${ }^{20}$ A lo largo de sus escritos podemos reconocer ese elemento materialista, principalmente en la Idelogía Alemana donde escribe que "la primera premisa de toda existencia humana y también por tanto, de toda historia, es que los hombres se hallen, para 'hacer historia', en condiciones de vivir. Ahora bien, para vivir hace falta comer, beber, alojarse bajo un techo, vestirse y algunas cosas más. El primer hecho histórico es, por consiguiente, la producción de la vida material misma". ${ }^{21}$ Ese proceso de producción es "el fundamento real" el que permite estudiar la historia sin disolverla en la "autoconciencia", "visiones", etcétera. ${ }^{22}$ Es en el Prólogo a la Contribución a la Crítica de la Economía Política, donde, en un texto que llegó a ser clásico, expone claramente el elemento material que permite interpretar objetivamente la historia, dice textualmente: "En la producción social de su existencia, los hombres establecen determinadas relaciones, necesarias e independientes de su voluntad, relaciones de producción que corresponden a un determinado estadio

20 Interpretamos los términos "materia", "materialista" utilizados por Marx en el sentido de ontológico, es decir, como ligados al ser. Dicho elemento ontológico es lo que le da objetividad al fenómeno estudiado, evitando de este modo el subjetivismo y el relativismo.

21 Marx, K. y Federico Engels, La ideología alemana. México: Grijalvo, 1987. p. 28.

22 Idem. pp. 40-41. 
evolutivo de sus fuerzas productivas materiales. La totalidad de esas relaciones de producción constituye la estructura económica de la sociedad, la base real sobre la cual se alza un edificio jurídico y político, y a la cual corresponden determinadas formas de conciencia social [...] No es la conciencia de los hombres lo que determina su ser, sino, por el contrario, es su existencia social lo que determina su conciencia [...] Así como no se juzga a un individuo por lo que éste cree ser, tampoco es posible juzgar a una época [...] a partir de su propia conciencia, sino [...] a partir de las contradicciones de la vida material." 23 Precisamente el hecho de que las relaciones de producción sean necesarias e independientes de la voluntad es lo que le proporciona el elemento objetivo al estudio de la historia.

De manera análoga, si queremos apresar la objetividad del objeto de estudio de la ciencia bibliotecológica, tenemos que encontrar un elemento dado de manera necesaria e independiente de la voluntad. Consideramos que esas actividades de las que hablan Setién y Gorbea se deben de ver más bien como procesos, no como formas de hacer, sino de ser. Continuando con nuestra analogía, esos procesos pueden ser tomados como relaciones informacionales que surgen independientemente de la voluntad de los individuos, porque en el transcurso de su vida para poder existir como seres humanos, éstos deben producir, almacenar, distribuir y usar información. Un caso específico de esa información es el de la información documental.

Un corolario de la afirmación anterior es que si las relaciones sociales surgen del ser mismo del hombre es porque es un ser social, si las relaciones de producción surgen del ser mismo del hombre es porque es un ser económico (productivo); entonces las relaciones informacionales surgen porque el hombre es un ser informacional. La actividad bibliotecaria, la actividad archivística, la actividad científico informativa, la actividad bibliográfica, son fenómenos de una sobreestructura que descansa sobre la base de unas relaciones informacionales. Posteriormente a esas actividades se les pueden buscar sentidos intencionales, de ahí el carácter hermenéutico de las ciencias del espíritu en las que se coloca a la ciencia bibliotecológica, pero

23 Marx, K. "Prólogo a la Contribución a la Crítica de la Economía Política", en Marx, K. Introducción General a la Crítica de la Economía Política/1857. México: Siglo XXI, 1991. pp.66-67. El subrayado es nuestro. 
aquí ya se trata de una intencionalidad no subjetiva individual, sino de una intencionalidad subjetiva genérica.

Lo que hemos llamado relaciones informacionales no deben tomarse como algo totalmente diferente a las relaciones de producción, son sólo una faceta distinta de éstas. Para producir es necesaria la creación de la información, y cuando ésta se produce, se crea y se usa información. Lo importante es detectar la necesidad objetiva de la aparición y existencia de esas relaciones informacionales.

Según se pudo observar en el desarrollo de esta exposición, la bibliotecología no es el producto de una invención arbitraria de una comunidad, sino que nace de necesidades reales y en su cuerpo teórico refleja relaciones objetivas entre elementos también objetivos, su futuro desarrollo estará determinado por el deseo de satisfacer esas necesidades y se adecuará al desarrollo de esos elementos y sus relaciones.

Es interesante e importante hacer una reflexión sobre las llamadas leyes bibliotecológicas de Ranganathan y analizarlas a la luz del planteamiento aquí expuesto. ${ }^{24}$ Esas leyes son más bien principios que rigen una actividad, son normas que permiten lograr una finalidad (recuérdese a Husserl), pero esos principios tienen como fundamento elementos objetivos reales (recuérdese a Hegel y a Marx). Si "los libros son para usarse", "los libros son para todos", "cada libro tiene su lector" y "se le debe ahorrar tiempo a los lectores", es porque los libros deben ser parte integrante del proyecto existencial del hombre, porque ellos permiten el autoconocimiento del espíritu humano objetivado y su ausencia en la vida del hombre conlleva a una existencia inauténtica, a una falta de comprensión de la existencia (naturaleza, hombre y sociedad), a una enajenación de la humanidad. Si "la biblioteca es un organismo en constante desarrollo" es porque está ligada al ser del hombre que no es más que "un poder ser", es decir, un ser en desarrollo y esa relación determina la dialéctica consecutiva de la biblioteca con el Hombre.

De esta manera podemos concluir que tal como nos lo advirtió Moulines los miembros de la comunidad científica que trabajan en la investigación de su área poseen determinados compromisos filosóficos implícitos que deben ser puestos en evidencia mediante un análisis metacientífico de

24 Ranganathan, S. R. The five laws of Library Science. Bangalore, India: Sarada Ranganathan Endowment for Library Science, 1989. 
esa disciplina. Esto no significa que podemos aseverar unívocamente que Ranganathan se basó en ese marco filosófico o que estaría de acuerdo con él, tal vez tenía presente una filosofía oriental, pero lo que sí podemos afirmar es que si aceptamos ese marco propuesto por nosotros, que a su vez está debidamente fundamentado, nos ayudará a comprender más profundamente la disciplina de la bibliotecología. Tal vez alguien proponga otro marco filosófico, pero tendría que fundamentarlo y con base en él fundamentar la bibliotecología. Lo atractivo de nuestra propuesta, según yo, es que se basa en la tradición filosófica occidental, comprensible para nosotros, respeta el realismo, contempla la verdad como correspondencia, se aleja de convencionalismos y pragmatismos, y no cae en relativismos, dogmatismos e irracionalismos. 
Fundamentación teórica Análisis de términos 



\section{ANOTACIONES METODOLÓGICAS}

D e acuerdo con nuestro programa una de las tareas a cumplir en la fundamentación de una disciplina es analizar y esclarecer, dentro de su marco teórico, el contenido de los conceptos centrales utilizados en dicha disciplina; esto es, dentro de la fundamentación teórica es necesario definir o redefinir esos conceptos y precisar bajo qué aspecto son enfocados. Pero quisiera antes de adentrarnos propiamente en el tema, realizar unas precisiones de carácter metodológico

\section{Término, objeto y concepto}

Como es sabido, la formación e introducción de definiciones ocupa un lugar muy importante en la metodología de la ciencia. Nosotros vamos a entender por definición a la operación lógica por medio de la cual se establece el nexo entre una expresión lingüística y el objeto que ésta designa. Dicho nexo se realiza a través de la especificación de un conjunto de propiedades y/o relaciones (predicados), los cuales nos sirven para identificar a los objetos que comparten esas propiedades o relaciones y, al mismo tiempo, nos permiten agruparlos como elementos de una clase determinada y de esta forma diferenciarlos de otros objetos que no poseen dichos predicados.

De acuerdo con lo anterior distinguimos tres elementos que toman parte en esta operación: un elemento de naturaleza lingüística (término), un elemento ontológico (el objeto denotado) y un elemento lógico-epistemológico (el concepto como forma del pensamiento). La relación entre estos elementos nos muestra la dialéctica de la formación y transformación de las definiciones, así como de su cambio y continuidad, y también nos permite orientarnos en el aspecto arbitrario y natural que contienen. Analicemos pues brevemente esos tres elementos. 
El término en cuanto tal, según nuestra opinión, sólo merece una atención especial en relación con el objeto que denota, y el concepto al que se le asocia en la comunidad epistémica, hecho que está en estrecha relación con el uso que se le da. Si hay conciencia de que un mismo objeto es denominado por diferentes términos, no existe un grave problema de comunicación y entendimiento, y sólo es necesario explicitar esa sinonimia. ${ }^{1}$

Hablando de una manera muy rudimentaria, si se sabe que los términos "Paco", "Pancho", "Francisco", "Emérito Doctor Don Francisco de Córdoba y Reyes", etcétera, denotan a un mismo objeto (persona), no surgen dudas al momento de emplear esos términos. Una cosa semejante sucedería en nuestra disciplina si se tuviera claro el significado y la sinonimia por ejemplo de términos como "biblioteconomía", "bibliotecología", "documentación" y "ciencia de la información". ${ }^{2}$ Si ese fuera el caso, tener nombres diferentes pero una denotación clara, aunque no sería una situación muy ortodoxa, no causaría mayores problemas, y el asunto se enmarcaría en un nivel pragmático, donde los sujetos se comunicarían traduciendo sus distintos términos con base en una sola denotación y un único sentido. Creo que no surgen dudas entre la comunidad epistémica correspondiente de que se está hablando de lo mismo, independientemente de que se utilice el término 'física clásica' o 'física de Newton'; o 'lógica clásica' y 'lógica extensional bivalente'. Pero el problema es que no sucede así en la esfera bibliotecológica, por lo que es necesario analizar los usos que se les da a algunos términos y las relaciones de éstos con sus denotaciones y conceptos.

El segundo elemento que interviene en este sistema semiótico es el objeto denotado, decimos objeto en el sentido amplio de la palabra, esa "cosa" de la que hablamos existe por el simple hecho de ser nombrada, aunque sea únicamente en el universo de nuestro discurso y esa existencia no exige necesariamente la existencia en el mundo real.

Los objetos nombrados pueden tener una categoría ontológica distinta. En primer lugar pueden ser elementos del mundo objetivo, por ejemplo los

1 Aunque lo ideal sería, como lo indican los epistemólogos clásicos, la univocidad en el lenguaje: un termino para un concepto, y un concepto para un término.

2 Como en el caso del Emérito Doctor Don Francisco, a veces se deben de buscar etiquetas llamativas, más aún cuando se buscan apoyos de instituciones especiales (UNESCO, CONACyT, etcétera), a Pancho no le darían esos apoyos, pero al emérito Doctor sí; tal vez a la bibliotecología no se los darían, pero a la ciencia de la información sí. 
cuerpos celestes, los elementos químicos, los seres vivos, la biblioteca, el libro, el lector, etcétera. En segundo lugar pueden ser idealizaciones existentes en un mundo construido mediante abstracciones, como "gas ideal", "conjunto", "punto infinitamente alejado donde se unen las líneas paralelas", "centro de gravedad" u otros objetos ideales con los que trabajan los científicos. Por último, también pueden ser un objeto mitológico o literario, como "pegaso" "unicornio", "centauro", "Otelo", "Pedro Páramo", "Iván Karamásov", "Don Quijote", "Gregor Samsa", "el actual rey de Francia", etcétera. ${ }^{3}$ Dentro del análisis de una teoría científica nos interesan los dos primeros tipos de objetos (los que existen en el mundo real y los objetos ideales creados con fines científicos).

Este elemento denotativo es el que le otorga objetividad a nuestro aparato conceptual y terminológico, y marca la pauta en la transformación de ciertos conceptos ( $v . g r$. masa, tiempo, planeta, estrella), el abandono de otros (flogisto, éter, movimiento al lugar natural) o la continuidad de determinadas características que pasan de un concepto antiguo a uno nuevo. Esto se debe a nuestra premisa realista de la que partimos: "la primacía del ser del mundo real con el que interactuamos"; y por consiguiente, reconocemos que aun los modelos más abstractos y las idealizaciones más elevadas tienen su origen en el ser de objetos reales o en necesidades objetivas del sujeto que los crea para resolver esas necesidades, y la comprobación de esas idealizaciones se realiza de acuerdo con su adecuación con el mundo real y de su capacidad para explicarlo. De esta manera, la evolución del concepto se encuentra en correspondencia con la evolución del objeto; y la comprobación de la corrección del primero se realiza de acuerdo con su capacidad para explicar al segundo. Se dice que un concepto es adecuado cuando, dentro de la clase que se forma a partir de las propiedades que se toman como necesarias para su elaboración, caen todos y sólo todos los objetos que se identifican como elementos del volumen del concepto; es decir, no se tienen objetos de más en esa clase, que sería tener una definición muy amplia, ni se tienen

3 Cada mundo en donde existen esos objetos (mundo posible) tiene sus entes que lo "habitan", nuestro mundo real es uno de tantos mundos posibles, otro mundo posible es el dado por la mitología griega, otro el de las abstracciones científicas, etcétera. No se debe atribuir a estos mundos posibles una existencia ontológica en sí, al estilo platónico, ellos fueron creados por un sujeto y dependen de él, si desaparece el sujeto desaparecerán ellos. 
objetos fuera de la clase que debiendo estar no lo están, que sería una definición estrecha. Ejemplo de una definición amplia sería definir hombre como animal bípedo, puesto que en la clase formada caen elementos no deseados como son las aves; ejemplo de una definición estrecha sería definir mamífero como animal vivíparo, ya que en ese caso, el ornitorrinco que es ovíparo, pero mamífero, no cae dentro de la definición.

El tercer elemento del sistema semiótico es el concepto entendido como forma del pensamiento, esto es, tratamos el concepto como la imagen ideal que ocurre en la mente del sujeto y que es el símbolo ideal que denota al objeto. Dicha denotación se realiza a través de ciertas propiedades que sirven como base para formar una clase y en función de ella clasificar los objetos que son elementos de dicha clase y los que no lo son. Este elemento es el que nos proporciona la forma lógica para analizar la evolución del concepto; dicha forma la podemos escribir de la siguiente manera: $X A(X)$ que se lee "el objeto $X$ de la correspondiente clase que cumple la propiedad ser $A$ ", donde la propiedad ser $A$, puede ser compleja; es decir, puede ser una composición de conjunciones, disyunciones, negaciones, condicionales y bicondicionales. Así por ejemplo, podemos decir que un objeto $x$ es $A$ si y sólo si ese objeto $x$ tiene las propiedades de ser $P$ y $Q$ y no es $R$, y si es $S$, entonces es $T$ o es $U$. De esta manera, simbólicamente tendríamos:

$$
x A(x) \equiv x\{(P(x) \& Q(x) \& \neg R(x)) \&(S(x) \supset[T(x) \vee U(x)])\}^{4}
$$

En el desarrollo histórico de una disciplina ciertos conceptos van cambiando, lo que significa que se les van agregando propiedades para irse limitando, o van eliminándose algunos atributos que ya no se consideran esenciales para darle cabida a más objetos que anteriormente no se incluían en el concepto; es decir, se realiza una generalización del concepto. Así por ejemplo podemos seguir la evolución del concepto "planeta":

4 De aquí en adelante representaremos las constantes lógicas de la siguiente manera: $\neg$ para la negación "no"; \& para la conjunción "y"; $\vee$ para la conyunción "o"; $\supset$ para la implicación "si ... entonces"; $\equiv$ para el bicondicional "si y sólo si"; $\forall$ para el cuantificador universal "todos", "cada uno"; $\exists$ para el cuantificador existencial "algunos", "existen". Utilizaremos $x, y, z, \ldots, x_{n}, y_{n}, z_{n}$, para variables individuales; $a, b, c, d, e, m, t$, y para constantes individuales; $P, Q, R, S, T, U, V, \ldots P_{n}, Q_{n}, R_{n}, S_{n}, T_{n}, U_{n}, V_{n}$ para predicados. Símbolos técnicos (,). La definición de término y fórmula bien formada es la acostumbrada para la lógica de predicados. 
1.- Antes de Copérnico se decía que planeta $(A)$ es un cuerpo celeste $(P)$ que se mueve alrededor de la Tierra $(Q)$ y las estrellas fijas $(R)$, con un movimiento circular $(S)$ y que posee una materia diferente a la terrestre $(T)$. Esto es:

$x$ es planeta $\equiv x\{P(x) \& Q(x) \& R(x) \& S(x) \& T(x)\}$.

De esta manera, la Tierra no es un planeta, pero la Luna y el Sol sí lo son.

2.- Para Galileo, un planeta sigue siendo un cuerpo celeste $(P)$, pero ahora se le añade la propiedad de que se mueve alrededor del Sol $\left(R_{l}\right)$, y se mantiene el atributo de tener un movimiento circular $(S)$. Esto significa que las propiedades 'moverse alrededor de la Tierra' $(Q)$, 'moverse alrededor de las estrellas fijas' $(R)$ y 'poseer una materia diferente a la terrestre' $(T)$ ya no se consideraron necesarias. Por lo que el concepto se transforma en: $x$ es planeta $\equiv x\left\{P(x) \& R_{1}(x) \& S(x)\right\}$.

Dentro de este concepto podemos incluir a la Tierra, pero al Sol ya no.

3.- Para Kepler, el concepto evoluciona modificando la propiedad $S$ 'tener movimiento circular', por $S_{1}$ 'tener un movimiento elíptico' y conservando $P$ y $R_{l}$. Por lo que su forma es:

$x$ es planeta $x \equiv\left\{P(x) \& R_{1}(x) \& S_{1}(x)\right\}$.

La extensión del concepto sigue siendo equivalente a la anterior.

4.- Para la astronomía contemporánea el concepto de planeta se amplía, se conservan las propiedad $P$ y $S_{1}$, pero se incluye una vez más el atributo $R$ 'moverse alrededor de las estrellas fijas', y se obtiene la siguiente forma: $x$ es planeta $\equiv x\left\{P(x) \& R(x) \& S_{1}(x)\right\}$.

En esta definición se puede observar que los objetos que caen dentro de la clase de planetas creció enormemente, en virtud de que toda estrella puede tener sus planetas.

De las cuatro definiciones dadas podemos decir que para la astronomía la última es la más adecuada porque los objetos denotados con el término 'planeta' presentan en la realidad las características que se les atribuye $\left(P, R\right.$ y $\left.S_{I}\right)$, y al mismo tiempo de acuerdo con esa misma realidad no es verdad que se mueven alrededor de la tierra, ni que sus órbitas son circulares, ni que están 
constituidos de una materia diferente a la terrestre. Es así como podemos observar que la corrección de los conceptos descansa en la realidad. 5

De lo expresado en el párrafo anterior se desprende que un concepto es una herramienta de trabajo intelectual. Por lo tanto es un instrumento para "algo", de aquí que no se pueda absolutizar y decir que se busca el concepto de $x$, como diciendo que se busca la esencia de $x$. Es importante tener presente que no es necesario proporcionar una definición completa y última. Un objeto puede ser definido de diferentes formas según el análisis que se desee realizar de él. Así por ejemplo, un libro puede ser visto y definido desde cualquier punto de vista, el económico, el del arte, el de la psicología, el de la filosofía, de la etnología, de la bibliotecología, etcétera, por lo que se pueden tomar propiedades económicas o estéticas o psicológicas o filosóficas o culturales o bibliotecológicas para definirlo. Pero las características se escogen de acuerdo con la tarea que hay que resolver y por lo tanto no estaremos buscando una definición exacta y absoluta. Todo estará en subordinación al campo de la disciplina donde se inserta la definición, a la exigencia metodológica que nos obliga a evitar ambigüedades o contradicciones y, sobre todo, a la TAREA que se desea cumplir. Si el problema lo podemos resolver con dar sólo un aspecto del objeto, eso es suficiente, pero si lo que nos exige no es una simple descripción entonces debemos abocarnos tan profundamente a su definición como sea necesario. ${ }^{6}$

Asimismo se debe tener presente que un concepto se encuentra dentro de una teoría, aunque el elemento objetivo, como lo hemos mencionado, tiene una función muy importante para el origen y la verificación de los conceptos, tampoco se debe olvidar la influencia opuesta que ejerce la teoría a los conceptos. El objeto puede tener infinidad de atributos, propiedades y relaciones, pero el investigador no se fija en todas ellas. ${ }^{7}$ Según Hempel "los

5 Aun en las llamadas definiciones nominales, su corrección descansa en ciertas propiedades externas al término elegido, en relaciones independientes que son descritas, explicadas, demostradas o predichas con ayuda del término que se define nominalmente. Si ésta no las describe, explica, demuestra o predice, no nos sirve esa definición nominal.

6 Por ejemplo, en la física al hablar de energía no se proporciona su status ontológico, ni su esencia, sino simplemente su característica numérica dada en la fórmula $E=m c^{2}$, lo que es suficiente para resolver las tareas que caen dentro de la física.

7 Al igual que un conductor no presta atención a todos los estímulos que actúan sobre sus órganos de los sentidos, sino sólo a los que intervienen directamente en su actividad. 
conceptos de la ciencia son los nudos de una red de interrelaciones sistemáticas en la que las leyes y los principios teóricos forman hilos". ${ }^{8}$ De este modo un concepto científico es un nudo de una trama, los hilos de la trama son las proposiciones que forman una teoría, y el significado de un concepto es su lugar en la trama. Un concepto no es algo simple que se puede captar o no, sino algo complejo que sólo puede aprenderse poco a poco; al comprender más hilos (proposiciones) se comprende más el concepto. Algunos conceptos se transforman porque algunos de los hilos que los conectaban se eliminan; otros se transforman, algunos nuevos se introducen y otros más se conservan. ${ }^{9}$ De esta manera podemos decir que el significado de los conceptos depende de la teoría en que aparecen, y que su precisión es directamente proporcional al grado de desarrollo y coherencia de la teoría. Esto implica que un concepto será más claro en una teoría más desarrollada que en una menos desarrollada. ${ }^{10}$ Por ejemplo, el concepto de 'campo eléctrico' fue en su inicio una idea vaga cuando Faraday en los años 40 del siglo pasado lo introdujo, utilizando metáforas y analogías con términos de la mecánica tales como 'tensión', 'fuerza', 'potencia'; pero dicho concepto se fue gradualmente aclarando a medida que la teoría en la que desempeña un papel tomaba una forma más precisa, hasta llegar a ser un concepto bien definido en la teoría electromagnética de Maxwell. De la misma manera los conceptos que introducimos; en este caso, el de 'libro', pueden ser en un principio un tanto imprecisos, pero servirán para desarrollar la teoría bibliotecológica y a su vez se presentará el efecto contrario: se irán aclarando a medida que la teoría bibliotecológica se desarrolle.

Empleando este análisis podemos identificar ciertos cambios en el concepto de "información", "usuario" e "institución informativa", y determinar el cambio de características que se les pueden ir agregando o suprimiendo para que continúen sirviendo como herramienta en la teoría bibliotecológica, principalmente en esta etapa donde la influencia de la tecnología

8 Hempel, C. Filosofía de la Ciencia Natural. Alianza, 1980. p. 94.

9 Como lo pudimos observar en el análisis de la evolución del concepto "planeta". El cambio de dicho concepto no es aislado, sino en correspondencia con la evolución de otros conceptos y enunciados generales como es el caso de "estrella", "los cuerpos celestes se mueven con un movimiento perfecto", entre otros.

10 Y se dio la relación dialéctica de que ese concepto a su vez coadyuva al desarrollo de la teoría. 
Bases teóricas y filosóficas de la bibliotecología

motiva la introducción de nuevos términos y la redefinición de los antiguos conceptos.

\section{DEFINICIÓN DE TÉRMINOS}

\section{Información. Concepto central en bibliotecología}

\section{El problema de la naturaleza de la información en bibliotecología}

Entre algunos de los conceptos básicos en la bibliotecología encontramos el de información, por lo que esclarecerlo significaría un gran avance para reafirmar su campo teórico y delimitar su objeto de estudio. Aunque existe un gran número de nociones de información, se puede decir que demasiadas, se observa la falta de consenso. ${ }^{11}$

Nuestra tarea es delimitar desde dentro de la bibliotecología cuál es el aspecto de "información" que le interesa y no agregar a la lista de conceptos de información otro más, sino encontrar un común denominador que permita establecer un enfoque rector que nos dé una pauta a seguir dentro del marco teórico de la investigación bibliotecológica. Para realizar esta tarea partiremos de una concepción filosófica y semiótica que nos proporcionará los instrumentos necesarios de ese concepto central que es la "información".

Uno de los problemas que hacen tan difícil definir el concepto de información es el hecho de que en este caso debemos dar información sobre la información, pues un fenómeno tan general tiene que ser delimitado (definido) con otro que tiene el mismo grado de generalidad, situación que puede

11 Cfr. Shera, Jesse. Los fundamentos de la educación bibliotecológica. México: UNAM/CUIB, 1990. p. 157.

Un buen número de nociones del concepto de "información" se puede encontrar en Armando Gómez, Villalpando, El objeto de estudio de la Ciencia de la Información. Tesis para obtener el grado de maestro en Ciencias de la Información. Guanajuato, Gto. 1990. También en Definiciones del concepto de información en España: 1970/1990. de García, Redondo Lourdes, proyecto dirigido por la doctora Emilia Currás. Curso de especialista universitaria en documentación pedagógica 1991/1992. Facultad de Ciencias de la Educación. Universidad Complutense. 
muchas veces conducir hacia paradojas. Recordemos la paradoja lógica de Russell o la paradoja semántica del "mentiroso". 12

El origen de estas paradojas y otras (de clases o conjuntos que se incluyen a sí mismos) es el hecho de una autodenominación o autoinclusión, ${ }^{13}$ y si se prohibe que se dé esa autodenominación o autoinclusión, entonces aunque no obtenemos su solución, sí, por lo menos, evitamos que se presenten estos problemas. De esta manera procedieron Russell con su teoría de tipos para excluir las paradojas lógicas, y Tarsky con la diferenciación del lenguaje objeto y metalenguaje para evadir las paradojas semánticas. Si bien eso aleja el peligro de las paradojas se presentan algunos inconvenientes: el lenguaje se empobrece, existen ciertas restricciones para usarlo y no se puede hablar de "todo". Además de que esto se logra en un lenguaje formal. No podemos hacer esto al hablar de información, al menos que encontremos otro concepto más general que él (lo que en teoría de la definición es establecer el género), porque aunque construyamos un metalenguaje para hablar sobre información, en este metalenguaje estará presente la información y no se puede evitar la autodenominación.

Sin embargo, cabe recalcar que si bien la definición de este término representa un gran problema, no debemos exagerar sus consecuencias; en matemáticas, por ejemplo, existen conceptos tales como "conjunto" o "función” que estrictamente son indefinibles, sólo se pueden proporcionar

12 Un ejemplo de paradoja lógica es cuando se hace la diferencia entre propiedades impredicables y predicables. Las primeras son aquellas que no se aplican a sí mismas, como la propiedad "ser perro", ella misma no es un perro; las propiedades predicables son las que se aplican a sí mismas, como la propiedad "ser propiedad". Si se toma la propiedad "ser propiedad impredicable" se pregunta ¿es una propiedad predicable o impredicable? Y se llega a la conclusión contradictoria de que esa propiedad es predicable si es impredicable y es impredicable si es predicable. En efecto, supongamos que "ser impredicable" es predicable, entonces se aplica a sí misma su propiedad, es decir es impredicable; ahora, si es impredicable, no se aplica a sí misma su impredicabilidad, es decir, es predicable.

La paradoja semántica del mentiroso tiene una estructura semejante a la anterior. Se tiene el enunciado "yo miento" y la cuestión es saber si ese enunciado es verdadero o falso; así se llega a la conclusión de que es verdadero si y sólo si es falso, y es falso si y sólo si es verdadero. Supongamos que es verdadero, entonces al decir "yo miento" se está mintiendo, es decir se está diciendo algo falso; por otro lado, si es falso el enunciado "yo miento", entonces yo no miento, por lo que es verdadero ese enunciado.

13 Otras paradojas son la del mayor número ordinal, la de Cantor, la de Richard, la de Jourdain, etcétera. La estructura de construcción es semejante en todas ellas. 
sinónimos o descripciones de ellos, pero esto no impide que esta ciencia continúe desarrollándose.

\section{Acercamiento filosófico}

El problema de la naturaleza de la información se presenta de forma encubierta en todas las acepciones que existen sobre información y cada una de ellas se fundamenta en una concepción filosófica determinada. Las preguntas a las que se deben de contestar son: ¿la información es una substancia, una cualidad o un fenómeno complejo en el que hay una unidad de substancia y cualidades? ${ }^{14}$ ¿es algo material o ideal (abstracto, no-material)? ¿si es algo ideal cómo se relaciona con lo material (si es que se relaciona)? o ¿si es algo material cómo se relaciona con lo ideal? ¿si es una cualidad por qué ella a su vez puede tener otras cualidades?

Si la respuesta a la primera pregunta es que la información es una substancia y además algo ideal, inmediatamente tenemos la sospecha de caer en un platonismo en el que se admite la existencia de un mundo independiente al material, habitado por esas substancias ideales, un mundo de las ideas. La información es algo que está más allá de los datos, de los símbolos, los cuales como envoltura material la acompañan. Esta posición nos recuerda las ideas de Frege (su división de lo objetivo real, lo subjetivo y lo objetivo noreal); de Popper con su teoría del tercer mundo, y de Husserl que nos hablan del mundo de los eidos.

Así Frege, por ejemplo, explica que lo objetivo es aquello que es independiente de mi conciencia, que no pertenece a mi experiencia interna y de lo que otros, al igual que yo, pueden ser conscientes. Todas las cosas que puedo percibir por medio de mis sentidos son objetivas, pero lo objetivo no se circunscribe a ellas, esto es sólo lo objetivo real. Existe además aquello que puede ser contenido de conciencia de muchos, no necesariamente perceptible por los sentidos y que es independiente de las ideas o sensaciones

14 En este caso seguimos parcialmente la división aristotélica de los diversos modos de ser. Por sustancia entendemos el modo de ser según el cual no se necesita de otro en el cual existir, es suficiente por sí mismo para actuar como sustrato o sujeto de otras categorías (cualidad, cantidad, relación, lugar, tiempo, situación, posesión, acción y pasión). Por otro lado, el término cualidad, lo empleamos de una manera más amplia que Aristóteles, quien la consideraba sólo una de las categorías; para nosotros cualidad es toda propiedad o relación que se le puede predicar a un sujeto, es decir, lo manejamos como un predicado en el lenguaje de la lógica contemporánea. 
privadas de cada uno; lo objetivo no real. En su obra El Pensamiento puede leerse: "Debe admitirse un tercer reino. Lo que pertenece a él coincide con las representaciones en que no puede ser percibido por los sentidos, pero con las cosas en que no necesita portador a cuyos contenidos de conciencia pertenezca. Así, p. ej., el pensamiento que expresamos en el teorema de Pitágoras es atemporalmente verdadero, verdadero independientemente de que alguien lo tome por verdadero". ${ }^{15} \mathrm{~A}$ este reino pertenecen los pensamientos, los cuales pueden captarse, poseerse y comunicarse intersubjetivamente.

Ahora bien, si aceptamos que el pensamiento no es vacío, sino que tiene información ( o si se quiere, para simplificar, es información) entonces existe el mundo objetivo no real de la información.

Pero esta posición origina problemas ontológicos muy complejos (o pseudoproblemas), entre los cuales podemos resaltar que deja sin explicar cómo es que se forma ese tercer reino ¿es eterno o tuvo un principio? ¿cómo el hombre llega a él? ¿por una intuición? y ¿cómo diferenciar una intuición intelectual de una no-intelectual, por ideas innatas? ¿cómo se relacionan esos tres mundos, por una armonía predeterminada entre ellos? Por otra parte, el estudio de la información, tomada en este sentido, sería un estudio únicamente lógico, una relación entre formas puras del pensamiento ¿pero qué clase de lógica, la clásica, la intuicionista, la para-consistente, la relevante ...? Por último, este enfoque iría en contra de nuestra premisa realista tomada anteriormente.

No se encuentra la posición de acuerdo con la cual la información se considere una substancia material. Más bien, si el enfoque parte del punto de vista materialista, se le considera o bien una cualidad (como organización del sistema o capacidad para organizarlo, como anti-entropía, como improbabilidad de la aparición de una señal, como bien económico, como necesidad primaria y social del hombre, como conocimiento objetivado, etcétera) o bien un fenómeno complejo (y entonces se le identifica con los datos, con una proposición, se le toma como un proceso de in-formación, etcétera).

15 Gottlob Frege. El pensamiento, en Investigaciones lógicas. Madrid: Tecnos, 1984. pp. 69-70. 


\section{Información como cualidad secundaria}

Nuestra posición será el tratar a la información en primer lugar como algo no material; esto es, algo ideal $(P)$, pero no subjetivo $(Q),{ }^{16}$ y en segundo lugar como una cualidad secundaria (en el sentido de Locke), ${ }^{17}(R)$, originada en una síntesis realizada por la actividad del sujeto en la que se estructuran propiedades presentes en el objeto dadas en las impresiones sensoriales $(S)$, (análogamente a las concepciones del origen del conocimiento de Kant, sin el apriorismo, y de Piaget), información que se objetiviza ( $T$ ) y existe en un mundo posible $(U)$ (como los lógicos lo manejan) pero sin hipostatizar ese mundo $(V)$.

Por lo que nuestro concepto de información es:

Definición1:

$x$ es información $\equiv((P(x) \& \neg Q(x)) \& R(x) \& S(x) \& T(x) \& U(x) \& \neg V(x))$

El argumento en el que nos basamos para afirmar que la información es algo no material es el siguiente: decimos que el espacio, el tiempo y el movimiento son atributos característicos de la materia; es decir, que todo objeto si es material tiene espacialidad, temporalidad y movimiento.

Pero nosotros constatamos que la información se transmite, no se transporta en el sentido literal de la palabra, puesto que no se quita de un lado y se lleva a otro, sino que se encuentra en el emisor y receptor al mismo tiempo, o más aún, que puede encontrarse en varios receptores simultáneamente. Lo que nos lleva a la idea de que por lo menos la información no posee el atributo de la espacialidad.

16 Se utiliza el término ideal en el sentido filosófico tradicional, es decir, como derivado de idea que está contrapuesta a la materia, de ahí por ejemplo las corrientes idealistas; y no en el sentido de ideal como perfección. Asimismo, al hablar de algo ideal pero no subjetivo debemos recordar la distinción que hemos hecho entre los pares ideal-objetivo y subjetivo-objetivo.

17 Locke distinguía dos tipos de cualidades: las primarias y las secundarias. Las primeras son las que son inseparables de los cuerpos, como la solidez, la extensión, la figura y la movilidad; las cualidades secundarias son las que no están en los objetos mismos sino como poderes de producir sensaciones por medio de las cualidades primarias, como los colores, los sabores, los sonidos. 
De las dos anteriores premisas que todo lo material tiene espacialidad, temporalidad y movimiento, y que la información no tiene espacialidad, podemos fácilmente deducir que la información no es material. 18

La objeción que se nos podría hacer es que la información tiene espacialidad en cuanto que se encuentra en una fuente determinada, en unos datos en un archivo, en la memoria de una máquina, en una grabación, en un documento, etcétera, y que lo que se duplica en los receptores es la copia de esa información. Sin embargo de ahí se deduce entonces que los sujetos no poseen la información sino sólo su reflejo, y se desprende el problema de qué tan fiel es ese reflejo y con qué objetividad pueden esos sujetos a su vez transmitir esa información. Sin embargo es reconocido que también los sujetos poseen la información y no sólo su copia.

Por otro lado algunos autores diferencian información de datos, tomando a la primera como el producto de la interpretación de los datos. ${ }^{19} \mathrm{La}$ información está más allá de los datos, ella no actúa directamente sobre nuestros órganos de los sentidos, sino que son los datos los que actúan sobre estos

18 El argumento es sencillo y para los interesados se muestra a continuación su formalización en la lógica de predicados de primer orden:

La primera premisa la podemos simbolizar en el lenguaje de ese sistema de la siguiente manera: $\forall x(M(x) \supset(R(e, x) \& R(t, x) \& R(m, x)))$ "Para toda $x$, si $x$ es $M$, entonces x está en relación con $e, t$ y $m$." En donde $x$ es ser un objeto, $M\left({ }_{-}\right)$es el atributo de ser material, $R\left(_{(-}\right)$es la relación de tener, $e$ es espacio, $t$ es tiempo y $m$ es movimiento. La forma de la segunda premisa es la siguiente: $\neg R(e, i)$ "No es verdad que i está en relación con $e$ ". Donde $i$ es información, $\mathrm{E}$ y $R$ se interpretan como anteriormente. De esas dos fórmulas podemos concluir $\neg M(i)$ "No es verdad que $i$ tiene la propiedad $M$ ", esto es, la información no es material. Los pasos que deben realizarse se muestran a continuación.

1. $\forall x(M(x) \supset(R(e, x) \& R(t, x) \& R(m, x)))$ premisa

2. $\neg R(e, i)$

premisa

3. $M(i) \supset(R(e, i) \& R(t, i) \& R(m, i)))$

de 1 por eliminación de $\forall$

4. $M(i)$

hipótesis complementaria

5. $(R(e, i) \&(R(t, i) \& R(m, i)))$

6. $R(e, i)$

7. $\neg M(i)$

de 3 y 4 por eliminación de $\supset$

de 5 por eliminación de \&

de 4-6 por introducción de $\neg$ (hay contradicción

entre 2 y 6 , lo que nos permite negar nuestra

hipótesis complementaria, eliminarla y

eliminar los pasos que dependen de ella).

19 Peter Bishop. Fundamentos de Informática. Madrid: Ediciones Anaya Multimedia. 1992. p. 8. 
últimos. De esta tesis también podemos inferir la naturaleza ideal de la información si tomamos el concepto de materia de Lenin, quien afirma que materia es aquello que existe independientemente del hombre y que actúa o es capaz de actuar directa o indirectamente sobre los órganos de los sentidos; ${ }^{20}$ es decir, si es materia entonces actúa sobre los órganos de los sentidos y, por lo tanto, si no actúa sobre los órganos de los sentidos, no es materia. ${ }^{21}$

Asimismo el admitir que la información es algo ideal nos acarrea el problema de que si se acepta su existencia como encerrada en los datos o teniendo como soporte a estos últimos, se reconoce una dualidad de realidades -lo material y lo ideal-y de ahí la cuestión de su relación y comunicación. Descartes resolvió esta cuestión diciendo que la hipófisis en el hombre es el lugar donde se comunican esas dos sustancias, pero por supuesto que en la actualidad esa respuesta ya no sería satisfactoria.

Al mismo tiempo se presenta el cuestionamiento: si la información es una entidad ideal entonces ¿la información es algo subjetivo? obvio que la respuesta es negativa, pero ¿cómo salvar su objetividad y su comunicación interpersonal? ¿debemos recurrir a la teoría de las ideas innatas, a una armonía predeterminada o a otra concepción metafísica así de compleja?

Partimos, como ya se dijo, del supuesto ontológico según el cual lo ideal aparece después de lo material, y del supuesto gnoseológico de que toda relación del hombre con el mundo exterior se realiza por un proceso que tiene su origen en los sentidos. Por lo tanto, siguiendo ese enfoque, la información siendo ideal debe de surgir posteriormente a la materia y tener su origen en las sensaciones de los sentidos.

De acuerdo con esto la información surge de una síntesis de lo objetivo y lo subjetivo, de los datos y unas estructuras del sujeto las cuales permiten procesar esos datos, interpretarlos, organizarlos y convertirlos en algo que puede tener valor de uso; nos permiten actuar y tomar decisiones. El hombre recibe

20 Vladimir Ilitch Lenin. Materialismo y empiriocriticism,. Obras completas. T. 18. Moscú: Progreso, p. 131 y 276.

21 Simbólicamente en la lógica de enunciados tenemos:

$P$ representa "ser materia" y $Q$ simboliza "actuar sobre los órganos de los sentidos". Por lo tanto, de las premisas si $P$ entonces $Q$ y no $Q$, obtenemos no $P$ :
1. $P \supset Q$
2. $\neg Q$
premisa
3. $\neg P$
premisa
de 1 y 2 por $\mathrm{mt}$. 
estimulaciones en los órganos de sus sentidos (ondas sonoras, rayos luminosos de determinada frecuencia y amplitud, etcétera) pero esos estímulos no son la información, se les tiene que dar una organización, una forma. Es importante en este punto recordar la etimología de la palabra "información": in-formar "dar forma".

La objetividad de la información viene dada por los datos que existen independientemente del sujeto, ellos actúan sobre los órganos de los sentidos y los podemos diferenciar de otros datos, de alucinaciones, de sueños, y estar seguros de que esa percepción de los datos no es una mala jugada del perverso genio cartesiano, ya que la práctica sirve como criterio último para demostrar la objetividad de la información.

Ahora bien, las estructuras empleadas para la estructuración del material empírico también tienen su valor objetivo, porque no están dadas de una manera a priori ni son sacadas arbitrariamente según el deseo de cada sujeto, sino que son el resultado de un proceso psicogenético ${ }^{22}$ y tienen raíces sociohistóricas concretas. Cada sociedad establece sus esquemas, pero cada sociedad históricamente concreta lo hace con base en relaciones reales del hombre con la naturaleza en el proceso de transformación de ésta y con relaciones de los seres humanos entre sí en el proceso de producción material, espiritual y biológico. Es esto a lo que U. Eco llama "convención cultural" que le da una función semiótica al signo ${ }^{23}$ o lo que los filósofos medievales llamaron proceso de imposición de las voces. Pero si bien el nexo signo-contenido es convencional, el nexo sujeto-contenido ya no lo es, puesto que se debe regir por el primer nexo y si no lo hace simplemente no comprenderá el contenido del signo.

Esta síntesis no es una creación totalmente nueva sacada del sujeto, es algo que estaba potencialmente en los datos y que para actualizarse necesitó de la actividad del sujeto. En la historia de la filosofía, J. Locke expresó la idea de que existen cualidades primarias y secundarias en las cosas, las primeras son cualidades de los cuerpos completamente inseparables de ellos, como la solidez, la extensión, la figura y la movilidad; las cualidades

22 Piaget, Jean. "Lógica formal y psicología genética”, en Deaño, A. y Delval, J. comp. Investigaciones sobre lógica y psicología. Madrid: Alianza Universidad, 1977.

También Piaget, J. El nacimiento de la inteligencia en el niño. México: Grijalvo, 1990.

23 Eco, U. Tratado de Semiótica general. Barcelona: Ed. Lumen, 1988. p. 42. 
secundarias realmente no se hayan en los objetos mismos, sino que son posibilidades de producir varias sensaciones en los hombres mediante las cualidades primarias, por ejemplo los colores, los sonidos y los sabores. No debe interpretarse esto como si las cualidades primarias fueran objetivas y las secundarias subjetivas. No habría cualidades secundarias si los cuerpos no poseyeran los poderes correspondientes para producirlas.

Siguiendo el discurso de este texto tendríamos los siguientes esquemas que históricamente se han dado:

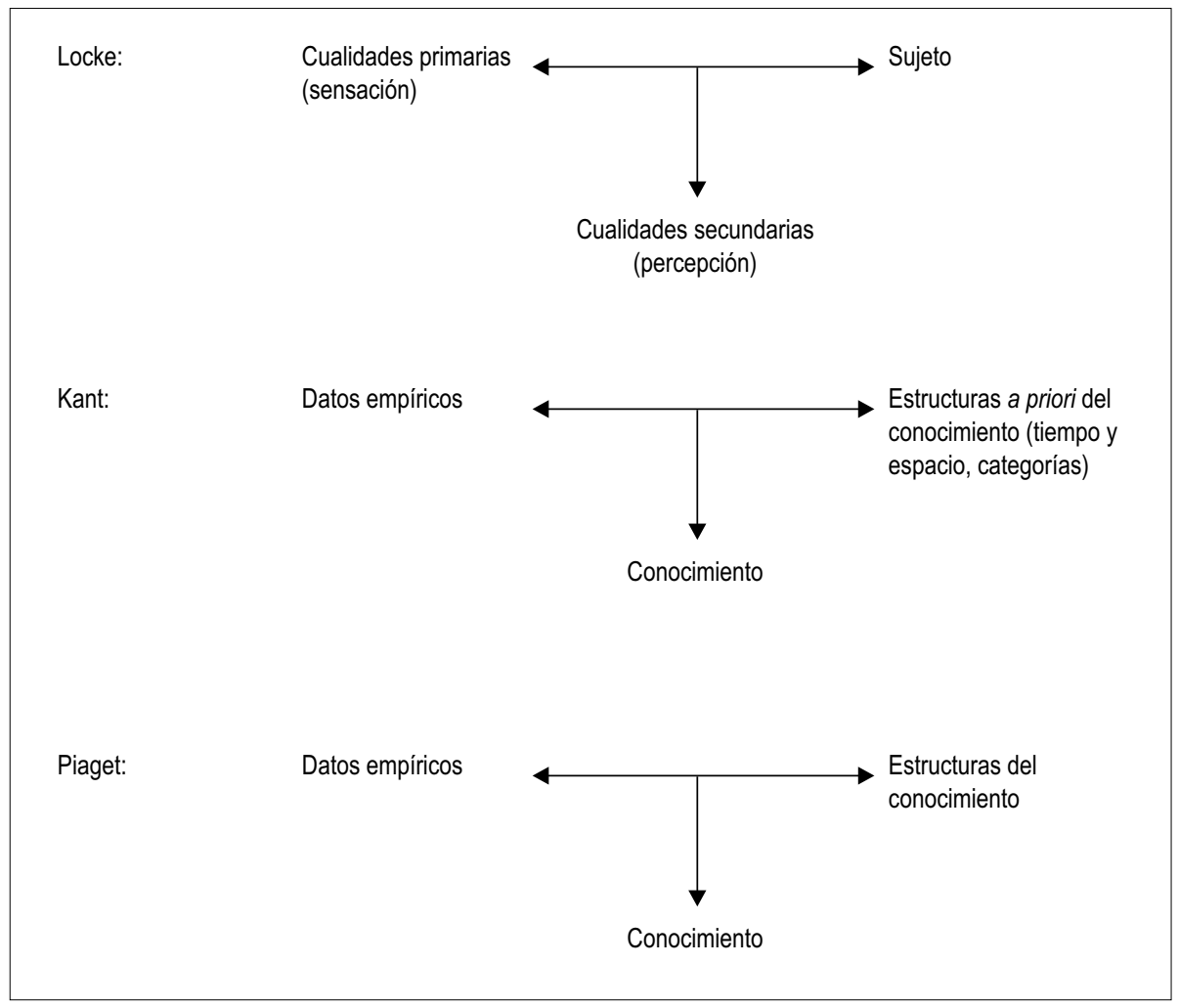

Si cambiamos en Locke cualidades secundarias por información, y en Kant y Piaget conocimiento por información, y le quitamos a Kant el apriorismo, tendremos nuestro enfoque de la información. 


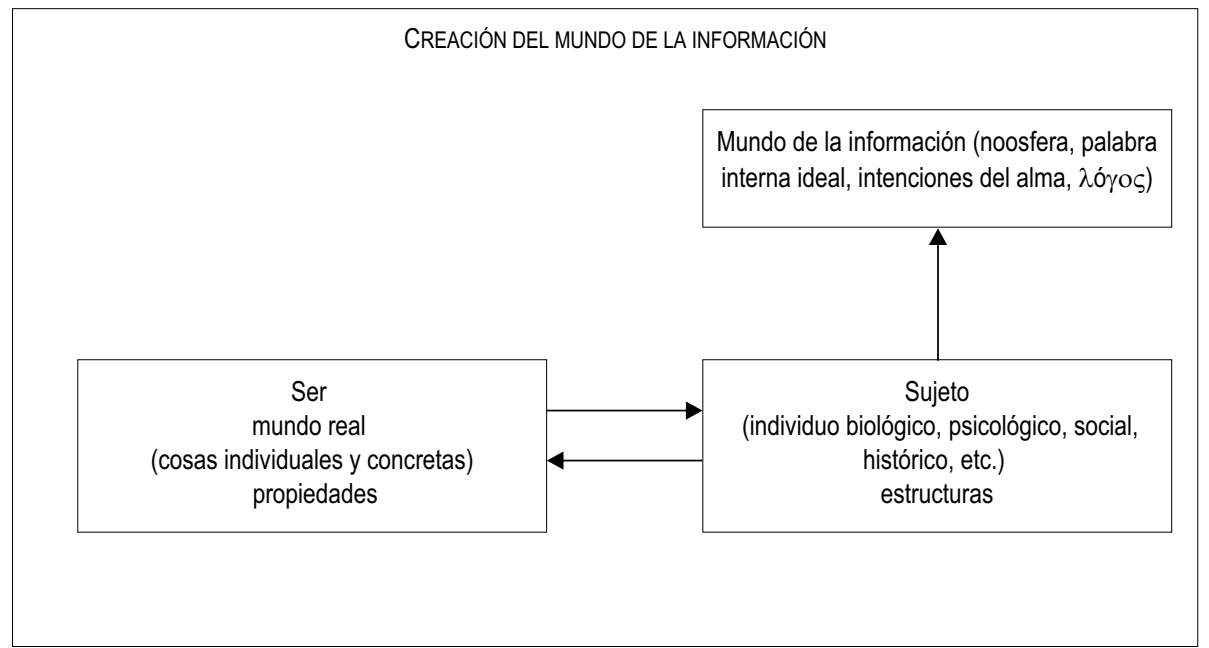

\section{El mundo de la información}

Pero además esa información se objetiva, en el sentido de que se hace objeto, se enajena de su creador y pasa a formar parte de un mundo ideal, que tiene su estructura y sus leyes, que puede ser expresado por un lenguaje formal, simbólico, para el "pensamiento puro", según expresión de su creador. ${ }^{24}$ Este mundo es un mundo posible, abstracto, que no existe en el sentido de Heidegger, puesto que está fuera del tiempo y del cambio, si se le introduce un nuevo objeto o relación se convierte en otro mundo posible. Ese mundo solamente es. Se le crea para hablar de él y trabajar con él.

Gracias a este mundo ideal se da la generalidad y la posibilidad de la comunicación: yo me conecto a ese mundo gracias al empleo de símbolos y mi interlocutor al estructurar esos símbolos también se conecta al mismo mundo y por lo tanto nos entendemos. Esta relación se puede representar gráficamente mediante el siguiente esquema:

24 Frege, Gottlob. Conceptografía. Un lenguaje de fórmulas semejante al de la aritmética para el pensamiento puro. México: UNAM, 1972. 


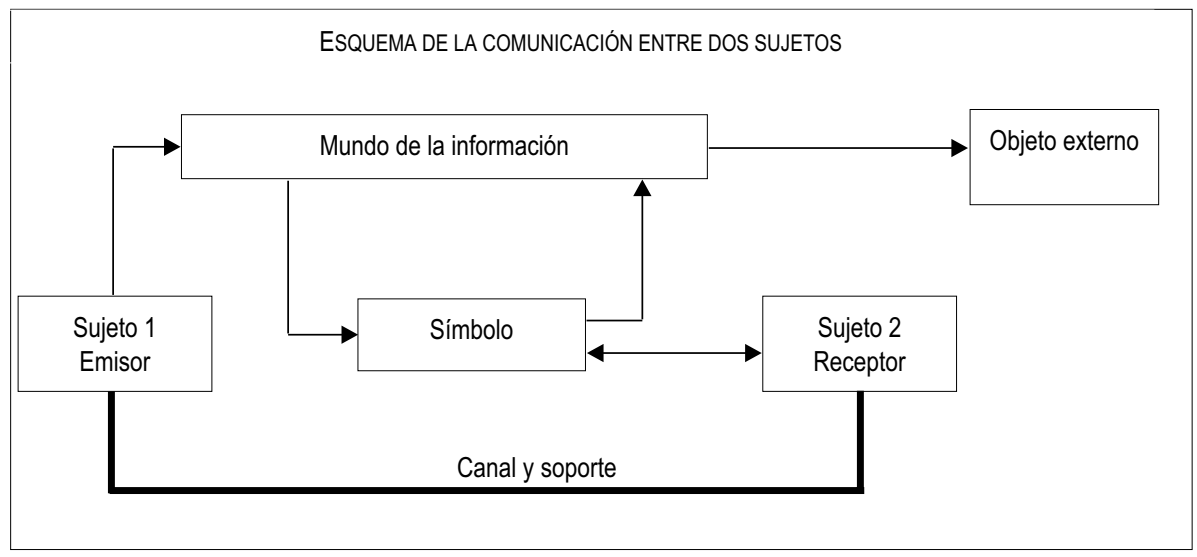

Para ejemplificar cómo se usa este mundo ideal podemos analizar la siguiente proposición: "Alejandro Magno era no-griego" ¿qué es lo que quiero decir al expresar esta proposición?25 En primer lugar que existe un universo de mi discurso $U$ : el conjunto de seres humanos. Dentro de ese universo se encuentra la clase de los seres humanos griegos. Llamemos a esa clase $G$. Se puede hacer el complemento de $G$ y obtenemos la clase $\neg G$ y por último se afirma que existe un elemento $\alpha$ que pertenece a $\neg G \alpha \in \neg G$.

Pero resulta que en el mundo real no existen clases (sólo objetos individuales) y tampoco operaciones entre clases. Todo nuestro discurso transcurre en un mundo ideal, el cual no tenemos al alcance de la mano; sin embargo en él realizo mis operaciones lógicas y puesto que los demás comprenden la información eso significa que los otros también tienen presente ese mundo ideal, que es ideal pero no subjetivo, que es pero que no existe, que es común a todos los hombres que tienen la llave para entrar a él y que fue creado por el hombre.

Empleando la terminología que se usó durante la discusión de los universales, podemos decir que la información se encuentra In re (en las cosas) potencialmente; Post rem (después de las cosas) de dos maneras, realmente en

25 Es seguro que el lector de estas líneas comprenderá la información de ese enunciado y de todo el conjunto de enunciados que ocurren en este apartado. Es más, si no está de acuerdo puede escribir una objeción a las ideas aquí expresadas y empezar una polémica académica, porque de lo contrario ¿por qué se toma la molestia en leer? Toda la evolución del género humano muestra que el hecho de la transmisión de información se da en la comunicación. 
los sujetos y formal-objetivamente, pero no realmente en el mundo de la información; y que Ante re no se encuentra. En algunas ocasiones se dice que la información está en las cosas, en los datos y se la llama información en sí, en contraposición a la información que se encuentra en los sujetos, a la que se le denomina información para otros. Desde nuestro punto de vista, el uso del término "información en sí" puede ser un tanto equívoco, puesto que se ontologiza en la realidad algo que está más allá de los datos pero que no sé qué es, lo que Fairthorne ha llamado la teoría del flogisto de la información. ${ }^{26}$

El mundo de la información está habitado por diferentes objetos de distinta naturaleza. El sentido de las expresiones (intenciones del alma o formas de pensamiento o los nexos que relacionan el signo con su denotatum), los significados de los enunciados, las formas lógicas del pensamiento, las relaciones entre esas formas del pensamiento, que permiten hacer inferencias de unas a otras y los postulados de significación son algunos de los entes que ocurren en ese mundo.

Asimismo ese mundo de la información es parte de otro mundo más amplio, llamémoslo Mundo posible $2\left(M p_{2}\right)$, en el que se encuentra el Sujeto con su intencionalidad y contexto, que influyen de manera determinante en la construcción del mundo de la información. 27

De acuerdo con las teorías semánticas de Peirce y Frege todo signo tiene dos características denotativas. Por un lado señala, designa un determinado objeto concreto, y por el otro expresa una serie de características sobre ese objeto que permiten identificarlo y diferenciarlo de todos los demás. A lo primero se le ha llamado denotatum, designatum o referente, en ocasiones significado (Bedeutung) y a lo segundo sentido (Sinn). Tomando también en cuenta la clasificación de las categorías semánticas y sintácticas del

26 Fairthore, R. A. "Use and mention in the information science", en Laurence Heilprin (ed). Proceedings of the Symposium on education for Information Science. Washington: Spar$\tan$ books, 1965. p. 10.

27 Cabe hacer la aclaración que este mundo de la información se diferencia del tercer mundo popperiano por su origen (es formado por la interacción del sujeto con el mundo físico), por su función (tiene una relación con el mundo físico que nos permite tener información sobre el mundo físico) y por su status ontológico (depende del sujeto y del mundo físico, como parte del $\mathrm{Mp}_{2}$, si desaparece el sujeto con su contexto, desaparece el mundo de la información.) 
lenguaje, podemos constatar que cada una de estas categorías debe tener o tiene sentido y denotatum.

La unidad mínima de expresión es el enunciado (proposición) y como tal es la categoría semántica y sintáctica central que nos lleva al mundo de la información. Los enunciados en la lógica clásica (extensional-referencial) tienen como denotatum a unos objetos abstractos que son "la verdad" y "lo falso". Esos objetos también habitan el mundo de la información.

Independientemente de las limitaciones de una lógica extensional (paradojas de la implicación material), lo que nos previene a no absolutizar dicha lógica, es importante tener presente que es muy diferente si un enunciado tiene un valor de verdad "verdadero" o uno "falso". Fox a este respecto señala que $X$ informa a $Y$ que $P$ si: 1.- $X$ dice a $Y$ que $P, 2$.- $X$ está en posición de conocer que $\mathrm{P}$ y si agregamos que una condición necesaria para el conocimiento es la verdad, entonces $\mathrm{P}$ es verdadera. Pero si $\mathrm{P}$ es falsa, $\mathrm{X}$ dice a $Y$ que $P$ y $X$ está en posición de conocer no- $P$, entonces $X$ desinforma a $Y .{ }^{28}$

En otras semánticas lógicas se toma como denotatum de los enunciados a las situaciones reales que éstos describen, entonces, como en el caso de los nombres individuales, debe existir un nexo entre el enunciado y la situación descrita. Dicho nexo se encuentra también en el mundo de la información.

El sentido de los enunciados está dado por los componentes que ocurren en él. Algunos identifican el sentido de los enunciados con el juicio, entendido éste como la forma del pensamiento en el cual se afirma o se niega la existencia de un atributo o relación (predicado) en un objeto. ${ }^{29}$

Dentro de la estructura de los enunciados asertóricos encontramos términos descriptivos y términos lógicos. Entre los primeros tenemos nombres de objetos, que a su vez pueden ser de objetos individuales o de clases de objetos, nombres de propiedades o de relaciones, y functores. Entre los términos lógicos se encuentran los cuantificadores, los conectivos y los operadores (modales, descriptivos y temporales, entre otros).

28 Christopher Fox. Information and Misinformation. West-Port: Greenwood Press, 1983. p. 184.

29 E. K.Voishvillo. Poniatie kak forma muishleniia. (El concepto como forma del pensamiento). Moscú: MGU, 1989. p. 9. 
Los nombres individuales, tales como "Luna", "Napoleón", "París", "Capital del imperio ruso fundada por el zar Pedro I a orillas del río Neva", designan cada uno a un objeto único y su denotatum es ese objeto concreto. Los tres primeros nombres, rigurosamente hablando, no tienen sentido propio, puesto que la estructura del nombre no nos dice qué características tiene el objeto nombrado con las cuales podemos distinguirlo de los demás objetos. Sin embargo existen un nexo asignado entre el nombre y su denotatum, y unas características que permitirán identificar al objeto. En ocasiones en la misma estructura del nombre se encuentra su sentido, como es el caso de "capital del imperio ruso fundada por el zar Pedro I a orillas del río Neva".

Existen nombres que designan no a un solo objeto sino a una clase de objetos, aunque también se aplica a un elemento cualquiera perteneciente a esa clase. (En gramática se les identifica con los sustantivos comunes). El denotatum de los nombres comunes es la clase de objetos que designa y su sentido son las características que permiten agrupar a determinados entes en una clase y diferenciarlos de otros (características comunes y distintivas de los elementos de la clase). En ocasiones el sentido de los nombres comunes se identifica con el concepto, tomado éste como una forma de pensamiento que resulta de hacer una generalización de objetos de una clase y la distinción mental de esos objetos con base en un conjunto de las características comunes y específicas de dichos objetos. ${ }^{30}$

El nombre de las propiedades o relaciones (predicados) y de las constantes lógicas se interpretan de la manera acostumbrada en la lógica clásica.

En el mundo de la información tienen lugar las relaciones entre las formas lógicas que permiten realizar inferencias que no están explícitas en los documentos (datos) pero que se pueden sacar a la luz mediante un análisis lógico. Con base en esto la ciencia de la información o informática, en el sentido de Mijaílov, puede cumplir su cometido.

En el mundo posible de la información se encuentran lo que Carnap llamó "los postulados de significación", que no son otra cosa que el sentido asociado a un signo por consenso. Por ejemplo, el enunciado "todos los solteros son hombres que no están casados" no es un juicio analítico (lógicamente), aunque si se toma en cuenta que "soltero" designa a hombres que no están

30 E. K. Voishvillo. Op. cit. p. 91. 
casados, entonces reemplazando "soltero" por su equivalencia tenemos "todos los hombres que no están casados son hombres que no son casados", lo que ya es un juicio analítico.

Como ya se expresó anteriormente, la intencionalidad del sujeto, su posición ante los signos y el contexto influyen en la construcción del mundo de la información. Así tenemos, por ejemplo, la frase "palabra de comunista" expresada en Rusia en los años 30 del siglo pasado tendría un sentido totalmente diferente a si se hubiera expresado en el mismo país a principios de los años 90.

Es importante señalar que ese mundo posible no es algo en sí independiente del mundo real, hay una relación entre ellos, la información es sobre el mundo real, y es esto lo que nos permite actuar en éste último.

Podemos concluir este apartado diciendo que la información que le interesa a la bibliotecología es esa entidad ideal, creada a partir de la estructuración de datos de acuerdo con ciertos nexos. Dicho ente ideal después se objetiva y forma un mundo abstracto común a todos aquellos que son capaces de realizar semejante estructuración.

La importancia y "utilidad" de esta interpretación de la información será analizada con más detenimiento en el apartado de la fundamentación gnoseológica, por el momento podemos adelantar que dicho enfoque nos permite esclarecer qué clase de "objeto" puede satisfacer las necesidades de información que presenta el usuario. Esto no es superfluo si tomamos en cuenta que, como algunos lo han afirmado, la bibliotecología como disciplina estudia cómo satisfacer las necesidades de información. ${ }^{31}$

En efecto, la inclusión del sujeto junto con su contexto de intenciones, intereses, motivaciones y cultura en general para crear e introducirse al mundo de la información da la pauta para la acción del bibliotecólogo. De acuerdo con la intencionalidad del usuario, el bibliotecario le abrirá a éste las puertas de ese mundo de la información en el que quiera "aventurarse" y posteriormente, si el sujeto así lo requiere, será su guía en ese mundo.

En ocasiones se pierde de vista esa función. Obviamente ningún bibliotecario espera al usuario y calcula, con base en la teoría de la información

31 Calva González, Juan José. "Una aproximación a lo que son las necesidades de información”, en Investigación Bibliotecológica. Vol. 5. N. 11. Jul.-Dic. 1991. p. 36. 
matemática o a la teoría de la información semántica, ${ }^{32}$ la cantidad de información requerida por este último. Pero ya no es tan obvia la "disfunción" del bibliotecario cuando se le ofrece al usuario, con el sólo hecho de presionar un botón, una enorme lista de datos sobre obras, tal vez con resúmenes e indicación exacta del lugar donde se pueden consultar, pero que puede resultar irrelevante (si es que al usuario no le interesa ese mundo de la información).

En segundo lugar, como consecuencia de lo anterior, este enfoque nos permite diferenciar las diversas clases de lecturas que puede realizar un sujeto de acuerdo con el mundo de la información al que se quiera ingresar; no es lo mismo hojear un libro, que leer para aprender o realizar una investigación científica, así como también se diferencia de las anteriores una lectura para buscar información que ayude a tomar una decisión en la esfera política, económica, administrativa o en la vida cotidiana, o leer para simplemente tener un goce estético o recreativo.

En tercer lugar, muy ligado a lo anterior, este enfoque de la información nos permite delimitar el objeto de estudio de la bibliotecología. Podemos identificar diversas disciplinas que estudian ese mundo de la información, pero las podemos diferenciar de acuerdo con la parte que de él estudian, con los medios utilizados para llegar a ese mundo y con la finalidad que persigue el sujeto al conectarse con ese mundo. Explicar y desarrollar esa concepción es de sumo interés e importancia pero no entra dentro de los límites de este apartado, es tarea de lo que nosotros hemos llamado "fundamentación gnoseológica", por lo que no lo abordaremos en este momento. Pasemos ahora a establecer la diferencia entre información y conocimiento.

\section{Información y conocimiento}

Dentro de este apartado se abordará de una manera más detallada la distinción entre información y conocimiento, tomando en cuenta las fuentes de cada una de ellas, la actividad necesaria para obtenerlas y los resultados propiamente dichos.

32 Posteriormente proporcionaremos más detalladamente estas fórmulas al hablar de un nuevo paradigma en bibliotecología. 
En primer lugar las fuentes de ambas son distintas. Ya hemos visto que la información tiene como origen los datos u objetos sensibles; ahora bien, el conocimiento, por su parte, tiene como fuente la información misma. Lo anterior significa que el conocimiento es un producto posterior a la información y que surge precisamente después del "lugar" en el que se quedó la información. Si esta última se elabora a partir de objetos materiales, para después aparecer como ente ideal, para que el conocimiento pueda llegar a tener lugar será necesario retomar ese ente ideal y a partir de él elaborarlo.

De la misma manera Shera distingue entre esos dos términos, así por ejemplo, expresa: “[...] distinguimos entre información y conocimiento [...] la información es el insumo del conocimiento, y siempre es recibida a través de los sentidos independientemente del número de artefactos que puedan intervenir entre transmisor y receptor. [...] El conocimiento es aquello que "sabe" un individuo, un grupo o una cultura, y por eso no puede haber conocimiento sin un conocedor. 33

En segundo lugar, esa elaboración se realiza con base en actividades diferentes. Mientras que para que se obtenga información es necesaria, como hemos mencionado, una síntesis que estructure las cualidades secundarias presentes potencialmente en los símbolos; para que se produzca el conocimiento es indispensable realizar otra serie de actividades, tomando como materia prima la información inicial. De este modo una vez que se tiene la información, ésta se somete a un proceso que va desde la memorización como etapa inicial, hasta etapas más complejas como el análisis, la síntesis, la aplicación y la valoración, que conducen a tener una comprensión más amplia y no sólo una identificación del significado de los datos iniciales.

Así, por ejemplo, al consultar un artículo que nos presenta una gráfica de los porcentajes de la distribución ocupacional de la población, en un principio se interpretan esos datos y el sujeto obtiene la información de que un determinado número de personas se encuentra laborando en el sector primario de la economía, que otros prestan sus servicios en el sector secundario, y otros más trabajan en el sector terciario, y que además existe un porcentaje de desempleados. Hasta ese momento el sujeto lector tiene únicamente información de lo que le dice la gráfica. Pero si desea tener conocimiento, será necesario, en primer lugar, manejar los porcentajes de los que se está

33 Shera, Jesse H. Op. Cit. p. 118. 
hablando, pero al mismo tiempo analizar qué metodología se utilizó, si ésta es adecuada o no, cómo se midió el desempleo, valorar críticamente los resultados y llegar a descubrir qué intereses movían al autor a presentar semejantes resultados. Esto es, a partir de la información, el sujeto lector debe realizar un análisis posterior, para de esta manera poder afirmar que tiene un verdadero conocimiento de la distribución de la población según su ocupación económica.

Lo anterior es importante porque por un lado, se distingue claramente la función del profesional de la información y la de un profesional de la educación. Es posible que el primero se preocupe por guiar al usuario a obtener conocimiento sobre la información que construyó a partir de la lectura de los documentos que se le proporcionaron, pero finalmente esa no es su misión esencial. Como su nombre lo indica, es un profesional de la información y no del conocimiento. Su función primordial recae en ayudar al usuario en el acceso al mundo de la información.

Por otro lado, la anterior distinción nos permite entender el proceso de aprendizaje de manera más autónoma, e incluso esbozar una fundamentación del enfoque cognoscitivo de la educación. El maestro estrictamente hablando no les proporciona conocimiento a sus alumnos, son ellos quienes tienen que elaborarlo a partir de la información que les proporciona el maestro y los libros.

Podemos representar esquemáticamente el ciclo completo de la información-conocimiento de la manera que se muestra en la siguiente página.

Finalmente la tercera distinción entre la información y el conocimiento se basa en la naturaleza propia de cada uno de ellos. Aunque tanto la información como el conocimiento son entes ideales, mientras la información es un ente ideal objetivado, tal como lo hemos demostrado, el conocimiento es un ente ideal subjetivado, ${ }^{34}$ esto es, epistemológicamente el conocimiento existe en el sujeto y sólo en el sujeto, al salir de éste se convierte en información. De esta manera, estamos en desacuerdo en la postulación del tercer mundo popperiano, el mundo de la ciencia; más bien aceptamos la existencia del mundo de la información, con todas las restricciones y limitaciones ontológicas necesarias, pero el mundo de la ciencia, es un mundo construido

34 Shera utiliza una expresión de Helprin, donde dice: "El conocimiento es información subjetiva". Idem. p. 128. 


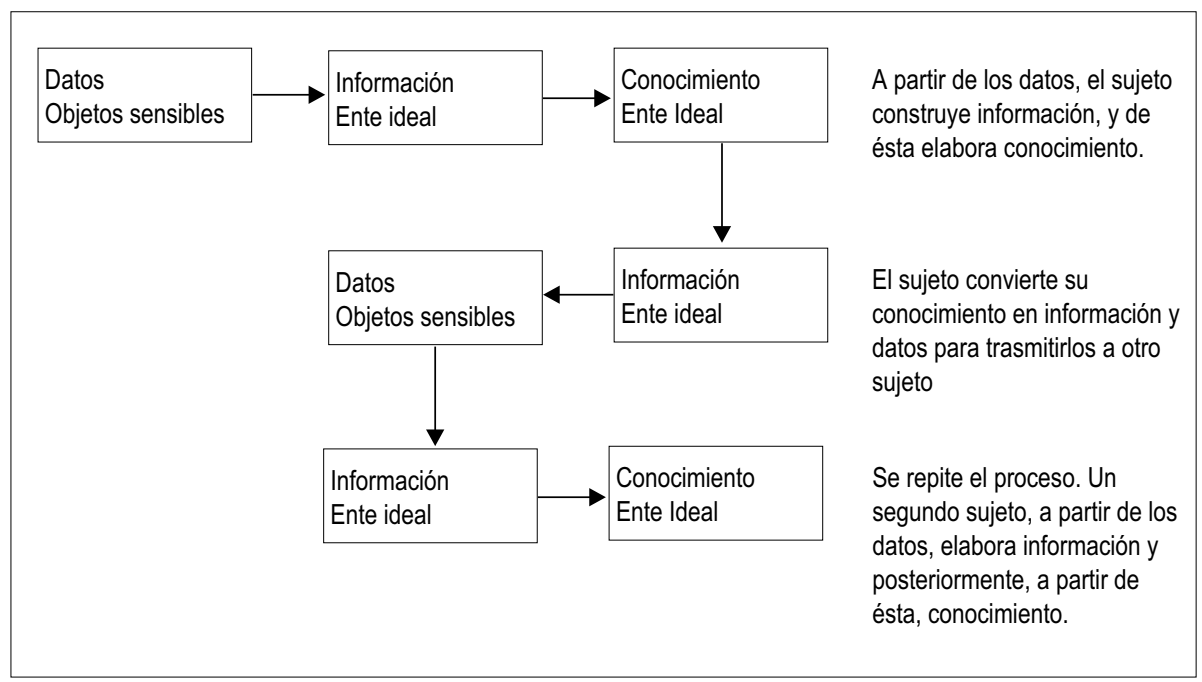

por los sujetos (científicos) y no puede evolucionar independientemente de ellos. De aquí se desprende que el profesional de la información, al trabajar con documentos, trabaja con información objetivada y no con conocimiento, éste último, está reservado a los sujetos, no a los documentos.

\section{Necesidad de información}

Después de haber analizado un concepto tan central como es el de la información, podemos abordar el análisis de otro concepto derivado del primero y que es el de NECESIDAD DE INFORMACIÓN. Si en un primer momento aclaramos qué vamos a entender por necesidad y teniendo presente el enfoque que tenemos de información, entonces podremos realizar la limitación del concepto "necesidad". Esto es, del contenido general de "necesidad" podemos pasar a un contenido más reducido, no de necesidad en general, sino de necesidad de información. 
Sin embargo no resulta una tarea sencilla determinar el sentido del término "necesidad". Al tratar de dar su significado, a menudo, se utilizan sinónimos u otros conceptos modales (posible, imposible, contingente) que a su vez requieren ser definidos.

Así por ejemplo, Ortega y Gasset expresa que "necesidad humana [es] todo aquello que, o es sentido como literalmente imprescindible -esto es, tal que sin ello creemos no poder vivir- [El subrayado es mío] o que, aunque podemos de hecho prescindir de ello, seguiríamos sintiéndolo como un hueco o defecto que había en nuestra vida." 35 En este texto podemos observar que se emplea el sinónimo "imprescindible" para explicar lo que es necesidad, y cuando se quiere aclarar el contenido del nuevo término se recurre a la modalidad "no poder". De la misma manera, Hernández Patricia al querer definir ya algo más restringido como las necesidades de información emplea el mismo recurso, definir una modalidad a través de otra; así escribe, "las necesidades de información de un individuo son aquellos conjuntos de datos que éste necesita poseer para cubrir un objetivo determinado." 36

Esta dificultad se puede encontrar incluso en escritos de tanta autoridad como son los del filósofo griego Aristóteles, quien escribió: "Se llama necesario aquello sin lo cual, como concausa no es posible vivir [...] También aquello sin lo cual no es posible que exista o se genere el bien, ni desechar el mal [...] Además lo forzoso y la violencia [...] Además lo que no puede ser de otro modo, decimos que es necesario; y según este sentido de lo necesario se dicen también necesarias en cierto modo todas las demás." 37 De esta manera, vemos que la última definición de necesidad está en la base de las demás acepciones de necesidad y la importancia para Aristóteles de esa definición se descubre porque él la repite en otros textos: "necesario es lo que no puede ser de otra manera". ${ }^{38}$ Así pues la necesidad se define a través de la negación y la posibilidad.

35 Ortega y Gasset, J. Misión y sentido del bibliotecario. Madrid: Revista de Occidente, 1962. p. 74.

36 Hernández Salazar, P. "El perfil del usuario de información”, en Investigación bibliotecológica. v. 7. n. 15. Jul.-dic. 1993. p. 17. El subrayado es mío.

37 Aristóteles. Metafísica. 1015a , 20-35.

38 Metafísica 1026, 30 ; Analítica I 88, 30. 
Pero el problema estriba en que existen varias acepciones de posibilidad y Aristóteles no especificó claramente a cuál de ellas correspondía la relación Necesario=no posible no. ${ }^{39}$ Por lo tanto, para comprender el sentido de la modalidad "necesario" recurriremos a otro enfoque que nos permita identificar la naturaleza misma de ese término evadiendo el empleo de otras modalidades.

Un problema central que se planteó en la historia de la filosofía en relación con la categoría de la necesidad es sobre su status ontológico. Algunos pensadores (los sofistas, Hume, y los neopositivistas, entre otros) negaron la existencia de la necesidad en el mundo; otros reconocían la existencia de la necesidad pero divergían en la explicación de su naturaleza. Así por ejemplo, Platón y los neoplatónicos, Leibniz y Hegel reconocían como fundamento de la necesidad un principio fuera de los límites del mundo material; otros por el contrario, como Demócrito, Aristóteles, Spinoza, afirmaban que dicho fundamento debía ser buscado en la naturaleza de las cosas mismas. Nosotros nos adherimos a la opinión de éstos últimos, pues consideramos que la necesidad existe en el mundo real y el desarrollo de la ciencia y de la práctica histórico-social ha demostrado que se pueden dar respuestas más sencillas y racionales a los problemas sin recurrir a entidades extramundanas que sólo complicarían nuestro sistema explicativo.

De esta manera, la necesidad es algo que existe objetivamente y que interviene como una característica de ciertos objetos, características, relaciones, estados o actividades. ¿Cuáles son las características de esta propiedad? Si consideramos que necesidad es un término modal podemos empezar su estudio con el análisis del término modalidad. Etimológicamente modalidad proviene del latín modus que significa forma, manera, medida. Por otra parte, recordemos que la tradición filosófica predicó la modalidad al ser, así por ejemplo la división del ente por los escolásticos con base en su forma de existir: ens per se y ens per alio o la afirmación de Kant de que la modalidad testifica la

39 Un primer tipo de posibilidad se interpreta como un grado más débil de un juicio asertórico, si se da $\mathrm{P}$ entonces es posible $\mathrm{P}$, y si de necesario $\mathrm{P}$ se implica $\mathrm{P}$, entonces por transitividad de necesario $\mathrm{P}$ es posible $\mathrm{P}$. Esto es, la necesidad y la posibilidad no son contrarias. El segundo tipo de posibilidad se identifica con la contingencia, lo que puede ser o puede no ser, y por lo tanto es contraria a la necesidad pero no a la realidad. Un tercer tipo de posibilidad es contraria a la necesidad y a la realidad y no equivale a lo contingente. Un cuarto tipo es interpretar la posibilidad como capacidad para actuar o estar en potencia de llegar a ser actual. 
forma de existir de los objetos para el sujeto. Si dejamos a un lado el subjetivismo, esto nos da la pauta para identificar la primera característica del concepto de la necesidad como modalidad.

La necesidad como modalidad es la forma (manera) de existir de los objetos. ${ }^{40}$ En este caso, "forma" debe entenderse como la medida en que se posee el ser. Este último enunciado puede generar cierta dificultad ¿cómo un concepto tan fundamental y primitivo como Ser puede ser de alguna manera cuantificado? De otra manera, si un objeto es, no tiene sentido preguntar si posee más o menos ser. (¿Quién tiene más ser un gusano de seda, una lombriz, una estrella o una obra de Leonardo da Vinci?) Por supuesto, el Ser en sí permanece sin ser tocado en el objeto. Pero la llegada del Ser a ese objeto depende de varios factores. ${ }^{41}$

Por lo tanto, la posesión del Ser (no desde el punto de vista del mismo objeto) no depende del objeto, sino de las causas, circunstancias, condiciones por las cuales el objeto es. En otras palabras, la posesión del Ser depende de la fundamentación de la existencia del objeto. Este pensamiento tiene su origen en Leibniz, el cual fue uno de los primeros que ligó la necesidad con la ley de la razón suficiente.

Así pues nuestra tarea consiste en determinar de dónde proviene la fundamentación de esa manera de existir que llamamos necesaria. Como ya lo indicamos anteriormente, seguimos la línea de los pensadores que reconocen la existencia real de la necesidad y que la fundamentan en la naturaleza de las cosas. En la historia de la filosofía Demócrito es el que más claramente expresa la tradición "realista" de la interpretación de la necesidad. Este filó-

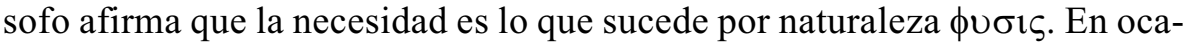
siones en lugar del concepto "naturaleza" se utiliza el término "esencia". Según nuestra opinión, este enfoque es más correcto porque la esencia es una categoría más abstracta que otras y por eso se justifica no definir esencia con

40 Se hablará de objeto en un sentido amplio, es decir, no sólo como una cosa, sino como todo lo que puede ser nombrado: fenómeno, proceso, relación, propiedad, abstracción, etcétera.

41 En este caso utilizamos una idealización muy fuerte consistente en que se toma la categoría del Ser como un principio independiente. Ser casi se "cosifica" y es capaz de actuar. Esto no debe simplificarse y tratarse metafísicamente como si el Ser es, la esencia es y su unión nos da la cosa. En realidad el Ser en sí como tal (como sujeto) no es, sólo está en las cosas, pero en el proceso del cambio, esas cosas obtienen su existencia y esto puede tomarse como la "llegada" del Ser a las cosas. 
ayuda de otros conceptos (ley, necesidad, causa), sino al contrario definir esos otros conceptos a través de la categoría esencia.

Cabe hacer la aclaración de que el concepto "esencia" no se interpreta metafísicamente como algo absoluto, inmutable, último fundamento de la realidad, y que existe realmente en cierto mundo ideal. Nosotros tratamos a esta categoría como un puente que une y comparte la gnoseología y la ontología. Por un lado la esencia como concepto gnoseológico refleja el objeto en determinada etapa del conocimiento, pero por otro no es algo solamente relativo y subjetivo, sino que la esencia existe objetivamente en el mundo como propiedad o conjunto de propiedades de los objetos. Este enfoque nos permite huir de la tentación de buscar una esencia última de los objetos ya que está ligado al proceso del conocimiento, y conforme se va desarrollando éste se van descubriendo nuevas propiedades, que llegan a ser esencias más profundas que antes no conocíamos, pero también nos da la posibilidad de escapar del relativismo puesto que esas esencias corresponden a realidades extramentales objetivas.

Lo último quedará más claro cuando se analice lo que se entiende por esencia. Para explicar este concepto utilizaremos el enfoque propuesto por E. K. Voishvillo en el libro El concepto como forma del pensamiento. Estamos de acuerdo con él en que no se puede hablar de la esencia de un objeto individual; sólo colocando al objeto en una u otra clase tiene sentido hablar de esencia. Por eso vamos a analizar a un objeto de una clase determinada observando sus propiedades. Descubrimos que existen propiedades que se tienen en unos objetos y están ausentes en otros objetos de la misma clase. Sin embargo existen propiedades generales comunes a todos ellos. Si se analizan estas propiedades es fácil advertir que unas surgieron bajo la influencia de circunstancias externas y pueden variar por experimentos o como resultado de otras causas por lo que no influyen en la existencia como tal. Otras propiedades forman un sistema donde unas determinan a otras. Por ejemplo, la propiedad $P_{1}$ determina a $P_{2}, P_{2}$ determina a $P_{3}, P_{3}$ determina a $P_{4}$, etcétera. Al final llegaremos a alguna(s) propiedad(es) $P_{n}$, que no es determinada por otra propiedad de ese sistema sino que, al contrario, ella misma determina a las otras propiedades. Esa propiedad o conjunto de propiedades es a lo que llamamos esencia. 
De esta manera, en determinada etapa del desarrollo de la ciencia podemos encontrar alguna característica $P_{i}$ que no es determinada por $P_{n}$, sino por $P_{n+1}$, y donde además $P_{n+1}$, que no es determinada por ninguna otra propiedad, determina a $P_{n}$. Por lo tanto, ahora la esencia del objeto es $P_{n+l}$ y así ha ocurrido una profundización en el conocimiento.

En resumen podemos decir que la esencia son las propiedades de las cuales proceden otras propiedades del objeto. Las propiedades que constituyen la esencia del objeto no son causadas por otras propiedades de ese objeto, sino por otras externas a él. Se puede decir que cuando apareció la esencia apareció el objeto mismo, y que la ausencia de la primera destruye la existencia del objeto como tal.

Una vez que se tiene la noción de esencia podemos decir que existen necesariamente: las propiedades, estados, relaciones y actividades que son determinados por la esencia; las relaciones causales por las cuales la esencia determina la aparición de propiedades, estados, relaciones, actividades; las relaciones entre esencias (leyes); y la relación entre propiedades, estados, relaciones y actividades necesarios.

Por lo tanto, si bien "las necesidades humanas son manifestaciones de reacciones que tiene el individuo", 42 se debe aclarar que esas reacciones surgen determinadas por ciertas propiedades esenciales del hombre. Por supuesto nunca existirá un consenso sobre cuál es la esencia del hombre, pero como ya lo mencionamos anteriormente, no nos interesa una respuesta última, sino una que esté de acuerdo con la tarea por resolver y con el estado actual del desarrollo de la ciencia y del pensamiento humano. Así por ejemplo una de las características esenciales del hombre es ser un ser vivo, lo cual significa que el hombre es un sistema abierto que tiene intercambio activo con su medio ambiente, toma ciertas sustancias de éste y le regresa a él otras; circunstancia de la que surgen necesidades fisiológicas como son la respiración, la alimentación, etcétera.

De la misma manera, regresando a la problemática que nos ocupa, podemos decir que las necesidades de información son estados que surgen determinados por una o varias propiedades esenciales del ser que las sufre $(P)$. Se

42 Calva G. Juan José. Op. cit. p. 34. 
puede afirmar que "las necesidades de información son el resultado de los problemas que se le presentan a un individuo en una situación específica". 43 ¿Pero por qué una situación específica puede originar una necesidad de información? ¿Por qué a la bibliotecología no le interesan ciertas necesidades de información y sin embargo decimos que cuando un animal busca el rastro de su presa también tiene una necesidad de información? La respuesta es porque la necesidad que nos ocupa está determinada por el tipo de problema que se trata de resolver y ligada a ello por el concepto de información que manejamos: la información como ente ideal creado con base en propiedades secundarias de objetos que fueron hechos originalmente para significar; es decir, documentos. Por lo tanto, son estados en los que se busca información documental $(Q) .{ }^{44}$ De esta manera tenemos:

Definición2: $x$ es necesidad de información $\equiv x(P(x) \& Q(x))$

Al analizar el planteamiento ontológico se tocaron asuntos de antropología filosófica y desde esa perspectiva es como abordaremos la visión de hombre que nos explicará qué son las necesidades de información que a nosotros nos interesan. Habíamos dicho que según Heidegger el hombre se caracteriza por ser un proyecto que se realiza a sí mismo. ${ }^{45}$ También por otra parte se habló de la tesis de Marx de que el hombre es un ser que satisface sus necesidades mediante un proceso de producción, que implica producir medios de producción de medios de producción y por último, como base de estas características o como resultado de ellas (por ahora no viene al caso discutir cuál de ellas es primero o si son simultáneas), tenemos otra propiedad inherente al hombre: la racionalidad. ${ }^{46}$

Esas propiedades y otras determinan que el hombre como especie y como individuo busque orientarse en el mundo que lo rodea, no de una

43 Idem. Idea tomada de Durrance, J. Information need. en Rethinking the library in information age. V II U. S. Office of Educational Research provement, office of library process, 1968. p. 159.

44 Decir que necesidad de información es un estado en el que se busca información no es una tautología o círculo en la definición, porque anterior e independientemente de esta definición se definió lo que es información y lo que es necesidad, además de que más adelante enunciaremos cuáles son las propiedades que determinan esos estados en el sujeto.

45 Heideger estaría totalmente en desacuerdo con la afirmación de que ese poder ser es la esencia del hombre, para él esta característica es un existenciario.

46 Se podrían agregar otras características, como el ser un ser social, dialógico y político entre otras. 
manera que busque la adaptación, sino la transformación y manipulación de su medio (natural, social y espiritual); es decir que experimente necesidades de información.

Si recordamos una de las clasificaciones de los signos según Peirce, los signos pueden ser signos-índices, signos iconográficos y símbolos; los primeros tienen significación por una relación causal (el humo como signo del fuego), los segundos por su similitud con lo significado (una fotografía como signo del objeto fotografiado), y los terceros por un proceso pragmático convencional. Estos últimos son creados precisamente para significar incluso sin la presencia real del denotatum. Los símbolos pueden ser inarticulados (como un grito de alegría) o articulados (el semáforo). Pero entre estos últimos tenemos una articulación entre estructuras que llamamos formas lógicas, que aunadas a una semántica nos permiten encontrar ciertas relaciones lógico-formales. Son estos últimos signos los que satisfacen las necesidades de información del hombre considerado desde el punto de vista bibliotecológico.

Así por ejemplo, la necesidad de información que mencionamos de un animal que busca a su presa será satisfecha por un signo-índice (el olor es signo de la presencia del animal buscado), se puede llegar a algunos signos más abstractos, como los gritos que comunican la presencia del depredador, pero nunca con la estructura lógica-formal de los símbolos.

Aquí es importante recordar la tesis de Mijailov de que una de las características inherentes de la información que estudia la informática, según su terminología, es su carácter lógico. 47

Ahora bien, teniendo presentes las características enunciadas del hombre como poder ser, como transformador de la naturaleza y como ser racional, podemos decir que sus necesidades de información son satisfechas para que el hombre cumpla determinados objetivos, los cuales se alcanzan de una manera consciente y planificada. Siguiendo a Ortega y Gasset distinguimos entre el hacer y el actuar "[...] todo lo que se hace se hace por algo y para algo; estos dos ingredientes definen el hacer [...] Enorme error es confundirla con lo que se llama actividad: el átomo que vibra, la piedra que cae, la célula que prolifica actúan pero no hacen. El pensar mismo y el mismo querer, en cuanto estrictas

47 Mikhailov A. I. y R. S. Giljarevski. Curso introductorio de Informática/Documentación. p. 19. 
funciones psíquicas, son actividades, pero no son hacer. Cuando movilizamos para algo y por algo nuestra actividad de pensar o la actividad de nuestros músculos entonces propiamente hacemos algo". ${ }^{48}$

El hombre busca información para hacer, no para actuar. Algunos de esos haceres son la investigación científica, el aprender, el realizar una actividad práctica teórica, estética recreativa, y el tomar una decisión en la esfera política, económica, administrativa o incluso en la vida cotidiana. Pero a diferencia de otras necesidades de información, las que son del interés de la bibliotecología son las necesidades de información documental, es decir, las que buscan la información en soportes hechos específicamente para transmitir información.

Debido a que ese hacer puede realizarse en determinadas áreas, las necesidades de información pueden restringirse y tipificarse de acuerdo con las áreas en las que se quiere "hacer algo", pero esas áreas también pueden limitarse a temas, tópicos, autores, etcétera, y llegar así a una clasificación de necesidades de información documental más estrecha de las personas que sufren esas necesidades de información y de las instituciones que puedan satisfacerlas.

Después de haber proporcionado la noción de información y de necesidad de información, podemos abordar lo que entendemos por usuario, documento e institución informativa dentro de la teoría bibliotecológica. Cabe aclarar que la definición de todos esos conceptos son relativas unas a otras y también a los ya mencionadas de información y necesidad de información; su sentido se muestra en la interrelación entre ellos. Por ejemplo, el documento no tiene razón de ser si no es en relación con la información que transmite y un posible lector que está dispuesto a "usar" el documento; o por el contrario, el término "usuario" sólo se entenderá en función de la información que desea obtener en un documento, para lo que se dirige a una institución informativa. Sin embargo consideramos que el concepto rector que nos evita caer en un círculo al darle la definición es nuestro concepto de información, de ahí el lugar central que le otorgamos.

48 Ortega y Gasset. Op. cit. p. 84-85. 


\section{Usuario}

El concepto de usuario ha sido utilizado principalmente en el área de servicios y dentro de lo que se ha denominado "formación de usuarios". Como en el caso de la información, no es nuestro objetivo proporcionar un listado de lo que se ha escrito en la literatura especializada sobre el tema. ${ }^{49}$ Utilizando las generalizaciones que Endean Gamboa realiza en su trabajo, podemos decir que se ha identificado al usuario con un grupo de personas en particular (estudiantes, investigadores, técnicos, "público en general", etcétera) que recurren a la biblioteca o se tiene una idea vaga, sin referente real, de lo que es el usuario. 50

Nosotros ubicaremos al usuario dentro de la dinámica del proceso de comunicación social documental. Como fácilmente se puede deducir de lo que escribimos en el apartado de la fundamentación ontológica y lo que entendemos por necesidad de información, el usuario es el ser humano (ideal) $P$ que por su estructura ontológica exige o puede exigir satisfacer ciertas necesidades que emanan de su ser específico $Q$. Las necesidades que le interesan a la bibliotecología son las necesidades de información documental.

Simbolizando tenemos Definición 3: $x$ es usuario $\equiv x(P(x) \& Q(x))$

Existen diferentes tipologías de usuarios, consideramos que el criterio para realizar la división de ese concepto es el tipo de mundo de la información al que necesite entrar el usuario, condicionado por el tipo de necesidad de información que tenga, lo cual a su vez estará determinado por el proyecto existencial que esté realizando. De esta manera, un estudiante tiene como proyecto adquirir conocimientos que le permitan terminar una carrera, de ahí su necesidad de información específica que lo lleva a acercarse al mundo de la información la cual le proporciona monografías, libros de textos; un investigador tiene como proyecto el encontrar y resolver problemas científicos, por eso busca artículos especializados, resúmenes, etcétera. Un niño tiene un "proyecto" concreto: crecer, por lo que le interesan libros que

49 Un exhaustivo análisis del concepto de "usuario" empleado en México en los últimos veinte años se encuentra en Endean Gamboa, Robert. El Usuario en la Bibliotecología. El caso de la educación de usuarios en México. Tesis para obtener el Título de Licenciado en Biblioteconomía. ENBA, SEP. México, 1994.

50 Ibid.pp. 2-3, 25, 42, 47. 
le estimulen la fantasía, le den conocimientos, en fin: la necesidad de información es lo que hace al usuario.

Es importante subrayar que dentro de este enfoque el usuario es el origen y fin de la actividad bibliotecaria. Él es quien motiva el proceso informativo con su deseo de satisfacer una necesidad de información y sólo con la satisfacción de ésta se culmina tal proceso.

Algunos han propuesto dividir el concepto "usuario" en dos clases: "usuario potencial" y "usuario real" (o actual que sería más apegado a la terminología aristotélica). ${ }^{51}$ El primero es el que tiene la capacidad de acudir a satisfacer su necesidad de información en una institución informativa documental, pero puede hacerlo o no; el segundo es el que actualiza esa posibilidad. En ocasiones puede tenerse la idea, por un lado, de que lo importante para el bibliotecario son los usuarios actuales, pero si se analiza nuestra definición se observa que el predicado $Q$ expresa "exige $Q_{1}$ o puede exigir $Q_{2}$ satisfacer necesidades de información", lo que en realidad es una disyunción $Q_{1} \vee Q_{2}$, por lo que se tendría:

Definición 4: $x$ es usuario $\equiv x\left(P(x) \&\left(Q_{1}(x) \vee Q_{2}(x)\right)\right)$, de donde se obtiene Definición 5: $x\left(P(x) \& Q_{1}(x)\right)$ es ser usuario actual y Definición 6: $x\left(P(x) \& Q_{2}(x)\right)$ es ser usuario potencial.

Para nosotros ambos usuarios son importantes en la actividad bibliotecaria. De este modo, para la planeación y selección de materiales se debe de tener presente al usuario potencial, no es posible esperar hasta que se aparezca un usuario real pidiendo cierto documento para incluir dicho documento en la colección, lo que hace imposible atenderlo inmediatamente, y si mañana viene otro usuario con otra demanda, entonces hasta ese momento se adquiriría otro libro, etcétera. Es indispensable tener de antemano un perfil de las necesidades de información que "usuarios potenciales" podrán

51 Velez Salas, C., M. A. Torres V. "Educación de usuarios en la red de bibliotecas del área Q-M-B de la UNAM”, en Encuentro de bibliotecarios de la UNAM (2: 1983: México, D. F.). Memoria. México: UNAM, 1984. p. 89 
presentar y que obviamente se irá completando y corrigiéndose con los usuarios reales. 52

Por otro lado también se le puede negar todo papel importante al usuario en la planeación de una biblioteca. Por ejemplo, se dice que por decreto quien ostenta el poder puede determinar abrir una biblioteca sin tomar en cuenta a quienes se atenderán o incluso sin saber con certeza si se atenderá a alguien, citando como caso típico la creación de la Biblioteca Nacional que no tiene como objetivo servir a un usuario particular. Consideramos que si esa autoridad tiene una visión de la realidad, su decreto estará basado en una necesidad real de la sociedad, y por lo tanto, si hay necesidad, hay sujetos que "padecen" esa necesidad, por consiguiente, la biblioteca que se abre por decreto ya tiene un objetivo y con base en ese objetivo se formará la colección. Con respecto a la Biblioteca Nacional podemos decir que sí tiene un "usuario", aunque sea una abstracción "de segundo nivel", el usuario es el mismo pueblo, que tal vez nunca la consulte, pero al que le sirve como uno de sus núcleos aglutinadores al tener reunida la producción espiritual de ese pueblo y además los intelectuales, las conciencias de la nación de hecho sí consultan las obras de esa biblioteca. Es interesante notar que una de las primeras acciones de las naciones que logran su independencia es fundar su Universidad Nacional, su Academia de Ciencias y su Biblioteca Nacional.

Ahora bien, como todo concepto, el usuario es una abstracción necesaria para teorizar. Como mencionamos al caracterizar a la ciencia ella nos da un conocimiento general, no es posible tener una teoría bibliotecológica para un sujeto $a$, otra para $b$, otra para $c$, etcétera. ${ }^{53} \mathrm{El}$ referente real, que buscaba Endean, es una clase compuesta de elementos individuales y concretos. Pero al mismo tiempo debemos señalar que metodológicamente, después de la generalización viene el movimiento contrario: de lo abstracto a lo concreto. Un sujeto con necesidades de información documental (usuario) es un

52 Un ejemplo muy concreto es la biblioteca especializada del CUIB/UNAM. La colección tiene un perfil muy específico, la gran mayoría de las obras versan sobre el tema de investigación del Centro, pero como dentro de las líneas de investigación en esa institución se aprobó la de filosofía de la bibliotecología, teniendo presente que iba a haber usuarios (investigadores) que requirieran de documentos sobre esta temática, se incluyeron obras de epistemología y filosofía de la ciencia, que después se fueron viendo completadas por peticiones muy concretas de obras sobre lógica, hermenéutica, filosofía del lenguaje, etcétera.

53 Por esta misma razón no nos es suficiente el trabajar con usuarios actuales únicamente. 
hombre que vive en una sociedad histórica concreta, clasista y que está ideologizado. El usuario en un momento dado es únicamente el sabio, el escriba y el sacerdote, pero en otro momento es el filósofo, el teólogo, y después puede ser el capitalista; con el movimiento de la Ilustración llega a ser el pueblo, y con el neoliberalismo es aquel que tiene el poder económico, etcétera. Por supuesto, la sociedad va determinando quiénes "tienen derecho" a tener necesidades de información documental, no se debe generalizar la visión presente a todas las épocas. Sin embargo, es necesario subrayar lo "relativo de esa relativización", esa realidad histórica es una concreción del esquema general, es el momento particular en lo universal. La "tradición" gadameriana o la sobreestructura marxista son las que condicionan el proyecto de vida de los miembros de la sociedad, pero ya teniendo ese proyecto surgen las necesidades para realizarlo, y si hay necesidades de información documental, en quienes las haya deberá darse un proceso informativo que involucra al documento y a la institución informativa documental.

Dentro de la misma sociedad puede haber diferencias específicas entre grupos, estratos, naciones. Pero esas diferencias no afectan de tal manera que se deba tener una teoría totalmente distinta para cada grupo, estrato o nación. Con frecuencia se escucha la exigencia de crear una bibliotecología latinoamericana y la crítica a los que "copian" teorías y prácticas del mundo desarrollado. ${ }^{54}$ Creo que no se debe absolutizar ese momento. Por supuesto que no es posible copiar prácticas, eso es un error, pero no teórico, sino precisamente práctico, porque la práctica se refiere a acciones, las cuales pueden darse en situaciones distintas, pero una teoría no puede ser distinta en un país y en otro. Al igual que no existe una odontología mexicana como teoría, no tiene por qué existir una bibliotecología mexicana como teoría, las hay como productos de una comunidad de científicos que pertenecen a una comunidad nacional, que ha desarrollado líneas de investigación y hecho aportes, pero que con sus especificidades han enriquecido al marco

54 Eso recuerda la dicotomía entre el "realismo socialista" y el "realismo no-socialista", la "historiografía socialista" y la "historiografía burguesa". 
teorico general. Curiosamente la misma teoría indica que para la práctica se deben tomar en cuenta las condiciones concretas de los usuarios. ${ }^{55}$

Por último es necesario hacer notar el rol epistemológico que juega el concepto de usuario en la teoría bibliotecológica. Al igual que el concepto de información, nuestra intención es alejarnos de especificaciones muy concretas para trabajar con abstracciones que nos permitan desarrollar la teoría en un mundo cambiante. Ya se ha mencionado la influencia de la tecnología en la bibliotecología, que se percibe de una manera más acentuada en los conceptos de documento y biblioteca (en seguida hablaremos de ellos). Cuando un documento es electrónico se pierde el concepto tradicional de libro que se tenía y en ocasiones se habla de que es otra realidad distinta y se pide hacer otra teoría para ella; lo mismo sucede con la biblioteca. Sin embargo también puede plantearse el caso de que los usuarios en un momento dado sean máquinas. ¿Eso implicará cambiar todo el modelo de hacer ciencia bibliotecológica? ¿quiénes sirvan a esos "usuarios cibernéticos" ya no serán bibliotecarios? Si se sigue el modelo tradicional parece que tendría que ser así, pero nosotros proponemos alejarnos de él para quedarnos con el modelo de "satisfacer necesidades de información", y en lugar de la propiedad $P$ "ser un ser humano" la modificaremos por $P_{1}$ "ser un ente", que puede ser un ser humano $P$ o una máquina $P_{2}$. Por lo que la definición quedaría:

\section{Definición 7:}

$x$ es usuario $\equiv x\left(P_{1}(x) \&\left(Q_{1}(x) \vee Q_{2}(x)\right)\right) \equiv x\left(\left(P(x) \vee P_{2}(x)\right) \&\left(Q_{1}(x) \vee Q_{2}(x)\right)\right)$.

Esto motivaría un desarrollo de la disciplina, se tendría que hacer una división en los servicios de acuerdo con el tipo de usuario que se presente: $x\left(P(x) \&\left(Q_{1}(x) \vee Q_{2}(x)\right)\right)$ : un ser humano, o $x\left(P_{2}(x) \&\left(Q_{1}(x) \vee Q_{2}(x)\right)\right)$ : una

55 Continuando con la comparación con la odontología mexicana, la anatomía y físiología de un mexicano es la misma que la de un francés o un sueco. Pero la alimentación rica en grasas, ácidos y azúcares de los mexicanos puede influir en su dentadura, por lo que los tipos de padecimientos y consecuentemente la profilaxis y la atención serán distintas. Incluso puede "inventarse" una técnica que dé resultados más positivos en un paciente mexicano que en otro de nacionalidad distinta, o que un procedimiento muy recomendable en otras latitudes no tenga los mismos resultados en México. Pero eso, lejos de demostrar que la teoría es distinta, demuestra lo contrario. Los resultados diferentes en un país y otro son consecuencia de fenómenos objetivos que pueden ser descritos por la teoría. 
máquina, por lo tanto habría una nueva forma más accesible de conservar, organizar y recuperar la información para los nuevos usuarios, se cambiaría la noción de información pragmática por la de una información sintáctica pragmática para los nuevos usuarios, etcétera. Pero sería un movimiento no de ruptura, sino de avance en un nuevo camino dentro del mismo programa de investigación científica. 56

\section{Documento}

Otro de los conceptos centrales en bibliotecología es el de documento, por lo que su análisis merece especial atención. Para su definición nos alejaremos de la dualidad materia-espíritu, ya que no se interpreta la información como algo ideal en un soporte material. Empezaremos por dos acepciones del término "documento" citadas por López Yepes. La unión Francesa de Organismos de Documentación define al documento como "toda base de conocimiento expresada en un soporte material y susceptible de ser utilizada para consultas, estudios o pruebas" 57 y con base en dicha definición, S. Briet expresa que el documento es "todo indicio concreto o simbólico, conservado o registrado con el fin de representar, reconstruir o probar un fenómeno físico o intelectual."58

El concepto así tratado posee un sentido muy amplio y todo puede ser interpretado como documento: todo aquello que tenga una expresión material y represente cierto fenómeno, y no sólo lo escrito, como manuscritos e impresos, folletos y hojas sueltas de propaganda, sino también los gráficos, fotografías, dibujos, planos, películas, discos, cintas magnetofónicas, estadísticas, e incluso cualquier cosa natural o los monumentos y objetos de la vida cotidiana producidos por el hombre.

56 Incluso nuestra fundamentación ontológica permanecería, puesto que esas máquinas no serían seres con teleología propia sino que el mismo ser humano les daría su función, que finalmente sería la misma: un nuevo instrumento para su proyecto de existencia. Así es como la información solicitada por esos nuevos usuarios sería al fin y al cabo para el hombre y por lo tanto seguiría siendo para hacer el ser del hombre, para el autoconocimiento del hombre, la desobjetivación del espíritu humano, etcétera, sólo que ahora indirectamente.

57 Cita tomada de López, Yepes J. ¿Qué es documentación? Madrid: Síntesis, 1993. p. 36.

58 Citado por López, Yepes J. La documentación como disciplina. Teoría e historia. Navarra: Eunsa, 1995. p. 134. 
Este enfoque tiene la ventaja de que explica la existencia de otros documentos además de los escritos. La tecnología nos ha dado la posibilidad de tener películas, microfilms, grabaciones sonoras, documentos electrónicos, etcétera, que son manejados por una institución informativa. Sin embargo por su amplitud engloba objetos que escapan a esa institución, por lo que en la escuela española incluso la museología es parte de la documentación.

Considero por tanto que es necesario restringir el uso del término documento propio de la bibliotecología. Para realizar esta tarea podemos recoger los elementos que se dan en la definición tomada del diccionario de bibliología "expresión del pensamiento por medio de signos gráficos (letras, dibujos, pintura, etcétera) sobre un soporte (piedra, pergamino, papel, lienzo, película, cinta, etcétera). ${ }^{59}$ Dichos aspectos son el aspecto simbólico (signos materiales) y semántico (pensamiento) del documento, que aunados al aspecto pragmático (sujeto creador y usuario) nos da un acercamiento semiótico al estudio del documento.

Desde el punto de vista del sujeto y tomando prestada terminología hegeliana, podemos decir que el documento es la objetivación del espíritu humano, en el sentido de que el espíritu humano se proyecta en el objeto creado por él, debido a que las creaciones siempre poseen parte de su creador. ${ }^{60}$ Así pues, observamos que un documento siempre tiene algo de la sociedad donde fue hecho y no sólo nos comunica la información que directamente se quiso plasmar al escribir el documento sino que además nos puede 'hablar' sobre la tecnología, los conocimientos, la escala de valores, etcétera de la comunidad donde fue escrito. ${ }^{61}$ Sin embargo esta propiedad no es específica del documento porque toda creación humana la posee, pero ella jugará un papel importante cuando se hable de la relación del libro con la institución informativa documental.

59 Diccionario de Bibliología y Ciencias afines- Martínez de Souza. Madrid, 1989.

60 Sonia Araceli Vargas empieza su libro La lectura y los adolescentes con un epígrafe un tanto poético de Sven Birkerts que refleja esa relación Espíritu-Documento (libro en este caso): "Porque para mí los libros no son objetos o medios para alcanzar un fin, son el símbolo y la encarnación de la vida del espíritu.” Garduño Vargas, Sonia Araceli. La lectura y los adolescentes. México: UNAM, CUIB: CCH Naucalpan: CNB, 1996. p. 3

61 Sobre este respecto, es preciso aclarar que entendemos al Espíritu humano como ser genérico del Hombre y no como una realidad hipostática, como el Espíritu Absoluto hegeliano. 
Continuando nuestro análisis con la visión pragmática, esto es, desde el punto de vista del sujeto, concebimos al documento como producto e instrumento de y para la realización del ser del hombre. En el apartado dedicado a la fundamentación ontológica hemos mencionado el análisis fenomenológico del ser del hombre realizado por Hiedegger, que permitió establecer la historicidad del ser humano, lo que condiciona la necesidad de poseer un proyecto de existencia al cual se van incorporando, como elementos de un plan general, cosas y otras personas. Para estructurar ese proyecto existencial se necesita la cultura heredada de los antepasados de ese ser humano; que en buena medida ha sido conservada y transmitida, entre otras cosas, por documentos.

En ocasiones se plantea la pregunta de el por qué de la necesidad de guardar documentos, el porqué de la memoria social, y la respuesta es sencilla: para SER, o más exactamente, para poder hacer su ser. Si el hombre es histórico, eso significa que tiene un pasado y un porvenir; y podemos constatar que sin memoria no hay pasado y sin éste, no se puede construir el futuro.

La memoria social proporciona el patrimonio cultural que le da identidad y ser a las sociedades. Es por esto que los conquistadores (Tlacaélel, la Inquisición, Stalin, etcétera) que deseaban tener un dominio más completo sobre los pueblos conquistados se preocupaban por aniquilar la memoria social de los vencidos, y uno de sus métodos para hacer esto era la destrucción de documentos y bibliotecas. Al perder su pasado los pueblos quedaban sin raíces y por lo tanto no había en qué apoyarse y con qué nutrirse.

De esta manera, podemos identificar dos propiedades que nos sirven para definir al documento: su 'capacidad de conservar la memoria social' $(P)$, y su 'función comunicativa social' $(Q)$. Pero además en todo lo dicho se encuentra implícita la función de los símbolos como 'instrucciones para utilizar instrumentos' $(R)$, entendidos estos últimos en el sentido general heideggeriano, como cosas (objetos o personas) que se pueden incrustar en el proyecto existencial del hombre.

El segundo elemento que nos ayuda a clarificar el significado del concepto documento es el aspecto semántico al que está íntimamente unido: la información. El documento además de ser una objetivación del Espíritu humano también es la objetivación del pensamiento, la materialización del 
$\lambda$ óros (logos) en un objeto; ${ }^{62}$ podemos caracterizar al documento como un $\lambda$ ó $\gamma \circ \varsigma$ en su ser-inauténtico. Encontramos un enfoque semejante en autores como Pietsch, quien afirma que "documento es la forma objetivada de una experiencia o de un conocimiento relacionado con determinado sector de las actividades del espíritu humano (principalmente con la ciencia, la técnica y la economía)" 63 y en López Yepes quien expresa que "desde una perspectiva antropológica y cultural el documento es la objetivación de un conocimiento en un soporte material con la posibilidad de ser transmitido. Objetivación y posibilidad de ser transmitido son las dos notas que configuran la naturaleza del documento". 64

\section{CREACIÓN DEL DOCUMENTO}

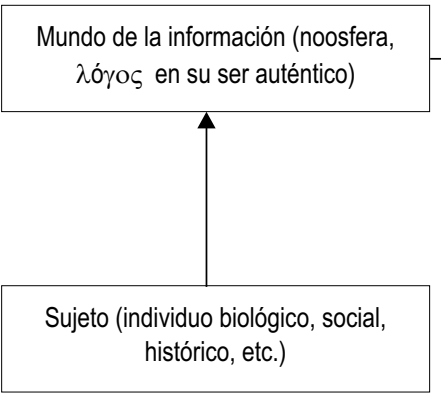

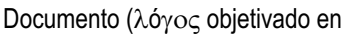
símbolos)

Pero al mismo tiempo que el documento es objetivación del $\lambda$ ó $\gamma$ os, también tiene la función primordial y específica de conducirnos nuevamente al mundo ideal del $\lambda o ́ \gamma o \varsigma$ del cual proviene. Semánticamente el documento

62 Donde tomamos el concepto de $\lambda$ ójos no únicamente como pensamiento racional, sino también como palabra interna ideal, que puede ser poética, religiosa, sentimental, mística, etcétera, pero que es hasta cierto punto racionalizada al ser pensada para ser expresada.

63 Cita tomada de López, Yepes J. La documentación como disciplina. Teoría e historia. Navarra: Eunsa, 1995. p. 146.

64 Idem. p. 154. 
nos transporta al mundo de la información, denota "intenciones del alma"; es decir, conceptos, juicios y argumentaciones. Pero además de esto cabe agregar que lo hace de una manera consciente y directa: fue creado específicamente para cumplir esa función. De esta manera, podemos concluir que el documento tiene como finalidad específica el convertir una vez más al $\lambda$ ó $\gamma$ o $\varsigma$ a su ser-auténtico: en ente ideal. ${ }^{65}$ Esto lo diferencia de otros objetos que también transmiten información pero de una manera indirecta; por ejemplo, un utensilio de cocina fabricado por un artesano de épocas pasadas nos puede proporcionar información sobre el grado de cultura de la sociedad en la que el utensilio era utilizado, el tipo de técnicas que dominaban, los hábitos alimenticios de esa sociedad; es decir, nos puede dar evidencias de otras muchas cosas, pero ese objeto fue creado con el fin directo no de informar, sino de ser usado para cocinar. Lo mismo podemos decir de objetos naturales, como un mineral o un animal, que pueden ser vistos como documentos, pero no de la ciencia bibliotecológica. 66

Sobre este aspecto cabe recordar lo que decía Ortega y Gasset sobre el libro como lo dicho porque debe ser dicho: "decir no lo que al autor le conviene para este u otro fin; sino lo que hay que decir sobre el objeto: el decir es fin del propio decir. El libro está, en potencia, diciendo siempre lo que hay que decir"; 67 y decir consiste en entregar un mensaje.

Esta función de transmitir información está muy ligada a la de ser medio de comunicación social. Se podría abordar la problemática de cuál implica a cuál: comunica porque conecta al mundo de la información o conecta al mundo de la información porque comunica. 68

Así pues, en este segundo momento, se establecen las propiedades 'ser una objetivación del pensamiento' $(S)$ y 'ser creado directa y conscientemente para conducirnos al mundo de la información' $(T)$ como propiedades necesarias para definir el concepto de "documento".

65 Parafraseando el Cuarto Evangelio podemos decir: "En el principio existía el $\lambda o ́ \gamma o \zeta$ y el

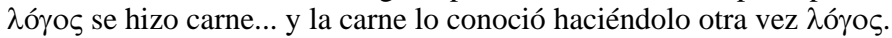

66 Ortega y Gasset, J. Op. Cit. pp. 83-84.

67 Ortega y Gasset, J. Op. Cit. pp. 83-84.

68 Para nosotros, dentro de nuestra ya conocida "posición idealista" (ver nota anterior: "En el principio existía el $\lambda$ ó $\gamma$ o...$)$ la respuesta es que el libro puede ser medio de comunicación social como consecuencia de que conduce al mundo de la información. 
Ahora bien, si caracterizamos al documento desde un punto de vista sintáctico, observamos que tiene una estructura sintáctica que expresa una forma lógica y lo convierte en agente capaz de introducir a la semántica, mencionada anteriormente; es decir, le añade la característica de 'poseer una sintaxis determinada, como un conjunto de enunciados con una forma lógica determinada' $(U)$.

Desde un punto de vista semiótico, podemos decir que el documento es el

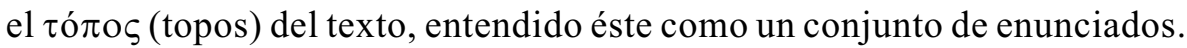
Los cuales a su vez se interpretan como la unión de la oración con el juicio, del significante con el significado, de la sintaxis con la semántica.

Por otro lado el documento también permite otra desobjetivación en el sentido de que la información a la que transporta, y que era parte de la esencia de su creador -el espíritu humano-, al ser consultada por un usuario, ya no está frente al sujeto, sino en el sujeto; ya no es objeto, sino parte del sujeto. Utilizando una vez más terminología hegeliana, podemos afirmar que en el momento de la apropiación ideal del contenido del documento ya no hay enajenación del espíritu humano, éste no pierde su esencia objetivada en sus creaciones, sino que, mediante una apropiación epistemológica de la esencia objetivada, tiene lugar el "autoconocimiento" del espíritu humano.

De esta manera, el documento "es un instrumento de autoconocimiento" $(V)$, autoconocimiento que puede, dadas las condiciones abstractivas del que consulte la obra, no llegar a la reflexión consciente, pero que siempre ocurre, en cuanto que al consultar un documento éste nos remite a la comunidad humana de la cual somos elementos. 69

Nuestro análisis no estaría completo, si no agregamos también que el documento "es producto de la actividad bibliotecológica" $(W)$, ya que un documento llega a serlo en el campo bibliotecológico sólo cuando es manejado, analizado, y colocado dentro de ciertas estructuras por el profesional de la

69 Así por ejemplo, independientemente de que una ama de casa consulte un libro de recetas de cocina con la finalidad inmediata de agradar a su familia con un guiso tradicional mexicano, o un dueño de negocios culinario lo haga con el objetivo de obtener ganancias económicas, o un "teórico" del arte culinario lo haga por el simple deseo de conocer más; todos ellos están de manera mediata, a través de sus fines inmediatos (obtener placer o dinero o conocimiento), siendo copartícipes de una creación que pertenece al pueblo mexicano. Obviamente, dicha receta es "mejor" que otra no conocida, que aunque pudiera ser muy exótica y suculenta, nunca se llegará a cocinar. 
información documental, lo que significa que el documento debe su ser, no sólo al autor original que objetiva la información ideal, sino también al bibliotecólogo que lo re-creó al retomar ese documento inicial salido del autor y agregarle información eminentemente bibliotecológica; esto es, al colocarlo dentro del sistema informativo documental. Sobre esta actividad adicional del profesional de la información documental en la creación de documentos bibliotecológicos hablaremos más detalladamente al analizar los diferentes tipos de documentos según su lugar ontológico y la actividad cognoscitiva que propician.

Por último, en relación con la característica anterior, es necesario señalar que el documento también "es un objeto susceptible de ser manipulado" $\left(P_{2}\right)$, es decir, un objeto sobre el que se puede dirigir una acción profesional y que cumple o puede cumplir las funciones, básicamente espirituales enumeradas anteriormente. Esta última aserción contiene implícita una visión diferente a la tenida desde la perspectiva del sujeto, en donde el documento, especialmente el libro, también se percibe como un sujeto que nos comunica, en ocasiones más de lo que el propio autor que lo creó deseaba hacerlo. Desde este enfoque, que podemos llamar hermenéutico, donde se da un diálogo entre pares iguales -lector y texto- se puede concluir que si un documento no es leído, no es documento; pero desde el punto de vista bibliotecológico, no debemos dejar de señalar que en este otro sentido el documento es un objeto con propiedades externas que lo hacen capaz de ser manejado con fines técnicos; y sólo potencialmente se ve como sujeto, que encuentra su pleno ser al ser consultado. 70

En conclusión, si reunimos todas las propiedades mencionadas anteriormente $\left(P, Q, R, S, T, U, V, W, P_{2}\right)$ en una definición obtenemos:

70 Esta aseveración de ver al documento y específicamente al libro como objeto puede chocar con el pensamiento "romántico" de los que ven al libro como "personas", con su historia, su verdad, como seres que nos brindan su amistad, su compañía, etcétera. Pero considero que es necesario hacer esa cosificación, aunque sea pasajera, para dar lugar al momento administrativo de la bibliotecología; y creo que nadie puede negar ese momento. Lo fatal es absolutizarlo. De la misma manera en administración sería imposible una generalización si los recursos humanos no se despersonalizan hasta cierto punto, porque de lo contrario tendríamos una teoría administrativa para secretarias altas y morenas, otra para las de estatura baja y rubias, otra para casadas, otra para solteras, etcétera. 
Definición 8:

$x\{P(x) \& Q(x) \& R(x) \& S(x) \& T(x) \& U(x) \& V(x) \& W(x) \& P(2)\}$,

Si analizamos el volumen de este concepto, podemos observar que en él se incluyen objetos tales como libros, periódicos, revistas, panfletos, actas administrativas, documentos electrónicos, hipertextos, etcétera.

\section{Tipos de documentos según su lugar ontológico y la actividad cognoscitiva que propician}

Una vez más recordaremos que el concepto proporcionado se encuentra en un sistema teórico determinado y no pretende ser un concepto onmiabarcante que puede funcionar en todas las ciencias. De esta manera cuando hablamos de documento dentro del ámbito bibliotecológico debemos estar conscientes de que tal vez sea una cosa distinta si se la considera desde el punto de vista histórico, criminalístico, literario, o cualquier otra rama del saber humano.

Podemos distinguir diferentes niveles de "ser documento" según el lugar que ocupe el objeto dentro de una ontología construida epistémicamente; esto es, según el tipo de objeto que "sea" en mundos epistemológicos construidos por científicos y, consecuentemente, según la actividad cognoscitiva a que den lugar y de la que son producto.

En un primer nivel se encuentran los objetos tal y como son, sin que haya intervenido para su aparición una intencionalidad de hacerlo documento para ser consultado por la comunidad. Así pues, se tiene en un primer momento el objeto en sí. Por ejemplo existe una mariposa que no tiene otra finalidad que ser mariposa y vuela por el bosque comportándose como ser vivo de una especie concreta; o existe una pistola que fue fabricada para ser pistola, esto es disparar si se jala el gatillo y tiene balas; o existe una carta que fue escrita como obra literaria epistolar de carácter particular y para comunicarle a una sola persona los pensamientos y sentimientos de su autor; $\mathrm{o}$ existe una foto que fue tomada para ser parte de un recuerdo familiar.

En un segundo nivel aparecen esos mismos objetos, mariposa, pistola, carta, foto y podemos agregar piedras, átomos, astros, otros seres vivos y hechos sociales, que contienen información para los especialistas de determinada disciplina, quienes los estudian y desentrañan los mensajes que esos objetos les indican, en el sentido de que son signos-índices de otras 
realidades, regularidades o intenciones en el caso de las ciencias sociales. En este nivel esos objetos se convierten en documentos para el trabajo del especialista, pasan de ser un objeto en sí, a ser un objeto para otro. Pueden ser físicamente los mismos objetos, pero simbólicamente ya tienen un significado adicional que no poseían cuando eran solamente objetos en sí. Por ejemplo la mariposa mencionada anteriormente deja de ser simplemente mariposa y se convierte en representante de una especie de la que se conocen su hábitat, sus hábitos de alimentación, reproducción, su función dentro del ecosistema al que pertenecen, etcétera. Así pues, un biólogo, al clavar en un alfiler a esa mariposa, le asocia toda la información anterior y esa mariposa llega a ser un documento producido por el especialista y será utilizada como tal por sus colegas o estudiantes. Cosa semejante sucede con la pistola, que pasa de ser un arma de fuego, a ser testimonio de un asesinato, y el criminalista le asigna la información de cuándo, dónde, por quién y contra quién fue utilizada; la misma transformación puede realizarse en el caso de la carta o la foto, cuando dejan de ser lo que eran inicialmente para convertirse en testimonios de un personaje, institución, hecho o situación histórica y se vuelven objeto de atención de literatos, historiadores, sociólogos u otro tipo de científico. Sólo después de que los especialistas de otras disciplinas han trabajado con esos objetos-documentos, descubierto la información que les interesaba, y conscientemente objetivado la información por ellos descubierta, los documentos adquieren otra naturaleza, cuya función es trasmitir esa información adicional, es entonces cuando pasan a manos del profesional de la información documental.

Es en este momento donde aparece el tercer nivel, que tiene lugar cuando el documento elaborado por el especialista entra en la jurisdicción del bibliotecólogo y éste se encarga de convertirlo en un documento bibliotecológico. Gracias a la acción de este profesional que inserta un documento dentro de lo que llamaremos sistema informativo documental, ${ }^{71}$ le agrega información al representarlo, organizarlo y prepararlo para ser recuperado por un usuario. Sólo llegado a este último nivel es cuando se puede hablar de documento en el sentido bibliotecológico.

71 Término y concepto que se abordará con más detalle en el siguiente capítulo. 
Si consideramos, como lo hemos hecho, que el documento es por un lado, objetivación de la información y que, por otro, el usuario desobjetiva esa información, queda la impresión de que el elemento bibliotecológico se reduce en el mejor de los casos, a un simple enlace mecánico entre esos dos procesos o, en el peor, a un receptáculo de documentos que son proporcionados por el autor y al cual recurren los usuarios para consultarlos. Pero si consideramos que el bibliotecólogo es, más que un intermediario pasivo, un agente activo, esto implica que existe una acción intencional, basada en estructuras de análisis que le permiten al producto intelectual salido del autor, convertirse en un documento en el sentido bibliotecológico estricto.

El documento que nos interesa no es el que existe como propiedad individual de alguien, ni el que se encuentra en una librería o sobre una mesa, sino el que el bibliotecólogo crea con su acción al ponerlo dentro del sistema de información documental. El documento dentro de ese sistema tiene un ser agregado que no tenía antes de ingresar a él. La acción del bibliotecólogo le da un nuevo sentido al documento inicial porque lo coloca dentro de un contexto específico que antes no tenía. Sólo después de esa acción el documento adquiere personalidad dentro del sistema de información documental, tomando el término personalidad en su sentido literal: la forma de presentarse a los demás, de tener rostro, de hablar a través de esa forma de presentarse. De la misma manera que la personalidad de un individuo no reside en su nombre y el lugar en que vive, esa personalidad del documento no se reduce a tener una etiqueta y encontrarse en un lugar determinado, cuestiones que pueden ser resultado de una acción técnica, irreflexiva, repetitiva y empírica; sino que está en estructuras más profundas, producto de una actividad intelectual, teórica y creativa. ${ }^{72}$ De no realizarse esa actividad intencional, la información objetivada, fuera del contexto del sistema de información documental, se puede convertir en olvidada y perdida en el caos de otras informaciones objetivadas que puede ser encontrada por casualidad; en tesoros desconocidos que no sirven de nada hasta que se hagan conocidos; en

72 Continuando con la analogía, podríamos decir que si para descubrir las estructuras profundas de la personalidad de un individuo es necesaria toda una investigación, por ejemplo, psicoanalítica, para conocer las estructuras de ese contexto informativo-documental es necesario hacer una investigación teórica, no menos profunda e interesante. 
medios de comunicación privada que necesitan hacerse públicos para que sean útiles a la sociedad.

Por ejemplo, el caso de la obra de San Agustín La ciudad de Dios, puede tomarse como un libro sobre apologética, iglesia primitiva y reino de Dios, ${ }^{73}$ pero por otro lado es posible considerarlo como un libro de filosofía política al lado de las obras de Platón, Aristóteles, Hobbes, Rousseau, etcétera, o una obra con una autoridad superior por ser parte de la Tradición cristiana (fuente también de Revelación), o una obra perniciosa que refleja una ideología basada en creencias falsas y encaminada a sostener el dominio de las clases dirigentes. Al mismo tiempo, con ayuda de esta propuesta teórica se puede explicar el por qué del caos de información en Internet: simplemente porque no existen documentos completos. Lo que ahí se encuentra no ha sido estructurado, analizado, manejado por los profesionales de la información y, debido a esto, cuando alguien se introduce a ese mundo, más bien se tropieza con información en lugar de realizar un encuentro planeado y deseado.

Ahora bien, esta actividad del sujeto para completar el ser del documento no implica relativismo porque esa actividad es sobre un objeto, el cual dirige dicha acción; la participación del sujeto es con base en las propiedades y atributos presentes en la materia prima con la que trabaja, no es una invención o creación ex nihilo, sino una transformación de algo que ya es. Al mismo tiempo, las estructuras empleadas para el manejo del documento también son objetivas porque responden a la realidad del sistema de información documental. ${ }^{74}$

De esta manera podemos distinguir claramente lo que es un documento en el contexto bibliotecológico de lo que son otros tipos de documentos, y así no querer abarcar un universo que rebasa las posibilidades cognoscitivas y prácticas dentro del contexto informativo documental.

\section{Libro}

Por la importancia histórica que poseen, vamos a analizar más detalladamente una subclase de la clase de documentos: los libros. Si la clase de los libros es una subclase de esta última, como lo son las clases de los objetos mencionados anteriormente (periódicos, revistas, etcétera), entonces

73 Esos temas están asignados a esa obra en el catálogo de la DGB de la UNAM.

74 Por eso afirmamos que es posible una investigación teórica sobre las estructuras que le son asignadas al documento. 
podemos concluir que el concepto de documento es el género y, con base en su limitación, mediante la especificación de propiedades, podemos llegar al concepto de libro, así como a los de otros objetos reunidos en subclases de la clase genérica.

Dichas características serán, a mi modo de ver, de carácter formal más que filosófico. Entre éstas incluiríamos 'el hecho de que el documento tiene una determinada extensión' $\left(P_{1}\right)$, para diferenciar el libro de revistas, artículos, "cuadernillos" y "el hecho de que el tema esté abordado de una manera más o menos acabada' $\left(Q_{1}\right)$, para diferenciarlo principalmente del hipertexto. De esta manera obtenemos:

Definición 9:

$x\left\{P(x) \& Q(x) \& R(x) \& S(x) \& T(x) \& U(x) \& V(x) \& W(x) \& P_{2}(x) \& P_{1}(x)\right.$ $\left.\& Q_{1}(x)\right\}$,

Ante la definición 9 surge el problema del soporte y de la forma física. Tradicionalmente en el concepto de libro se incluía la característica de ser de "carne y hueso"; es decir, de ser un compuesto de páginas escritas $\left(R_{1}\right)$ o impresas reunidas por uno de sus lados $\left(S_{1}\right)$ y con cubierta $\left(T_{1}\right)$. Simbólicamente $\left\{\left(\left(R_{1}\right) \vee\left(S_{1}\right)\right) \&\left(T_{1}\right)\right\}$. Lo que nos da:

Definición 10:

$x\left\{P(x) \& Q(x) \& R(x) \& S(x) \& T(x) \& U(x) \& V(x) \& W(x) \& P_{2}(x) \& P_{1}(x) \&\right.$ $\left.Q_{1}(x) \&\left(R_{1}(x) \vee S_{1}(x)\right) \& T_{1}\right\}$,

Pero observamos que la definición 10 es un concepto histórico, porque deja fuera documentos que en su momento se consideraron libros, como son las tablillas, los códices y los rollos, y a su vez encuentra problemas con ejemplares contemporáneos de naturaleza electrónica. Si adoptamos la definición 10, entonces tenemos que aceptar que los ejemplares encontrados en las cuevas de Qumram no son libros sino Rollos; que el poema de Gilgamesh publicado por una editorial contemporánea es un libro, y no así su versión antigua en tablillas que, los 'Libros' de Historia de Herodoto son un libro en su edición impresa, pero no así en su forma original de Rollo, y que las versiones digitalizadas de esos tres documentos serán semejantes a las versiones originales, en las cuales no son libros. Pero los Rollos del Mar Muerto se encontraban en la biblioteca del Monasterio de los esenios en 
Qumram, el Poema de Gilgamesh en la biblioteca de la Antigua Mesopotamia, los trabajos de Herodoto en la biblioteca de Alejandría, y las versiones electrónicas de estas obras están en bibliotecas contemporáneas. La palabra biblioteca, como es de todos sabido, proviene del griego $\beta \imath \beta \lambda$ os (biblos) que comúnmente se traduce como 'libro'. Para algunos el problema entonces será más profundo y el hecho mencionado por nosotros significa que el concepto de 'biblioteca' también está cambiando. Por supuesto que esto tiene lugar, recordemos que indicamos anteriormente que un concepto no es algo aislado sino una trama en la que la teoría juega un papel relevante. ${ }^{75}$ Lo que pretendo mostrar es que existe un continuo en el que el 'libro' se trata independientemente de su forma física, ya que el mismo término $\beta i \beta \lambda$ os inicial- mente denotaba el material del que se hacían los "libros": la corteza vegetal, el papiro, pero se siguió conservando aun cuando el material utilizado dejó de ser el papiro; consecuentemente consideramos que la última característica no es esencial para nuestros fines. De esta manera, proponemos la definición 9 como la representación de la forma lógica del concepto libro. Podemos posteriormente ir limitando ese concepto para obtener subclases de libros según el soporte:

Si $U_{l}$ es 'estar escrito en papiro y tener la forma de rollo', entonces el concepto:

Definición 11:

$x\left\{P(x) \& Q(x) \& R(x) \& S(x) \& T(x) \& U(x) \& V(x) \& W(x) \& P_{2}(x) \& P_{1}(x) \&\right.$ $Q_{1}(x) \& U_{1}(x)$,

nos denota a la clase de los rollos que, con justo derecho, pueden ser tratados como libros.

Si $V_{l}$ es 'estar escrito en tablillas', entonces obtenemos:

Definición 12:

$x\left\{P(x) \& Q(x) \& R(x) \& S(x) \& T(x) \& U(x) \& V(x) \& W(x) \& P_{2}(x) P_{1}(x) \& Q_{1}\right.$

(x) \& $\left.V_{1}(x)\right\}$,

75 Cuestión que abordaremos en el apartado dedicado al análisis de la institución informativa. 
la cual representa a la clase de las obras escritas en tablillas y que también son libros.

Si $Q_{2}$ es 'tener un soporte electrónico', entonces tenemos:

Definición 13:

$x\left\{P(x) \& Q(x) \& R(x) \& S(x) \& T(x) \& U(x) \& V(x) \& W(x) \& P_{2}(x) \&\left(P_{1}\right) \&\right.$ $\left.\left(Q_{1}\right) \& Q_{2}(x)\right\}$,

que designa a los libros electrónicos que a su vez presentan características propias, como el poder ser leídos saltando de un lugar a otro según el tema afín que traten, el hecho de que se limite la lectura a las líneas que permita la pantalla de la máquina, etcétera.

Sobre este punto cabe señalar que la última afirmación designa, según la propiedad $P_{1}$, a documentos con texto terminado y no abierto como es el caso del hipertexto, que puede ligar infinidad de textos, y puede estar siempre construyéndose con nuevas relaciones. Sin embargo si en un momento dado, como resultado de una búsqueda de textos sobre un tema, se termina la sesión, se objetiva ese resultado (y se hace una impresión o se archiva en la máquina), ese resultado puede ser considerado como libro, además de que recordemos que el predicado $P$ 'ser un medio de conservar la memoria social' implica la permanencia en el tiempo para que la sociedad lo pueda consultar. Si lo que nos interesa es el proceso de vincular términos y no el resultado, no tenemos un libro.

Al mismo tiempo, utilizando la definición 8 como género, podemos ir obteniendo otros tipos de documentos, al irles agregando propiedades específicas.

Para concluir, como en el caso del concepto de usuario, debemos señalar el aspecto histórico-concreto del concepto de documento. Las propiedades que señalamos como distintivas de él, se concretizan en una sociedad determinada. Así por ejemplo, se afirmó que el documento tiene como función particular el hecho de transportarnos al mundo de la información, y el de ser instrumentos de conservación, comunicación y autoconocimeinto; pero se puede observar que en determinadas épocas el documento "iba en contra de esas funciones", como lo muestran los índices y catálogos que registraban las obras prohibidas, que visto desde una mirada contemporánea, lejos de 
permitir la comunicación social (democrática), la reprimían; pero aquí el concepto de comunicación social actual lo estamos proyectando a una época que lo entendía de otra manera. Al fin y al cabo, esos documentos cumplían con su función comunicativa, porque se hacía del conocimiento de "los guardianes", quienes tenían el derecho de poseerlo. Asimismo, descubrimos que esos documentos son la objetivación del espíritu humano de su época, y con su ayuda podemos descubrir la cosmovisión que dominaba, la escala de valores que poseían, etcétera.

\section{Documento y $\beta 1 \beta \lambda \mathrm{os}$ (biblos)}

Dentro del análisis del concepto de documento es interesante hacer una relación entre este término y sus derivaciones de Documentación, como disciplina que estudia el campo relacionado con éste, así como Centro de documentación, como la institución donde tiene lugar el fenómeno documental; y la palabra biblos, también con sus derivados bibliotecología y biblioteca, como disciplina e institución respectivamente, donde el centro semántico recae en el sentido de biblos; ya que, a nuestro juicio, existe un mal entendido que provoca cierta subestimación del sentido histórico y del alcance de la significación que tienen éstos últimos términos.

Una discusión abierta ya por Otlet, quien introdujo los términos $d o c u$ mento, como un objeto de cualquier naturaleza que contiene información, para de esta manera poder abarcar no sólo al libro sino a otro tipo de objetos documentales; ${ }^{76}$ y donde Documentación designa un campo destinado al estudio de todos ese objetos que contenían información y, por consiguiente, no sólo al libro; lo cual parece haber dejado desprotegido el término bibliotecología y arrumbado en el desván de la historia, o por lo menos haberlo restringido a una clase específica de documentos. Consideramos que un análisis del vocablo original biblos, nos permitirá defender la actualidad de dicha palabra.

La primera parte de las palabras bibliotecología y biblioteca, como ya lo mencionamos anteriormente, proviene del vocablo griego $\beta \imath \beta \lambda$ os que comúnmente se traduce como libro, ya que su equivalente latino corresponde

76 Acepción por cierto demasiado amplia y que nos preocupamos líneas anteriores por delimitar y precisar. 
a liber, y de ahí pasó al lenguaje occidental. ${ }^{77}$ Sin embargo, si analizamos el término biblos, tal como aparece en el pensamiento griego y helenista, encontramos que no es exactamente así. En su sentido original, biblos designaba el material con el que estaban fabricados los objetos sobre los que se escribía. Pero después su acepción pasó a ser esos objetos mismos. Con una visión modernista ese significado inicial se trasladó a los objetos que la revolución de la invención de la imprenta originó y que tenían características semejantes a los biblos originales: eran los objetos resultado de cuando se escribía. 78

Si reflexionamos sobre el uso actual de la palabra "libro" aplicado a obras escritas antes de la invención de la imprenta, encontramos cierta discordancia entre lo que eran y lo que actualmente se entiende que eran. Así por ejemplo, se habla del "Libro de los muertos" de los egipcios; de los " $\mathrm{Li}$ bros de Historia" de Herodoto; de los "Libros de la Metafísica" de Aristóteles; de los "Libros de la Biblia"; de los "Libros" perdidos de la Antigüedad; de los "Libros" que escribieron San Agustín, Santo Tomás y en general aquellos que escribieron los autores medievales. Sin embargo, estrictamente hablando, todos esos escritos no eran libros, tal como los entendemos actualmente; eran o rollos de papiro, o pergaminos en el caso de la antigüedad, o eran códices en el caso de la edad media. Incluso podemos llegar a la conclusión de que la gran Biblioteca de Alejandría, si seguimos interpretando biblos como libros, no contenía libros, sino rollos, y por consecuencia no era una biblioteca. ${ }^{79}$ Sin embargo, todos reconocen que en Alejandría existió una biblioteca, porque contenía biblos, los cuales eran precisamente objetos con información objetivada, hechos para ser leídos, objetos de conservación y transmisión de información.

De esta manera encontramos que biblos puede ser interpretado como documento; es decir, no sólo como libro en su sentido contemporáneo, con determinada forma y elementos estructurales, por lo que al afirmar que la

77 Basta recordar, por ejemplo, que la palabra en lengua inglesa para designar "biblioteca" es Library, o que "bibliófilo" es el amante de los libros.

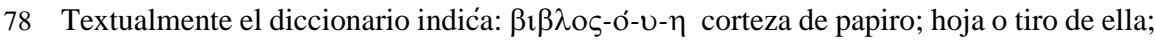
escrito; libro; documento, carta; división de una obra. Diccionario Griego-Español. Barcelona: Bibliograf. S. A., 1973.

79 En inglés se conservó la etimología latina de liber para el vocablo Library -biblioteca. 
bibliotecología no puede tener una acepción más general que abarque el estudio de todo tipo de documento en su flujo informativo, o que la biblioteca sólo es una colección de libros, está olvidando el sentido original de la palabra biblos. En ocasiones se indica que el término actual de documento refiere más a la información que al soporte, por lo que no es exactamente igual a biblos. Sin embargo, aunque inicialmente biblos tenía en cuenta el material posteriormente se despojó de ese significado original, y si tomamos en cuenta la mentalidad griega y su idea de logos como palabra interna, pensamiento, palabra, estaríamos menospreciando esa visión que siempre tuvo en cuenta el aspecto mental, ideal, suprasensible de la realidad y de los significados. La Biblioteca de Alejandría, resguardaba sus biblos, no por su soporte material, sino por el logos que contenían. El trabajo que realizaron sobre catalogación, la identificación de autores y los nombres de los biblos, derivados de las primeras palabras que contenían, muestran claramente el respeto y la importancia que le daban a un término que siglos después se denominaría información.

Así pues, este análisis nos ha conducido a la conclusión de que no es necesario buscar un nuevo término para el estudio de los documentos, si es que ya existe el de bibliotecología, ya que la acepción exacta de biblos no es sólo la de libros, como la que actualmente se tiene, sino la de un objeto que contiene un logos.

\section{Institución informativa documental}

El tercer elemento central en la teoría bibliotecológica que analizaremos a continuación es la institución informativa documental. La primera precisión que debemos realizar es que el concepto anterior está formado por lo que en teoría de la definición se denomina género y diferencia específica. El primero está denotado con los términos "institución informativa" y el segundo, la diferencia específica, por "documental”. Lo anterior evita caer en ambigüedades ya que el ser genérico de la institución informativa se puede especificar en distintos tipos de instituciones informativas: periodismo, televisión, radio, etcétera, que no caen dentro del campo que estamos analizando; pero si se restringe la institución informativa al ámbito documental, entendiendo por documento lo que se analizó en el apartado anterior, está 
claro que nos referimos a la institución encargada de proporcionar información documental.

Una primera característica que resalta al analizar la institución informativa documental es que es un organismo creado por la sociedad y que cumple una función social $(P)$, de ahí que hayamos elegido el término institución y no seguir el consenso general de llamarla unidad de información. El hecho de ser un instituto social significa que su existencia se debe a una necesidad social y que -al igual que los institutos políticos (Estado, u otros que históricamente han aparecido: partidos, ministerios o secretarías de estado, presidencia, congreso, en el caso de las democracias representativas) o jurídicos (policía, Ministerio Público, juzgados, Suprema Corte de Justicia)-, se inserta dentro de la estructura de la sociedad para el buen funcionamiento de ésta, independientemente de las personas que ocupan un cargo dentro de esa institución. Pero esa característica institucional no absorbe el elemento subjetivo de los individuos que le dan vida, y no debe convertirse en un sistema con existencia autónoma y autorreferencial a despecho de la finalidad con que tal institución fue creada. ${ }^{80}$

Ahora bien, si se trata de una institución social, el caso de las bibliotecas particulares de determinados personajes debe ser explicado desde esta perspectiva. En el caso que nos interesa consideramos que sería más preciso hablar de colecciones particulares y sólo indirectamente de bibliotecas particulares, en cuanto que le permiten a dicho personaje participar en el entramado social debido al papel que juega como personalidad importante dentro de la ciencia, el arte, la política u otro campo de la cultura. Pero estrictamente hablando esa colección particular se convierte en biblioteca cuando pasa a ser de interés público, cuestión que no hay que confundir con su propiedad y las condiciones para tener acceso a ella, pues éste bien puede ser gratuito y abierto, o tener un costo y ser restringido.

Ahora bien, dentro del contexto general de nuestra teoría y en relación con los conceptos anteriormente analizados, además de ser un instituto social, consideramos que la institución informativa documental es el "espacio" que propone las condiciones necesarias para la satisfacción de las

$80 C f$."El sistema de información documental ¿un sistema autorreferencial y autopoiético?”, en Revista Interamericana de Bibliotecología. Medellín, Colombia: Universidad de Antioquia. Escuela Interamericana de Bibliotecología. Vol. 22. N. 2. pp. 51-65. 
necesidades mencionadas del usuario $(Q) \mathrm{y}$, consecuentemente, permite la desobjetivación del logos $(R)$. Asimismo la institución informativa es el "lugar" donde no sólo se conserva la producción intelectual impresa de la humanidad, sino donde se puede dar y se da el autoconocimiento del espíritu humano objetivado en documentos $(S)$, además de que es un agente dentro del proceso de comunicación social y de la comunicación personal donde el autor encuentra su lector $(T)$.

De esta manera obtenemos la siguiente definición:

Definición 14:

$x$ es una institución informativa $\equiv x(P(x) \& Q(x) \& R(x) \& S(x) \& T(x))$

Como podemos observar, dentro de esta definición formal dejamos fuera la conservación de documentos, mencionada sólo como de paso en la exposición en lenguaje natural, además de que no se integra a la definición propuesta un atributo que ha sido considerado por muchos autores como central del concepto que estamos analizando: la organización de documentos e información. ${ }^{81}$ Nosotros dejamos implícitos esos atributos porque la teleología de la institución informativa, expresada en la conjunción de los cuatro predicados, es la que determina esas características y otras propias de la institución informativa, como son la selección de documentos, la misma conservación y organización y, en ocasiones, la elaboración de documentos secundarios: análisis, resúmenes, bibliografías , etcétera.

Sobre este aspecto, por ejemplo, se ha discutido la afirmación de Shera de que "todas las funciones de la biblioteca convergen en la conservación [...] la conservación es básica y fundamental para la biblioteca". ${ }^{82}$ Según nuestra opinión, la expresión "ser básica y fundamental" debe interpretarse en el sentido de "ser condición necesaria", es decir, se afirma que la conservación es condición necesaria para la biblioteca: ' $A$ es condición necesaria para $B$ ', que en su forma lógica implicativa es $\neg A \supset \neg B$ 'si no se da $A$, entonces no se da $B^{\prime}$; si no se da la conservación, no hay biblioteca; en nuestro caso no se da

81 Cfr. Susana Sander Villarino, “¿Qué es la biblioteca?”, en Edición Conmemorativa del X Aniversario del Centro Universitario de Investigaciones Bibliotecológicas. T. 1. México: CONACULTA, DGB, CUIB, 1992. pp. 33-42.

82 J. Shera, Op. cit. p. 142. Las cursivas son mías. 
la satisfacción de las necesidades informativas del lector, o no se da la objetivación del espíritu humano o la de $\log o V$, etcétera, si no hay conservación.

Ahora bien, si escribimos la contraposición a la implicación anterior tenemos: $B \supset A$, 'si hay biblioteca entonces hay conservación'; de acuerdo con nuestro enfoque: si hubo satisfacción de necesidades, entonces hubo conservación de documentos. De acuerdo con esto y recordando nuestro enfoque de esencia como la propiedad o conjunto de propiedades que determinan la aparición de otras propiedades, tenemos que lo que implica a otras propiedades, en este caso la conjunción propuesta, es un atributo esencial y la conservación es una función de la conjunción dada. ${ }^{83}$ La afirmación de que la conservación es para Shera un elemento necesario sine qua non es posible la actividad bibliotecaria, se ve reforzada por otra aserción del mismo autor en el que expresa que "[...] el punto focal de esta actividad [del bibliotecario] es ese momento en que un libro, un registro gráfico, pasa a manos del lector. Si esto sucede frecuente y fructuosamente puede decirse que la biblioteca es exitosa; pero si nunca toma lugar, nada de lo que la biblioteca pueda ser o hacer justificará su existencia." 84 Es decir, se puede conservar magníficamente una gran cantidad de documentos, organizarlos perfectamente, etcétera, pero si no llega al lector el documento, que no sólo ha demandado el usuario sino también aquel que satisface la necesidad informativa del solicitante, entonces la biblioteca no tiene razón; de ser, es decir, es un absurdo. De esta manera, este enfoque nos permite determinar que no todo conjunto de libros (bodega, librería) constituye una biblioteca, ya que no en todos los casos se dan las condiciones para satisfacer las necesidades de información.

En este momento cabe hacer dos observaciones. En primer lugar, como se habrá observado, utilizamos el término institución informativa y no biblioteca, como lo hace Shera. Esto se explica por el hecho de que distinguimos diferentes tipos de instituciones informativas de acuerdo con la necesidad que satisface, al mundo de la información que conecta y al documento que utiliza para realizar las dos funciones antes señaladas. Si lo que interesa es la información científica obtenida a través de análisis de documentos $(U)$

83 Si quisiéramos ser más estrictos tendríamos que analizar la conjunción propuesta para determinar que ciertos predicados en ella son implicados por otros. No lo haremos y dejaremos a un lector más atento esa tarea.

84 J. Shera, Op. cit. p. 203. 
para satisfacer necesidades muy especializadas, tenemos un Centro de Información. Por lo que tenemos:

Definición 15:

$x$ es un Centro de información $\equiv x(P(x) \& Q(x) \& R(x) \& S(x) \& T(x) \& U$

$(x))$.

Si lo que se conserva y organiza para servir a determinados usuarios son documentos producidos por un Sujeto (individual o institucional) ( $V$ ) tenemos un archivo, de donde:

Definición 16:

$x$ es un archivo $\equiv x(P(x) \& Q(x) \& R(x) \& S(x) \& T(x) \& V(x))$.

Si lo que se posee son colecciones de libros $\left(P_{1}\right)$, tenemos una biblioteca:

Definición 17:

$x$ es una biblioteca $\equiv x\left(P(x) \& Q(x) \& R(x) \& S(x) \& T(x) \& P_{1}(x)\right)$.

Esta última institución -la biblioteca- también se subdivide en subclases, pero el criterio que sirve de base a esa división continúan siendo los tipos de usuarios que atiende y las necesidades que satisface, el mismo nombre de las subclases indican qué tipo de usuarios y necesidades atiende: escolares, si atiende a niños cuyas necesidades informativas derivan de su actividad escolar $\left(Q_{1}\right)$; universitarias, si atiende a estudiantes $\left(R_{1}\right)$; infantiles, si su foco de atención es servir a usuarios de determinada edad e intereses $\left(S_{1}\right)$; especializadas, si sirve a un grupo específico de investigadores, políticos, capitalistas en la esfera productiva, financiera o comercial $\left(T_{1}\right)$; públicas, si tiene que atender a un usuario general $\left(U_{l}\right)$; nacionales, si su función es servir como elemento de identidad nacional $\left(P_{2}\right)$.

En el contexto contemporáneo las funciones de las instituciones informativas pueden ser mixtas, pues no se da un tipo "químicamente puro". Puede haber bibliotecas que también hagan análisis de documentos, o centros de información que brinden los materiales primarios; o bibliotecas especializadas que sirvan a estudiantes, etcétera. 
La segunda observación que es necesario realizar es que los términos utilizados: "Espacio" " "lugar" se entienden no de una manera física tridimensional, sino como el $\tau$ ó $\pi$ o (topos) que sólo proporciona las condiciones para la

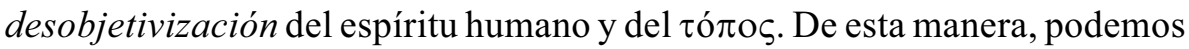
desprendernos del nexo institución informativo -edificio, para dar cabida a otro tipo de instituciones informativas: las bibliotecas ambulantes $\left(Q_{2}\right)$, móviles $\left(R_{2}\right)$, electrónicas $\left(S_{2}\right)$, etcétera, e incluso, virtuales $\left(T_{2}\right)$, si es que éstas realmente pueden proporcionar las condiciones mencionadas. En este caso, como lo hicimos con la definición de documento, podemos ir delimitando el concepto genérico de institución informativa documental para ir especificando, mediante la adición de propiedades, el tipo determinado de institución que se tiene. Por ejemplo, una biblioteca especializada electrónica sería:

Definición 18:

$$
x\left(P(x) \& Q(x) \& R(x) \& S(x) \& T(x) \& P_{1}(x) \& T_{1}(x) \& S_{2}(x)\right) .
$$

Para reforzar nuestra propuesta teórica aquí expuesta podríamos una vez más apoyarnos en Ranganathan. La dialéctica existente entre información, usuario, necesidad de información, documento e institución informativa, origina y es originada por los famosos cinco principios bibliotecológicos propuestos por el teórico hindú. Si se analizan estos principios se descubrirá la asombrosa convergencia entre esos principios y nuestra propuesta. "Los libros son para usarse", "los libros son para todos", "cada libro tiene su lector", "ahorra el tiempo de los lectores" y "la biblioteca es un organismo en constante crecimiento" es, todo ello, la consecuencia de lo que nosotros hemos definido como información, documento, usuario e institución informativa. Por ejemplo, la proposición "los libros son para usarse" es implicada por el hecho de que un documento es un objeto que tiene como función desobjetivizar el tó $\pi$ o ( y que cuando se "usa" cumple esa función y si no se usa no es un documento en sentido estricto, sino una mercancía, un objeto de adorno, una "cosa" en un estante que potencialmente podría llegar a ser un documento completo, que conduce al mundo de la información. El enunciado "Los libros son para todos" es comprensible a la luz de la noción de desobjetivación del espíritu humano y el hecho de que si no se da esa desobjetivación, se produce la enajenación del hombre; la humanidad es propietaria de sus mismas creaciones. "Cada libro tiene su lector" es el resultado de lo que la 
institución informativa realiza al brindar las condiciones para satisfacer con documentos las necesidades de información de los usuarios. Los dos últimos principios tienen relación con la teleología de la institución informativa: servir al usuario y crecer para servir en un mundo cambiante y a usuarios también cambiantes.

Por último también debemos de contextualizar la definición de institución informativa documental que acabamos de proporcionar, como lo hicimos con documento y usuario. La institución informativa no es el agente que siempre, en todos lados y a todos, conduce al mundo de la información sino que, como elemento de la sobreestructura ideológica, está influenciada por la forma de comunicación social aceptada históricamente. Como indicamos al analizar al usuario, que éste iba cambiando, así la institución informativa va también evolucionando, en correspondencia con el ideal de comunicación social que históricamente se tiene, pero siempre conectada con ese proceso comunicativo y tratando de servirlo. Es por ello que en ocasiones, más que directamente fomentar la transmisión de información, se acentúa la propiedad de conservar, resguardar y proteger los tesoros de la sabiduría ante los no-iniciados, los no-dignos, que perturbarían más que coadyuvarían a la comunicación social. Pero si se hace eso es precisamente para que la circulación social aceptada se lleve a cabo de una manera más eficiente. 85

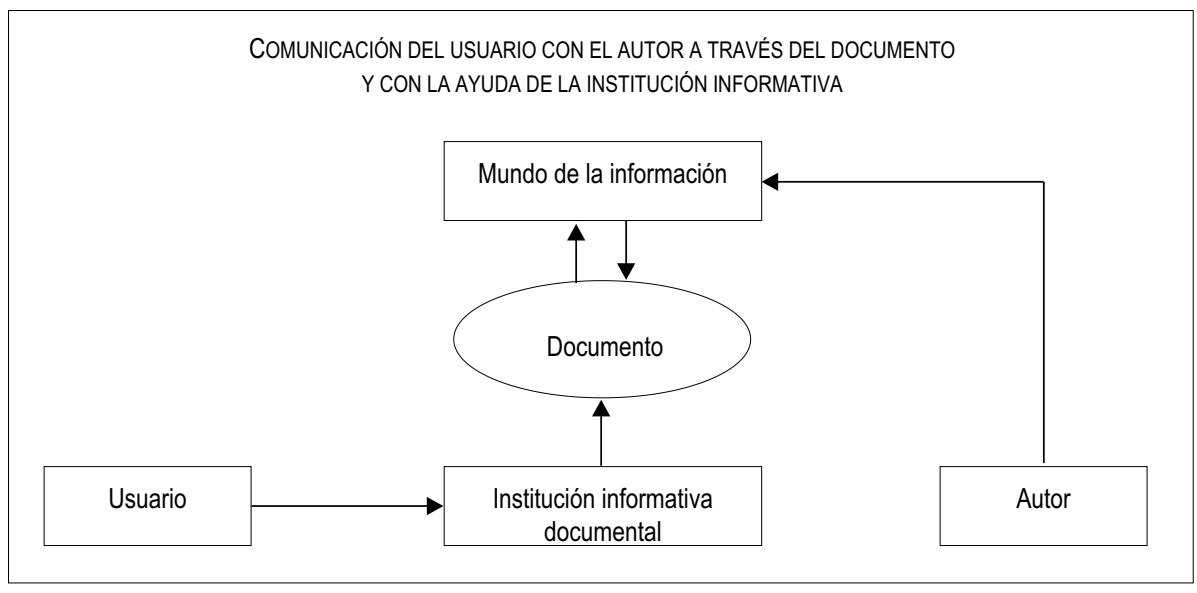

85 No se debe identificar "comunicación social" con "comunicación democrática". Lo social ha existido siempre, lo democrático no. 


\section{El profesional de la información documental}

Un elemento muy importante dentro de la institución informativa documental es el sujeto que con su acción le da vida. Al afirmar que la institución informativa documental proporciona las condiciones necesarias para la desobjetivación del logos objetivado, se parte del supuesto de que es un sujeto quien crea esas condiciones. A continuación analizaremos ese elemento subjetivo: el profesional de la información documental. ${ }^{86}$

De acuerdo con Habermas, la sociedad moderna se caracteriza por su afán de dominio y control de la naturaleza e incluso de la sociedad y de los fenómenos humanos ${ }^{87} \mathrm{El}$ tipo de racionalidad que se preocupa por la eficacia de ese interés de dominio: la exacta correspondencia entre los medios y los fines, desentendiéndose de toda valoración de los fines, es la racionalidad instrumental.

En ocasiones, es posible encontrar profesionales de la información documental en quienes predomina ese tipo de racionalidad y que tienen como parte central y final de su trabajo a la administración, las técnicas, procedimientos y tecnologías que le permiten organizar los documentos "racionalmente". 88 Dicha organización es una organización despersonalizada, incluso los sujetos que toman parte en ese sistema: usuario y profesional de la información documental, son tratados como objetos. El profesional de la información documental se ve como un simple servidor en el sentido computacional; esto es, una máquina que cumple con la función de interface entre el usuario y la red, que sirve de enlace entre las exigencias de los clientes usuarios y las capacidades de la red para satisfacer esas exigencias. Y de ahí el temor a ser desplazado por las computadoras, porque instrumentalmente son más veloces, más económicas y menos conflictivas.

86 Nuestra posición acerca de esta problemática se encuentra más ampliamente presentada en: Miguel Ángel Rendón Rojas, "El papel del profesional de la información en el acceso y uso de la información documental", en La información en el inicio de la era electrónica: Información, sociedad y tecnología. T. II. México: UNAM-CUIB, 1998. pp. 241-271.

87 J. Habermas, Ciencia y técnica como ideología. Madrid: Tecnos, 1984.

88 Actualmente con la introducción de las tecnologías de la información esta tendencia es más fuerte, aunque anteriormente también se daba al hacer énfasis únicamente en el aspecto técnico. 
Sin embargo ese temor es infundado porque la identidad específica del profesional de la información no descansa en su función instrumental. Desde nuestro enfoque (la bibliotecología como una de las ciencias del espíritu) es posible constatar que el proceso informativo documental es un diálogo entre elementos "subjetivos" (en el sentido de sujetos, de seres humanos). De este modo, el profesional de la información es un ser humano, lo cual, siguiendo a H. Arendt, ${ }^{89}$ es sinónimo de ser activo, lo que significa no sólo laborar para satisfacer necesidades físicas y biológicas, ni tampoco únicamente trabajar para producir objetos artificiales (técnica y civilización), sino un ser que actúa en la esfera de lo público, donde se es creativo, reflexivo, libre y se tiene responsabilidad. ${ }^{90}$ Debido a esto el profesional de la información es actor y no un miembro pasivo dentro del sistema del que es elemento, porque se necesita de un SUJETO y no de un objeto (como el servidor, y el administrador electrónicos) para poder tener un diálogo intersubjetivo.

Un usuario puede recurrir a un "sistema experto", a un catálogo en línea o a Internet, pero siempre con la intención de tener acceso a, como la hemos llamado, una información pragmática; esto es, una información del sujeto y para el sujeto, donde las variables que integran el contexto del sujeto tienen gran importancia, aunque en ocasiones ellas pueden estar implícitas y no llegar a ser descubiertas explícitamente, lo que consecuentemente conllevaría a que el sujeto pudiera no ser comprendido, cosa que se lograría sólo después de un diálogo de dos sujetos: el usuario y el profesional de la información.

La función instrumental, que puede ser proporcionada por el elemento tecnológico es muy importante, pero no esencial, el criterio para caracterizar y evaluar la esfera bibliotecológica es el intencional, que lo da la acción del profesional de la información, incluso cuando externamente aparezca una forma tecnológica que presuntamente despersonaliza la actividad bibliotecológica. Sin embargo en todos los casos es necesario el trabajo de un sujeto, lo cual se da antes, durante y posteriormente al accionar el instrumento tecnológico. Es necesario un trabajo anterior porque el sistema experto ha sido "capacitado" por sujetos expertos, y las bases de datos, las posibles conexiones, etcétera han sido programadas por sujetos con base en

90 No sólo como práctico el profesional de la información antes que profesional es un científico de la información, sólo gracias a ello puede ser un profesional. 
las necesidades del sujeto; asimismo es indispensable un trabajo simultáneo al accionar tecnológico porque el profesional de la información está junto a la máquina para resolver problemas de los usuarios y controlar posibles fallas y, finalmente, se da un trabajo del sujeto posterior al accionar el objeto tecnológico porque se debe realizar la evaluación del servicio prestado.

Por lo anterior, en primer lugar podemos afirmar que el profesional de la información es un agente activo dentro del circuito de la comunicación social. Precisamente es el profesional de la información quien con su actividad hace posible las condiciones para desobjetivar la palabra interna convertida en símbolo; es decir, es él quien abre las puertas del mundo de la información: si deja de hacer eso, deja de ser profesional de la información.

La activa influencia en la comunicación social la podemos constatar en cuanto que con su acción el profesional de la información puede permitir y estimular o entorpecer y deformar la comunicación social dependiendo de que cumpla o no con su función de proporcionar las condiciones necesarias para que su usuario se introduzca en el mundo de la información y dialogue con los textos y sus autores.

En segundo lugar, el profesional de la información es un colega dentro de la construcción del conocimiento científico. Como es sabido, una de las características propias del conocimiento científico es que los resultados obtenidos se hacen del dominio de la comunidad científica. Los profesionales de la información, sin ser miembros de la comunidad epistémica de la ciencia particular en que laboran, participan en la vida de ella porque coadyuvan a su existencia, con su actividad permiten que los científicos puedan disponer de una de las herramientas indispensables para su trabajo: la información que los conduce al conocimiento de otros sujetos y a elaborar el suyo propio.

Ahora bien, proporcionarle herramientas al científico es, al mismo tiempo, involucrarse como científico en su área de conocimiento: el fenómeno informativo documental, ${ }^{91}$ en la construcción del edificio de la ciencia; y por lo tanto, la relación, al hacer ciencia, se da entre científicos, es decir, entre colegas.

91 No sólo como práctico el profesional de la información antes que profesional es un científico de la información, sólo gracias a ello puede ser un profesional. 
De esta manera el profesional de la información no es un sirviente o un miembro inferior del sistema informativo documental que no tiene igualdad de derechos con los otros elementos del sistema. Tal profesional debe tener disposición y disponibilidad para atender a los usuarios que pueden ser de diversos tipos y no sólo científicos, pero esto no debe llevar a una desigualdad en la división del trabajo: unos son los trabajadores intelectuales, los que toman decisiones, y otros son los trabajadores manuales, los subordinados. Asimismo satisfacer las necesidades de información no implica satisfacer todos los deseos y hasta caprichos de los usuarios, sino sólo ayudarlos en cuanto usuarios; es decir, seres humanos con necesidades de información.

El hecho de "satisfacer necesidades de información de sujetos" es una afirmación neutra que señala no una jerarquización entre elementos sino una especialización en los elementos del sistema social, el cual, como verdadero sistema, implica no la subordinación entre sus elementos sino su interdependencia. Aún más, los sujetos que supuestamente están para ser servidos sólo están en posibilidad de cumplir con su función dentro del sistema si reciben la ayuda esperada, de lo contrario no podrán hacerlo.

Por otro lado, concebir como inferior al profesional de la información también sería criticable, pues si la bibliotecología propone y aporta los elementos para el diálogo, entonces no es posible que el profesional de la información se encuentre en un nivel inferior que su interlocutor, puesto que en ese caso, el diálogo, causa teleológica de todo el accionar, no se llevaría a cabo, ya que si uno de los interlocutores se ve como un instrumento, se pierde como sujeto y por lo tanto el diálogo no tendría lugar. (Faltaría uno de los dialogantes y se convertiría en un monólogo de dominio).

Por último, del mismo modo en que una institución informativa documental no es por esencia una empresa o institución educativa, el profesional de la información no es un comerciante de la información ni un educador. Puede llegar a serlo, pero eso no es una característica sine quan non para ser un profesional de la información. 
Fundamentación filosófica

Gnoseología 

espués de haber analizado los principales elementos del aparato conceptual de la teoría bibliotecológica y de haber realizado el análisis de las bases ontológicas de esa disciplina, nos dispondremos a retomar la fundamentación filosófica pero ahora desde el punto de vista gnoseológico; es decir, se abordará la problemática del objeto de estudio de la disciplina y la especificidad de dicho estudio, así como la relación y diferencia con otras disciplinas afines. Para cumplir con esta tarea proponemos que la investigación bibliotecológica se realice desde una nueva perspectiva. Nuestro objetivo es demostrar que el enfoque tradicional se ha visto superado por la evolución de los objetos con los que tenía que ver la bibliotecología, pero eso no significa su total abandono, sino el que se tenga una nueva visión más abstracta que se adapte y explique los cambios sin renunciar definitivamente al pasado y sin abandonarse a la tecnología o a la mercadotecnia.

Sin embargo adoptar esa nueva perspectiva no es un rompimiento paradigmático total tomado en el sentido kuhniano, sino la profundización y precisión de lo que Lakatos ha llamado núcleo central por un lado, y en la aceptación de nuevos elementos y visiones (teorías) en el cinturón protector, por el otro. Esta nueva perspectiva metateórica nos permitirá distinguir la identidad propia de la ciencia bibliotecológica como sistema de conocimientos y diferenciarla con otras áreas del saber, pero ya no desde una amorfa situación en donde por tener unos límites indeterminados se invadan terrenos propios de otras disciplinas o se sea invadido por ellas, sino desde la plena conciencia de su ser único e individual, y al mismo tiempo intentará tender un nexo entre la innovación y la tradición. 


\section{HACIA LA PRECISIÓN DEL NÚCLEO DURO DEL PROGRAMA DE INVESTIGACIÓN CIENTÍFICA EN BIBLIOTECOLOGÍA}

A finales del siglo pasado y principios de éste, los físicos se enfrentaron a una revolución en su ciencia. Se habían acostumbrado a tratar con un objeto de estudio estable e intuitivamente comprensible: la materia y su movimiento. La materia tenía ciertas características constantes, entre las cuales se contaba principalmente su masa, además de la impenetrabilidad, la localización espacio-temporal en tres dimensiones, etcétera. Pero en un momento de su desarrollo se encontraron fenómenos que no respondían a esa concepción tradicional de la materia; más aún, que estaban en contradicción con ella. La materia se les disipaba de las manos y se perdía en un modelo matemático, lo que llevó a expresar que "la materia desaparece y lo que queda son las ecuaciones". Realmente si se les pide a los físicos que nos digan qué es energía, entropía, fuerza, etcétera, se limitarán a darnos ciertas fórmulas matemáticas.

Actualmente en bibliotecología sucede un fenómeno semejante, el objeto tradicional de la disciplina: el libro y la biblioteca, se escabulle, se transforma y se desplaza hacia otros fenómenos (documentos, bases de datos, redes, centros de documentación, bibliotecas electrónicas) que distan mucho de ser semejantes a lo que se venía manejando. Incluso en ocasiones se llega a hablar de un espacio cibernético y una realidad virtual, los cuales realmente son intangibles. Los profesionales de la bibliotecología están en desventaja con los físicos porque a ellos no les quedan ni siquiera ecuaciones con las cuales trabajar. Por lo anterior se hace necesario replantear la visión teórica con la cual enfrentar los cambios producidos en la disciplina, y poder abarcar y explicar esa nueva problemática.

Algunos han querido seguir el ejemplo de la física y refugiarse en modelos matemáticos, sobre todo por existir una teoría que ofrece ese refugio. ¿Pero es ése el camino? ¿Se le debe dejar el camino a la disciplina de las computadoras basada en la teoría matemática de la información, o en la lógica clásica formal y la electrónica? Algunos otros para salir de esa situación han optado por tratar a la información como mercancía e intentan convertir a la disciplina en una servidora de intereses comerciales en las que el Marketing es el núcleo sobre el cual gira la disciplina.

Al examinar las obras que analizan el problema gnoseológico que nos ocupa en este momento, observamos una línea de teóricos entre los cuales 
existe consenso al expresar que el objeto de estudio de la bibliotecología gira en torno de la información, ${ }^{1}$ por lo que la cuestión ahora es explicitar cómo el concepto de información, expuesto en párrafos anteriores, ayuda a comprender el contenido del concepto de bibliotecología como teoría. Para lograr una mejor exposición confrontaremos nuestra noción de información con otros posibles enfoques, y explicaremos en qué forma nuestro concepto de información se inserta en esa nueva perspectiva teórica de la bibliotecología.

Para el análisis que realizaremos partiremos de un enfoque semiótico. Si tomamos en cuenta que en la concepción clásica de la semiología los elementos básicos de un sistema semiótico es la tríada signo, significado y sujeto, y de acuerdo con esto las ramas de la semiótica son la sintaxis, que estudia la relación de los signos entre sí; la semántica, que estudia la relación del signo con el significado; y la pragmática que estudia la relación entre el signo y el usuario, entonces podemos decir que es posible la existencia de una teoría sintáctica de la información, de una teoría semántica de la información y de una teoría pragmática de la información.

Consideramos que la teoría sintáctica de la información está desarrollada en la Teoría Matemática de la Información de Shannon y Weaver, además de que existe la Teoría Semántica de la Información creada por Bar-Hillel y Carnap. Sin embargo, según nuestro punto de vista, esas dos teorías no son aptas para ser el eje sobre el que se debe mover la bibliotecología, por lo que propongo un enfoque pragmático de la información (en el sentido semiótico), que aunque aún no tiene el grado de teoría, sí nos puede ayudar para explicar las tareas que cumple la bibliotecología. Expondremos brevemente

1 Así por ejemplo, encontramos los siguientes enunciados representativos de lo que sucede en el campo teórico de la bibliotecología: "La Bibliotecología es la ciencia que estudia el registro, y flujo del conocimiento y de la información; así como de la circulación social de los medios que la contienen para hacer posible su uso y su organización”, Lafuente López, Ramiro y Estela Morales Campos. Reflexiones en torno a la enseñanza de la bibliotecología, en Investigación bibliotecológica. V. 6. N 12, p. 25-33. México: UNAM, CUIB, 1992. p. 25.

“[...]la materia prima de la bibliotecología es la información”. Calva González, Juan José, Una aproximación a lo que son las necesidades de información, en Investigación bibliotecológica. V. 5. No 11, p. 33-38. México: UNAM, CUIB, 1991. p. 33.

"De la Bibliotecología al sistema de conocimientos científicos bibliológico-informativo." Setién Quezada, Emilio y Salvador Gorbea Portal, en Investigación bibliotecológica. V. 8. No 16, p. 21-25. México: UNAM, CUIB, 1994. p. 21. 
las dos primeras teorías y expresaremos las causas de sus limitaciones para explicar lo que es la información en bibliotecología.

\section{TEORÍA SINTÁCTICA DE LA INFORMACIÓN}

Como ya indicamos, en concordancia con lo que se entiende por sintaxis y con la tesis central de la Teoría Matemática de la Información, es posible afirmar que la primera, la teoría sintáctica de la información, ya está desarrollada con la Teoría Matemática de la Información de C. E. Shannon y W. Weaver ${ }^{2}$ y el concepto de información que en ella se maneja es una información sintáctica.

En efecto, si la sintaxis se abstrae de todo contenido semántico y centra su atención sólo en cómo se forman y transforman los signos, y si de manera semejante la Teoría Matemática de la Información toma en cuenta únicamente las señales independientemente de todo significado, entonces es válido interpretar dicha teoría como una teoría a nivel sintáctico. Cabe mencionar que dicha semejanza entre sintaxis y Teoría Matemática de la Información ha sido señalado por U. Eco. ${ }^{3}$

La teoría matemática de la información nació dentro del campo de la ingeniería y tecnología de la comunicación, y se le reconoce como uno de sus principales aportes el haber proporcionado la característica cuantitativa del concepto de información. Sobre este respecto Rapoport indica que "la noción de la cantidad de información es una Gran Idea (sic) en la ciencia, similar a la definición de "cantidad de materia"... "cantidad de energía"... o "cantidad de entropía". 4

C. E. Shannon y W. Weaver generalizaron los aportes de investigadores anteriores y proporcionaron nuevas ideas para redondear lo que actualmente se conoce como Teoría Matemática de la Información. Ellos han subrayado que la cantidad de información en el mensaje no es lo que se está diciendo, sino lo que se podría decir; esto es, que la cantidad de información se considera independientemente de todo contenido semántico y se define

2 Shannon, C. E. y W. Weaver. The Mathematical Theory of Communication. Urbana, University press, 1962.

3 Eco, U. Tratado de Semiótica General. España: Lumen, 1988. p. 78.

4 Rapaport, A. "What is information?" en Introduction to information science. Comp. y ed. by Saracevic Tekfo. New York \& London: Bowker Company, 1970. pp.5-12. 
estadísticamente de acuerdo con el número de mensajes en el repertorio de la fuente con base en la cantidad de señales de las que dispone. La cantidad de información de un mensaje transmitido de un sistema emisor a un sistema receptor es función de su improbabilidad de que ocurra el mensaje.

Ya es quizá de todos conocida la fórmula para calcular la cantidad de información. Si se tiene una fuente que dispone de $n$ signos, no necesariamente equiprobables, entonces la cantidad de información $H$ de esta fuente se obtiene de acuerdo con la siguiente relación:

$H=-P(1) \log (P(1))-P(2) \log (P(2))-\ldots-P(n) \log (P(n))$, donde $P(i)$ es la probabilidad de aparición de la señal $i$, es decir, $H=-\sum_{i=1}^{n} P(i) \log (P(i))$.

En el caso de que una fuente disponga de $n$ signos equiprobables la fórmula de Shannon puede tomar la siguiente expresión:

$$
H=-\sum_{i=1}^{n} P(i) \log (P(i))=-n\left(\frac{1}{n} \log \left(\frac{1}{n}\right)\right)=-\log \left(\frac{1}{n}\right) .
$$

La Teoría Matemática de la Información está directamente en conexión con el uso de máquinas debido a que, como ya se indicó, surge dentro del campo de la tecnología de las comunicaciones, y según Escarpit ${ }^{5}$ conlleva a un esquema mecanicista de la comunicación en el que el canal ocupa un lugar primordial. Escarpit propone representar gráficamente ese esquema de la siguiente manera:

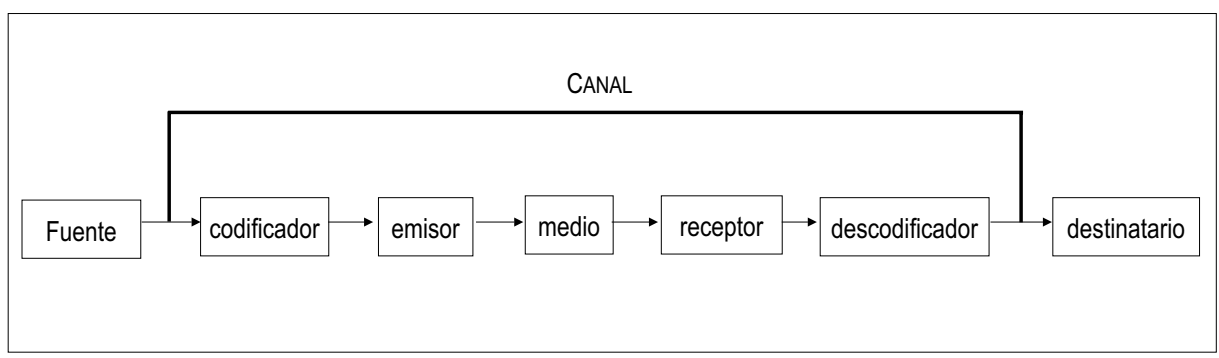

5 Escarpit, R. Teoría general de la información y de la comunicación. Barcelona: Icaria, 1981. p. 34. 
En la actualidad, con la automatización de los servicios bibliotecarios, se hace mucho énfasis en esta teoría de la información. Podemos reconocer que ciertamente significó una gran aportación para la explicación y control de todo lo que hay de físico en ese proceso de transmisión, o más bien dicho de manejo sintáctico, de la información. En la ingeniería de la telecomunicación el significante (signo) es muy importante y se busca que posea ciertas cualidades, tales como resistencia al ruido, facilidad de codificación y descodificación, velocidad de transmisión; el significado en sí, no les interesa a los ingenieros sino en la medida que pueda influir sobre el significante.

Al crecer la influencia de esta teoría se replantea el papel de las máquinas y del hombre en la actividad informativa. En ocasiones se afirma que la computadora no sólo es portadora de información sino también creadora de nueva información, por lo que se la identifica como una máquina inteligente, que de esta manera libera (¿desplaza?) al hombre de ciertas actividades, para que éste se dedique a otras superiores.

La explicación que se da es sencilla y coherente: la máquina tiene unos datos en su memoria electrónica y un(os) algoritmo(s) que le permite(n) trabajar con esos datos; con esos dos elementos puede reestructurar los datos y presentarlos de una forma diferente, proceso que en realidad se puede tomar como creación de una nueva información. (Tal vez a una persona jamás se le hubiera "ocurrido" estructurar de tal manera los datos con que contaba).

Tal parece que el bibliotecario se convirtiera en un empleado que no es responsable ni a quien le interesan las intenciones del emisor y del destinatario, y que circunscribe su papel al de un simple intermediario pasivo entre los autores y sus lectores.

El problema es claro y de acuerdo con el tratamiento que le demos al concepto de información será la respuesta a la interrogante planteada. Si aceptamos el enfoque semiótico del estudio de la información, aceptaremos que el producto que nos ofrece la máquina es una información sintáctica. En efecto, lo único que hace la máquina es "jugar”, manipular, combinar los signos que tiene a su disposición de acuerdo con ciertas reglas que se le han dado. Por lo tanto, el proceso que tiene lugar en la máquina es un proceso sintáctico (emplea solamente signos y reglas de formación y transformación de palabras con esos signos) y consecuentemente el producto de ese proceso también es sintáctico. Si a eso se le desea llamar información y a la 
actividad que lo produjo se le califica como intelectual, será, para evitar equívocos, con las limitantes aquí expresadas.

Ahora bien, esto es importante para el tecnólogo, pero no se debe olvidar que el canal y los signos no lo son todo, la información que nos interesa gira en torno del hombre y sus intenciones, intereses y motivaciones, por lo que se deben de tomar en cuenta estos elementos para desarrollar una teoría de la información más completa, apta para ser utilizada por la bibliotecología.

Asimismo no se debe olvidar el hecho de que la Teoría Matemática de la Información fue creada para una determinada área de la tecnología, por lo que importar unos conceptos y teorías de un campo de conocimiento a otro exige no perder de vista el por qué y para qué se hizo esta importación. Puede ser útil para nuestros objetivos, pero si se abusa de ello es posible que los resultados no sean tan positivos como se esperaba. Por ejemplo, un biólogo, al tratar de determinar la cantidad de energía requerida por un organismo para realizar cierta actividad no va a utilizar la fórmula y unidades de medida que ofrece la física, él hablará de calorías y no de newtones o joulons.

\section{Teoría semántica de la información}

Debido a que la Teoría Matemática de la Información no tiene en cuenta el contenido de los símbolos sino únicamente la frecuencia con que éstos puedan ocurrir, y que en ocasiones se aplican estos resultados y terminología a campos en los cuales el término información tiene un sentido semántico, se hizo necesario desarrollar una Teoría Semántica de la Información. R. Carnap y Y. Bar-Hillel crearon dicha teoría con base en el sistema de lógica inductiva de probabilidades propuesto por Carnap. ${ }^{6}$

En virtud de que dicha teoría es conocida sólo daremos un breve resumen para después expresar nuestra posición. El sistema en el que se trabaja puede ser la lógica proposicional. La idea central es que en ese sistema, a cualquier fórmula $Q$, formada por un número n de proposiciones atómicas, se le puede asociar un conjunto de disyunciones de todas esas proposiciones atómicas o sus negaciones; con la condición de que en cada disyunción ocurra cada proposición atómica o su negación, pero no las dos al mismo tiempo. Así, a la fórmula $Q$ formada por una sola proposición atómica $p$ se le asocia

6 Bar-Hillel, Y. y R. Carnap. "Semantic Information”, en Introduction to Information Science. Compiled and edited by Tekfo Saracevic. New York, 1970. p. 18-23. 
el conjunto de dos disyunciones (cada una con un disyunto) $\{p, \neg p\}$; si la fórmula $Q$ tiene dos proposiciones atómicas, $p$ y $q$, entonces el conjunto de disyunciones estará formado por cuatro elementos, por ejemplo si $Q$ es $p \& q$, sus disyunciones serán: $\{\mathrm{p} \vee \mathrm{q}, \mathrm{p} \vee \neg \mathrm{q}, \neg \mathrm{p} \vee \mathrm{q}, \neg \mathrm{p} \vee \neg \mathrm{q}\}$. La fórmula para encontrar el número de disyunciones de una expresión es $2^{n}$, donde $n$ es el número de proposiciones atómicas. De esta manera, la fórmula $((p \& q) \vee \neg r)$ $\supset(s \& t)$, donde ocurren 5 proposiciones atómicas tendrá 32 disyunciones y uno de sus posibles disyunciones será: $\{p \vee q \vee r \vee \neg s \vee \neg t)$.

A cada disyunción se le va a denominar elemento de contenido. A la clase de todos los elementos de contenido que una proposición $Q$ lógicamente implica, se le llamará CONTENIDO de $Q$ y se le simbolizará como Cont. (Q). Desde el punto de vista de la lógica se puede demostrar que cualquier proposición atómica tiene como contenido la mitad de todos los elementos de contenido, una tautología ninguno y una contradicción todos.

Carnap propone el concepto de "contenido de Q" Cont.(Q) como explicatum del término "información de la proposición Q" desde un punto de vista semántico. Existe una relación entre Cont.(Q) y la clase de las negaciones de los estados de cosas contenidas en el valor de $\neg Q$, por lo que las propiedades de $\operatorname{Cont}(Q)$ pueden ser derivadas del concepto de probabilidad de $\neg Q$.

Por otro lado, señalan los autores que no sólo es importante saber qué es la información contenida en una proposición, sino que también se debe de poder medir la cantidad de esa información. Se propone la siguiente igualdad $\operatorname{Cont}(Q)=\operatorname{Prob} .(\neg Q)$ y teniendo en cuenta el teorema del complemento, se obtiene: Prob. $(\neg Q)=1-\operatorname{Prob} .(Q)$, por lo que resulta que la cantidad de información fluctúa entre 0 y 1: $0<$ Cont. $(Q)<1$. Si $Q$ es tautología entonces Cont. $(Q)=0$ y si $Q$ es contradicción, Cont. $(Q)=1$.

Posteriormente Bar-Hillel y Carnap ofrecen una segunda noción cuantitativa de la información, la cual puede calcularse con la siguiente igualdad: ${ }^{7}$

$$
\text { Infor. }(Q)=\log \left(\frac{1}{\operatorname{Prob} .(Q)}\right)=-\log (\operatorname{Prob} .(Q))
$$

7 Es interesante hacer notar la semejanza de esta fórmula con la obtenida por la teoría matemática de la información. 
La Teoría Semántica de la Información está formalizada y en ella se pueden demostrar ciertos teoremas que en su esencia convergen con la Teoría Matemática de la Información y con principios de la lógica formal clásica; pero precisamente este hecho la hace alejarse de lo que "nuestro sentido común" está acostumbrado a ver como evidente. Tal vez esto no sea una desventaja sino la confirmación de su cientificidad, ya que la ciencia, como se sabe, tiene como objetivo ir más allá de la explicación que da el sentido común. Quizá es más evidente que el sol gira alrededor de la tierra o que la distancia más corta entre dos puntos es una línea recta, pero la ciencia nos explica que el caso es lo contrario a lo que a primera vista se percibe como evidente. ¿Es éste el caso? Parece no ser así, puesto que muchos lógicos se han preocupado no por explicar por qué lo más evidente no es la explicación que la ciencia toma, sino buscar que la ciencia se adecue a lo evidente. ${ }^{8}$

En el plano de la cantidad de la información se dice que una tautología no tiene información y que una contradicción contiene toda la información posible. Pero esto es consecuencia de tomar como base para la Teoría Semántica de la Información a la Lógica Clásica. Parece claro, cuando se habla de tautologías, decir que "o el enemigo atacará al amanecer o no atacará al amanecer", es no decir nada (este enunciado es una sustitución de la ley del tercero excluido), pero ya no es tan evidente decir que las contradicciones contienen toda la información. ${ }^{9}$

Por ejemplo, parece obvio que una disertación doctoral contiene más información que un artículo sobre el mismo tema. Ahora bien, supongamos que el artículo contiene un error que lleva a una contradicción ¿podemos decir por esto que el artículo contiene toda la información sobre el tema? ¿Un bibliotecario que quiere dar un mejor servicio tiene que recomendar ese artículo con contradicciones en lugar de la disertación?10

8 De esta manera han surgido distintos sistemas lógicos: relevante, intuicionista, no-monotónica, etcétera.

9 Incluso resulta chocante al sentido común aceptar que si una tautología carece de información entonces ¿por qué se le paga un salario a un profesor de lógica que enseña tautologías? ¿se le debe pagar aunque no esté transmitiendo información?

10 La respuesta a esta última pregunta es abierta, depende de lo que el usuario desee saber. Para alguno la contradicción no tendrá valor y deseará conocer la versión más completa y acabada del tema; para otro será importante conocer la contradicción para encontrar otra solución, para descubrir su origen, para realizar una crítica, etcétera. 
Por otro lado, la Teoría Semántica de la Información aunque sí toma en cuenta el significado de los enunciados, interpreta ese significado de una manera extensional, debido a que se basa en la Lógica Clásica; es decir, el significado de las proposiciones son dos objetos abstractos: la verdad y lo falso, y se deja también a un lado el sentido de los enunciados, el contexto y la intencionalidad del sujeto. Por lo que a nuestro juicio también se pierde gran parte de la riqueza del mundo de la información.

Si se desea determinar el sentido de los enunciados es preciso incluir al sujeto que enuncia esas proposiciones, ya que el sentido de los enunciados depende de la intencionalidad del sujeto y su contexto, pero entonces nos encontramos ya en otro campo que es el de la pragmática.

\section{Enfoque pragmático de la información}

De acuerdo con nuestro punto de vista, la información es una cualidad secundaria de los objetos que es elaborada por los sujetos a partir de la estructuración de propiedades presentes en esos objetos. Las estructuras utilizadas por el sujeto para interpretar esas propiedades objetivas se encuentran condicionadas por el desarrollo psicogenético del individuo y por su contexto socio-histórico-cultural. Como resultado de esa estructuración se crea un ente ideal que se objetiva y llega a formar el mundo de la información. Una vez más deseamos resaltar el hecho de que el mundo de la información se construye, no se crea (inventa) ni se descubre; esto es, no es una creación ex nihilo, sino que para su elaboración se toma cierta materia prima: propiedades presentes en las cosas; pero tampoco se descubre como un ente objetivo per se, porque no es algo que exista ya hecho: es necesaria la acción del sujeto para su aparición. Un documento no contiene información como una bolsa de naranjas; el sujeto no tiene más que enfrentarse a las naranjas para verlas e irlas sacando de la bolsa; pero en el documento no es así, la información surge únicamente cuando el sujeto a través de ese documento llega al mundo de la información; ese paso del símbolo a la información es una actividad que se realiza y se repite cada vez que se lleva a cabo la estructuración de datos por diferentes sujetos o por el mismo sujeto. Si no se conocen las reglas de estructuración para que esos símbolos nos conduzcan al mundo de la información, el documento puede estar ahí enfrente de nosotros y no decir nada. El hombre se conecta a ese mundo también a través de 
objetos sensibles, pero a la bibliotecología le interesan ciertos objetos específicos, creados especialmente para conectar al mundo de la información: los signos lingüísticos articulados.

Según nuestra opinión lo importante en esta visión de la información consiste en el rol que juega el sujeto para crear y conectarse al mundo de la información; en este enfoque se salva lo que hemos venido subrayando: el contexto del sujeto, lo que Gadamer llama pre-juicios para la comprensión, y todo el acervo cultural, psicológico, social, etcétera que influyen en la dialéctica del sujeto con el mundo de la información.

¿Qué nos proporciona este enfoque de la información? Consideramos que lo esencial es el camino para precisar el núcleo duro del programa de investigación científica en la disciplina. Parece aventurado hablar de un ente ideal, que no existe realmente en nuestro mundo y quién sabe en donde está, pero precisamente esto nos permite abandonar una ontología de "primer nivel", donde se está acostumbrado a trabajar con objetos concretos, tangibles, individuales. ${ }^{11}$ Debido a ese pobre nivel de abstracción, cuando el libro material o la biblioteca material le dejan paso a entes más abstractos, se percibe un sentimiento de inquietud, "la materia desaparece y no nos quedan ni siquiera ecuaciones". Pero eso no sucede si nos "mudamos" a una ontología superior, donde habiten entes abstractos ideales y generales; por supuesto éste no será el lugar donde estarán cómodos administradores de libros y técnicos.

La información como ente ideal no desaparece y es esto lo que se debe de tener presente. Por ejemplo ¿cuál es el problema de la catalogación y clasificación? Es un problema de representación, de organización y sistematización, no de libros o de documentos o de bits, sino de contenidos, de información. Pueden variar los sistemas de clasificación y catalogación, puede evolucionar el soporte de los documentos, pueden transformarse los canales de comunicación entre el usuario y la institución informativa, pero siempre el objetivo inicial y final es que el usuario llegue al mundo de la información. Se siente la renuencia a abandonar los sistemas tradicionales de clasificación, se tiene la preocupación de asignarle a cada libro su lugar, 12 pero

11 El punto infinitamente alejado donde se cruzan la líneas paralelas tampoco existe en nuestro mundo.

12 ¿No era a cada libro su lector? es decir, que el lector, con base en el lugar accesible que tiene el libro, pueda adentrarse al mundo de la información que le ofrece el documento. 
el aparente caos de documentos o notaciones no lo es, si es posible recuperar para cada usuario específico la información que demanda.

Asimismo se habla del peligro de crear una torre de Babel si no se unifican los criterios para catalogar y clasificar, por lo que si se sigue la corriente sintáctica se deben unificar los lenguajes y sistemas computacionales. Por supuesto que si nos quedamos en una información sintáctica, el problema de la traducibilidad es enorme, pero si enfocamos esa cuestión desde el ángulo pragmatista defendido por nosotros, ese problema no tiene por qué agobiarnos.

El esquema de comunicación propuesto por nosotros y apoyado en la rama lingüística de la pragmática posibilita la explicación de cómo ocurre la traducibilidad. Nuestro esquema, a diferencia del que Escarpit expone como mecanicista y que es propio de la tecnología de la comunicación, no es lineal entre dos sujetos, sino indirecto a través del mundo de la información, con ayuda de señales. ${ }^{13}$

El signo, que es tal por una convención, tiene como significado directo al mundo de la información y sólo indirectamente a través de éste al objeto externo. Por otro lado, ese mundo de la información denota directamente a los objetos externos y lo hace de una manera natural, no convencional. Podríamos imaginar un lenguaje en el que la serie de signos 'feo' significara exactamente lo que en español significa 'bonito'; éstas son meramente convenciones circunstanciales. Pero es claro que podríamos traducir de un lenguaje a otro, porque contamos con un criterio objetivo natural (aunque ideal) que es el mundo de la información. La descodificación de los signos se realiza con base en los nexos de ese signo con su denotatum en lenguaje fregeano tomando en cuenta el sentido de los signos; en nuestra terminología, con base en el mundo de la información. Es así como se realizan en sí todas las traducciones de un lenguaje a otro y donde las más exactas tratan de recuperar el contexto e intenciones del autor para no traicionar el pensamiento de este último. De manera semejante, si un documento en cierto sistema de clasificación se representa de determinada manera y otro sistema cambia la notación, no debe haber gran problema si es que ambas simbologías nos dan el referente ideal semejante; incluso su ubicación topográfica puede variar en

13 El esquema de comunicación que proponemos se encuentra en el apartado en donde hablamos sobre el concepto de información. 
una misma biblioteca, pero el contenido, la información, siguen estando al alcance de quien los requiera.

Por otro lado la presente visión de la información nos permite identificar el tipo de información que requieren los usuarios, la cual no es una necesidad de información sintáctica que pueda ser satisfecha por una computadora con una gran potencia en bits, sino necesidades de información pragmática donde el símbolo tiene significado para el sujeto, y las cuales tienen que ser satisfechas precisamente con información pragmática. 14

Asimismo este enfoque nos ayuda a comprender la diferencia entre la actividad de una máquina y la de un hombre. Un signo, usando la terminología medieval o la fenomenológica contemporánea, representa intenciones del alma y esa intención le servirá al sujeto para actuar de determinada manera y adentrarse más en el mundo de la información para obtener conocimiento, recreación, o aquello que desee de acuerdo con un fin determinado. Incluso un signo reestructurado que le ofrezca la computadora será un signo digno de interpretarse o reinterpretarse según su postura intelectiva. La máquina no puede realizar esta actividad teleológica debido a su naturaleza sintáctica.

La bibliotecología no puede ignorar este hecho, debe coadyuvar en esos haceres los cuales pueden ser: la investigación científica; el aprendizaje; la realización de una actividad práctica teórica, estética o recreativa; y la toma de decisión en la esfera política, económica, administrativa o incluso en la vida cotidiana. Según ese hacer (intencionalidad) será el mundo posible que determine el mundo de la información en el que el sujeto se "aventure".

\section{LA CIENCIA BIBLIOTECOLÓGICA}

Con ayuda de este enfoque y con base en qué parte del mundo de la información se estudie, en los datos que se utilicen para conectarse a ese mundo, y en la finalidad que se persiga al conectar al hombre con ese mundo, será posible diferenciar las distintas disciplinas que estudian el mundo de la información.

14 Si existe necesidad fisiológica de comida no hay porqué ofrecer agua para satisfacerla, tal vez servirá de algo pero no completamente; y de la misma manera, si se tiene necesidad de información pragmática no hay por que ofrecer información sintáctica. 
Es así como aparecen las Ciencias de la Comunicación, que estudian cómo se conecta el hombre con ese mundo para dárselo a conocer a otros hombres; y el periodismo, que se propone a partir de hechos producir información y crear opinión pública. Y si se utilizan documentos que fueron creados primariamente no para llevarnos al mundo de la información, pero que indirectamente se pueden emplear para eso, como por ejemplo las obras de arte, los utensilios de uso cotidiano o cultural, los objetos naturales (minerales, animales, plantas), entonces tenemos la museología.

Sin embargo cuando el conocimiento se refiere al campo fenoménico de documentos, información, usuarios e institución informativa documental tal como los hemos definido en el apartado anterior, se tiene la disciplina que es el centro de análisis del presente trabajo y que denominamos Ciencia Bibliotecológica o simplemente Bibliotecología (con letra mayúscula, para diferenciarla de otra bibliotecología, disciplina que se inserta dentro de la primera).

El objeto de estudio de esa ciencia general es el SISTEMA INFORMATIVO DOCUMENTAL (SID), el cual aparece por la interrelación de los elementos ya mencionados: documento, institución informativa documental, mundo de la información y usuario.

Podemos representar gráficamente al sistema de información documental de la siguiente manera:

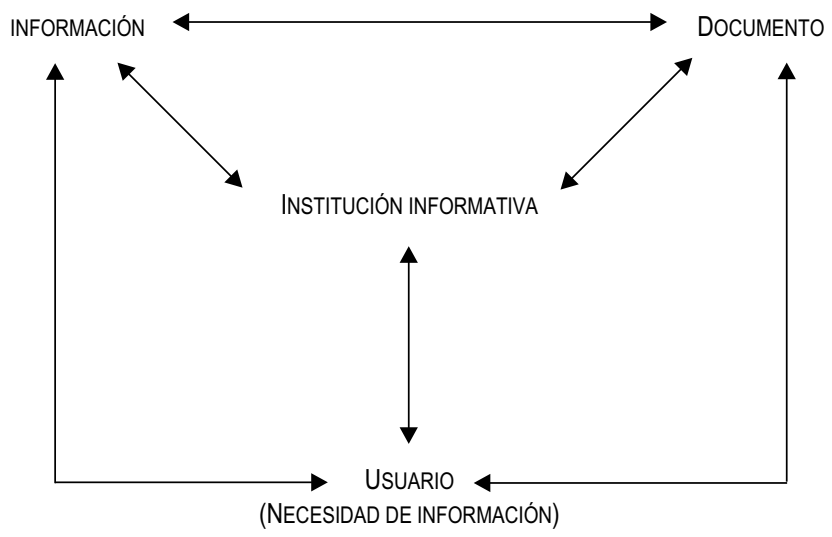


La interacción entre esos elementos es motivada por la finalidad de satisfacer necesidades de información documental del usuario a través del ingreso de éste al mundo de la información mediante los documentos proporcionados gracias a la actividad de la institución informativa documental.

El ciclo de información documental consiste entonces en que un usuario, al tener una necesidad de información, se pone en contacto con la institución informativa documental para obtener un documento que lo conduzca al mundo de la información para satisfacer dicha necesidad. Sin embargo aunque ese ciclo concreto se cierra en ese momento, queda abierta la posibilidad para que continúe el flujo de información, porque por un lado el mismo usuario, al ya tener satisfecha su necesidad de información inicial puede plantearse un nuevo problema porque la información recibida le abre nuevos horizontes teóricos, lo que implicaría que tenga una nueva necesidad de información y el ciclo empezaría una vez más. Al mismo tiempo, por otro lado, ese usuario que obtuvo la información requerida la puede utilizar para crear un nuevo documento, que a su vez puede ser requerido por otro usuario para satisfacer ahora la necesidad de información de este segundo sujeto, lo que origina que dé comienzo un nuevo ciclo informativo. Lo anterior lo podemos representar de la siguiente manera:

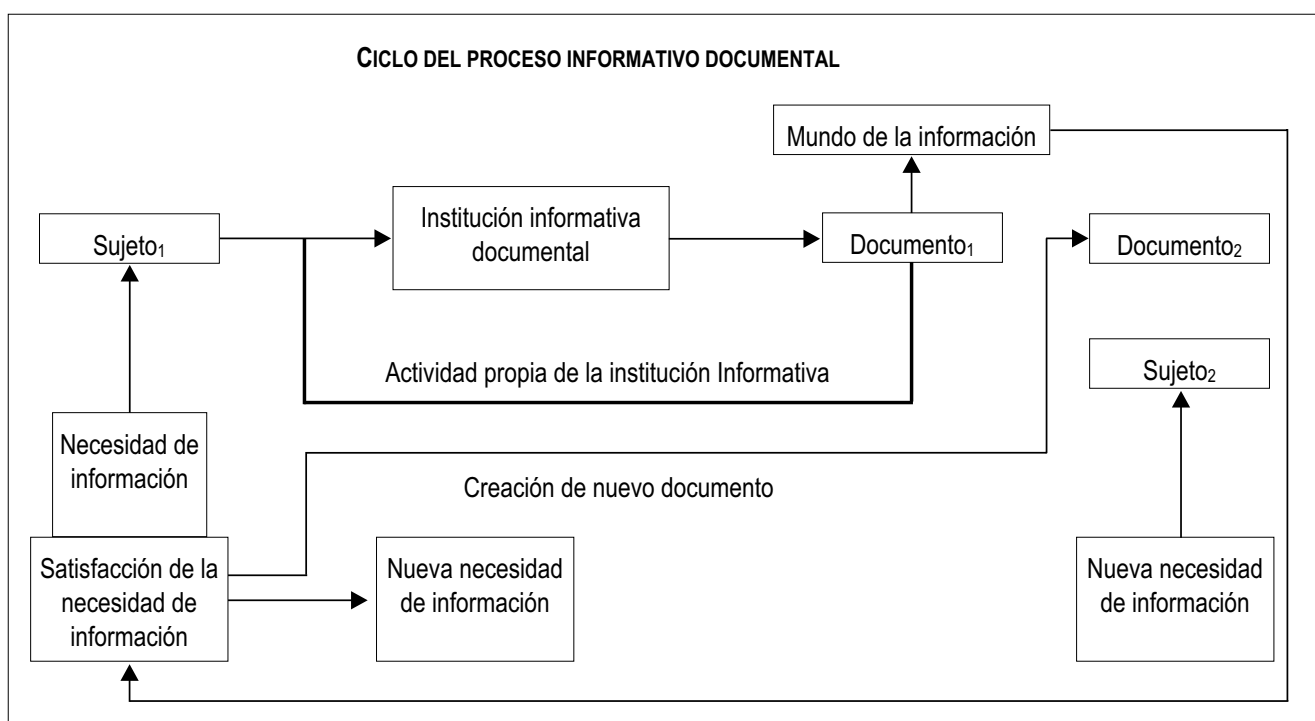


Teniendo presente este objeto de estudio sistémico, que es único, que se aborda desde una perspectiva específica y que no se pierde en el fluir de los procesos sino que es el ámbito donde se llevan a cabo esos procesos, es posible entender y determinar las diferentes áreas que son objeto de atención para la ciencia bibliotecológica. Ésta estudia lo relacionado en primer lugar con el usuario en todo lo referente a ser informacional; en segundo lugar con la institución informativa documental, lo que abarca lo arquitectónico, lo administrativo,el uso de tecnologías, etcétera; en tercero con el documento, lo que tiene que ver con su creación, historia, forma de distribución, incluidos aquí el análisis de su forma y contenido, y también su manipulación técnica, representación, organización, sistematización y difusión; y por último con la información y estudios métricos, flujo, etcétera.

Conocer los elementos y las leyes que rigen la dinámica del SID para que los usuarios, motivados por una necesidad de información, se comuniquen con la "noosfera" a través de los documentos y efectúen las actividades que deben realizarse para que se dé esa comunicación, es, precisamente, la tarea de la ciencia bibliotecológica.

El sistema informativo documental es, como lo hemos indicado, tomando la terminología de Lakatos, "el núcleo central" de la disciplina, ${ }^{15}$ y nos permite, en primer lugar, identificar de una manera clara lo que le da identidad propia a la disciplina, marca sus fronteras, y la diferencia de otros cuerpos de conocimiento; $y$, de esta forma, le permite relacionarse con otras áreas del saber, pero ya no desde una posición indeterminada donde se diluye en otras disciplinas y en nombre de la interdisciplina esconde su falta de especificidad e individualidad como rama del conocimiento autónomo; en segundo lugar nos da la posibilidad de distinguir las disciplinas que se encuentran dentro de esta ciencia; y en tercer lugar nos da la pauta para seguir la evolución histórica de la ciencia bibliotecológica sin perdernos en la pura innovación y el rompimiento, sino descubriendo un eje que pasa por las diferentes etapas y salva, de esta forma, el problema de la tradición.

$15 C f r$. Lakatos, I. "Falsification and the methodology of research programmes", en Criticism and the growth of knowledge. I. Lakatos y A. Musgrave, coomps. Cambridge: Cambridge university press. pp. 91-196. 
A continuación presentamos un esquema que refleja las relaciones interdisciplinarias a partir de un núcleo central dado por el objeto de estudio propio de la disciplina, y desde donde se relaciona con otros sistemas y otros saberes. ${ }^{16}$

\section{SISTEMA DE LAS FORMAS PURAS}

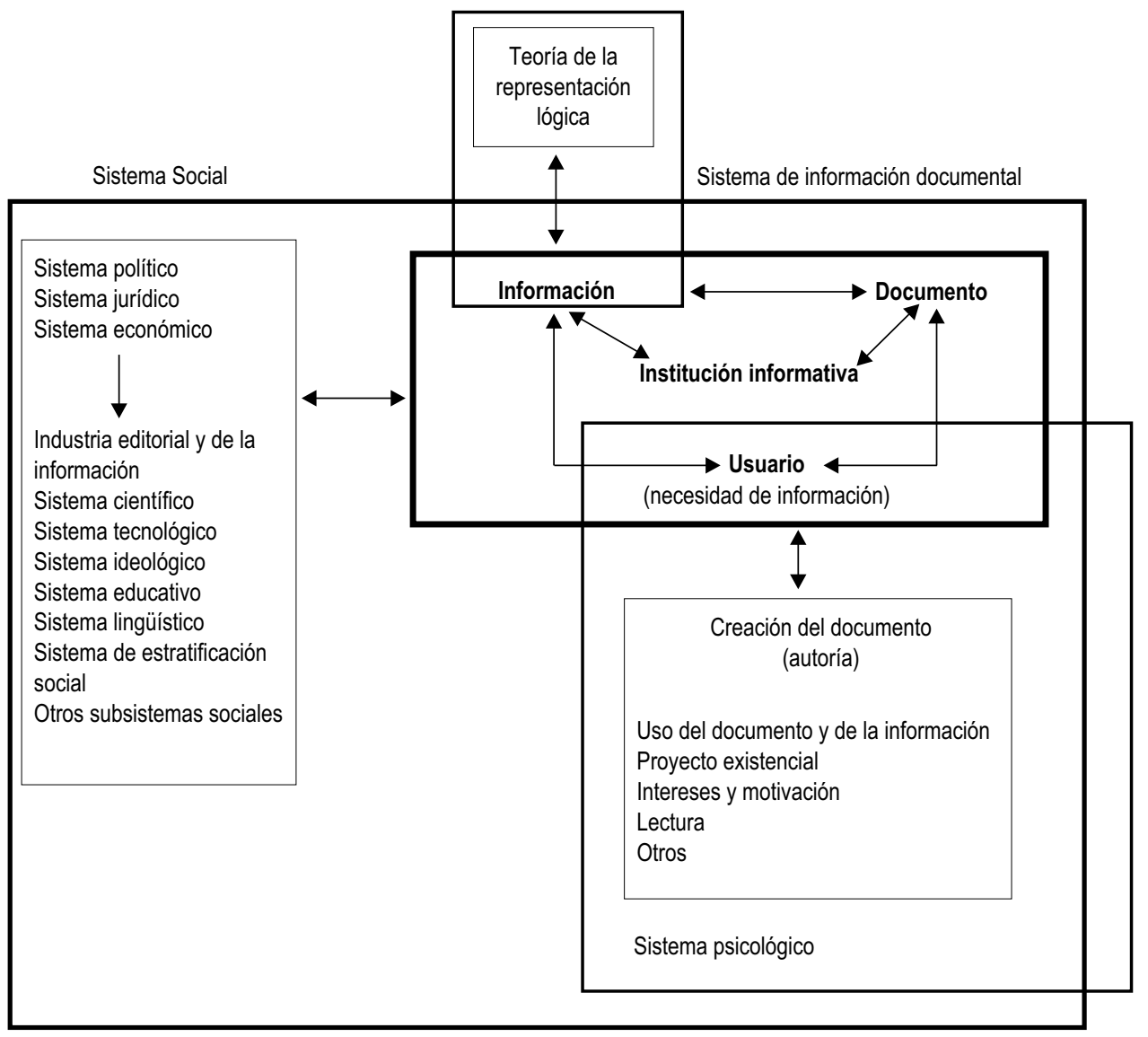

16 Cada sistema o subsistema es estudiado por una teoría particular. 
De esta manera, afirmamos que es importante para la disciplina que estudia el sistema de información documental (SID) investigar el sistema jurídico o político, por ejemplo, pero ya no de una forma per se; no es necesario que el científico del SID sea un experto en derecho o en politología, pero sí tener los conocimientos indispensables en esas esferas que influyen en el sistema de información documental. De igual forma se ha discutido si es importante o no investigar la industria editorial y de la información, la respuesta es obvia, únicamente en cuanto ese sistema económico tiene relación con el sistema que realmente es el centro de interés. La perspectiva de los estudios es claramente desde el sistema central Y NO AL REVÉS, no es la visión tecnológica, por ejemplo, la que le impone sus instrumentos y concepciones al SID, sino que es la exigencia de este último la que le demanda a la tecnología lo que necesita para su funcionamiento.

Lo mismo sucede con las relaciones con el sistema psicológico, ya que al ser un elemento del SID un ser humano, se debe conocer a éste, las necesidades de información que desea satisfacer, cómo se crean los documentos, cómo utiliza la llave para desobjetivar la información objetivada en documentos (lectura), cómo usa los documentos, etcétera, sin que se 1legue a ser un experto psicólogo. Asimismo se relaciona con el sistema, que hemos denominado de las formas puras, en cuanto que el SID necesita para su explicación de relaciones lógicas (sistemas deductivos y de clasificación), de conceptualizaciones y de representaciones de la información, entre otras cosas.

El anterior esquema no sistematiza y no pretende sistematizar todas las interrelaciones de la disciplina que estudia al SID con otros campos del conocimiento, por ejemplo, entre otras falta la relación con la arquitectura y la administración de la institución informativa; con la física, la química y la biología para la conservación de documentos, o con la historia que permite comprender el devenir histórico de los elementos que componen al SID y el del mismo sistema. Lo que se persigue es mostrar el punto desde donde se realizan dichas interrelaciones. Lo que consideramos como una aportación importante de este enfoque es que no se habla de una amalgama de conocimientos que forman una disciplina, sino de una interacción de una unidad con identidad propia que "dialoga" como individuo con otras esferas del saber. 
De ese mismo núcleo central, al analizar los elementos, estructuras y procesos que se encuentran dentro del sistema, emanan los diferentes subsistemas que deben ser estudiados. Un esquema de ellos, y que es más detallado del que proporcionamos inicialmente cuando hablamos del ciclo del proceso informativo documental, es el propuesto por Salvador Gorbea en el seminario para identificar las áreas de investigación dentro del Centro Universitario de Investigaciones Bibliotecológicas de la UNAM y que es el siguiente:

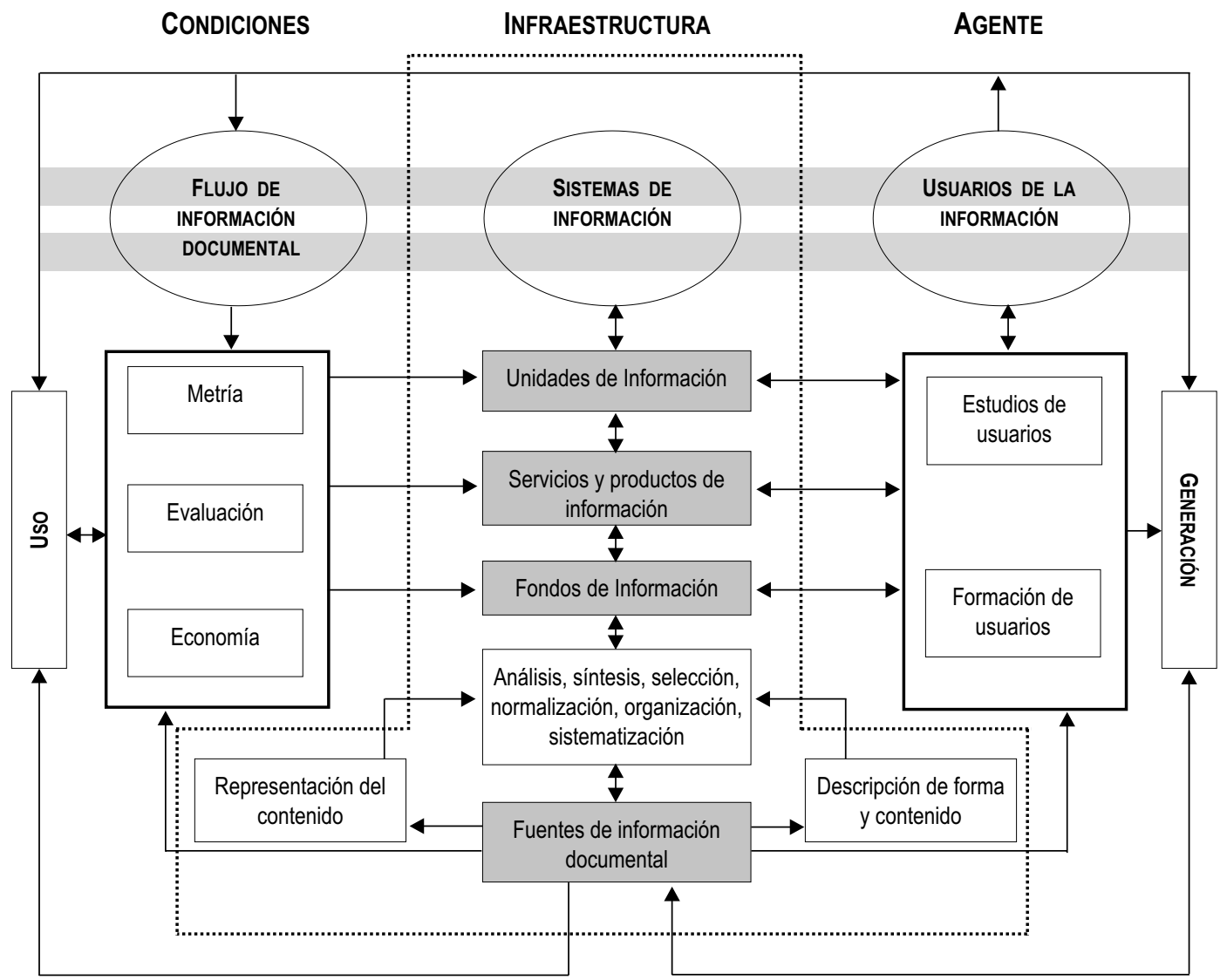


El sentido del anterior esquema consiste en que dentro del SID existe una dinámica cíclica que tiene dos direcciones; por un lado, del agente hacia la generación de la información y por otro, del mismo agente hacia el uso de la información. Podemos afirmar que estos ciclos se encuentran en una dialéctica de unidad en la diversidad y diversidad en la unidad. La generación de la información desemboca en la creación de fuentes de información documental (proceso que a su vez requirió el uso de información); y el uso de información parte de las fuentes de información documental donde terminó el proceso de generación de información (pero a su vez el uso de información en ocasiones conduce a la generación de nuevas fuentes de información documental). Pero para que se dé esa dinámica, es necesario apoyarse en lo que se denomina infraestructura del sistema: a partir de las fuentes de información documental se realiza la representación del contenido y la descripción de la forma y el contenido, para que, con base en estos dos procesos, se lleve a cabo al análisis, síntesis, organización y sistematización de los materiales, lo que permite la creación de los fondos de información y referencia, así como el desarrollo de colecciones, y consecuentemente es posible ofrecer servicios y productos de información en el marco de las unidades de información. Todo esto relacionado, por un lado, por supuesto con el usuario $\mathrm{y}$, por el otro, con las condiciones que permiten (flujo de información), orientan y retroalimentan (metría, evaluación y economía) la dinámica del proceso para hacerlo más humano, eficaz y eficiente. ${ }^{17}$

El nombre de la disciplina que hemos identificado es difícil encontrarlo porque el término escogido puede causar la impresión de que se le da prioridad a uno de los elementos del sistema. Por ejemplo, si optamos por el nombre de documentación, parecería que es el documento el objeto de estudio central, si la llamamos ciencia de la información, se observa un énfasis en el elemento "información", si lo denominamos bibliotecología, parece que se subraya como parte central del estudio la institución informativa documental

17 Las definiciones de algunos términos empleados en este esquema se encuentran en Gorbea Portal, Salvador. "Uso de modelos matemáticos en la evaluación de colecciones: teoría y método", en Primer seminario internacional sobre desarrollo de colecciones. María del Carmen Negrete Gutiérrez, coord. México: UNAM-CUIB, 1998. pp. 83-110; así como en Cruz Paz, Andrés, "En torno a los conceptos documento, fuente y recurso en la ciencia de información", en Ciencias de la información. V. 23. N. 4. La Habana: IDICT, 1992. pp. 267-272. 
y particularmente la biblioteca. Tampoco adoptamos el plural de ciencias de la información documental porque consideramos que no se trata de ciencias, sino de una ciencia con ciertas disciplinas que la componen, como es el caso de la matemática por ejemplo, que incluye a la geometría, la aritmética, el álgebra, la trigonometría, el cálculo, etcétera, y no es el caso que esas disciplinas sean autónomas como la física, la química, la biología, la astronomía o la geología en las ciencias naturales.

La denominación es cuestión de uso pragmático, dejamos a la comunidad epistémica que determine el nombre, lo importante es la cuestión conceptual, ese nombre representa a la ciencia que estudia al sistema de información documental, no sólo a un elemento de él, no sólo a la información, no sólo al usuario, no sólo a la institución informativa, no sólo al documento, sino a la interacción de éstos cuando el usuario requiere satisfacer necesidades de información y lo hace a través de documentos facilitados por una institución informativa documental. A esa disciplina le podemos llamar Bibliotecología (con mayúscula y agregarle la terminación General); le podemos llamar ciencia bibliotecológica y de la información; ciencia de la información, documentación, etcétera, pero lo importante es determinar el referente del término que se elija, cosa que a nuestro juicio es lo que hemos hecho.

Por otra parte, afirmamos que existen disciplinas internas dentro de la ciencia bibliotecológica porque esos elementos generales: información, documento, institución informativa documental y usuario, pueden aparecer con una forma específica diferente en varios contextos, y generar las disciplinas que identificamos siguiendo a Setién. ${ }^{18}$ la ciencia de la información, la archivología, y la bibliotecología.

La primera se centra en el análisis de documentos que conducen a un tipo de usuarios -especialistas- hacia una parte del mundo de la información: la información científica, obtenida con ayuda de métodos de análisis, y gracias a que en el mundo de la información existen relaciones entre sus elementos, puede proporcionar información que no estaba presente en los documentos iniciales, pero que es posible inferir y explicar dentro de una institución informativa documental que en este caso es un centro de información

18 Setién, Emilio. Problema Ramal "Bibliotecas y Promoción informativo cultural" 19911995. p. 34-39, en Bibliotecas, 1992. Revista del Sistema de Bibliotecas Públicas. N. 1/2. Año 30/Ene. Dic. pp. 33-76. 
o de documentación. La archivología trabaja con ciertos documentos -documentos de archivo-, producidos por un sujeto (persona u organización) y dichos documentos llevan a ciertos usuarios, principalmente historiadores, hacia otra parte del mundo de la información que tiene un carácter eminentemente histórico, con la particularidad de que los documentos se encuentran en una institución informativa documental que es el archivo. La bibliotecología, en su acepción especial (con minúscula) se ocupa de estudiar cómo ciertos documentos que aparecen como colecciones bibliotecarias, a través de una institución informativa documental, que es la biblioteca, pueden poner en contacto (accesar) con el mundo de la información a los usuarios que en este caso son lectores.

Precisamente, conocer las leyes que rigen esa comunicación de los lectores con la "noosfera" a través del fondo bibliotecario, motivada tal comunicación por una necesidad de información y las actividades que deben realizarse para que se dé esa relación, es la tarea de la bibliotecología. De esta manera podemos constatar que los cuatro elementos señalados como integrantes del núcleo duro aparecen en las tres disciplinas, pero cada uno de ellos tiene una forma específica según la disciplina de la que se trate. Así por ejemplo se tienen las colecciones bibliotecarias (forma específica de documento), la biblioteca (forma específica de institución informativa), la información a la que conducen dichas colecciones (forma específica de información) y los lectores (forma específica de usuarios), surgiendo de esta manera la bibliotecología en su acepción particular. $\mathrm{O}$ en otros casos esos elementos aparecen como documentos de archivos (manifestación concreta de documento), archivo (manifestación concreta de institución informativa), información a la que conducen esos documentos de archivo (manifestación concreta de información) y usuarios de archivo (manifestación concreta de usuarios), y formar un sistema determinado que estudia la archivística; o pueden manifestarse como documentos elaborados a partir del análisis, resúmenes, etcétera de documentos primarios (otra forma determinada de documento), centros de información o documentación (forma determinada de institución informativa), información científica a la que conducen los documentos mencionados (forma determinada de información) y usuarios específicos como científicos, políticos, empresarios, etcétera (forma determinada de usuarios), e integrar un sistema que es estudiado 
por la ciencia de la información. En estos casos, el núcleo central, el SID, aparece en formas específicas formando sistemas particulares de información documental que son estudiados por disciplinas específicas. Pero esos sistemas continúan teniendo la misma infraestructura y orientándose y apoyándose en las condiciones y en el agente señalados en el segundo esquema, de tal manera que existe un rasgo común entre los sistemas.

Por último, el sistema de información documental históricamente se ha manifestado de distintas formas y presentado distintas apariencias, y si consideramos que "fenómeno" es precisamente lo que aparece, podemos decir que el fenómeno informativo documental ha cambiado y seguirá cambiando, pero que su esencia permanece. ${ }^{19}$ Así, por ejemplo, hubo un momento en que el SID tuvo su forma externa como:

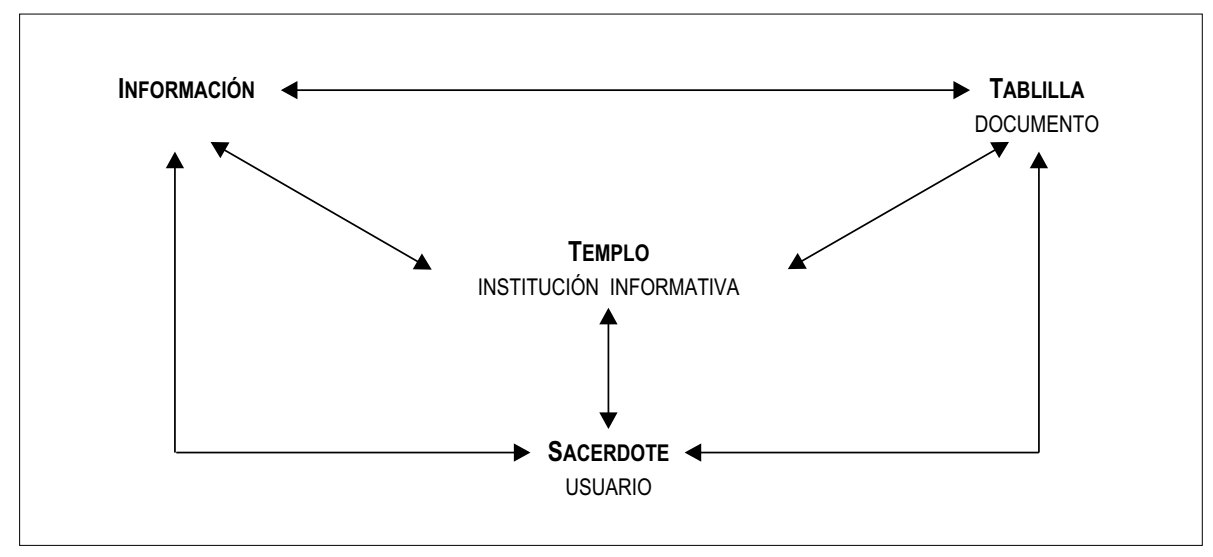

Y por supuesto la estructura de sus subsistemas era mucho más simple que la actual.

Posteriormente el sistema siguió evolucionando, la información se objetivó en diversos materiales y distintas formas, (papiros, pergaminos, libros manuscritos); las instituciones informativas se presentaron como bibliotecas conventuales, eclesiales o de universidades medievales; los usuarios

19 Por ejemplo, la presentación de una realidad que conocemos como agua puede variar, el fenómeno que aparece ante nosotros puede ser algo líquido, sólido o gaseoso, pero la esencia permanece independientemente de sus manifestaciones fenoménicas, siendo siempre $\mathrm{H}_{2} \mathrm{O}$. 
fueron clérigos y después seglares estudiantes de universidades (filósofos, teólogos, médicos, juristas, etcétera). Con la invención de la imprenta el fenómeno una vez más cambió y se manifestó de la siguiente forma:

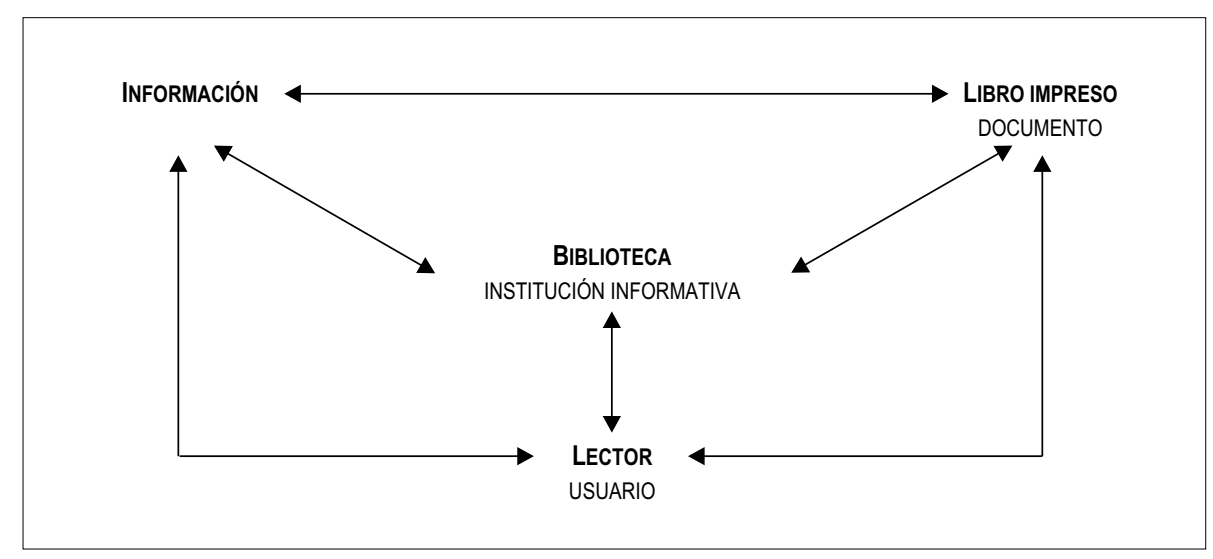

El cambio continuó y en la actualidad podemos identificar, entre algunas otras posibles, por ejemplo la siguiente otra forma del SID:

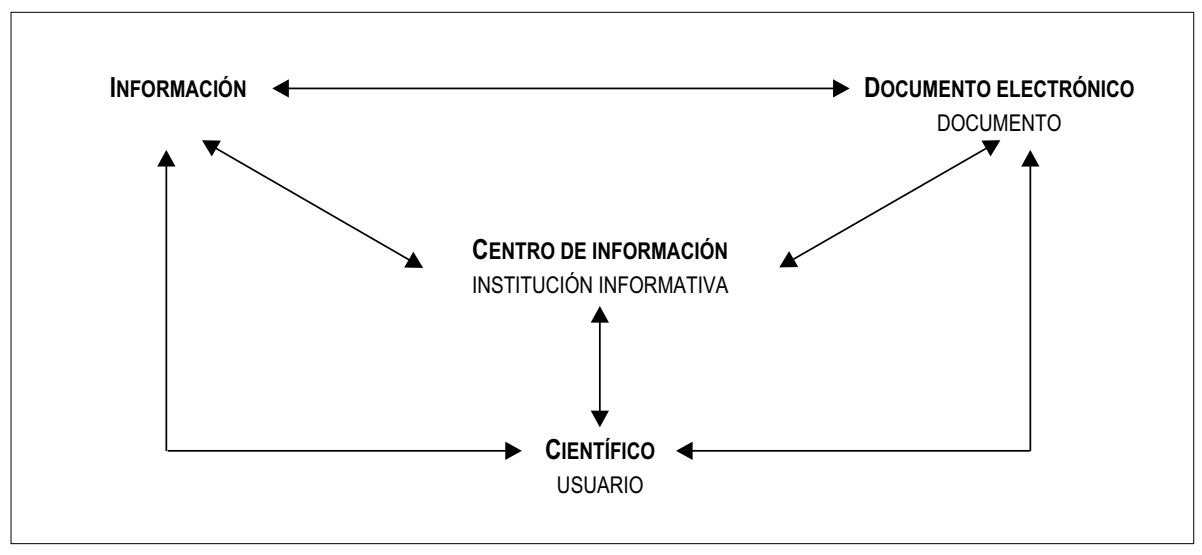

Al observar el cambio fenoménico del SID, identificamos un elemento constante en ese sistema. La información, por su naturaleza ideal, se encuentra siempre presente, por lo que podemos comprender la importancia 
que tiene para el sistema, y de ahí la atención que le prestamos al analizar los términos en el capítulo dedicado a la fundamentación teórica, no obstante haber declarado que el centro, principio y fin de la disciplina era el usuario. De igual forma la importancia del concepto de información se refleja en cuanto que con su ayuda pudimos definir los otros conceptos del sistema.

\section{LA BIBLIOTECOLOGÍA COMO EMPRESA O INSTITUCIÓN EDUCATIVA}

Por último, para aclarar y reafirmar nuestra posición realizaremos algunas observaciones sobre las tentativas de convertir a la bibliotecología en un apéndice de la mercadotecnia y sobre la reacción contraria a esta última, que ve como uno de los objetivos finales de la disciplina el hecho de ser un agente educativo.

Por lo que se refiere a la primera tendencia podemos señalar que, además de la ausencia de una conciencia clara sobre lo que es la bibliotecología, es la realidad política y económica de la sociedad de los últimos dos decenios del siglo $\mathrm{XX}$, lo que ha llevado a adoptar la tesis de Hayek y colegionarios ideológicos del neoliberalismo, y que es tal realidad la que ha determinado que se incluya en la mayoría de los planes de estudio a nivel licenciatura o posgrado una materia encaminada a enseñar cómo crear valor agregado a la información y cómo administrarla "racionalmente". En ocasiones ha llegado a tener más peso el punto de vista según el cual lo importante es ser "gestores de información"; esto es, que el objetivo de la enseñanza de los estudiantes de hoy sea que el profesional de mañana pueda salir al mercado, única instancia que según el neoliberalismo rige natural y apropiadamente las relaciones entre individuos, con una mercancía valiosa. Este hecho redunda en forma inmediata en que el profesional de la información percibe por sus servicios un decoroso salario para vivir, y en forma mediata recibe el reconocimiento por parte de la sociedad de la "importancia" de su profesión y de esta manera se justifica la existencia de una disciplina que enseña cosas tan útiles.

Sin embargo consideramos que el hecho de que la disciplina tome a la información como mercancía equivale a ignorar el sentido primario de las necesidades de información. Como lo mencionamos al realizar las anotaciones metodológicas sobre la definición, un objeto puede ser visto desde 
diferentes perspectivas: puede ser muchas cosas. Por supuesto que la información puede ser tomada como mercancía ¡pero sólo dentro del mercado, no dentro de la teoría! El alimento, para retomar el ejemplo en la industria alimenticia, también puede ser considerado como mercancía, pero en las investigaciones teóricas se toma exclusivamente como un objeto que satisface las necesidades fisiológicas del hombre, por lo que se estudia en sus estructuras nutritivas.

Necesariamente en una sociedad mercantilista si se descubre que un objeto satisface una necesidad y que consecuentemente posee valor de uso, entonces ese objeto será observado como asiento de un valor de cambio. Sin embargo al científico no le interesa en primer lugar el valor de cambio que pueda tener ese producto, sino las propiedades objetivas que posee al aparecer como fenómeno. Empleando la terminología de Marx, en una sociedad fetichista como la contemporánea, donde las relaciones se ven mediatizadas por cosas y los objetos se asocian con propiedades no inherentes a ellos, ${ }^{20}$ todo puede aparecer con valor de cambio: el alimento, el agua, la salud, la educación, el espacio como medio de transporte de ondas para la comunicación electrónica, etcétera; pero para un teórico eso es secundario y lo primero que debe investigar son las propiedades objetivas de esos objetos. En nuestro caso la propiedad primordial de la información es satisfacer las necesidades de información del hombre a través de documentos y con ayuda de una institución informativa, para completar y realizar su proyecto de existencia (como estudiante, investigador, productor, político, hombre de negocios, etcétera), y así moverse en este mundo y para, en un plano filosófico, alejarse de la enajenación del espíritu humano.

Si tomamos otro ejemplo, podría decirse que sería inaceptable que en una facultad de química se diera prioridad a la enseñanza de cómo hacer productos para venderlos y cómo venderlos en detrimento de la teoría química. Por lo menos en una universidad eso sería adulterar la función cognoscitiva que tiene la ciencia. Esto no significa negarse a ver la realidad o tener una visión del científico como trabajador en su torre de cristal sin que sus descubrimientos se inserten de una manera práctica en la sociedad; pero, reiteramos una vez más, no se le puede dar más importancia al modo de hacer que al modo de

20 De ahí se deduce que tomamos al valor de uso como inherente al objeto y el valor de cambio como adquirido desde fuera. 
ser; se debe desarrollar el lado teórico de la disciplina. Esto es, si se descubren leyes que rigen las relaciones de los objetos estudiados, indirectamente los descubrimientos tendrán una aplicación para algo, y consecuentemente, si dichos descubrimientos sirven para algo, se podrán vender.

Como mencionamos al hablar de la relación entre las disciplinas prácticas y teóricas: toda práctica descansa en una teoría, eso es lo que se debe investigar en el plano académico. Es posible que existan instituciones lucrativas donde el usuario pase a ser "cliente", pero para servir bien a su cliente es necesario realizar ciertas actividades que estén de acuerdo con una teoría. El hecho de ser "empresas informativas" no cambia la esencia de la institución informativa, sólo podríamos agregarle a la definición proporcionada un atributo más: el cobrar dinero por sus servicios. Independientemente de que un pedagogo aplique su teoría en una institución de paga o una gratuita, sigue siendo pedagogo, su teoría pedagogía, sus clientes, alumnos y su institución escuela; o un médico no deja de ser tal, de tener ciertos conocimientos de anatomía, fisiología y de trabajar en un hospital, independientemente de si atiende a sus clientes o pacientes en un hospital privado o público. De la misma manera, una institución informativa no dejará de serlo aunque sea lucrativa, un usuario seguirá siéndolo aunque pague por serlo. Lo importante es no perder la diferencia entre el contexto y los principios. El principio es la teoría, el contexto es nuestra sociedad mercantilista.

Por otra parte existe el punto de vista que se inserta dentro de una tradición que podríamos llamar humanística y que tiene como ideal el desarrollo integral del ser humano. Para los representantes de este enfoque, la bibliotecología tiene una función más amplia que la de estudiar el proceso de la circulación social de la información documental, y la biblioteca es más que un agente en este proceso; para ellos, la bibliotecología teóricamente y la biblioteca prácticamente son elementos educadores.

Existe dentro de la competencia de la esfera de la bibliotecología lo que se conoce como formación (educación, instrucción) de usuarios. En un sentido instrumentalista, lo más apropiado es hablar de instrucción de usuarios para que utilicen óptimamente las fuentes de información, con el fin de recuperar la información requerida. Sin embargo, en ocasiones el énfasis se hace no en lo instrumental, sino en lo "intelectual", el bibliotecario es responsable de enseñar no cómo usar los instrumentos, sino cómo usar la información, 
empezando así el discurso de Formación en el uso de formación, el cual es definido por la Maestra Patricia Hernández como "el proceso de intercambio de experiencias o saberes significativos sobre el uso de la información [el subrayado es nuestro M. A. R.], con el fin de que la persona que la usa, de acuerdo con su proceso cognoscitivo pueda cambiar su actitud y aptitud en forma más positiva, optimizando dicha utilización al máximo." 21 La misma autora resalta la actividad de P. Knapp en la Universidad de Wayne por conceptualizar la biblioteca como un centro donde se da el proceso de enseñanza y, podríamos agregar, de aprendizaje, y los cursos en la Facultad de Ingeniería en la UNAM en 1972 donde "el énfasis estaba dado en el aprovechamiento del conocimiento y no en la transmisión de técnicas de almacenamiento y recuperación de la información."22

Ante esta situación surge el cuestionamiento sobre la validez de dicha afirmación. ¿forma parte de las responsabilidades del bibliotecario el formar usuarios para enseñarlos a usar la información? lo que a su vez implicaría que el bibliotecario tendría que investigar la teoría de esa acción didáctica. Según nuestra opinión, la frase "usar la información de forma más positiva" es equivalente a "pensar bien", donde "bien" se entiende en el sentido de razonar correctamente y quizá también, si no nos desviamos del ideal educativo integral, bien en el sentido ético.

Sin embargo, si realizamos una vez más una comparación entre el bibliotecólogo y el químico, podríamos descubrir que el objetivo del químico es investigar cómo se obtienen compuestos, mezclas, reacciones, pero no en educar cómo usar esas mezclas, eso sería una cuestión personal de carácter creativo y moral. La Química no es responsable de que un individuo no esté en condiciones de "ver" que las substancias que tiene ante sí pueden combinarse para obtener un compuesto nuevo, ni tampoco lo es de que el científico use esas substancias para crear un artículo para beneficio de la sociedad o por ejemplo para armamento químico. Por supuesto que el profesor de química tiene una obligación moral de guiar a sus alumnos para que "usen" sus

21 Hernández Salazar, Patricia. Formación en el uso de información: la instrucción computarizada como alternativa. Tesis para obtener el grado de Maestro en Bibliotecología. México: UNAM, FFL, 1996. h. 20.

22 Idem. h. 10 y 15. 
conocimientos químicos de una manera positiva, pero en ese momento está actuando no como químico, sino como educador.

De la misma manera la bibliotecología descubre cómo conectar al usuario con la información que necesita, pero no es responsable de que ese usuario la use para obtener conocimiento o sólo como datos para pasar un examen; el usuario puede tener la información a la mano, pero la chispa intelectual para combinarla y realmente conocer puede estar ausente y el bibliotecario en cuanto bibliotecario está fuera de esa esfera. De la misma manera el profesional de la información no es responsable del uso moral que se le dé a la información, un usuario puede solicitar por ejemplo Mi lucha de Hitler para hacer un análisis del totalitarismo o para fundamentar una nueva teoría fascista de explotación. Si el bibliotecario interviene como filtro y escoge qué información proporcionar y qué no, está actuando como censor, papel ajeno a su finalidad primaria.

El objetivo del bibliotecario es servir de enlace activo entre los documentos y el mundo de la información, no el de proporcionar conocimientos, enunciado que se comprende por la distinción que hacemos entre información y conocimiento; si la información es un ente ideal objetivado, el conocimiento es un ente ideal subjetivado; es decir, es la información convertida en creencias verdaderas en un sujeto, JUSTIFICADAS OBJETIVAMENTE y resultado de un proceso creativo de comprensión, análisis, síntesis y valoración. Dicho proceso es objeto de estudio de la pedagogía, no de la bibliotecología.

Si se afirma que el proceso de conocimiento es objeto de la teoría bibliotecológica, entonces se plantea el problema de la identidad de la bibliotecología como disciplina, porque en ese caso sería una rama de la pedagogía. Sobre este respecto Shera, aunque le otorgaba un lugar muy importante al conocimiento, es muy claro cuando escribe que "si la bibliotecología ha de subsistir como profesión [y como teoría M. A. R.] por derecho propio, debe abandonar sus intentos de asumir los atributos de otra profesión -educación, trabajo social, liderazgo de grupo- y replegarse hacia sus verdaderos objetivos." 23

23 Shera, J. Op. cit. p. 192. 
El cómo usar la información es algo que queda fuera de la competencia bibliotecológica inmediata, los bibliotecólogos no son pedagogos; no educan, así como tampoco son moralistas. La inquietud educativa sobre el uso de la información es mediata en cuanto que los bibliotecólogos son científicos sociales y en esa medida comparten la responsabilidad de su objeto. ${ }^{24}$ Por otro lado, históricamente las bibliotecas han estado ligadas a centros de educación. Es quizá por esto que se insertan en ese proceso educativo, pero lo hacen como un eslabón de una cadena más amplia.

La finalidad de la distinción entre dar conocimiento y proporcionar las condiciones para obtener información es epistemológica, tiene como finalidad "atrapar" y distinguir el objeto de estudio de la disciplina; no es nuestro objetivo negar toda posibilidad de que la bibliotecología se inserte en el desarrollo integral del hombre; lo puede hacer, sobre todo si está inserta en una institución de enseñanza. Los agentes que enseñen a pensar, llámense escuelas, universidades, bibliotecas, medios masivos de comunicación, etcétera, siempre serán benéficas para una sociedad que, cada día más, está perdiendo la capacidad de ser crítica, creativa y preocupada por el bien común.

24 Cuestión muy importante y que merece ser investigada dentro de lo que nosotros hemos llamado fundamentación axiológica. 


\section{CONCLUSIONES}

omo resultado de la investigación realizada podemos proponer las si-
guientes conclusiones:

La bibliotecología es una disciplina que tiene su fundamento ontológico en el ser del hombre, por lo tanto no es una invención arbitraria, o un instrumento para hacer, sino para SER. (Cap. 2. Fundamentación ontológica)

La bibliotecología proporciona los elementos necesarios para integrar un proyecto existencial de vida, para que el hombre llegue al ser-auténtico, para evitar la enajenación del espíritu humano y para la existencia misma del sujeto. (Cap. 2. Fundamentación ontológica)

Las relaciones informacionales surgen independientemente de la voluntad del ser humano y por consiguiente tienen una existencia objetiva, lo que a su vez nos permite inferir la objetividad del campo fenoménico de la ciencia bibliotecológica. (Cap. 2. Fundamentación ontológica)

El aspecto técnico de los procedimientos para el quehacer bibliotecario descansa en un aspecto teórico bibliotecológico, por lo que el científico de la información debe desarrollar su investigación para ayudar al profesional de la información. (Cap. 2. Fundamentación ontológica)

La objetividad de los objetos que originan la teoría bibliotecológica condiciona la objetividad de la teoría. (Cap. 2. Fundamentación ontológica)

Debido al carácter social del documento, usuario e institución informativa documental la bibliotecología cae dentro de las ciencias del espíritu. (Cap. 2. Fundamentación ontológica)

La información es una entidad ideal resultante de la síntesis que realiza el sujeto al estructurar los datos que recibe. Posteriormente se objetiva y llega 
a formar el mundo posible de la información, en el cual "habitan" ciertos entes y rigen determinadas leyes y relaciones. Esta información la denominamos pragmática porque el sujeto, con su intencionalidad y contexto, juega un papel central en la creación y recreación de tal información. (Cap. 3 Fundamentación Teórica)

Las necesidades de información son estados condicionados por ciertas propiedades esenciales del ser que las sufre y que lo motivan a buscar información. Dichas propiedades son las mencionadas en la fundamentación ontológica: el ser del hombre como proyecto que se realiza a sí mismo como un ser-en-el-mundo, el ser del hombre como productor y transformador de su realidad, el movimiento al autoconocimiento del espíritu humano, y la necesidad de realizarse como sujeto dialogante. Pero la necesidad que le interesa a la bibliotecología es una necesidad de información documental; es decir, una información que puede ser obtenida a través de documentos que poseen una sintaxis lógica determinada. (Cap. 3 Fundamentación Teórica)

El documento se toma como un producto social y cultural, que es el resultado de la objetivación del espíritu humano y del pensamiento, y tiene como función conservar la memoria social. De los diferentes tipos de documentos, la bibliotecología centra su atención en aquellos que fueron creados expresamente con el fin de comunicar "intenciones del alma" y que tienen una estructura lógica articulada y han pasado a través de las manos del profesional de la información documental. De lo anterior se desprende que aquellos objetos que pueden generar información pero que no cuentan con la estructura sintáctica y semántica expresada, no son tomados en cuenta por la bibliotecología. (Cap. 3 Fundamentación Teórica)

El usuario es el ser humano (ideal) que por su estructura ontológica exige o puede exigir satisfacer ciertas necesidades que emanan de su ser específico. Las necesidades que le interesan a la bibliotecología son las necesidades de información documental, y de acuerdo con el tipo de mundo de la información al que necesite entrar el usuario, será la tipología de éste último. (Cap. 3 Fundamentación Teórica)

El usuario es el origen y fin de la actividad bibliotecaria. Es él quien motiva el proceso informativo con su deseo de satisfacer una necesidad de información y sólo con la satisfacción de ésta se culmina tal proceso. (Cap. 3 Fundamentación Teórica) 
La institución informativa documental es, por un lado, un agente dentro del proceso de comunicación social y de la comunicación personal donde el autor encuentra su lector, y por el otro, es el "espacio" que propone las condiciones necesarias para satisfacer las necesidades de información documental del usuario, y el "lugar" donde no sólo se conserva la producción intelectual impresa de la humanidad, sino donde se puede dar y se da el autoconocimiento del espíritu humano objetivado y permite su desarrollo. "Espacio" y "lugar" se entienden no de una manera física tridimensional, sino como el $\tau$ ó $\pi$ o (topos), que sólo proporciona las condiciones para la desobjetivización del espíritu humano y del $\lambda$ ó $\gamma \circ \varsigma$ (logos). De esta manera, es posible desprendernos del nexo institución informativa-edificio, para dar cabida a otro tipo de instituciones como las bibliotecas ambulantes, móviles, etcétera, e incluso, virtuales, si es que ellas realmente pueden proporcionar las condiciones mencionadas. De la misma manera, este enfoque nos permite determinar que no todo conjunto de libros (bodega, librería) constituye una biblioteca, ya que no en todos los casos se dan las condiciones para satisfacer las necesidades de información. (Cap. 3 Fundamentación Teórica)

Todos esos elementos deben de ser vistos en una realidad concreta para su correcta comprensión, el documento, el usuario y la institución informativa han ido evolucionando en la forma en que realizan sus propiedades. (Cap. 3 Fundamentación Teórica)

El objeto de estudio de la bibliotecología es el sistema informativo documental que está formado por los siguientes elementos: información, documento, institución informativa documental y usuario; y por la dinámica de dicho sistema. (Cap. 4 Fundamentación gnoseológica)

El sistema informativo documental es el núcleo duro de la ciencia bibliotecológica, aquello que proporciona el elemento de continuidad y tradición; y la aparición de diferentes conceptos, teorías y concepciones acerca de ese núcleo es el cinturón protector que proporciona el elemento de cambio e innovación. (Cap. 4 Fundamentación gnoseológica)

De la interacción de los elementos anteriores se derivan los conceptos y leyes bibliotecológicos, así como las técnicas de la actividad bibliotecaria. (Cap. 4 Fundamentación gnoseológica) 
Se propone un cambio de visión que por un lado permita explicar cuestiones que escapaban al marco tradicional de la bibliotecología y que por el otro marque la pauta del desarrollo de la disciplina. El nuevo paradigma gira en torno al concepto de información que manejamos, como ente ideal objetivado y del cual se derivan los otros conceptos centrales. La bibliotecología estudia ese objeto ideal pero en función de un sujeto. Este enfoque nos permite abandonar una ontología de "primer nivel", donde reinan objetos concretos: el libro material, la biblioteca material, pero deja de funcionar como fundamento ontológico si éstos, debido al desarrollo tecnológico, dejan su paso a entes más abstractos: libro electrónico, biblioteca electrónica, espacio cibernético. El problema puede resolverse si nos "mudamos" a una ontología superior, donde habitan entes abstractos, ideales, generales, y el que por supuesto no será lugar para administradores y técnicos. La bibliotecología se interesa porque los usuarios tengan acceso al mundo de la información al que ciertos documentos los pueden conducir. Puede evolucionar la forma del documento, de la institución informativa y del usuario mismo, pero la información como objeto ideal al cual tiende un usuario con necesidad de información, al cual transmite un documento y con el cual conecta una institución, permanecerá. (Cap. 4 Fundamentación gnoseológica)

Los conocimientos bibliotecológicos, aunque pueden aplicarse en mercadotecnia y pedagogía, no son esencialmente inherentes a esas esferas. (Cap. 4. Fundamentación gnoseológica) 


\section{BibLiOgRAFía}

Belkin, Nicholas J. "The cognitive viewpoint in information science", en Journal of Information Science. V. 16. N. 1, 1990. pp. 11-15.

Bishop, Peter. Fundamentos de Informática. Madrid: Ediciones Anaya Multimedia, 1992. $656 \mathrm{p}$.

Bonitz, Manfred. "Information-Knowledge-Informatics", en International Forum on Information and Documentation. V. 15. N. 2. 1973. pp. 281-294.

Boyce, Bert R. y Donald H. Kreft. "Principles and theories in information science", en Annual Review of Information Science and Technology. V. 20, 1985. pp. 153-178.

Brown César, Javier. Elementos para una teoría bibliotecaria. México: ENBA, 2000. 224 p.

Brown, Harold I. La nueva filosofía de la ciencia. Madrid: Tecnos, 1984. $235 \mathrm{p}$.

Bunge, Mario. Epistemología. Barcelona: Ariel, 1980. 275 p.

Calva González, J: J: "Una aproximación a lo que son necesidades de información”, en Investigación Bibliotecológica. V. 5. N. 11, 1991. pp. 33-38.

Campbell, Jeremy. El hombre gramatical: información, entropía, lenguaje y vida. México: Conacyt/FCE, 1989. 418 p. 
Bases teóricas y filosóficas de la bibliotecología

Chalmers, A. F. ¿Qué es esa cosa llamada ciencia? México: Siglo XXI, 1991. $245 \mathrm{p}$.

Chubarian, O. S. Bibliotecología general. La Habana: Editorial Científico Técnica, 1976.

Coreth, E. Cuestiones fundamentales de la Hermenéutica. Barcelona: Herder, 1972. 263 p.

Cruz Paz, Andrés. "En torno a los conceptos documento, fuente y recurso en la ciencia de información", en Ciencias de la información. V. 23. N. 4. La Habana: IDICT, 1992. pp. 267-272.

Curras, E. La información en sus nuevos aspectos. Madrid: Paraninfo, 1988. $307 \mathrm{p}$.

Dhyani, Pushpa. Information science and libraries. New Delhi: Atlantic Publishers \& Distributers, 1990. 288 p.

Diccionario Griego-Español. Barcelona: Bibliograf. S. A., 1973.

Durrance, J. "Information need", en Rethinking the library in information age. V II U. S. Office of Educational Research provement, office of library process, 1968.

Eco, U. Tratado de Semiótica general. Barcelona: Ed. Lumen, 1988. 463 p.

Endean, Gamboa Robert A. El usuario en Bibliotecología. Tesis para obtener el Título de Licenciado en Biblioteconomía. Escuela Nacional de Biblioteconomía y archivonomía. México, D. F. 1994. 134 h.

Fairthore, R. A. "Use and mention in the information science", en Laurence Heilprin (ed). Proceedings of the Symposium on education for Information Science, Washington: Spartan books, 1965.

Ferraris, Mauricio. La hermenéutica. México: Taurus, 2000. 179 p. 
Feyerabend, P. K. Tratado contra el método. Madrid: Tecnos, 1981. 329 p.

Fox. Christopher. Information and Misinformation. West-Port: Greenwood Press, 1983. 223 p.

Frege, G. Conceptografía. México: UNAM/IIF, 1972. 270 p.

- -. Investigaciones lógicas. Madrid: Tecnos, 1984. 146 p.

Gadamer, Hans-George. Philosophical Hermenéutica. Berkeley: University of California Press, 1976. 243 p.

- -. Verdad y método I. Fundamentos de una hermenéutica filosófica. Salamanca: Sígueme, 1997. 697 p.

Gómez, Villalpando Armando. El objeto de estudio de la Ciencia de la Información. Tesis para obtener el grado de maestro en Ciencias de la Información. Guanajuato, Gto. 1990. 81 p.

Gorbea Portal, Salvador. "Uso de modelos matemáticos en la evaluación de colecciones: teoría y método", en Primer seminario internacional sobre desarrollo de colecciones. María del Carmen Negrete Gutiérrez, coord. México: UNAM-CUIB, 1998. pp. 83-110.

Gorbea Portal, S. y E. Setien Quesada. "De la Bibliotecología al Sistema de Conocimientos científicos Bibliotecológico-Informativo", en Investigación Bibliotecológica. V. 8. N. 16. pp. 21-25. México: UNAM, CUIB, 1994.

Grondin, Jean. Introducción a la hermenéutica filosófica. Barcelona: Herder, 1999. 269 p.

Habermas, Jürgen. Ciencia y técnica como ideología. Madrid: Tecnos, 1984. $181 \mathrm{p}$.

- -. La lógica de las ciencias sociales. Madrid: Tecnos, 1990. 510 p. 
Bases teóricas y filosóficas de la bibliotecología

Halloran, James D. "Information and comunication: Information is the answer, but what is the question?", en Journal of Information Science. V. 7. N. 4-5. p. 159-167.

Hanson, N. R. Patterns of discovery. Cambridge: Cambridge University, 1961. $240 \mathrm{p}$.

Harmon, Glynn. "The interdisciplinary study of information. A Review Essay", en Journal of Library history, 1987. V.22. N. 2. p. 206-227.

Hegel, G. W. Enciclopedia de las ciencias filosóficas. México: Porrúa, 1985.

Heidegger, M. "Carta sobre el humanismo", en Realidad, $\mathrm{N}^{\circ} 7^{\circ}$. Buenos Aires, 1948. pp. 13-25 y No 9 pp. 343-367.

- -. El Ser y el tiempo. México: FCE, 1980.

Hempel, Carl G. Filosofía de la ciencia natural. Madrid: Alianza, 1973. $168 \mathrm{p}$.

-- La explicación científica: estudios sobre la filosofía de la ciencia. Buenos Aires: Paidós, 1979. 485 p.

Hernández Salazar, P. "El perfil del usuario", en Investigación Bibliotecológica. V. 7. N. 15. pp. 16-22. México: UNAM, CUIB, 1993.

--. Formación en el uso de información: la instrucción computarizazada como alternativa. Tesis para obtener el grado de Maestría en Bibliotecología. México: UNAM, FFL, 1996.

Husserl, Edmund. Investigaciones lógicas, 1. Madrid: Alianza Editorial, $1985.382 \mathrm{p}$.

Jolley, J. L. Ciencia de la información. Madrid: Guadarrama/Mcgraw Hill, 1968. 253 p.

Kibirige, H. M. "Theoretical foundations of development information science", en The international Information \& Library review, 1993. V. 25. N. 1. p. 1-14. 
Kim, Young Whan y Jin H, Kim. "A model of knowledge based information retrieval with hierarchical concept graph", en Journal of Documentation. V. 46. N. 2. June 1990. p. 113-136.

Kuhn, T. "Afterwords", en P. Horwich (ed) World Changes. Thomas Kuhn and the Nature of Science. Cambridge, Massachusetts, 1993. pp. 311-341.

--. "Dubbing and Redubbing: The Vulnerability of Rigid Designation", en W. Savage (ed), Scientific Theories. Minnesota Studies in the Philosophy of Science. Vo. XIV. Minneapolis: University of Minnesota Press, 1990. pp. 298-318.

- - La estructura de las revoluciones científicas. México: FCE, 1971. $319 \mathrm{p}$.

Lafuente López, R. "La síntesis crítica del conocimiento bibliotecológico: su valor para la investigación bibliotecológica", en Investigación bibliotecológica. V. 3. N. 6. pp. 3-10. México: UNAM, CUIB, 1988.

Lafuente López, R. y Estela Morales. "Reflexiones en torno a la enseñanza de la bibliotecología", en Investigación Bibliotecológica. V. 6. N. 12. pp. 25-33. México: UNAM, CUIB, 1992.

Lakatos, I. "Falsification and the methodology of research programmes", en Criticism and the growth of knowledge. I. Lakatos y A. Musgrave, coomps. Cambridge: Cambridge university press. pp. 91-196.

- -. Historia de la ciencia y sus reconstrucciones racionales. Madrid: Tecnos, 1974. $158 \mathrm{p}$.

- -. La metodología de los programas de investigación científica. Madrid: Alianza Editorial, 1983.

Lenin, Vladimir Ilitch. Materialismo y empiriocriticismo. Obras completas. T. 18. Moscú: Progreso. 422 p.

Lilley, Dorothy B. y R. W. Trice. A history of information science 19451985. San Diego: Academic Press, 1989. 338 p. 
Bases teóricas y filosóficas de la bibliotecología

López, Yepes José. La documentación como disciplina. Teoría e historia. Navarra: Eunsa, 1995. 337 p.

López, Yepes José. ¿Qué es documentación? Madrid: Síntesis, 1993. $157 \mathrm{p}$.

Martínez de Sousa, José. Diccionario de Bibliología y Ciencias afines. Madrid: Fundación Germán Sánchez Ruiperez, Piramide, 1989. 851 p.

Marx, Karl. "Carta al editor de Otyechestvenniye Zapisky". (1877), en Correspondence 1846-1895. New York: International Publishers, 1936. pp. 352-355.

--. "Prólogo a la Contribución a la Crítica de la Economía Política", en Marx, K. Introducción General a la Crítica de la Economía Política/1857. México: Siglo XXI, 1991. 123 p.

Marx, K. y Federico Engels. La ideología alemana. México: Grijalvo, 1987. $746 \mathrm{p}$.

--. Manuscritos económico-filosóficos de 1844. Bogotá: Editorial Pluma, 1980. $171 \mathrm{p}$.

Mikhailov. A. I. y otros. Fundamentos de la informática. La Habana: Nauka y Academia de Ciencias de Cuba. Instituto de Documentación en información científica y técnica. 1973. 2 v. 718 p.

Moulines, C. Ulises. Exploraciones metacientificas. Madrid: Alianza Editorial, 1982. 371 p.

Neill, S. D. Dilemmas in the study of information. West-port: Greenwood Press, 1992. 184 p.

Nitecki, Joseph Z. "The concept of information-knowledge continuum. Implications for Librarianship", en Journal of Library history, 1985. V. 20. N. 4. p. 387-407.

Ortega y Gasset, J. La misión del bibliotecario y sentido del bibliotecario. Madrid: Revista de Occidente, 1962. 
Piaget, Jean. "Lógica formal y psicología genética”, en Deaño, A. y Delval, J. comp. Investigaciones sobre lógica y psicología. Madrid: Alianza Universidad, 1977.

--. El nacimiento de la inteligencia en el niño. México: Grijalvo, 1990.

Popper, K. R. El desarrollo del conocimiento científico: conjeturas y refutaciones. Buenos Aires: Paidós, 1967. 463 p.

--. La lógica de la investigación científica. Madrid: Tecnos, 1973. 451 p.

Ranganathan, Shiyali Ramamrita. The five laws of Library Science. Bangalore, India: Sarada Ranganathan Endowment for Library Science, 1989. $449 \mathrm{p}$.

Rapaport, A. "What is information?", en Introduction to Information Science. Comp. y ed. by Saracevic Tekfo. New York \& London: Bowker Company, 1970. p. 18-23.

Rendón Rojas, Miguel Angel. "Algunas peculiaridades de la ciencia bibliotecológica”, en Investigación Bibliotecológica. V. 10. N. 21. México: CUIB, UNAM, 1996. pp. 22-26.

- -. "Cuestiones epistemológicas de la ciencia bibliotecológica y de la información", en Informare "Ciência da Informação\&Epistemologia”. Rio de Janeiro, Brasil: CNPQ/IBICT - UFRJ/ECO, 1999. V.5. N. 2. pp. 31-37.

- -. "El papel del profesional de la información en el acceso y uso de la información documental", en La información en el inicio de la era electrónica: Información, sociedad y tecnología. T. II. México: UNAM-CUIB, 1998. pp. 241-271.

- -. "El sistema de información documental ¿un sistema autorreferencial y autopoiético?", en Revista Interamericana de Bibliotecología. Vol. 22. N. 2. Medellín, Colombia: Universidad de Antioquia. Escuela Interamericana de Bibliotecología. pp. 51-65. 
Bases teóricas y filosóficas de la bibliotecología

Rendón Rojas, Miguel Angel. "Hacia un nuevo paradigma en Bibliotecología”, en Transinformaçao. V. 8. N. 3. S. P. Brasil: PUCCAMP, 1996. pp. 17-31.

--. "La ciencia bibliotecológica y de la información ¿tradición o innovación en su paradigma científico?”, en Investigación Bibliotecológica. Vol. 14, N. 28. México: CUIB, UNAM, 2000. pp. 34-52.

--. "La información como ente ideal objetivizado", en Investigación Bibliotecológica. V. 9. N. 18. México: CUIB, UNAM, 1995. pp. 17-24.

--. "Las tareas para la fundamentación de la Bibliotecología", en Investigación Bibliotecológica. V. 8. N. 17. México: CUIB, UNAM, 1994. pp. 4-9.

- -. "Un análisis filosófico de la Bibliotecología", en Investigación Bibliotecológica. V. 10. N. 20. México: CUIB, UNAM, 1995. pp. 9-15.

Rendón Rojas, Miguel Angel y Marina Dimitrievna Okolova. "La representación extrema del estetismo, del intelectualismo y del moralismo en política", en Analogía filosófica. Año X. N. 2, 1996. México, 1996. pp. 151-173.

Ruiz, Rodríguez Antonio Angel. "Relación entre las ciencias de la información", en Boletín de la Asociación Andaluza de Bibliotecarios. Año 3. N. 8. Jul-sep. 1987. pp. 5-15.

Russell. B. Los problemas de la filosofía. México: Nacional, 1975. 187 p.

Russell, B. y Whithead, A. N. Principia Mathematica. Madrid: Paraninfo, $1981.471 \mathrm{p}$.

Sander Villarino, S. ¿Qué es la biblioteca?, en Edición Conmemorativa del X Aniversario del Centro Universitario de Investigaciones Bibliotecológicas. T. 1. México: CUIB, CONACULTA, 1992.pp.33-42.

Saracevic, Tekfo. Introduction to information science. New York: R. R. Bowker, 1970. $751 \mathrm{p}$. 
Escarpit, Robert. Teoría general de la información y de la comunicación. Barcelona: Icaria, 1981. 318 p.

Schleiermacher, F. "Hermeneutics", en Hermeneutics: The Handwritten Manuscrips. Missoula, Montana: Scholar Press, 1997.

--. Monólogos. Barcelona: Anthropos, 1991. 170 p.

Sequeira, Ortiz D. y Sequiera, Ortiz Z. La Bibliotecología como ciencia. San José, Costa Rica: Publitex, 1988. 218 p.

Setién, Emilio. "Problema Ramal "Bibliotecas y Promoción informativo cultural" 1991-1995", en Bibliotecas, 1992. Revista del Sistema de Bibliotecas Públicas. N. 1/2. Año 30/Ene. Dic. pp. 33-76.

--. Servicios de información. La Habana: Editorial Pueblo y Educación, $1983.138 \mathrm{p}$.

Setién Quezada, Emilio y Salvador Gorbea Portal. "De la Bibliotecología al Sistema de Conocimientos Científicos Bibliológico-Informativo", en Investigación bibliotecológica. V. 8. N. 16. México: UNAM/CUIB, 1994. pp. 21-25. p. 22.

Shannon, C. E. y W. Weaver. The Mathematical Theory of Communication. Urbana, University press, 1962.

Shera, J. Los fundamentos de la educación bibliotecológica. México: UNAM/CUIB, 1990. $520 \mathrm{p}$.

Stegmüller, Wolfgang. La concepción estructuralista de las teorías. Madrid: Alianza Editorial, 1981. 132 p.

Tarsky. A. La concepción semántica de la verdad y los fundamentos de la semántica. Buenos Aires. Nueva Visión,1972. 74 p.

Thompson, James. A history of the principles of librarianship. London: C. Bingley, 1977. $236 \mathrm{p}$.

Thuillier, P. La manipulación de la ciencia. Madrid: Fundamentos, 1975. $330 \mathrm{p}$. 
Bases teóricas y filosóficas de la bibliotecología

Tordera, Antonio. Hacia una semiótica pragmática. El signo en Ch. S. Peirce. Valencia: Presval, 1978. 158 p.

Vattimo, G. Introducción a Heidegger. Barcelona: Editorial Gedisa, S. A., 19

Velez Salas, C. y M. A. Torres V., en "Educación de usuarios en la red de bibliotecas del área Q-M-B de la UNAM.", en Encuentro de bibliotecarios de la UNAM. México: UNAM, 1984.

Vickery, Brian Campbell. Information science in the theory and practice. London. Butterworths, 1987. 384 p.

Vijaya, Kumar P. y Sood S. P. Library ahd information science. A general knowledge encyclopedia. Delhi: Mehra offset Press, 1979.320 p.

Voishvillo. E. K. Poniatie kak forma muishleniia (El concepto como forma del pensamiento). Moscú: izdatelstvo Moskovskogo universitieta, $1989.239 \mathrm{p}$.

Warner, Julian. "Semiotics, information science, documents and computers", en Journal of Documentation, V. 46. N. 1. 1990. p. 16-32.

Wittgenstein, L. Tractatus Lógico Filosófico. Madrid: Revista de occidente, 1962. $209 \mathrm{p}$. 
Bases teóricas y filosóficas de la bibliotecología. La segunda edición consta de 500 ejemplares. Coordinación editorial, Ignacio Rodríguez Sánchez. Formación editorial, Carlos Ceballos Sosa. Revisión especializada, Francisco González y Ortiz. Centro Universitario de Investigaciones Bibliotecológicas/ UNAM. Fue impreso en papel cultural ahuesado de 90 gr. en Desarrollo Gráfico Editorial, S. A. de C. V., ubicados en Municipio Libre 175, Nave Principal, Col. Portales, México D.F. Se terminó de imprimir en el mes de mayo de 2005. 